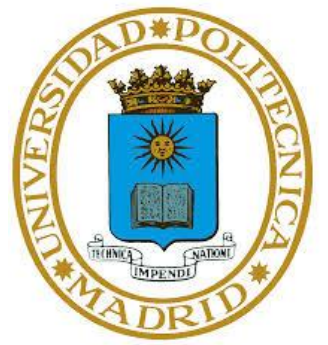

\author{
UNIVERSIDAD \\ POLITÉCNICA DE MADRID \\ E.T.S DE INGENIEROS DE CAMINOS, \\ CANALES Y PUERTOS
}

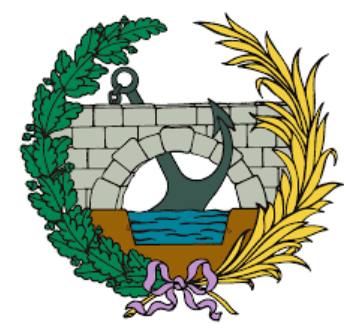

\title{
OPTIMIZACIÓN DEL DISEÑO GEOMÉTRICO DE GLORIETAS MEDIANTE ALGORITMOS GENÉTICOS
}

TESIS DOCTORAL

\section{JUAN LUIS RUBIO MARTÍN}

Ingeniero de Caminos, Canales y Puertos

Madrid, 2017 
DEPARTAMENTO DE INGENIERÍA CIVIL:

TRANSPORTE Y TERRITORIO

E.T.S. de Ingenieros de Caminos, Canales y Puertos

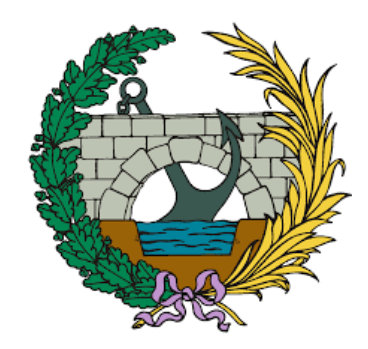

\title{
OPTIMIZACIÓN DEL DISEÑO GEOMÉTRICO DE GLORIETAS MEDIANTE ALGORITMOS GENÉTICOS
}

TESIS DOCTORAL

Juan Luis Rubio Martín

Ingeniero de Caminos, Canales y Puertos

\author{
DIRECTORES: \\ Rafael Jurado Piña \\ Doctor Ingeniero de Caminos, Canales y Puertos \\ José María Pardillo Mayora \\ Doctor Ingeniero de Caminos, Canales y Puertos
}

Madrid, 2017 


\section{DEPARTAMENTO DE INGENIERÍA CIVIL: TRANSPORTE Y TERRITORIO}

\section{E.T.S. de Ingenieros de Caminos, Canales y Puertos}

Tribunal nombrado por el Mgfco. y Excmo. Sr. Rector de la Universidad de Madrid, el día de de 2017.

Presidente:

Vocal $1^{\mathrm{o}}$ :

Vocal $2^{\circ}$ :

Vocal $3^{\circ}$ :

Secretario:

Realizado el acto en defensa y lectura de la Tesis el día de

de 2017 en la E.T.S de Ingenieros de Caminos, Canales y Puertos de la Universidad Politécnica de Madrid.

Acuerdan otorgar la calificación de

EL PRESIDENTE

LOS VOCALES

EL SECRETARIO 
A mi madre:

Elisa 


\section{AGRADECIMIENTOS}

Estas líneas representan el punto y final de la tesis. El camino recorrido hasta llegar aquí ha sido difícil, y tengo claro que sin la ayuda de las personas que paso a citar no hubiera sido posible realizar este trabajo.

En primer lugar, quiero agradecer el esfuerzo y la implicación que han demostrado mis directores de tesis, Rafael Jurado y José María Pardillo, en enseñarme cómo se ha de elaborar de forma rigurosa una investigación. En cada etapa de la tesis me habéis orientado y respondido mis dudas con maestría, ofreciéndome confianza y vuestro valioso tiempo. Muchísimas gracias por el aprendizaje recibido y por vuestra ayuda en todo momento.

En segundo lugar, quiero dar las gracias a mi pareja, María, por aguantar mis ausencias y por creer ciegamente en mí. Tu alegría es un regalo que espero disfrutar cada día junto con esa pequeña persona que hemos conocido recientemente y que concentra todo nuestro amor.

Los valores personales más importantes que he adquirido se los debo a mis padres, Juan Luis y Elisa, de los que he aprendido, entre otras muchas cosas, que hay que trabajar duro para conseguir los objetivos. Vuestro apoyo incondicional ha sido fundamental y mi agradecimiento se queda corto para todo el merecimiento. Junto con ellos, quiero dar las gracias al resto de mi familia y, en especial, a mi hermana Eli y mi sobrino David, porque siempre estáis cerca de mí, a pesar de la distancia.

A continuación quiero dar las gracias a Sergio, Andrés, Jesús y Edu. Vosotros me conocéis como nadie y los buenos ratos que hemos compartido han resultado ser la medicina perfecta en los momentos de agobio. No quiero olvidarme del resto de mis amigos y amigas, porque en algún momento me habéis aguantado hablando de glorietas con la mejor de las sonrisas. 
Por último, quiero extender mi agradecimiento a mis compañeros de PROSER, INSERCO, ECOURBE y CEMOSA, por prestaros a ayudarme ante cualquier duda y sobre todo por enseñarme cómo se trabaja en esta magnífica profesión. 


\section{RESUMEN}

Las glorietas son un tipo de nudo que canaliza los flujos procedentes de tres o más accesos por medio de una calzada anular. De la experiencia acumulada en países de todo el mundo se deduce que en muchos casos este tipo de nudo ofrece numerosas ventajas respecto a las intersecciones convencionales. Por este motivo, se ha extendido su aplicación como solución alternativa a las intersecciones urbanas e interurbanas convencionales.

La definición del trazado en planta de una glorieta es un proceso iterativo en el cual se deben establecer las características de un número importante de elementos geométricos para posteriormente comprobar el comportamiento de la misma en relación a una serie de criterios y objetivos relacionados con la circulación y la seguridad.

Actualmente las técnicas de trazado existentes permiten definir la geometría y comprobar los objetivos de una manera dinámica. Esto facilita la generación y la validación posterior de las soluciones. Sin embargo, y a pesar del continuo perfeccionamiento de los medios técnicos disponibles, presentan algunas limitaciones importantes que imposibilitan que el proceso de diseño sea totalmente mecanizado y que puedan abarcarse todos los casos de diseño posibles. Además, no se aportan criterios para determinar en qué sentido modificar los valores de los parámetros geométricos que definen el trazado en planta para que el resultado global sea satisfactorio, ya que los objetivos perseguidos son contrapuestos. Como consecuencia, la cantidad de iteraciones que se pueden llevar a cabo antes de adoptar una solución final queda limitada por motivos de tiempo y coste.

En esta investigación se ha planteado el desarrollo de un procedimiento que imite las prestaciones de un experto humano en la tarea del diseño en planta de una glorieta mediante la definición de un modelo de optimización. Las variables de decisión están representadas por unos parámetros que permiten definir completamente la geometría de la glorieta. El criterio que permite juzgar la calidad de las distintas soluciones se centra en la evaluación de la consistencia de velocidades. Como restricciones se impone el resto de los objetivos perseguidos en el diseño de la planta y las especificaciones de la 
norma de diseño aplicable. La resolución del problema matemático se realiza mediante el diseño de un algoritmo genético.

Para posibilitar la aplicación del modelo se ha desarrollado un programa de ordenador muy flexible que permite encontrar la solución óptima de trazado de forma automatizada para cualquier configuración de las alineaciones de acceso. La metodología desarrollada se ha contrastado a través de su aplicación a dos casos reales. Los resultados muestran en ambos casos que las soluciones convergen hacia el óptimo de diseño en el cual se minimiza la consistencia de velocidades y se satisface el sistema de restricciones establecido. 


\section{SUMMARY}

Roundabouts are an intersection design that channelizes the traffic flow from three or more legs through a circulatory roadway. Experience accumulated in different countries around the world shows that, in many cases, this type of intersection affords advantages over conventional intersections. For this reason, its application as an alternative solution to intersections in single-carriageway urban and rural roads has become widespread

Roundabout horizontal design is an iterative process through which a significant number of variables (geometric elements) are defined. In addition, the operational performance of the resulting geometry has to be checked to assess its compliance with a series of objectives related to traffic flow conditions and safety.

At present, existing design techniques allow defining the roundabout layout and checking the objectives in a dynamic way. This facilitates the generation and subsequent validation of the solutions. However, despite the continuous improvements of the available technology, it still presents some important limitations that make impossible a fully mechanized design that takes into consideration all the possible solutions that fulfill the objectives. In addition, these objectives are in conflict and current methods do not provide criteria to guide the modification of the geometric parameters to achieve a satisfactory final result. As a consequence, the number of iterations that can be performed before adopting a final solution is limited in time and cost.

A new procedure has been proposed in this research. It emulates the performance of a human expert roundabout designer, using an optimization model. Design variables are represented by geometric parameters. The criterion that measures the quality of the different solutions focuses on the evaluation of speed consistency. The rest of the design objectives as well as the applicable design specifications are introduced as restrictions. The solution to the mathematical problem is achieved by means of a genetic algorithm.

To ensure the applicability of the model, a very flexible computer program has been developed. It allows finding the optimum lay out solution in an automated way for any 
configuration of the legs alignments. The developed methodology has been tested in two real cases. The results show in both cases that, by adequately modifying the decision variables when employing the optimization algorithm, the solutions converge towards the optimum design, that is, consistency speed is minimized while the resulting design complies with the constraints. 


\section{ÍNDICE}

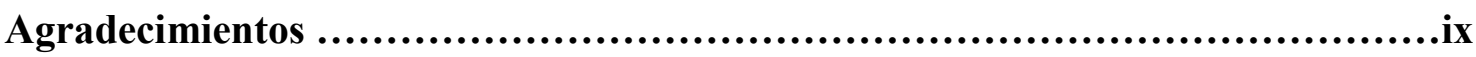

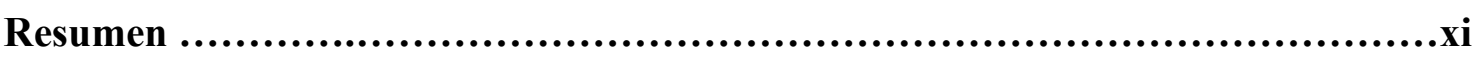

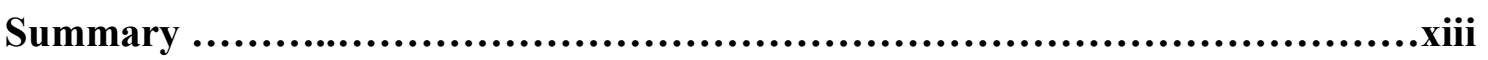

CAPÍTULO 1. INTRODUCCIÓN

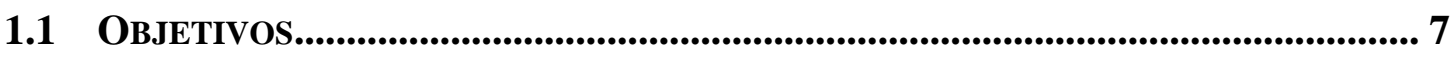

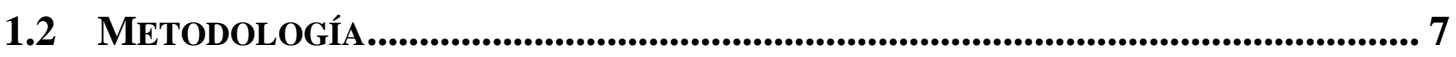

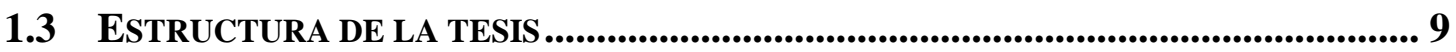

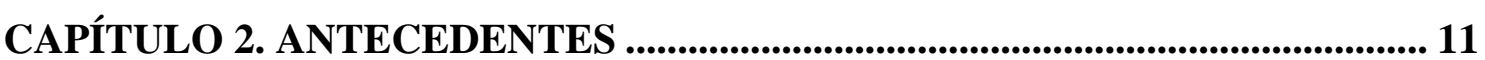

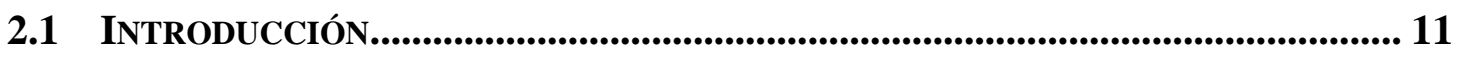

2.2 PROCEDIMIENTO DE DISEÑO DE GLORIETAS ..................................................... 11

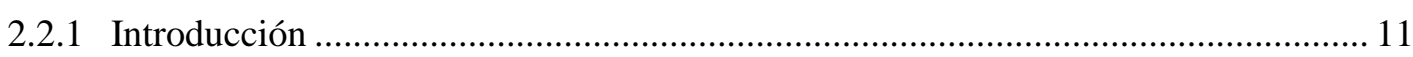

2.2.2 Evolución histórica de las intersecciones giratorias .................................................. 12

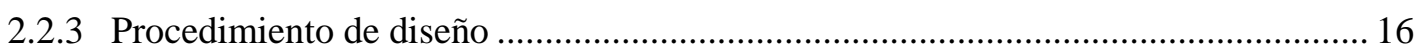

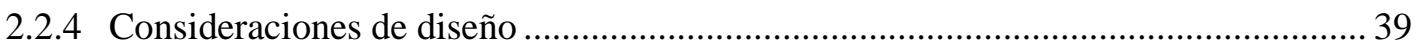

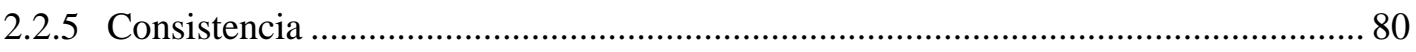

2.3 APLICACIONES INFORMÁTICAS DE DISEÑO ................................................. 97

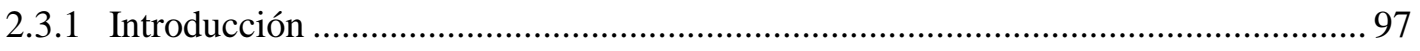

2.3.2 Programas integrados de trazado de obras lineales ................................................... 98

2.3.3 Programas específicos de diseño de glorietas ......................................................... 101

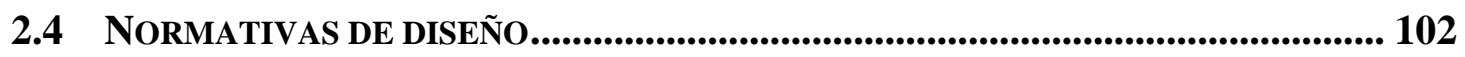

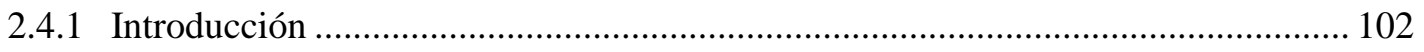

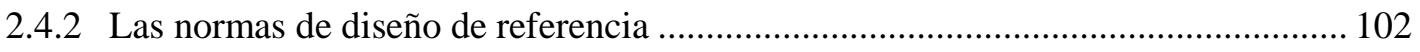

2.4.3 Diámetro exterior (diámetro del círculo inscrito).................................................... 105

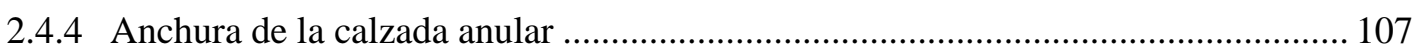

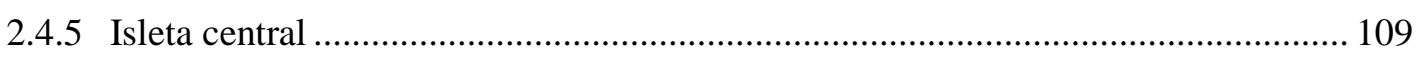

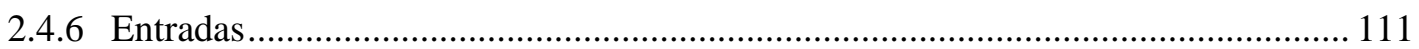

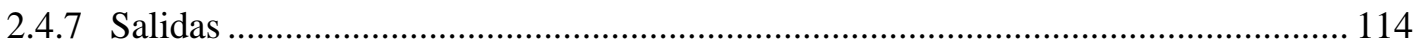




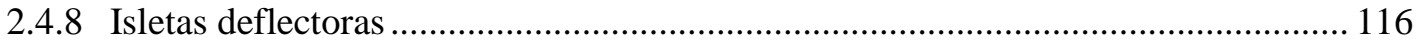

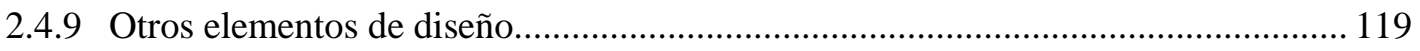

2.4.10 Influencia de los parámetros de diseño en la capacidad y la seguridad. .................. 122

2.5 PRocedimientos HeURísticos DE OPTIMIZACIÓN......................................... 123

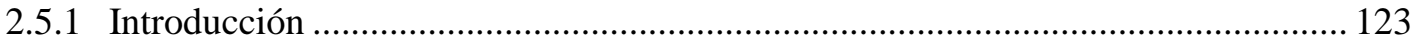

2.5.2 La Investigación de Operaciones. ...................................................................... 123

2.5.3 Herramientas de programación matemática............................................................ 125

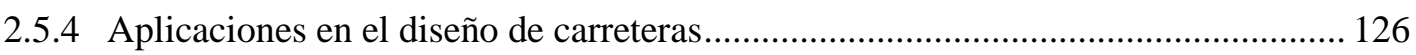

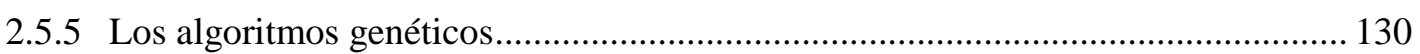

CAPÍTULO 3. FORMULACIÓN DEL PROBLEMA DE OPTIMIZACIÓN ..... 137

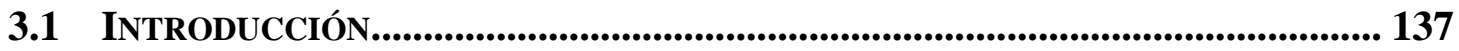

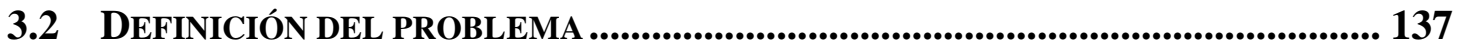

3.3 MODELO MATEMÁTICO ....................................................................................... 139

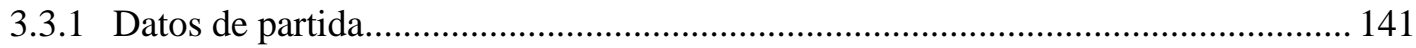

3.3.2 Variables de decisión ......................................................................................... 142

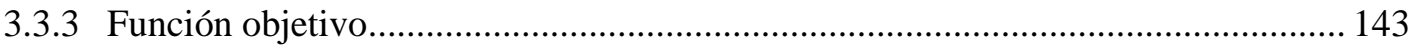

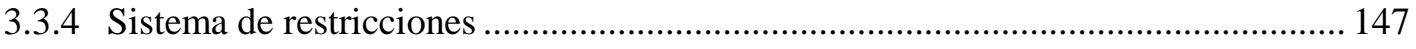

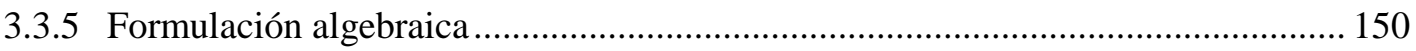

CAPÍTULO 4. RESOLUCIÓN MEDIANTE TÉCNICAS DE PROGRAMACIÓN MATEMÁTICA ........................................................................................................... 153

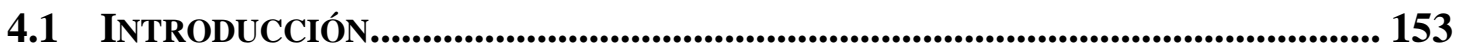

4.2 ESTRUCTURA GENERAL DEL ALGORITMO ...................................................... 153

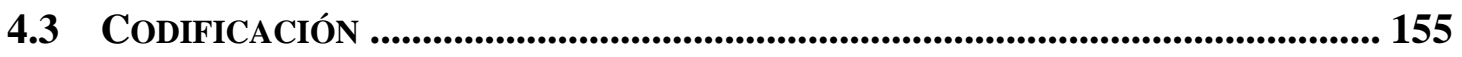

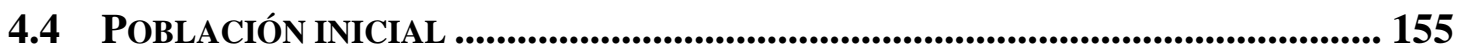

4.5 CONSIDERACIÓN DEL SISTEMA DE RESTRICCIONES EN EL ALGORITMO.......... 156

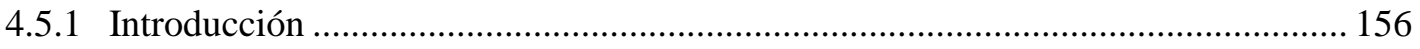

4.5.2 Funciones de penalización ................................................................................ 157

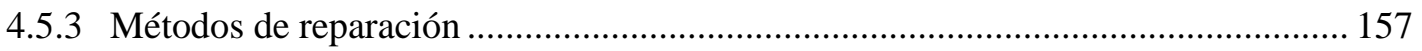

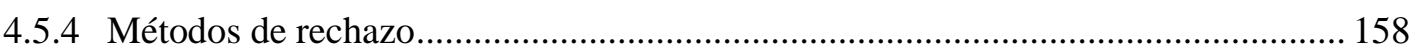

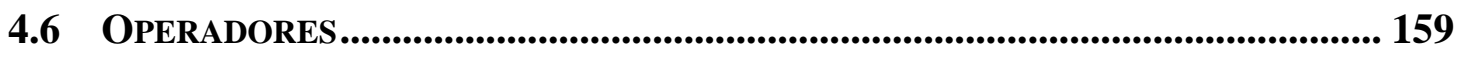




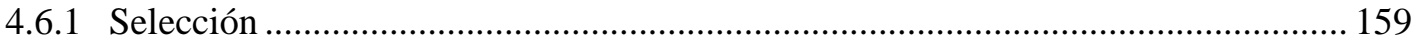

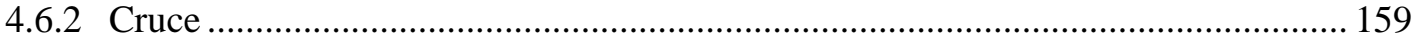

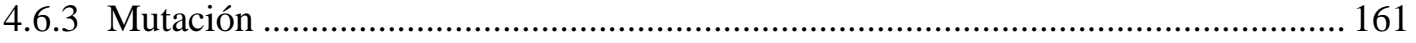

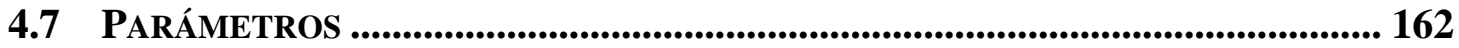

4.8 ESTRUCTURA DEL PROGRAMA DE ORDENADOR ............................................. 163

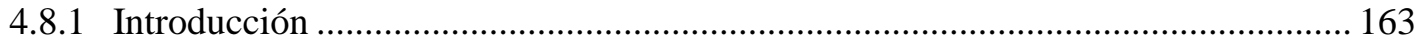

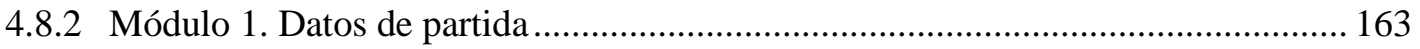

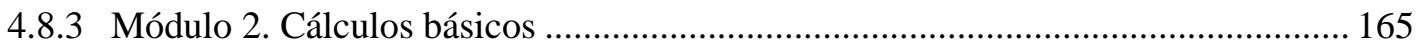

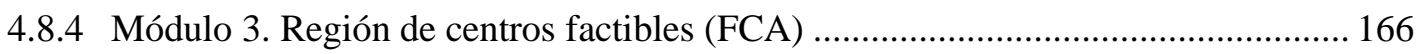

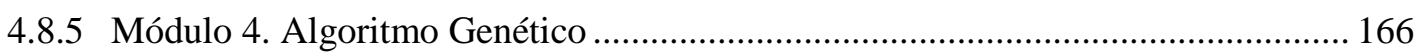

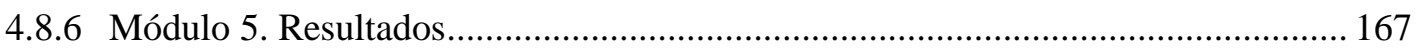

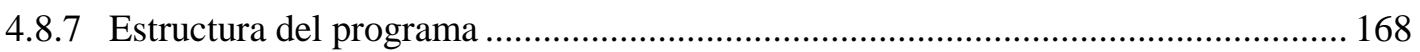

CAPÍTULO 5. ALGORITMOS AUXILIARES .......................................................... 169

5.1 INTRODUCCIÓN................................................................................ 169

5.2 DEFINICIÓN AUTOMÁTICA DE LA GEOMETRÍA (AX-1) ................................... 169

5.2.1 Construcción básica de la geometría de un acceso.................................................... 170

5.2.2 Construcción alternativa de la geometría de accesos próximos ............................... 172

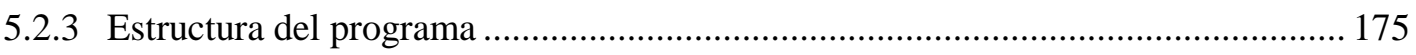

5.3 CÁlCULO DE TRAYECTORIAS Y VELOCIDADES (AX-2) .................................... 177

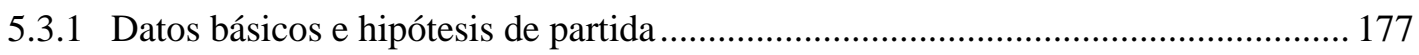

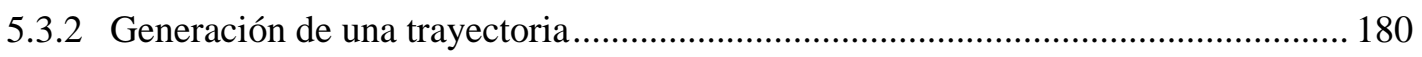

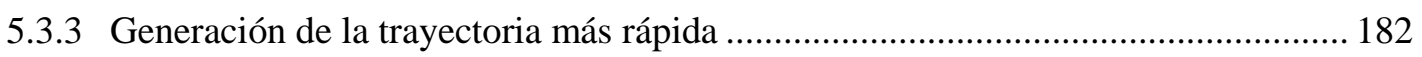

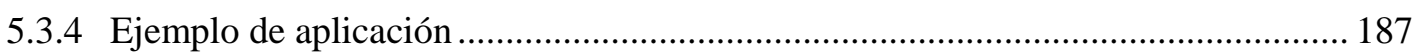

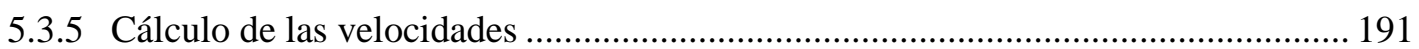

5.4 REGIÓN DE CENTROS FACTIBLES (AX-3) .............................................. 191

CAPÍTULO 6. APLICACIONES EXPERIMENTALES......................................... 193

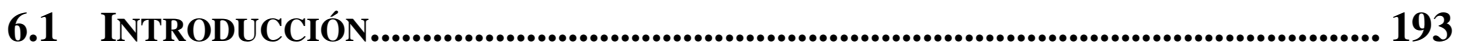

6.2 CONSTRUCCIÓN DE UNA NUEVA GLORIETA DE UN CARRIL ............................. 193

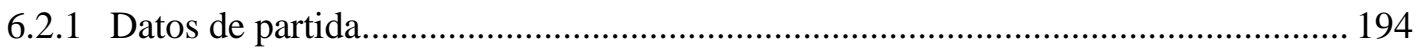

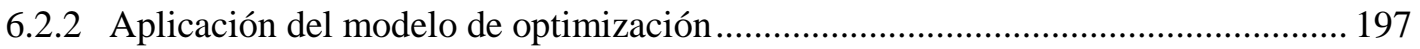

6.3 REMODELACIÓN DE UNA GLORIETA EXISTENTE. ........................................... 202 


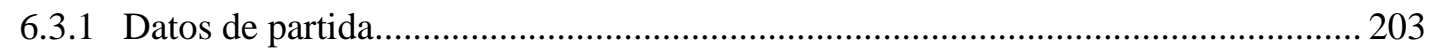

6.3.2 Aplicación del modelo de optimización.................................................................. 205

6.4 ANÁLISIS DEL COMPORTAMIENTO DEL MODELO ............................................ 211

CAPÍTULO 7. CONCLUSIONES ................................................................................... 213

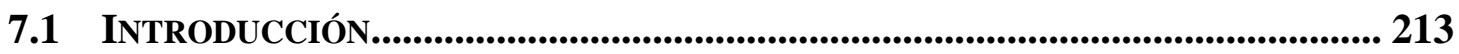

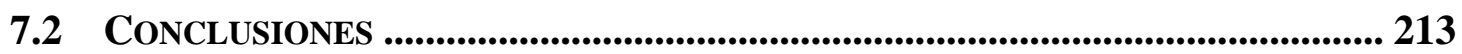

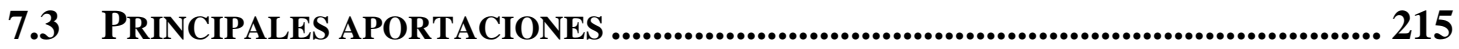

7.4 FUTURAS LÍNEAS DE INVESTIGACIÓN .......................................................... 216

8. CAPÍTULO 8. BIBLIOGRAFÍA ............................................................................. 217 


\section{ÍNDICE DE FIGURAS}

\section{CAPÍTULO 1}

Figura 1. 1 Objetivos del trazado en planta de glorietas. ........................................... 4

Figura 1.2 Sistema convencional de diseño en planta de glorietas. .............................. 5

\section{CAPÍtUlo 2}

Figura 2. 1 Conversión de una intersección giratoria a glorieta.................................. 14

Figura 2. 2 Alternativa a los diseños convencionales de glorietas. ............................. 15

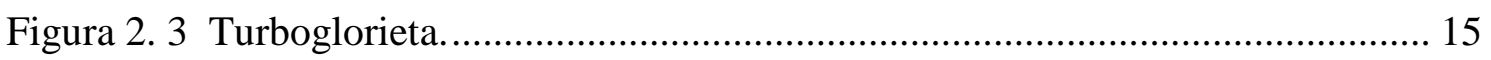

Figura 2. 4 Puntos de conflicto: intersección convencional vs glorieta. ....................... 17

Figura 2. 5 Deflexión en el perfil de velocidades en el paso por glorieta. ..................... 18

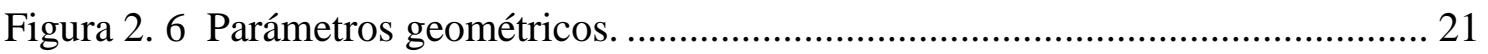

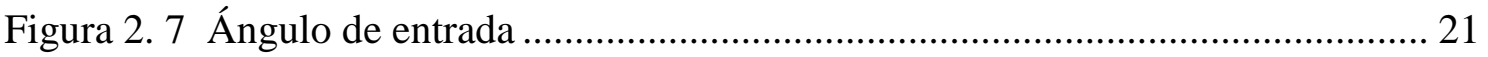

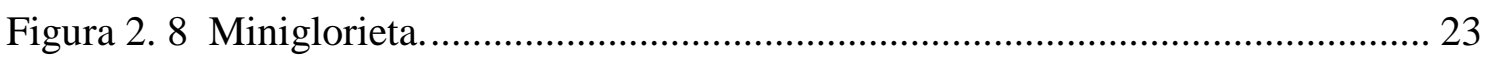

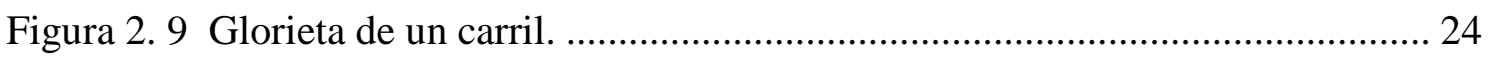

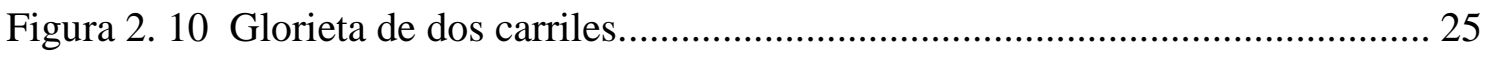

Figura 2. 11 Funcionamiento en glorietas multicarril (sin selección de carril)............. 26

Figura 2. 12 Funcionamiento en glorietas multicarril (con selección de carril)............ 26

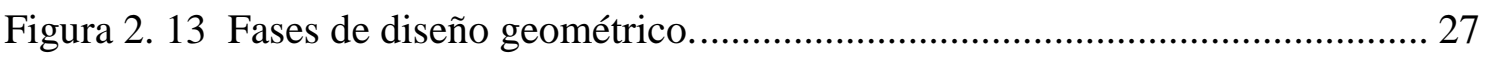

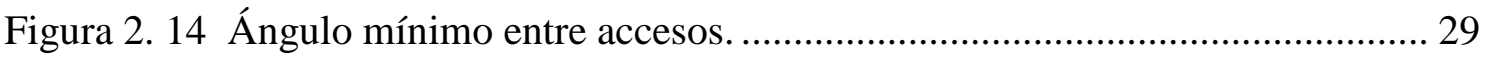

Figura 2. 15 Posiciones de los ejes de acceso respecto del centro de la glorieta. ......... 29

Figura 2. 16 Método “alberta" de señalización horizontal. .......................................... 35

Figura 2. 17 Iluminación en glorietas: periférica (izquierda) y central (derecha)......... 36

Figura 2. 18 Parámetros geométricos con mayor incidencia en la capacidad. ............... 44

Figura 2. 19 Relaciones entre capacidad y parámetros geométricos............................. 45

Figura 2. 20 Gorjal para el paso de los vehículos de mayor longitud. ......................... 52

Figura 2. 21 Condicionante en alzado del paso de los vehículos de mayor longitud.... 53

Figura 2. 22 Distribución del número de accidentes por modos. ................................ 57

Figura 2. 23 Porcentaje de accidentes fatales por modos........................................ 57

Figura 2. 24 Tipos de colisión (izquierda) y accidentes (derecha) en glorietas. ........... 59 


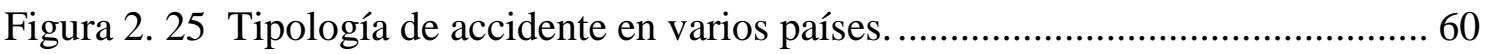

Figura 2. 26 Parámetros geométricos con una mayor influencia en la seguridad. ........ 62

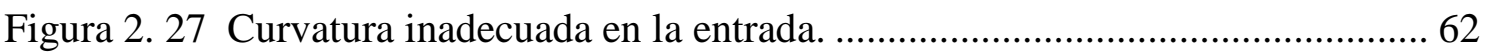

Figura 2.28 Parámetros geométricos relacionados con la siniestralidad...................... 67

Figura 2. 29 Cálculo del radio de la trayectoria de entrada.......................................... 72

Figura 2. 30 Recomendaciones para el cálculo de la trayectoria de entrada................ 72

Figura 2. 31 Cálculo del radio de la deflexión. ............................................................. 73

Figura 2. 32 Solape de trayectorias naturales en la entrada........................................ 74

Figura 2. 33 Puntos de conflicto en peatones: intersección convencional vs glorieta... 77

Figura 2. 34 Prolongación del carril bus en la entrada hacia una glorieta...................... 80

Figura 2. 35 Trayectorias según el método de la norma de EE.UU. ............................ 90

Figura 2. 36 Trayectorias según el método de la norma de Wisconsin (EE.UU).......... 90

Figura 2. 37 Trayectorias según el método de la norma de Idaho (EE.UU). ............... 91

Figura 2. 38 Trayectorias según la normativa de Australia...................................... 92

Figura 2. 39 Relación entre velocidades y los radios horizontales............................... 94

Figura 2. 40 Radios críticos en el método de evaluación de la consistencia de EE.UU.

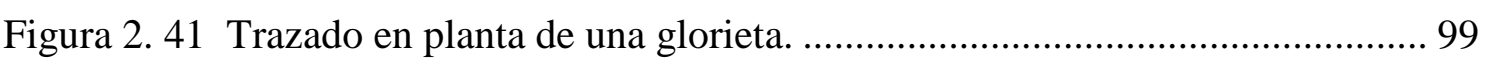

Figura 2. 42 Polígono de localización del centro de la glorieta. ................................ 107

Figura 2. 43 Anchura variable de la calzada anular. ................................................. 108

Figura 2. 44 Modificación de la forma de la isleta para promover la deflexión. ........ 110

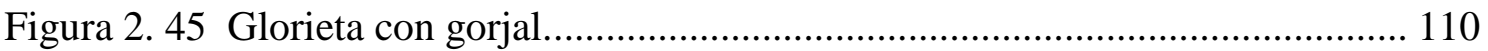

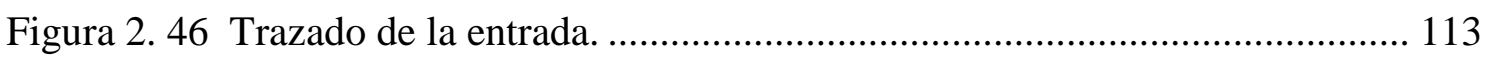

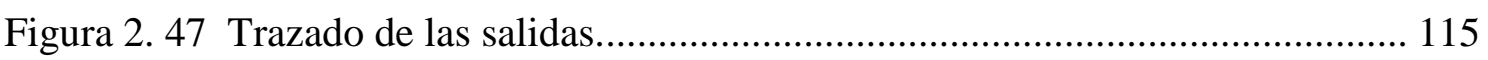

Figura 2. 48 Construcción para conseguir espacio adicional en isletas....................... 117

Figura 2. 49 Tipología de isletas deflectoras............................................................. 118

Figura 2. 50 Curvas sucesivas en el carril de entrada a una glorieta.......................... 119

Figura 2. 51 Abocinamiento de la entrada de forma gradual. .................................... 120

Figura 2. 52 Duplicación del carril de entrada mediante carril de cambio de velocidad.

Figura 2. 53 Datos de partida. Modelo de Easa and Mehmood (2004)...................... 128

Figura 2. 54 Cálculo de trayectorias. Modelo de Easa and Mehmood (2004)............. 129

Figura 2. 55 Estructura de la población de un algoritmo genético............................. 131 
Figura 2. 56 Esquema básico de un algoritmo genético. 132

Figura 2.57 Cruza: un punto (a las izquierda) y dos puntos (a la derecha). 134

\section{CAPÍTULO 3}

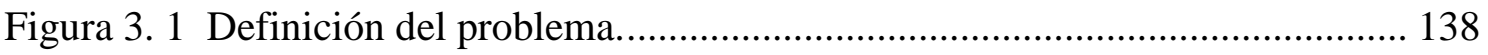

Figura 3. 2 Identificación de los elementos del problema de optimización. ................ 140

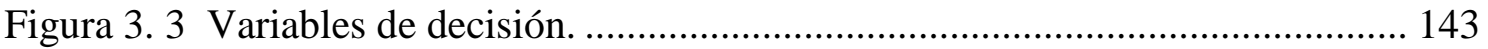

Figura 3. 4 Identificación de las componentes de la función objetivo. ........................ 146

\section{CAPÍTULO 4}

Figura 4. 1 Estructura del algoritmo genético 154

\section{CAPÍtUlO 5}

Figura 5. 1 Construcción geométrica de un acceso.

Figura 5. 2 Construcción del arco común entra las entradas y las salidas consecutivas.

Figura 5. 3 Construcción alternativa en una entrada y una salida consecutiva. 174

Figura 5. 4 Resguardos 178

Figura 5. 5 Tipos de trayectorias. 179

Figura 5. 6 Cálculo de la trayectoria directa. 181

Figura 5. 7 Reconstrucción de la trayectoria directa. 181

Figura 5. 8 Cálculo de la trayectoria con deflexión. 182

Figura 5. 9 Definición de los puntos de entrada y salida (TD). 184

Figura 5. 10 Definición de los puntos auxiliares (TDF). 185

Figura 5.11 Cálculo de trayectorias: glorieta de estudio. 187

Figura 5.12 Cálculo de trayectorias: resultados del ejemplo de aplicación. 188

Figura 5. 13 Cálculo de trayectorias: resultados del ejemplo de aplicación (II). 190

Figura 5.14 Cálculo de la región de centros factibles (FCA). 192 


\section{CAPÍTULO 6}

Figura 6. 1 Caso I. Conversión de un nudo de tres tramos a glorieta.......................... 194

Figura 6. 2 Caso I. Datos de partida: alineaciones de los accesos.............................. 195

Figura 6. 3 Caso I. Región de centros factibles....................................................... 197

Figura 6. 4 Caso I. Huella de las soluciones geométricas factibles............................ 198

Figura 6. 5 Caso I. Evolución del valor de la función objetivo con las generaciones. 199

Figura 6. 6 Caso I. Solución (geometría y trayectorias)............................................ 200

Figura 6. 7 Caso I. Solución (implantación en el territorio)....................................... 200

Figura 6. 8 Caso II. Remodelación de una glorieta multicarril. ................................. 203

Figura 6. 9 Caso II. Datos de partida: Alineaciones de los accesos. ........................... 204

Figura 6. 10 Caso II. Región de centros factibles....................................................... 206

Figura 6. 11 Caso II. Huella de las soluciones geométricas factibles. ....................... 207

Figura 6. 12 Caso I1. Evolución del valor de la función objetivo con las generaciones. 207

Figura 6. 13 Caso II. Solución (geometría y trayectorias)........................................ 208

Figura 6. 14 Caso II. Solución (implantación en el territorio). .................................... 209 


\section{ÍNDICE DE TABLAS}

\section{CAPÍTULO 2}

Tabla 2. 1 Porcentaje de reducción del número de accidentes en varios países............. 56

Tabla 2. 2 Criterio de consistencia del diseño de una vía. ............................................ 84

Tabla 2. 3 Criterio de consistencia en la velocidad de operación de una vía................ 84

Tabla 2. 4 Criterios de consistencia para el diseño de glorietas en España................... 96

Tabla 2. 5 Criterios para el control de velocidades en las normas de diseño................. 97

Tabla 2. 6 Valores del diámetro exterior en las principales normas de diseño. .......... 106

Tabla 2. 7 Anchura de la calzada anular en las principales normas de diseño............. 108

Tabla 2. 8 Anchura de entrada en las principales normas de diseño......................... 111

Tabla 2. 9 Radio exterior de entrada en las principales normas de diseño................... 113

Tabla 2. 10 Anchura de salida en las principales normas de diseño. ........................... 115

Tabla 2. 11 Radio de salida en las principales normas de diseño................................ 116

Tabla 2. 12 Longitud de las isletas deflectoras según las principales normas de diseño. 118

Tabla 2. 13 Influencia de los elementos de diseño en la capacidad y la seguridad..... 122

Tabla 2. 14 Investigaciones sobre la optimización del trazado de carreteras............... 127

\section{CAPÍtULO 5}

Tabla 5. 1 Datos de partida. Ejemplo de aplicación del cálculo de trayectorias. 187

\section{CAPÍTULO 6}

Tabla 6. 1 Caso I. Datos de partida: valores mínimos de los parámetros geométricos.

Tabla 6. 2 Caso I. Umbrales de las variables de decisión. 197

Tabla 6. 3 Caso 1. Solución: valores de las variables de decisión. 201

Tabla 6. 4 Caso I. Solución: velocidades. 201

Tabla 6. 5 Caso II. Datos de partida: valores mínimos de los parámetros geométricos. 
Tabla 6. 6 Caso II. Umbrales de las variables de decisión......................................... 205

Tabla 6. 7 Caso II. Solución: valores de las variables de decisión.............................. 209

Tabla 6. 8 Caso II. Solución: velocidades. ................................................................ 210 


\section{CAPÍTULO 1. INTRODUCCIÓN}

El objetivo de esta tesis es desarrollar un procedimiento automatizado que ayude al proyectista en la definición de la geometría en planta de una glorieta, de forma que se satisfagan los requerimientos funcionales con condiciones de seguridad óptimas y se mejoren las técnicas de trazado existentes.

La glorieta es un tipo de nudo constituido por una calzada anular (generalmente circular) con sentido de circulación único, a la cual conectan unas vías de acceso (o patas) cuyos diseños son interdependientes. El funcionamiento del tráfico en una glorieta se basa en el establecimiento de la prioridad de paso para los vehículos que circulan por la calzada anular, generándose así un mecanismo de autorregulación que exige ciertas condiciones (MF, 2012):

- Los vehículos que pretendan entrar a la calzada anular deben ceder el paso a los que ya circulen por ésta.

- Los vehículos que entren en la calzada anular, en lugar de trenzarse a una velocidad relativamente alta con los vehículos que ya circulen por ella, se deben insertar en los huecos existentes entre éstos últimos; lo cual requiere que por la calzada anular la circulación se desarrolle a una velocidad relativamente reducida.

- La velocidad de entrada a la calzada anular (y en menor medida la de salida de ella) se debe controlar mediante la imposición de unas inflexiones adecuadas en la trayectoria de los vehículos, generadas con la propia disposición de las patas y la implantación de unas isletas deflectoras, que además cumplen la función de separación de los tráficos de salida y de entrada.

La definición de la geometría de una glorieta requiere la consideración de un número elevado de variables o parámetros de diseño. Son principalmente las dimensiones y la posición de la calzada anular, y la geometría (anchura de calzada y trazado) de la entrada y la salida de cada pata de acceso. 
En el proceso de diseño, se deben fijar unos valores de los parámetros tales que la geometría resultante permita alcanzar unos objetivos predefinidos relacionados con el funcionamiento de la circulación, la seguridad y el coste. En particular, funcionalmente el trazado en planta debe satisfacer cinco requerimientos (Kuhlow, 2011): una adecuada capacidad, un apropiado acomodo de los vehículos de mayor longitud, unas condiciones de seguridad satisfactorias, un conveniente acomodo de los flujos de los usuarios no motorizados y una adecuada canalización de las trayectorias de los vehículos.

En primer lugar, el diseño debe proporcionar una capacidad suficiente para que el tráfico opere con un adecuado nivel de servicio en la hora punta. Esta comprobación es generalmente llevada a cabo al comienzo del diseño y condiciona fundamentalmente las dimensiones mínimas de la glorieta y el número de carriles en las entradas. Los métodos de cálculo de la capacidad han sido objeto de investigación durante muchos años y para realizar el estudio se pueden utilizar diferentes paquetes informáticos. Una muestra de las principales aplicaciones informáticas son RODEL (Crown, 1992), SIDRA (Akçelik y Associates, 2004) y VISSIM (PTV, 2007).

En segundo lugar, es necesario comprobar que el diseño de la glorieta permite el paso y giro no forzado del vehículo de mayor longitud que tenga una probabilidad razonable de utilizarla (denominado vehículo patrón). Para su análisis, se puede realizar una comprobación manual, o bien, hacer uso de uno de los diferentes programas informáticos existentes. Por ejemplo, el software AutoTurn (Carrasco, 1996) permite dibujar, en un entorno de $\mathrm{CAD}$, el área barrida de un vehículo siguiendo una trayectoria a diferentes velocidades.

En tercer lugar, la geometría debe favorecer la moderación de velocidades y su consistencia. Este aspecto es clave para la seguridad y condiciona de manera significativa la geometría final del diseño (NHCRP, 2010; AUSTROADS, 2011). En términos generales, la consistencia mide el grado en que un determinado diseño de carretera alcanza el objetivo de evitar la aparición de maniobras en la conducción que puedan desencadenar en un accidente, debido a la vulneración de las expectativas del 
conductor. Existen muchas formas de evaluar la consistencia. La más común se basa en la estimación de las velocidades de operación ${ }^{1}$ y su análisis.

En las normas de diseño que han adoptado este concepto se especifica que las velocidades de operación deben resultar lo más homogéneas posibles y proponen dos criterios para evaluar la consistencia: limitar las diferencias de velocidad de las corrientes de tráfico en conflicto y entre las alineaciones que componen cada una de las trayectorias de paso por la glorieta. Otro criterio habitual relacionado con el control de las velocidades consiste en la imposición de una velocidad máxima de entrada a la calzada anular.

El estudio de la seguridad del diseño conforme a los criterios especificados requiere la modelación previa de las trayectorias de los vehículos y el análisis de los perfiles de velocidad $^{2}$ asociados a estas trayectorias. En la práctica, la definición de las trayectorias es un proceso muy laborioso ya que no existen herramientas informáticas que permitan realizar esta tarea de una forma automatizada para toda la casuística que se pueda presentar de disposición de las patas y de la calzada anular.

Otro aspecto del diseño relacionado con la seguridad es la visibilidad. Desde cada acceso se deben valorar tres situaciones. La primera, de aproximación, establece un despeje necesario para poder percibir la glorieta con suficiente antelación; se suele fijar desde un punto situado en el acceso a una distancia antes de la marca de detención igual a la necesaria para detenerse sin rebasarla. La segunda, de inserción, se refiere a un área mínima visible de la calzada anular y el acceso anterior desde un observador situado en la entrada. De esta forma el conductor puede elegir un hueco en la circulación para realizar la incorporación a la calzada anular. La tercera, se refiere a la visibilidad de los pasos de peatones situados en el propio acceso antes de llegar a la calzada anular y en la

\footnotetext{
${ }^{1}$ La velocidad de operación es la velocidad a la que los conductores circulan por una vía ó elemento geométrico. Aunque se desarrollará una vez construida la vía, se han elaborado formulaciones para estimarla con mayor o menor fiabilidad (puede ser condicionada por un número importante de variables) en fase de diseño geométrico.

${ }^{2}$ El perfil de velocidades es la representación gráfica de las velocidades de operación a lo largo del trazado de una trayectoria.
} 
siguiente salida. En este trabajo no se han considerado los condicionantes relativos a la visibilidad debido a que su estudio depende de las características del trazado en alzado.

En cuarto lugar, se deben considerar las necesidades de peatones y/o ciclistas, para que en caso de que sus trayectorias entren en conflicto con las de los vehículos, se garanticen unas adecuadas condiciones de seguridad. Para satisfacer esta necesidad generalmente se establecen ciertos condicionantes en los parámetros de diseño y en los perfiles de velocidades deducidos de la geometría final.

Por último, en glorietas con más de un carril en los accesos, se debe garantizar que la geometría favorezca un correcto guiado de los vehículos en las entradas a la calzada anular y en las salidas desde ésta para evitar que se solapen las distintas trayectorias. Como en el caso anterior, esto se puede conseguir condicionando el valor de los parámetros que definen la geometría de la glorieta.

De forma esquemática, las necesidades del trazado en planta se han representado en la Fig. 1.1.

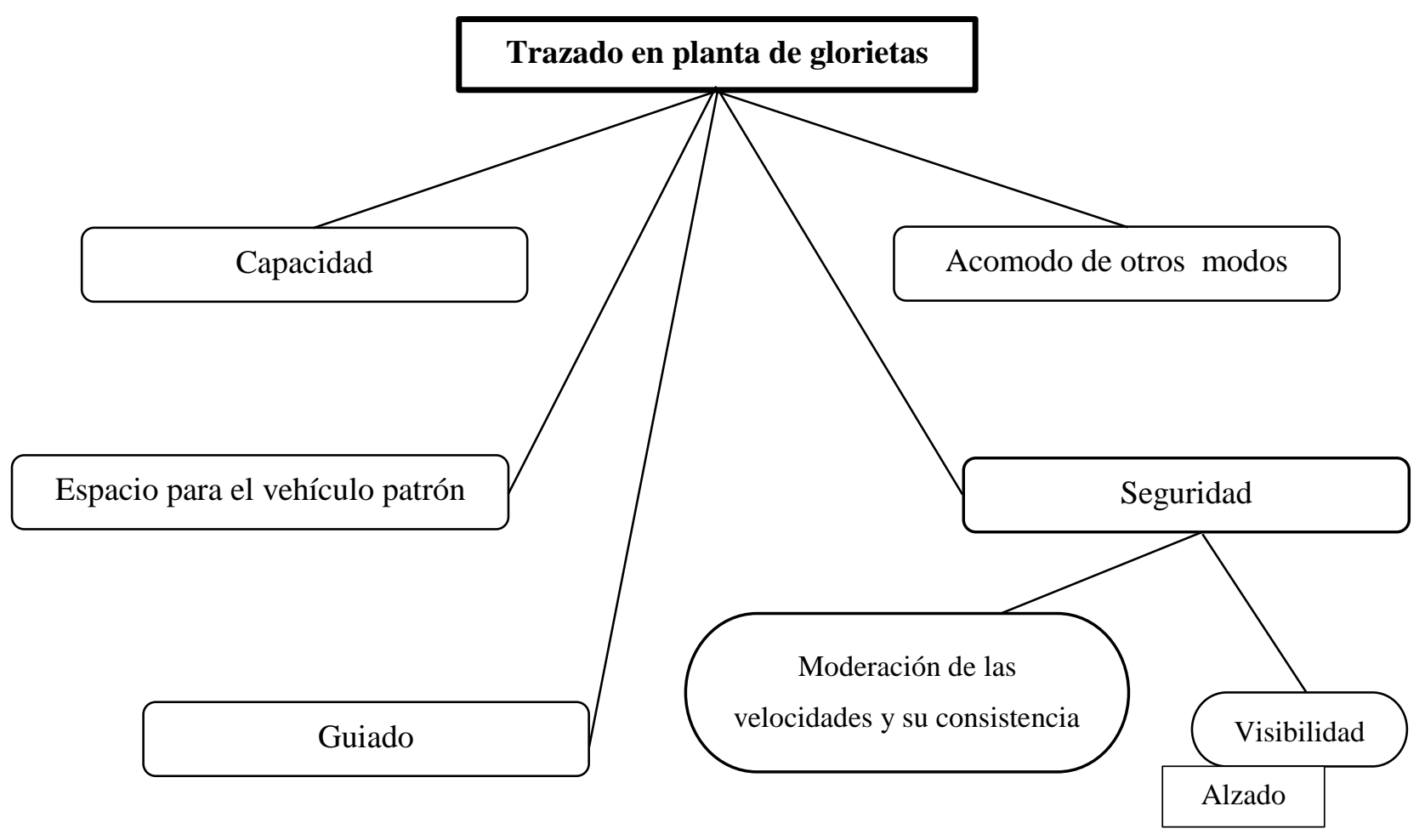

Figura 1. 1 Objetivos del trazado en planta de glorietas. 
Los diferentes objetivos entran en conflicto durante el proceso de diseño por lo que se debe analizar el comportamiento de la glorieta conforme a cada uno de ellos, y en la medida de lo posible llevar a cabo una evaluación desde una perspectiva global.

El procedimiento habitual de definición del trazado, representado esquemáticamente en la Fig. 1.2, es un proceso iterativo que parte de la asignación inicial de unos valores a los parámetros de diseño, los cuales se van modificando mediante la técnica de prueba y error, comprobando en cada iteración la bondad de las soluciones generadas conforme a los objetivos planteados.

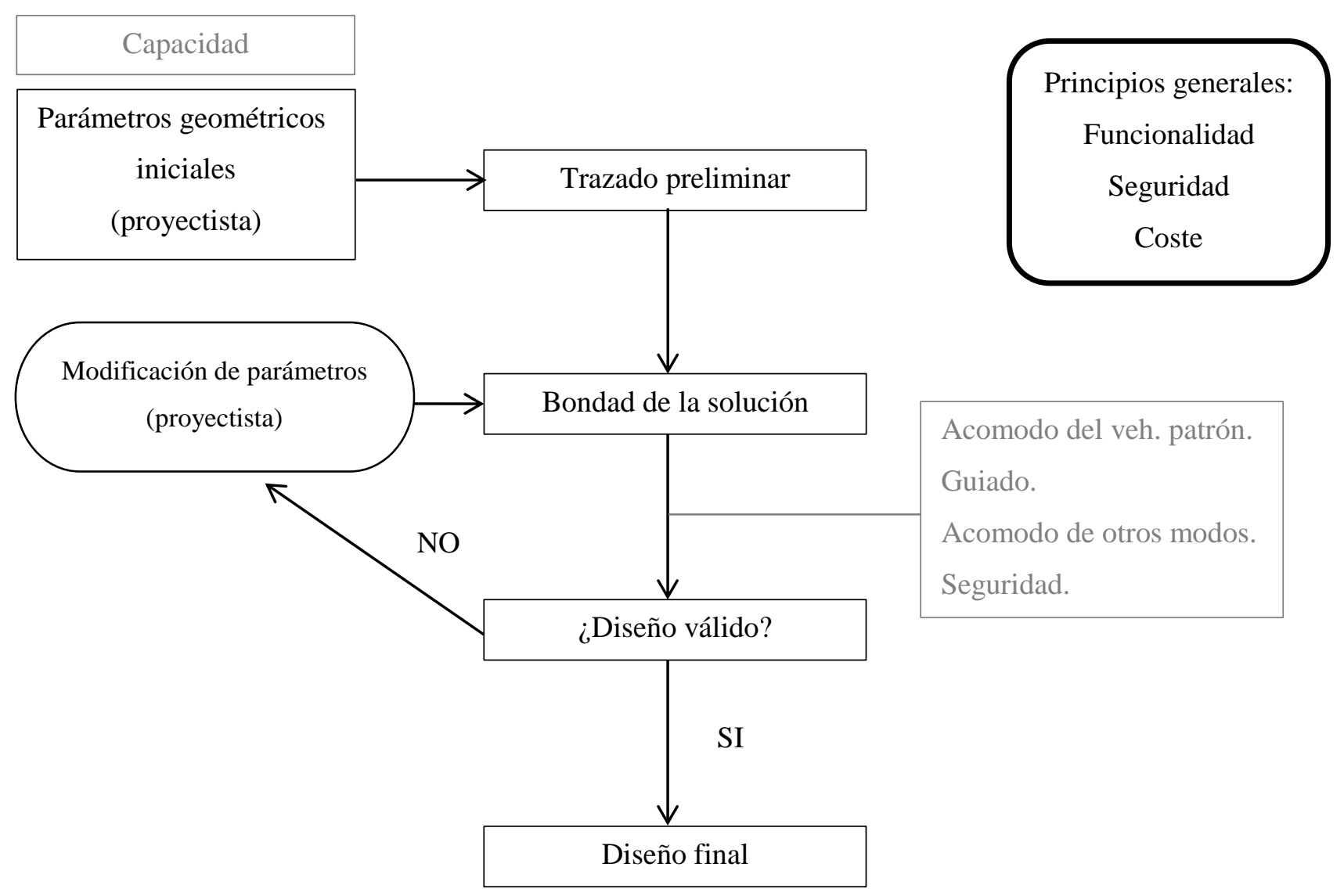

Figura 1.2 Sistema convencional de diseño en planta de glorietas.

Mediante los programas integrados de trazado de obras lineales es posible generar la geometría de una glorieta a partir de la definición de un conjunto de ejes de replanteo. Este proceso es laborioso y requiere la utilización posterior de otros programas para llevar a cabo la evaluación del diseño en planta conforme a los objetivos descritos. 
Como consecuencia, la cantidad de iteraciones que se pueden llevar a cabo antes de adoptar una solución final estará limitada por motivos de tiempo y coste.

Algunos programas específicos de diseño de glorietas, como TORUS (Ramos et. al, 2010), permiten la definición interactiva de la geometría en planta y la evaluación de manera dinámica del trazado propuesto. De esta forma, el proyectista puede ver fácilmente cómo afecta un cambio en el trazado a los objetivos establecidos, por lo que dispone de un mayor tiempo para considerar diferentes opciones y aplicar su buen juicio. A pesar de ser herramientas muy útiles para generar soluciones, presentan algunos aspectos que pueden ser mejorados:

- El trabajo sigue siendo manual y está sujeto al criterio del proyectista, que decide el valor de los parámetros de diseño de acuerdo a su experiencia y las recomendaciones de la norma.

- En la comprobación de la seguridad del diseño, no se puede realizar para todos los casos posibles el cálculo de las trayectorias y, por tanto, la evaluación de la consistencia.

- No se aportan criterios para decidir la mejor situación de la calzada anular ni tampoco información sobre el sentido en el cual se deben modificar los parámetros de diseño (los objetivos son contrapuestos) en las iteraciones manuales.

En esta investigación se desarrolla un procedimiento que permite llevar a cabo la búsqueda automática de la geometría de una glorieta de forma que queden satisfechos los objetivos funcionales de diseño planteados. El procedimiento utiliza técnicas heurísticas de optimización y puede ser fácilmente implementado en un programa de ordenador, lo cual facilita su empleo por los profesionales del sector. El procedimiento imita el proceso de diseño seguido por un proyectista experto y supera las limitaciones de las herramientas informáticas de diseño actuales. 


\subsection{OBJETIVOS}

El objetivo general de esta tesis es desarrollar un procedimiento que ayude al proyectista en la definición de la geometría en planta de una glorieta, satisfaciendo los requerimientos funcionales y con unas condiciones óptimas desde el punto de vista de la seguridad.

Para alcanzar este objetivo general, se han establecido una serie de objetivos parciales:

- Desarrollar un procedimiento que permita la definición geométrica de la glorieta a partir de la selección de una serie de variables escalares (parámetros de diseño).

- Elaborar un procedimiento para la definición de las trayectorias de los vehículos a partir de la geometría en planta.

- Elaborar un procedimiento para determinar la región en la cual se puede ubicar el centro de la glorieta.

- Elaborar un algoritmo de optimización que permita llevar a cabo la búsqueda de la solución geométrica más adecuada dentro del espacio de soluciones potenciales posibles, de forma que se satisfagan los requerimientos funcionales con condiciones de seguridad óptimas.

\subsection{Metodología}

Para alcanzar los objetivos anteriores, el trabajo de investigación se desarrolló en las siguientes etapas:

1. Estado del arte y revisión normativa. 
Consulta de las investigaciones realizadas sobre el tema objeto de la tesis y análisis de las normativas internacionales sobre diseño de glorietas.

2. Desarrollo del modelo de optimización.

a. Formulación del problema.

En esta fase se parte de la descripción de la esencia del problema de diseño para alcanzar posteriormente una formulación matemática del mismo. Comprende las siguientes tareas:

- Análisis y descripción de las variables que intervienen en el diseño de una glorieta.

- Identificación de las variables de decisión a considerar en el modelo de optimización y desarrollo de los constructores geométricos necesarios para el cálculo de la geometría de la glorieta a partir de los valores de estas variables.

- Definición de la función objetivo.

Análisis de los criterios que permitan evaluar la calidad de cada diseño geométrico de glorieta posible. Esta tarea requiere el desarrollo de unos constructores geométricos necesarios para el cálculo de las trayectorias y de las velocidades en ellas.

- Definición del sistema de restricciones.

Identificación de las condiciones que permiten acotar el dominio de búsqueda conforme a la realidad del problema y a los objetivos que se desean alcanzar. Se desarrolla un procedimiento específico que permite determinar la región en la cual se puede ubicar el centro de la glorieta.

- Formulación algebraica del problema.

Se lleva a cabo una formulación matemática del problema de optimización de manera que sirva de punto de partida para su resolución posterior mediante el empleo de alguna de las técnicas numéricas existentes. 
b. Resolución del problema matemático.

En esta fase el problema matemático formulado en la etapa anterior es resuelto utilizando técnicas heurísticas de optimización basadas en algoritmos genéticos.

c. Análisis de resultados.

Análisis de los resultados mediante la aplicación práctica del modelo en glorietas de diferentes tipologías comprobando el comportamiento de los códigos informáticos generados.

3. Conclusiones.

Obtención de las conclusiones sobre el modelo de optimización, aportaciones originales desarrolladas en las tesis e identificación de futuras líneas de investigación.

\subsection{ESTRUCTURA DE LA TESIS}

El contenido de la investigación se presenta a lo largo de ocho capítulos.

Capítulo 1 - Introducción. Presentación del problema y de los objetivos de la tesis.

Capítulo 2 - Antecedentes. En este capítulo se han resumido las principales conclusiones de la literatura científica en lo que se refiere a los aspectos de interés sobre el diseño de glorietas y las técnicas de optimización.

Capítulo 3 - Formulación del problema de optimización. En este capítulo se presenta la esencia del problema real y se define el modelo matemático que se ha desarrollado para realizar la optimización.

Capítulo 4 - Resolución mediante técnicas de programación matemática. En este capítulo se presenta la resolución del problema matemático formulado mediante un procedimiento heurístico y la aplicación informática que permite realizar los cálculos. 
Capítulo 5 - Algoritmos auxiliares. Este capítulo describe una serie de procedimientos que ha sido necesario elaborar para poder aplicar el modelo y que permiten la construcción automática de la geometría a partir de unos parámetros geométricos, la definición de las trayectorias para una determinada geometría y la delimitación de un área en el espacio en el cual se puede situar el centro de la glorieta.

Capítulo 6 - Aplicaciones experimentales. En este capítulo se muestra la aplicación del modelo de optimización en el estudio de dos casos reales y se discuten los resultados obtenidos.

Capítulo 7 - Conclusiones. En este capítulo se presentan las principales conclusiones obtenidas, se describen las principales aportaciones y se proponen futuras líneas de investigación que pueden complementar el contenido de este trabajo.

Capítulo 8 - Referencias. En este capítulo se muestra la relación de bibliografía utilizada y que ha sido citada en el texto. 


\section{CAPÍTULO 2. ANTECEDENTES}

\subsection{INTRODUCCIÓN}

De acuerdo a la metodología que se ha propuesto, el punto de partida de esta tesis doctoral es la revisión de las publicaciones realizadas sobre el tema objeto de la investigación. Mediante el estudio de los antecedentes es posible sentar las bases teóricas sobre las que se fundamentan todos los desarrollos posteriores.

El capítulo se ha dividido en cuatro apartados. En el primero, se resume el estudio de los elementos que permiten la definición de la geometría de una glorieta y se analizan los procedimientos de diseño aceptados internacionalmente. A continuación, se presentan las principales aplicaciones informáticas que se han desarrollado para ayudar al proyectista en el encaje del trazado. En tercer lugar, se realiza una revisión de las principales normas de diseño publicadas a nivel mundial y de los valores recomendados en éstas para los parámetros de diseño. Finalmente, se analizan los procedimientos heurísticos de optimización y las aplicaciones llevadas a cabo hasta la fecha actual al diseño geométrico de carreteras e intersecciones.

\subsection{Procedimiento DE DISEÑO DE GLORIETAS}

\subsubsection{Introducción}

El estudio de los procedimientos de diseño de glorietas se inicia con un apartado dedicado al análisis histórico de las intersecciones giratorias. A continuación, se describirán los procedimientos generales de diseño de glorietas y, de forma detallada, los aspectos a tener en cuenta en el diseño: la capacidad, las necesidades de área barrida del vehículo patrón, la seguridad, el acomodo de otros modos y el guiado. Por último, y debido a la importancia en la investigación, se llevará a cabo una revisión detallada del 
concepto de consistencia del trazado en carreteras particularizando posteriormente para el caso de glorietas.

\subsubsection{Evolución histórica de las intersecciones giratorias}

A principios del siglo pasado, las grandes ciudades empezaron a registrar problemas importantes de saturación en los encuentros de calles.

En respuesta a este problema, el arquitecto francés E. Hénard (1.849 - 1.923) propuso un nuevo modelo de intersección para la ciudad de París que presentaba las siguientes características (Darder, 2005): sistema de circulación giratorio y en el mismo sentido alrededor de un obstáculo central, acondicionamiento de las entradas y salidas en los accesos, zonas de refugio para peatones, sistema de señalización mediante carteles flecha y sistema de iluminación en el centro de la plaza circular.

Según Hénard, mediante las intersecciones giratorias (circulares) se mejoraban las condiciones de seguridad debido a la reducción en el número de puntos de conflicto $^{3}$, principal problema atribuido a los cruces de la época, y a la modificación del tipo de accidente, ya que se evitaba el cruce de trayectorias mediante trazadas secantes característico de las intersecciones convencionales. Después de varios proyectos, en 1907 se instala la primera intersección giratoria en la conocida plaza Charles de Gaulle de París.

Sin conocer la solución desarrollada por Hénard, W. Eno (1.858 - 1.945) en 1905 pone en servicio la primera plaza circular en la ciudad de Nueva York. La diferencia entre las dos propuestas radica en el tamaño de la isleta central. Hénard sostiene que debe tener un diámetro mayor que $8 \mathrm{~m}$ y Eno argumenta un diámetro inferior (Darder, 2005). En Gran Bretaña, la primera intersección giratoria se construye en 1909 en la ciudad de Letchworth (Sollershott Circus).

\footnotetext{
${ }^{3}$ Un punto de conflicto materializa un lugar en el que se puede producir una interacción entre dos vehículos (convergencia, divergencia, cruce,...) ó entre un vehículo y un peatón.
} 
En los primeros diseños no se asigna regla de prioridad. En 1910, Francia desarrolla la conocida como "regla de prioridad a la derecha", en intersecciones, norma que posteriormente fue adoptada en diferentes países. La aplicación en las intersecciones giratorias significó asignar la prioridad a los vehículos que acceden a la calzada anular.

El factor decisivo de diseño de las intersecciones circulares es la longitud de trenzado entre un acceso y el siguiente. Para proporcionar capacidad, esta longitud debe ser importante ya que las colas se generan en la calzada anular. Como consecuencia, el tamaño de las intersecciones circulares es muy importante. Este aspecto dificulta su inserción en el territorio por lo que, cuando no existe disponibilidad de espacio, surge la necesidad de regular la prioridad (semáforos, señalización, etc).

En el período entre la década de los años veinte y cincuenta se expande la construcción de intersecciones giratorias en medios urbanos e interurbanos. Cabe destacar el caso de Reino Unido, país en el que se generaliza su diseño y donde se inician las primeras investigaciones sobre capacidad.

Después de la segunda guerra mundial el parque automovilístico crece y los problemas de saturación en las intersecciones circulares son muy evidentes. Para solucionar este problema, los ingenieros ingleses deciden modificar la regla de prioridad y asignar ésta a los vehículos que circulan por la calzada anular. Es el origen de las "glorietas modernas" (a partir de aquí simplemente glorietas ${ }^{5}$ ). Después de una prueba en 83 intersecciones saturadas, Reino Unido instaura de forma oficial la regla de prioridad en la calzada anular en el año 1966 convirtiendo a las glorietas en un tipo de intersección más eficiente que sus predecesoras.

El primer impacto de la modificación de la regulación de la prioridad es la reducción en el tamaño de la calzada anular. En la Fig. 2.1 se muestra un caso real de la conversión de una intersección giratoria con prioridad para los vehículos que acceden al cruce

\footnotetext{
${ }^{4}$ La regla de prioridad a la derecha establece que, en intersecciones sin señalizar, se debe ceder el paso al vehículo que se aproxima por la derecha.

5 En realidad el primer uso oficial del término glorieta se hizo en una circular (MOT 302) publicada en 1929 por el Ministerio de Transportes de Reino Unido.
} 
(círculo exterior) a otra con prioridad para los vehículos que circulan por la calzada anular (círculo interior).

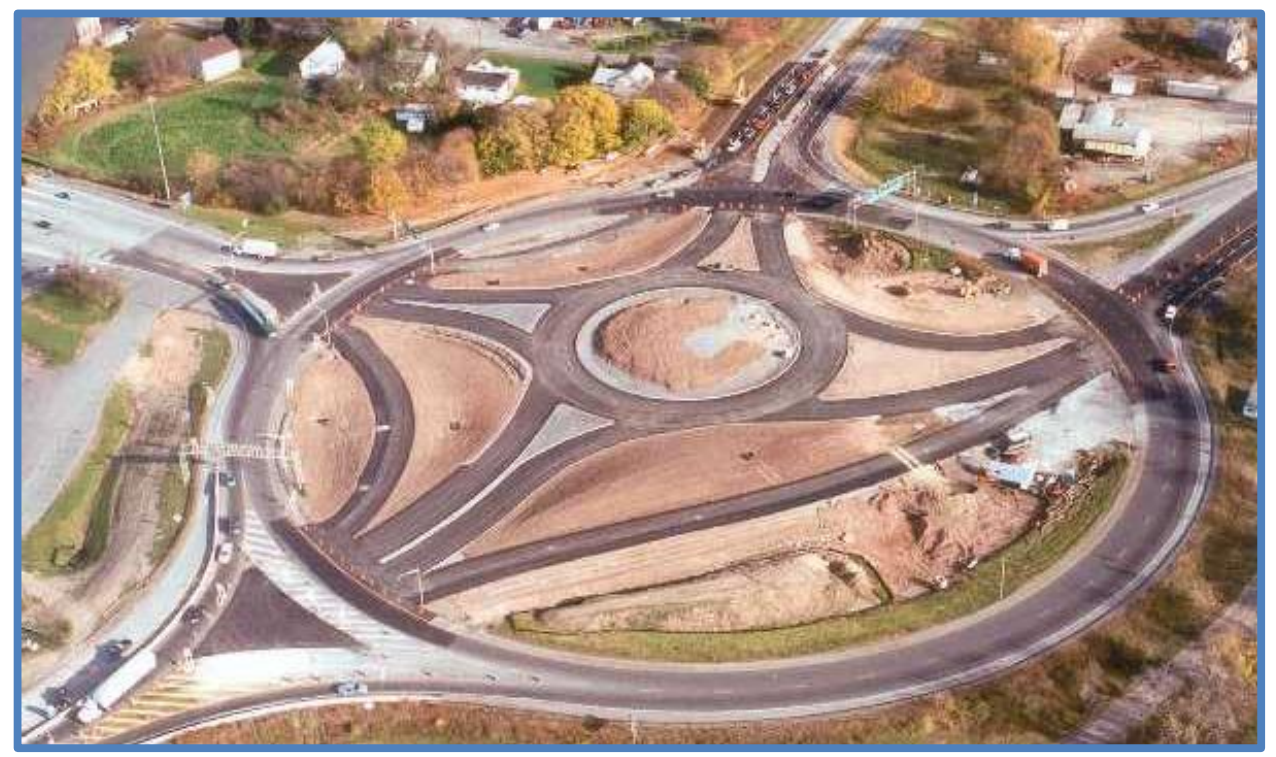

Figura 2. 1 Conversión de una intersección giratoria a glorieta.

Fuente: McCulloch, 2005.

Con la nueva regulación, las glorietas presentan dos características básicas: la deceleración del vehículo en las entradas y la relevancia de la anchura de la entrada en la capacidad. Otras diferencias con las primeras intersecciones giratorias son la inaccesibilidad de la isleta central y la prohibición de aparcamientos en la calzada anular y en los accesos.

En los años siguientes, la asignación de la prioridad a la calzada anular se extiende hacia el resto de países (Kennedy, 2008): Suecia (1967); Noruega y Dinamarca, en la década de los setenta; Australia, Francia, Alemania, Holanda, Bélgica y Suiza, en la década de los ochenta; y, Estados Unidos, en la década de los noventa. En España, se instaura a raíz de la Ley de Circulación estatal de 1990. Las glorietas se convierten en un tipo de intersección muy empleada.

En la actualidad, el diseño de glorietas continúa evolucionando. Las nuevas propuestas mantienen la filosofía de los primeros diseñadores: segregar movimientos para minimizar el número de puntos de conflicto. Tollazi y Rencelj (2014) presentan varias alternativas a los diseños convencionales de glorietas. En la Fig.2.2 se muestra, a la izquierda, una glorieta con dos ramales segregados mediante un paso inferior para 
albergar los giros a izquierdas y, a la derecha, una glorieta con cuatro carriles segregados a nivel para los giros entre la entrada y la salida consecutiva.
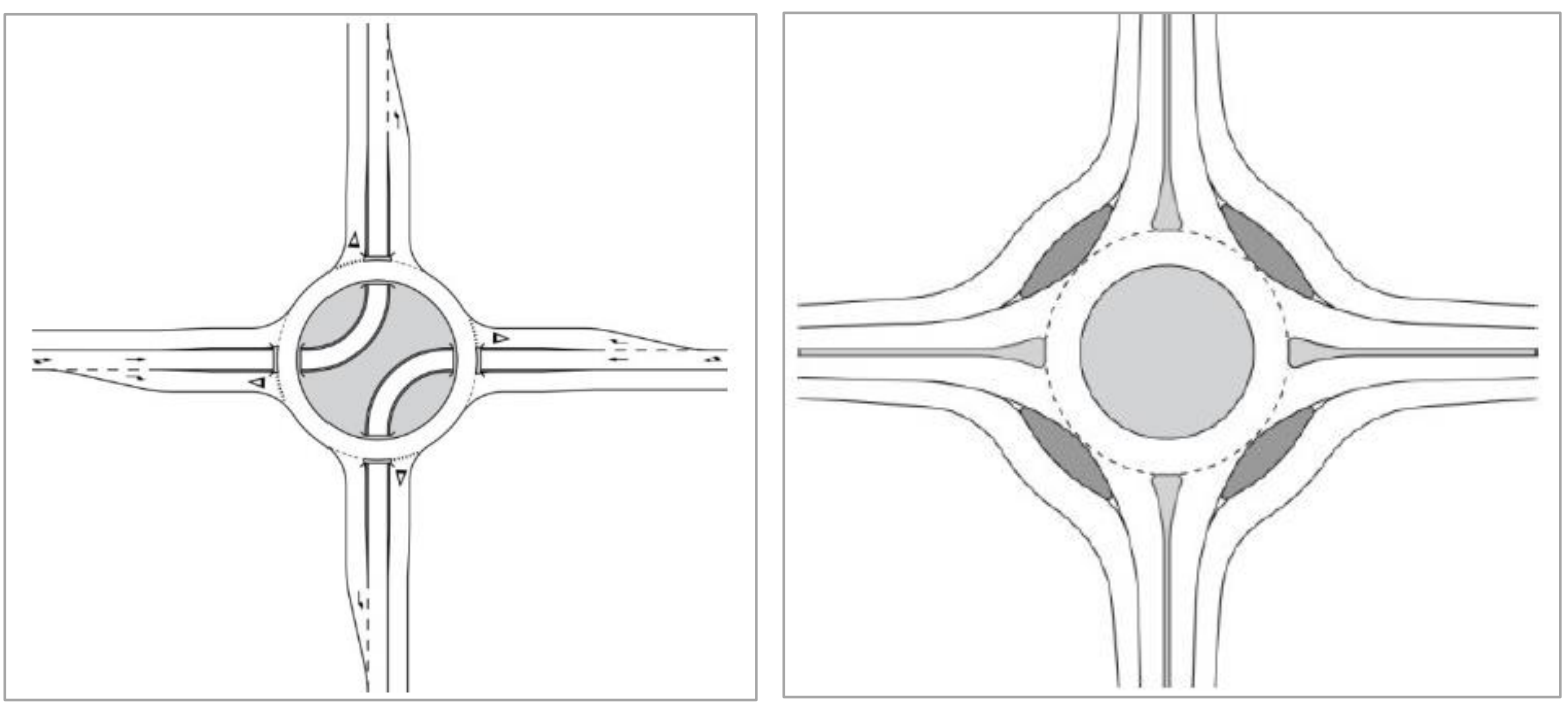

Figura 2.2 Alternativa a los diseños convencionales de glorietas.

Fuente: Tollazi y Rencelj (2014).

Un caso muy conocido es el de la denominada turbo-glorieta (Fig.2.3). Esta tipología tiene su origen en los Países Bajos y fue desarrollada por Fortuijn y Harte (1997). Su nombre se debe a la forma que presenta la isleta central, similar a la del turbo de un vehículo. Presenta dos características diferenciadoras de las glorietas convencionales: se inserta un carril en la isleta central y no se permite el cambio de carril en la calzada anular.

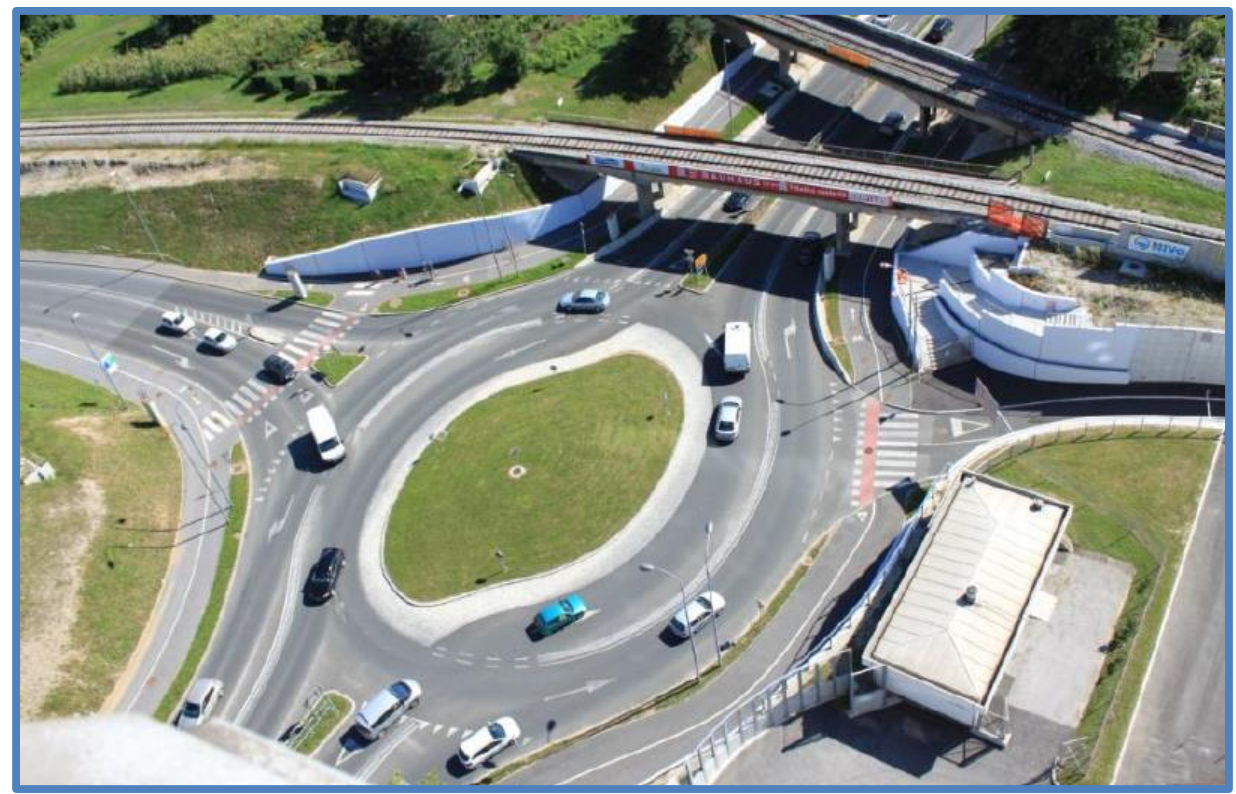

Figura 2.3 Turboglorieta.

Fuente: Rencelj et al., (2011). 


\subsubsection{Procedimiento de diseño}

\subsubsection{Introducción}

En este apartado se realiza el estudio de los procedimientos de diseño en glorietas. Para alcanzar este objetivo, se han elaborado siete apartados. En primer lugar, se describen las características generales de las glorietas y se identifican los parámetros geométricos de diseño. A continuación, se definirán los tipos de movimientos que pueden efectuar los vehículos que acceden a la intersección y la clasificación de los diferentes tipos de glorietas. Posteriormente, se describirán de forma detallada las fases de diseño geométrico. Para finalizar, se resumen los aspectos principales relativos a la construcción y explotación de la infraestructura y se enumeran las ventajas e inconvenientes de las glorietas en comparación con las intersecciones convencionales.

\subsubsection{Características generales}

Las características fundamentales de las glorietas son:

- Prioridad en el anillo. Los vehículos que acceden a la calzada anular desde los distintos accesos deben ceder el paso a los vehículos que se encuentran circulando en ella. Por tanto, se rompe la regla general de prioridad a la derecha de las intersecciones no señalizadas. El sentido de circulación depende de cada país: si se circula por la derecha, el sentido en la calzada anular es antihorario, y si se circula por la izquierda, el sentido es horario. En esta investigación, y si no se especifica lo contrario, se asume que el sentido de circulación es antihorario.

- Reducción del número de puntos de conflicto. Las diferentes interacciones (convergencia, divergencia, cruce, etc) que pueden producirse en un nudo se materializan en lo que se denomina punto de conflicto. Las condiciones de circulación mejoran cuando se minimiza el número de puntos de conflicto que, además, pueden terminar en accidentes (MF, 2012). 
El modo de funcionamiento en las glorietas permite reducir el número de puntos de conflicto respecto a las intersecciones convencionales. Como se observa en la Fig.2.4, en una intersección de cuatro tramos se reduce de 32 a 8 puntos de conflicto.

Otro apartado muy importante para la seguridad está relacionado con el tipo de accidente. En las glorietas, las trayectorias no se cruzan, sino que convergen o divergen. Además se eliminan los giros a izquierdas. Como consecuencia, se disminuye la frecuencia y la severidad de los accidentes.

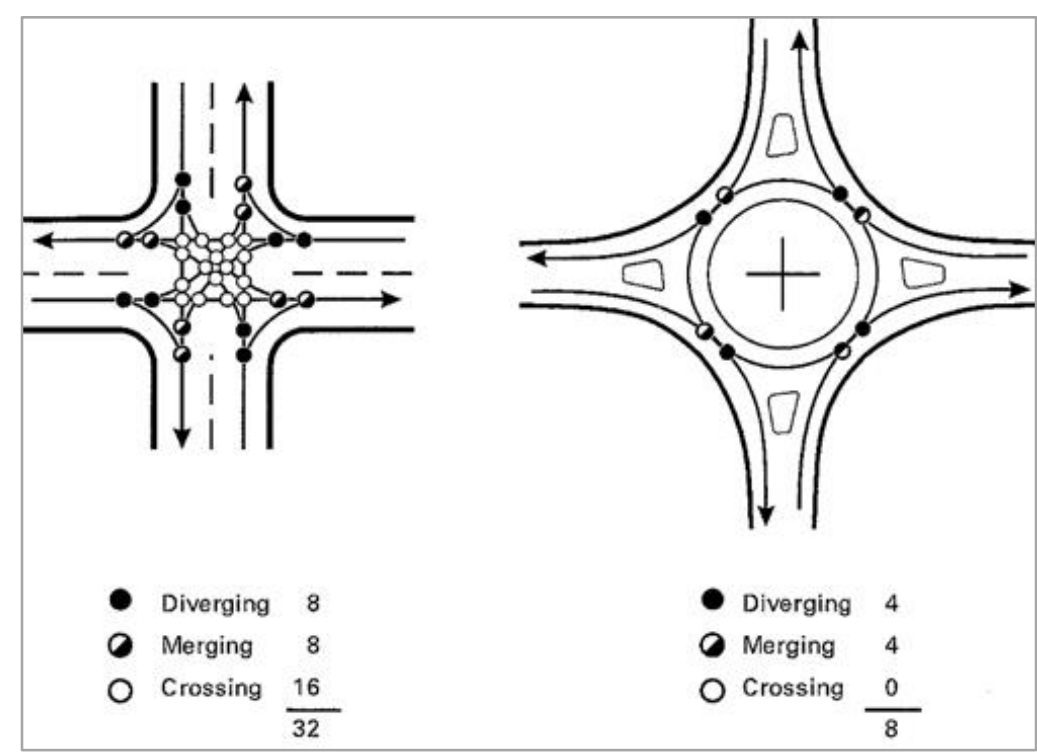

Figura 2. 4 Puntos de conflicto: intersección convencional vs glorieta. Fuente: NCHRP (2010).

- Regulación de la prioridad. Las entradas están reguladas mediante una señal de "Ceda el Paso", luego los vehículos no necesitan detenerse antes de entrar en la calzada anular si valoran que existe un hueco suficiente. No son glorietas las intersecciones en las que se establece, en uno o más accesos, la señal de "Stop", se utiliza semaforización o no se dispone ningún elemento de regulación. La calzada anular no presenta regulación.

- Deflexión de velocidades. Si se estima y representa gráficamente la velocidad de operación de un vehículo a lo largo del trazado de una vía se puede obtener el perfil de velocidades. 
En una glorieta, el trazado de las entradas y las salidas mediante formas curvadas y la presencia de la isleta central generan varias curvaturas en las trayectorias de paso. Esto provoca una deflexión en el perfil de velocidades.

Este fenómeno se puede observar en la Fig.2.5. En el gráfico se muestran tres perfiles de velocidad para una trayectoria recta de paso por una glorieta. En todos los perfiles representados las velocidades se moderan (en el caso menos favorable, línea inferior del gráfico, se produce una reducción de velocidad de $40 \mathrm{~km} / \mathrm{h}$ a $26 \mathrm{~km} / \mathrm{h}$ aproximadamente). Este aspecto representa una de las características esenciales de la geometría y favorece las condiciones de la seguridad vial.

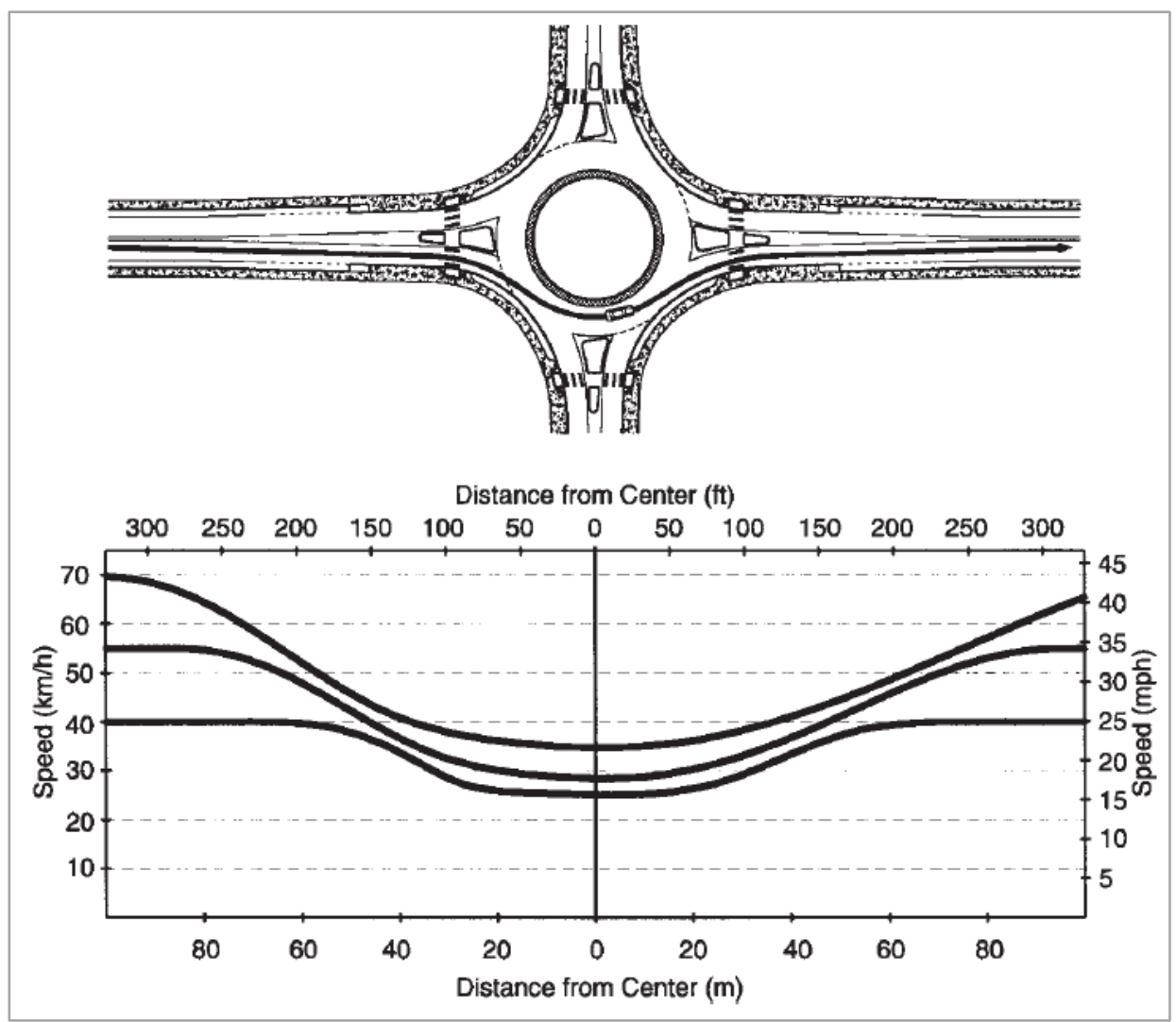

Figura 2.5 Deflexión en el perfil de velocidades en el paso por glorieta. Fuente: FHWA (2000). 


\subsubsection{Parámetros geométricos}

El trazado geométrico de una glorieta se realiza a partir de la definición de una serie de parámetros geométricos. Los usuales se han representado en la Fig.2.6, y se describen a continuación:

- Coordenadas del centro. Posición de la glorieta en el territorio. Depende de las condiciones particulares del proyecto.

- Isleta central. Es el área situada en el centro de la glorieta alrededor del cual circula el tráfico. De forma general, está elevada y está prohibida la circulación a través de ella. En casos particulares, se sitúa a nivel y es posible franquearla (miniglorietas). También se puede habilitar en el exterior una zona franqueable para facilitar el paso de los vehículos más grandes denominada gorjal o gorguera. La forma no tiene por qué ser circular.

- Calzada anular (giratoria). Calzada alrededor de la isleta central por la que circulan los tráficos de acuerdo al sentido de giro.

- Diámetro exterior (diámetro del círculo inscrito). Es el diámetro del borde exterior que define la calzada anular. Con formas circulares se puede determinar como la suma de las dimensiones de la isleta central y dos veces la anchura de la calzada anular.

- Isleta deflectora: es un área elevada o simplemente pintada que se sitúa entre la calzada de entrada y de salida de cada acceso. Por tanto, define los bordes interiores de las entradas y salidas (radio interior de entrada y salida). Presenta las siguientes funciones: separa los tráficos, impone curvatura en las trayectorias y proporciona refugio para peatones.

- Anchura de aproximación: es la anchura original de la calzada en el acceso sin tener en cuenta las modificaciones que impone el diseño de la glorieta. 
- Radio o borde exterior de entrada (curvatura de aproximación). Límite exterior de la calzada del acceso en la entrada.

- Radio o borde interior de entrada. Límite interior de la calzada del acceso en la entrada.

- Radio o borde exterior de salida (curvatura de salida). Límite exterior de la calzada del acceso en la salida.

- Radio o borde interior de salida. Límite interior de la calzada del acceso en la salida.

- Anchura de entrada. Dimensión de la calzada en el acceso (en la línea de ceda el paso) para los vehículos que acceden. Se mide perpendicularmente a través de una línea que va desde el punto de intersección del borde interior con el diámetro del círculo inscrito hasta el borde exterior.

- Anchura de salida. Dimensión de la calzada en el acceso para los vehículos que salen. Se mide perpendicularmente a través de una línea que va desde el punto de intersección del borde interior con el diámetro del círculo inscrito hasta el borde exterior.

La definición geométrica se completa con las provisiones para peatones y ciclistas, y que consisten básicamente en la definición y el acondicionamiento de itinerarios y puntos de cruce.

Otro concepto muy utilizado en el diseño, y que se deduce a partir de la geometría, es el denominado ángulo de entrada. El valor de este ángulo se obtiene trazando las tangentes a las líneas medias de la calzada en la entrada y en el anillo tal y como se muestra en la Fig.2.7. 


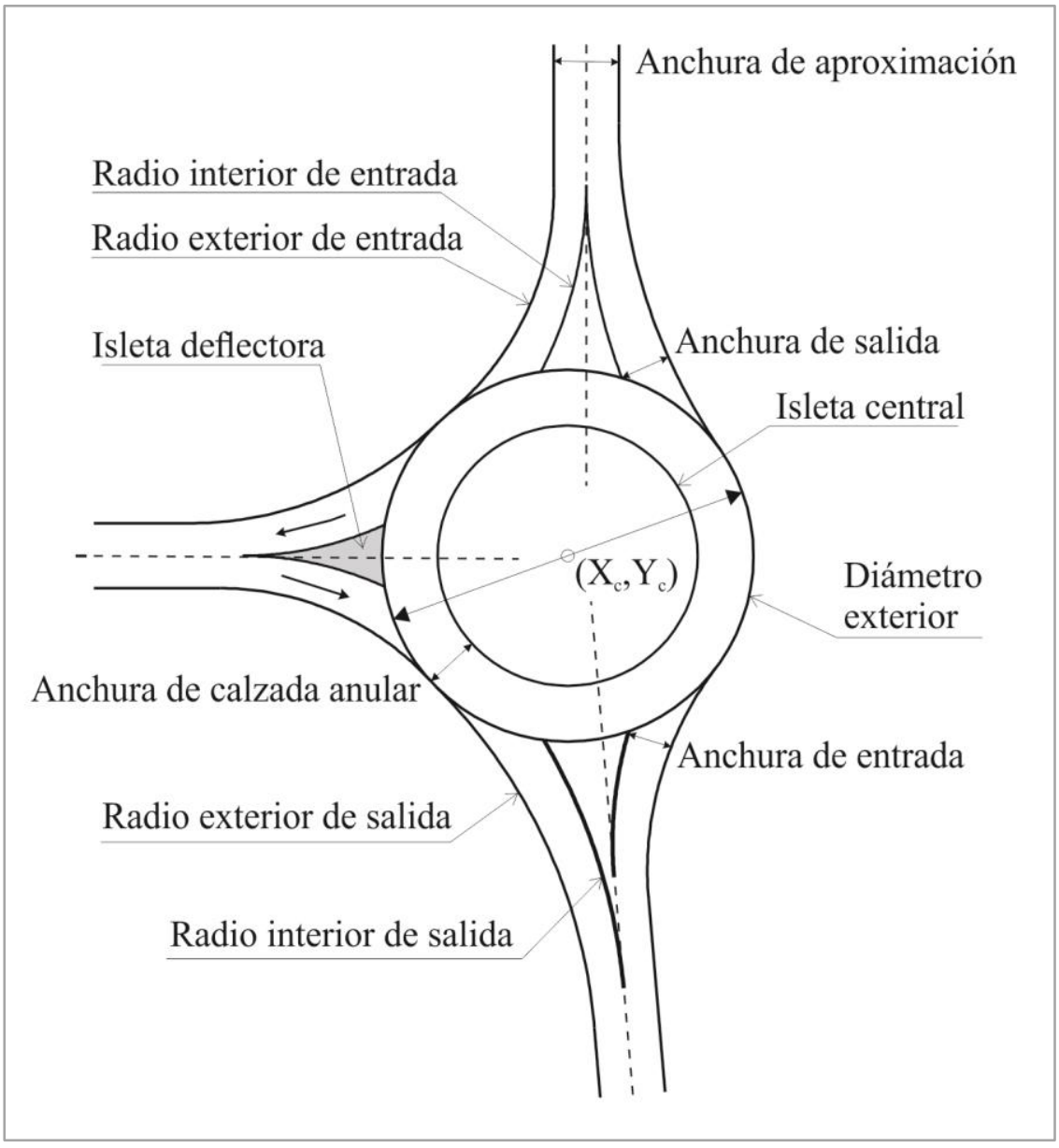

Figura 2. 6 Parámetros geométricos.

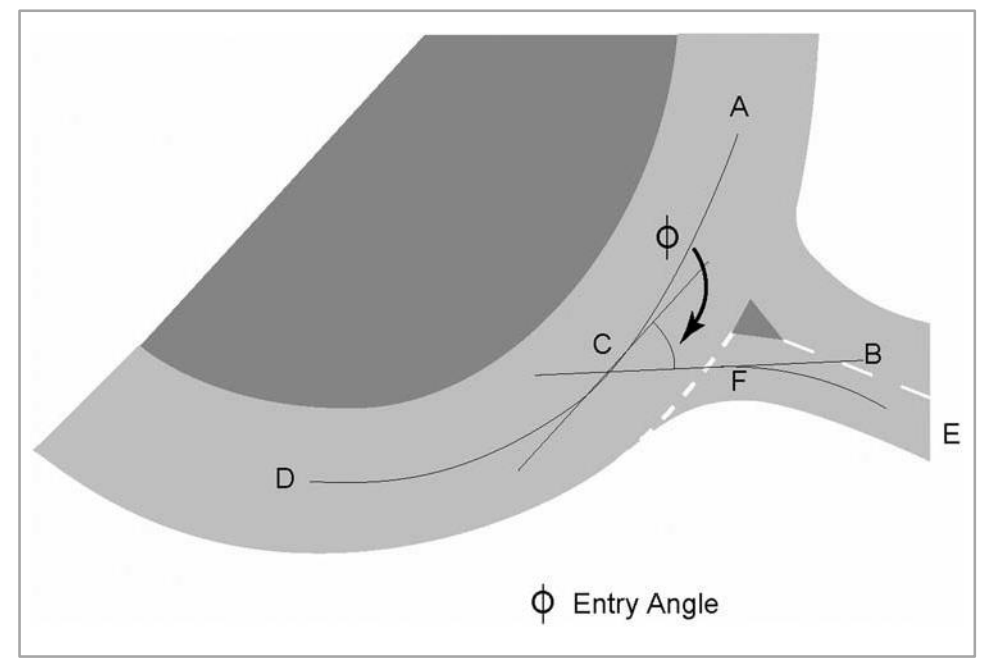

Figura 2. 7 Ángulo de entrada

Fuente: HA, 2007. 


\subsubsection{Tipos de movimiento}

Los vehículos y resto de modos permitidos para circular por una glorieta pueden efectuar diferentes movimientos cuando acceden por un acceso (pata) a la intersección:

- Un giro (aproximadamente) a la derecha. Se toma la primera salida después de entrar.

- Un movimiento de paso, con una trayectorias más o menos recta entre una entrada y una salida situada (aproximadamente) enfrente de la misma.

- Un giro (aproximadamente) a la izquierda.

- Cambio de sentido.

Salvo que existan carriles segregados, todos los movimientos participan de la circulación por la calzada anular.

\subsubsection{Clasificación}

Para clasificar las glorietas se pueden considerar diferentes criterios: según el tamaño del diámetro exterior (miniglorietas, glorietas compactas y grandes glorietas); según el medio de implantación (urbanas, periurbanas e interurbanas); según la morfología de la isleta central (circulares, elípticas y dobles); y, por último, según el número de carriles en los accesos (glorietas de un carril y glorietas de dos o más carriles).

En las principales normas de diseño de glorietas se establece una división en función del número de carriles en los accesos y el tamaño de la isleta central. Atendiendo a este criterio, se pueden considerar tres tipos fundamentales: miniglorietas, glorietas de un carril y glorieta de dos o más carriles.

Las miniglorietas (Fig.2.8) son características de ambientes urbanos de bajas velocidades $(<50 \mathrm{~km} / \mathrm{h})$. Presentan un diámetro exterior de tamaño reducido que suele oscilar entre 10 y $25 \mathrm{~m}$. La isleta central se diseña franqueable, o semifranqueable, para permitir el paso de los vehículos de mayor longitud. Las entradas pueden presentar 
formas curvadas para mejorar la deflexión de las velocidades aunque, si existen limitaciones de espacio, se insertan directamente en la calzada anular. Los circuitos peatonales para cruzar la intersección son reducidos lo que facilita su tránsito. Los ciclistas utilizan la intersección como el resto de vehículos.

La experiencia acumulada con miniglorietas muestra resultados satisfactorios en cuanto a la capacidad y la seguridad de la intersección. Pueden acoger intensidades de hasta 15.000 vehículos/día (NCHRP, 2010). Presentan por lo general un coste reducido, en el orden de los 10.000 euros (Brilon, 2008).

Las miniglorietas son una medida recomendada para el "calmado de tráfico" (2008) recomienda no utilizar miniglorietas donde concurra alguna de las siguientes circunstancias: límite de velocidad mayor a $50 \mathrm{~km} / \mathrm{h}$, doble carril en los accesos, nuevas intersecciones, flujo en el acceso menor de 500 vehículos/día y con una configuración de cinco patas o más.

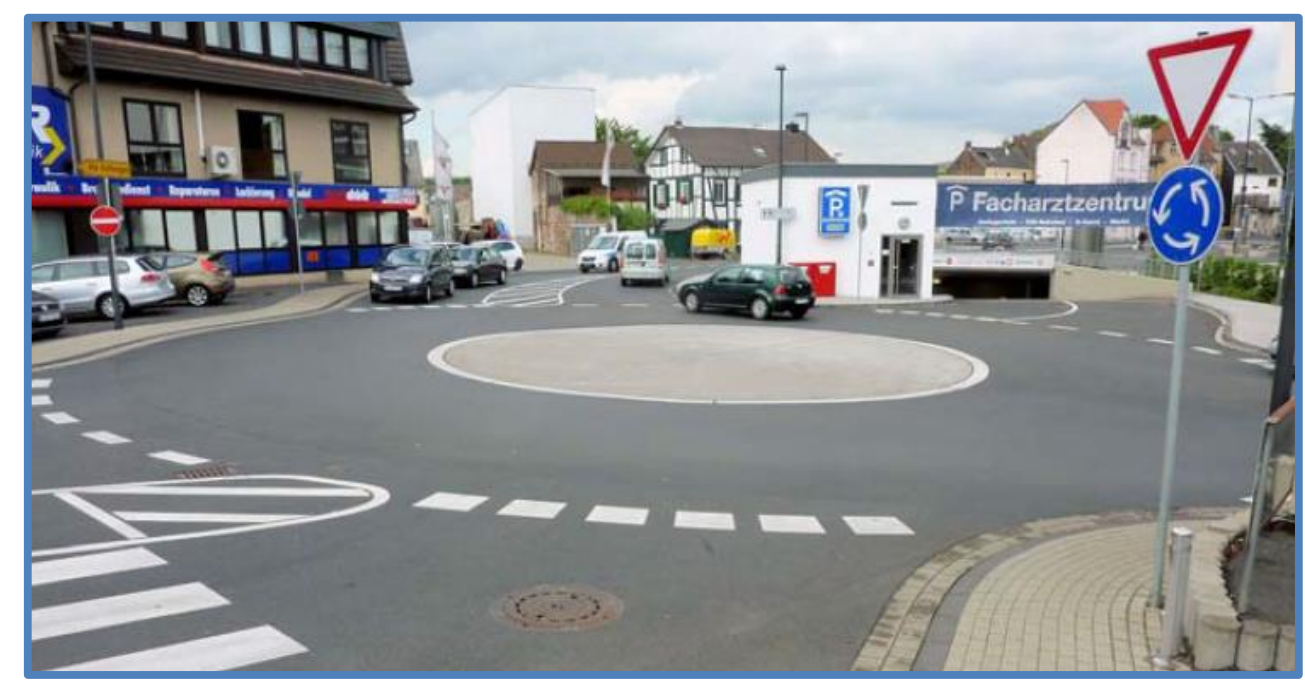

Figura 2. 8 Miniglorieta.

Fuente: Brilon, 2014.

Las glorietas de un carril (Fig.2.9) pueden localizarse en diferentes entornos con un diámetro exterior de entre $25-50 \mathrm{~m}$. Todos los accesos y la calzada anular presentan un carril. Generalmente incluyen: isletas deflectoras elevadas, isleta central no franqueable

\footnotetext{
${ }^{6}$ Con la denominación de "calmado de tráfico" se hace referencia a una serie de medidas de diferente naturaleza que tienen el objetivo de moderar las velocidades y favorecer la seguridad de peatones y ciclistas.
} 
y pasos de peatones. Los resultados de seguridad en comparación con las intersecciones convencionales son satisfactorios, sobre todo en ambientes interurbanos. La capacidad puede alcanzar hasta 25.000 vehículos/día (NCHRP, 2010).

Está recomendado que los ciclistas no utilicen la calzada anular con intensidades muy altas de tráfico. En estos casos se debe implementar un circuito exterior.

El funcionamiento en glorietas de un carril es idéntico en todos los países: el usuario decelera en la aproximación hasta alcanzar la señal de "Ceda el Paso", evalúa un hueco para incorporarse al flujo de la calzada anular, recorre el anillo hasta el destino deseado y, por último, inicia el proceso de aceleración en el movimiento de salida.

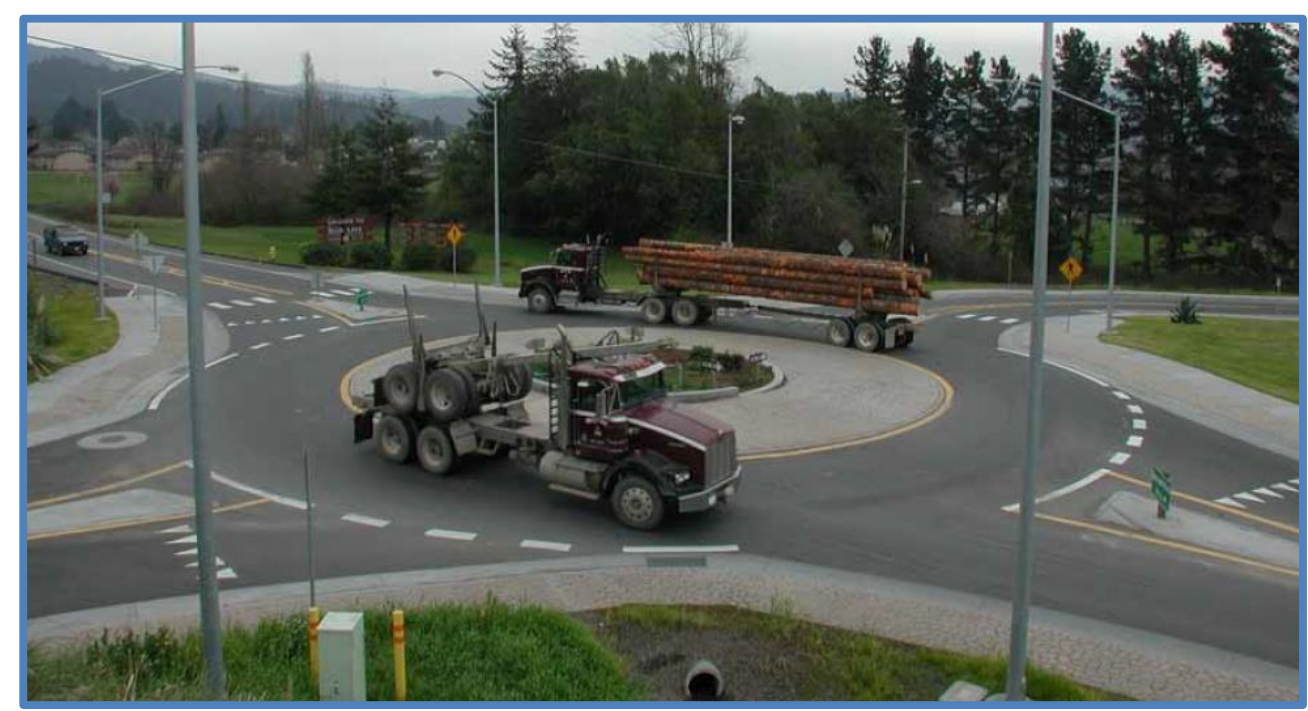

Figura 2. 9 Glorieta de un carril.

Fuente: Weinberger, 2005.

Las glorietas de dos o más carriles (multicarril) (Fig.2.10) presentan en, al menos un acceso, dos o más carriles (NCHRP, 2010). Generalmente esta tipología incluye: isletas deflectoras elevadas e isleta central no franqueable. Dependiendo del número de carriles en los accesos, la calzada anular debe permitir la circulación de varios vehículos circulando en la misma sección.

Las velocidades de recorrido son superiores en comparación con el resto de tipologías. A diferencia de las glorietas de un carril, resulta muy importante la señalización y el guiado de los vehículos hacia la calzada anular para evitar el solape de las distintas 
trayectorias. La seguridad es más problemática que en glorietas de un carril y presentan resultados satisfactorios en cuanto a capacidad.

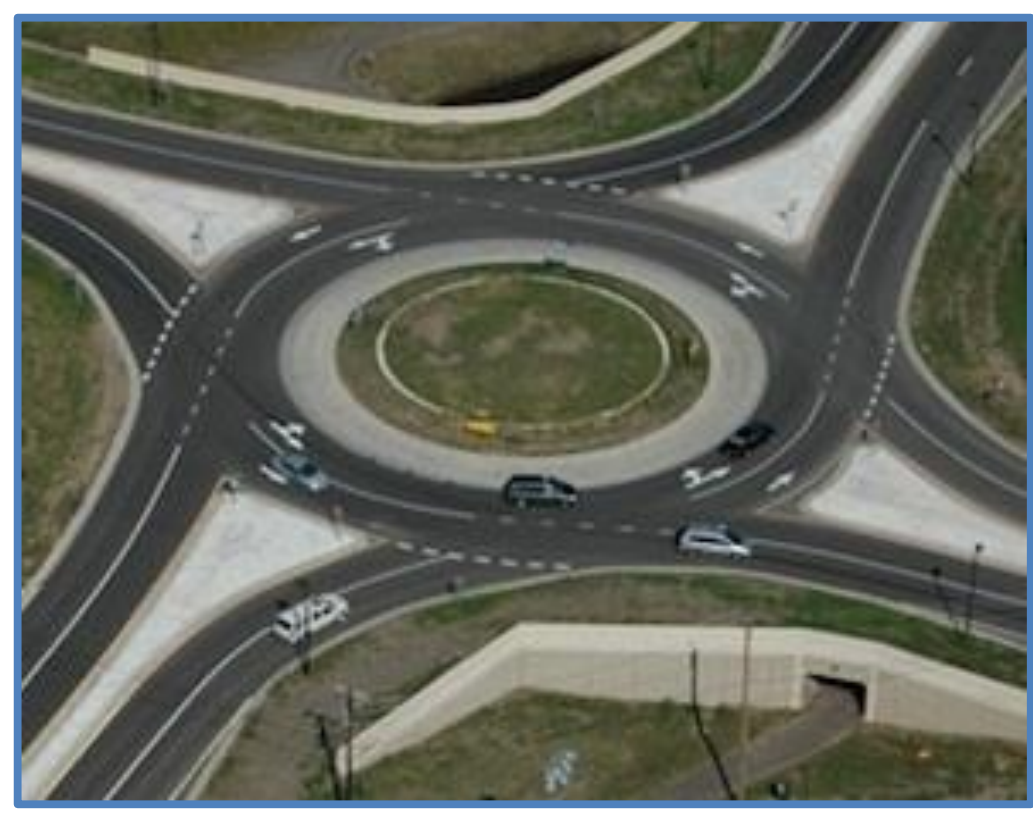

Figura 2.10 Glorieta de dos carriles.

Fuente: Gustafson, 2011.

En glorietas multicarril el funcionamiento puede variar dependiendo de si se encuentra jerarquizado el uso de los carriles y se admiten trenzados en la calzada anular. Se distinguen principalmente dos modos de funcionamiento.

En el primero (Fig. 2.11), el usuario decide en la entrada el carril en el acceso que considere más adecuado. Dentro de la calzada anular, la norma es indicar los movimientos cuando se desee cambiar de carril, cediendo el paso, y situarse en el carril exterior para efectuar la salida. Si se llegase al punto de salida en un carril interior, está prohibido cortar la trayectoria de los vehículos situados en el exterior. En esos casos, se debe realizar un nuevo giro completo por el anillo para alcanzar esta posición realizando un trenzado. Este modo de funcionamiento ha sido el tradicional en el caso de España aunque se tiende, y así viene recogido en la nueva normativa de nudos (MF, 2012), al segundo modo.

En el segundo (Fig. 2.12), el usuario debe desplazarse en la entrada al carril que le marque la señalización. La selección obligatoria del carril está de acuerdo con el 
movimiento que se va a realizar en la calzada anular. Normalmente, el carril más a la derecha en la entrada se suele utilizar para girar de frente o a la derecha. Los carriles situados más a la izquierda para seguir de frente o girar a la izquierda. La calzada anular presenta igualmente direcciones señalizadas.

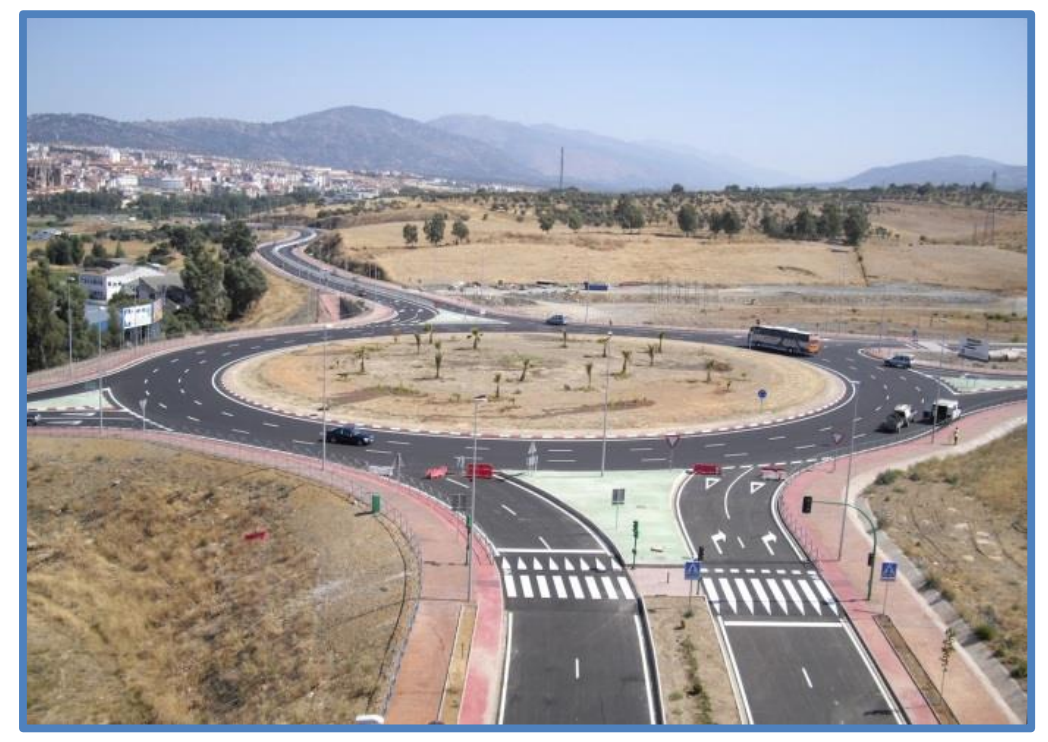

Figura 2. 11 Funcionamiento en glorietas multicarril (sin selección de carril). Fuente: http://lascarreterasdeextremadura.blogspot.com.es/.

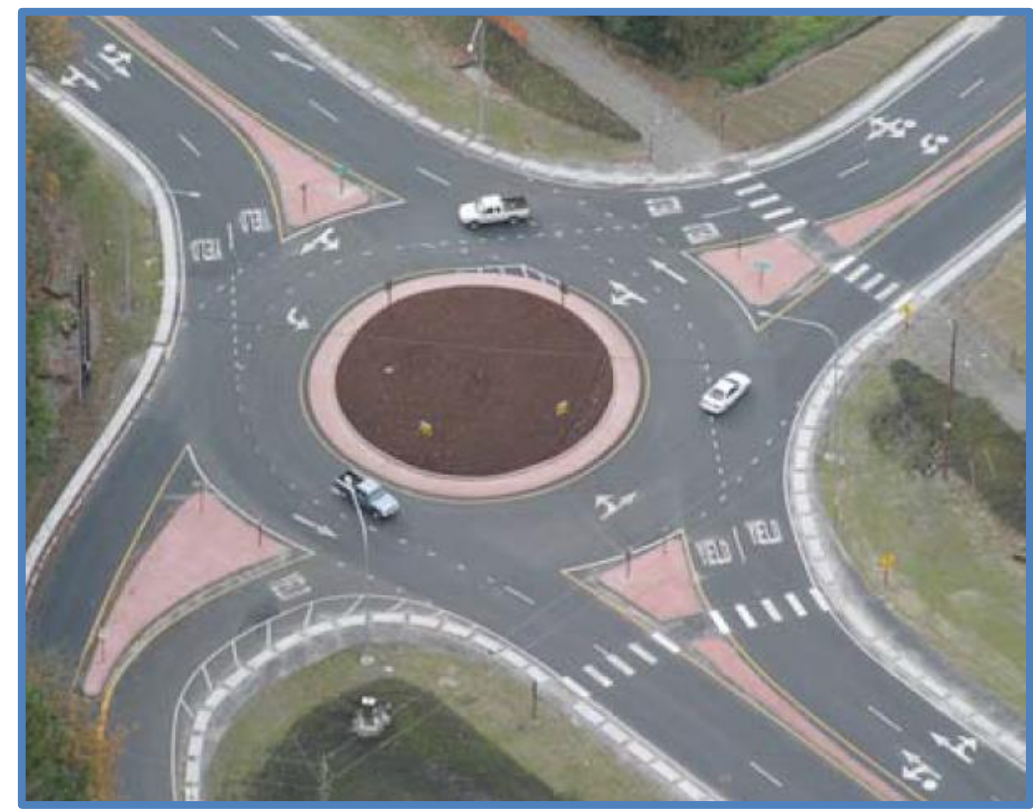

Figura 2. 12 Funcionamiento en glorietas multicarril (con selección de carril). Fuente: Ritchie, 2005. 


\subsubsection{Fases de diseño geométrico}

En el diseño de glorietas cada proyecto es específico y responde a sus condiciones particulares. Por tanto, es un trabajo difícil de estandarizar.

Los investigadores y especialistas en glorietas han propuesto diferentes metodologías que tiene el objetivo de establecer, de una forma genérica, las fases necesarias para realizar el diseño de una glorieta. En lo que se refiere a este documento, se considera el esquema mostrado en la Fig.2.13 que divide este proceso en cuatro fases.

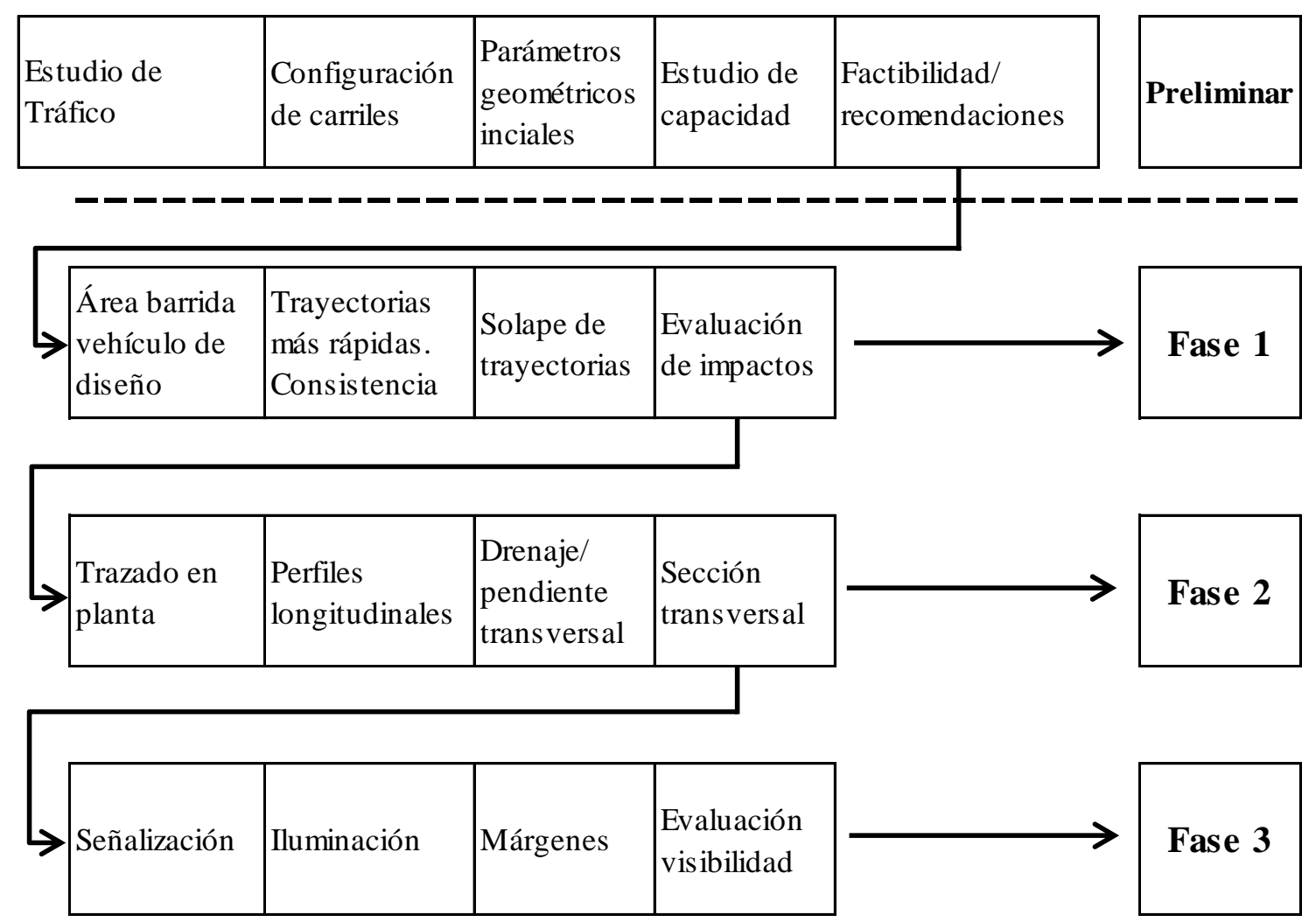

Figura 2. 13 Fases de diseño geométrico.

Fuente: Kuhlow, 2011; WisDOT, 2008.

A continuación, se describen los trabajos contenidos en cada una de las fases de diseño geométrico. 


\section{$\underline{\text { Fase Preliminar }}$}

El proceso de diseño se inicia evaluando los tráficos. Se debe calcular la intensidad horaria de todos los movimientos, la composición del tráfico y la prognosis hasta el año horizonte.

Los tráficos estimados se componen de acuerdo a un diagrama del que se deduce para cada acceso: un flujo de entrada, un flujo de salida y, en la calzada anular, un flujo de circulación.

A continuación, se suele establecer la configuración de los carriles en los accesos y la calzada anular, que debería resultar lo más simple posible. Para realizar este trabajo, se pueden consultar las recomendaciones realizadas por algunas administraciones. Por ejemplo, el Departamento de Transportes del Estado de Nueva York establece, para las intensidades horarias previstas en un acceso, los siguientes umbrales (McCulloch, 2005):

- Entre 0 y $1000 \mathrm{veh} / \mathrm{h}$ un carril puede ser suficiente.

- Entre 1000 y $1300 \mathrm{veh} / \mathrm{h}$ puede ser necesario implementar dos carriles aunque el estudio de detalle debe decidir si con un carril se alcanza el nivel de servicio adecuado.

- Entre 1300 y $1800 \mathrm{veh} / \mathrm{h}$ son necesarios dos carriles.

- Más de 1800 veh/h serán necesarios dos o más carriles en el acceso.

El siguiente paso es realizar la asignación de los parámetros geométricos iniciales. Para completar esta tarea es necesario tomar decisiones sobre: la disposición de las patas de acceso, la posición y el tamaño de la glorieta, las dimensiones del vehículo patrón y las necesidades para el acomodo de los usuarios no motorizados (peatones y ciclistas).

La disposición de accesos recomendada es con ejes separados a igual distancia y ángulos entre ellos de $90^{\circ}$, o próximos a este valor. En la norma de España de Nudos (MF, 2012) se recomienda que no resulte inferior a 60 gones el ángulo subtendido al centro de la glorieta por dos puntos de intersección de la calzada anular: uno con la 
trayectoria más desfavorable de entrada por un acceso, y otro con la trayectoria más desfavorable de salida por el acceso siguiente (Fig.2.14). En la nueva norma de Trazado de España (MF, 2016) se dispone además que la separación entre accesos medidos sobre el borde exterior de la calzada anular entre puntas de isletas será mayor o igual que veinte metros.

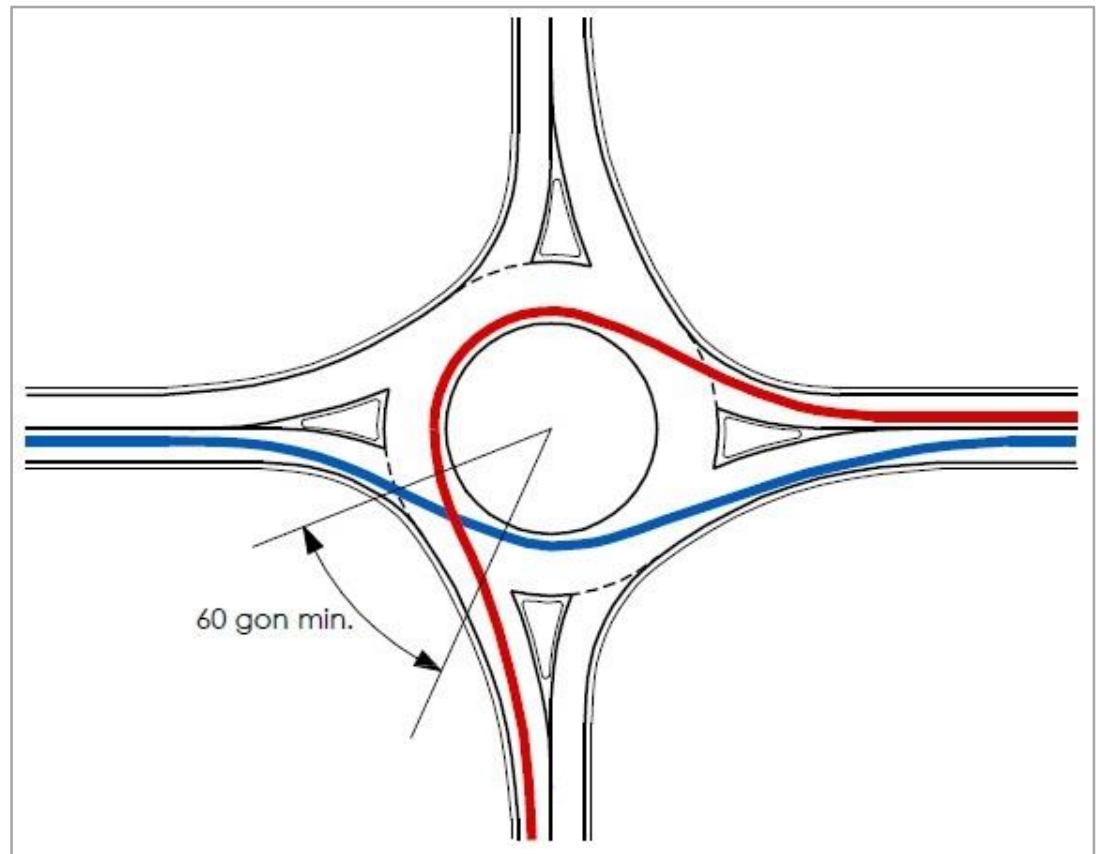

Figura 2. 14 Ángulo mínimo entre accesos.

Fuente: MF, 2012.

A nivel individual, el eje de un acceso puede incidir respecto al centro de la glorieta de tres formas según se representa en la Fig.2.15.

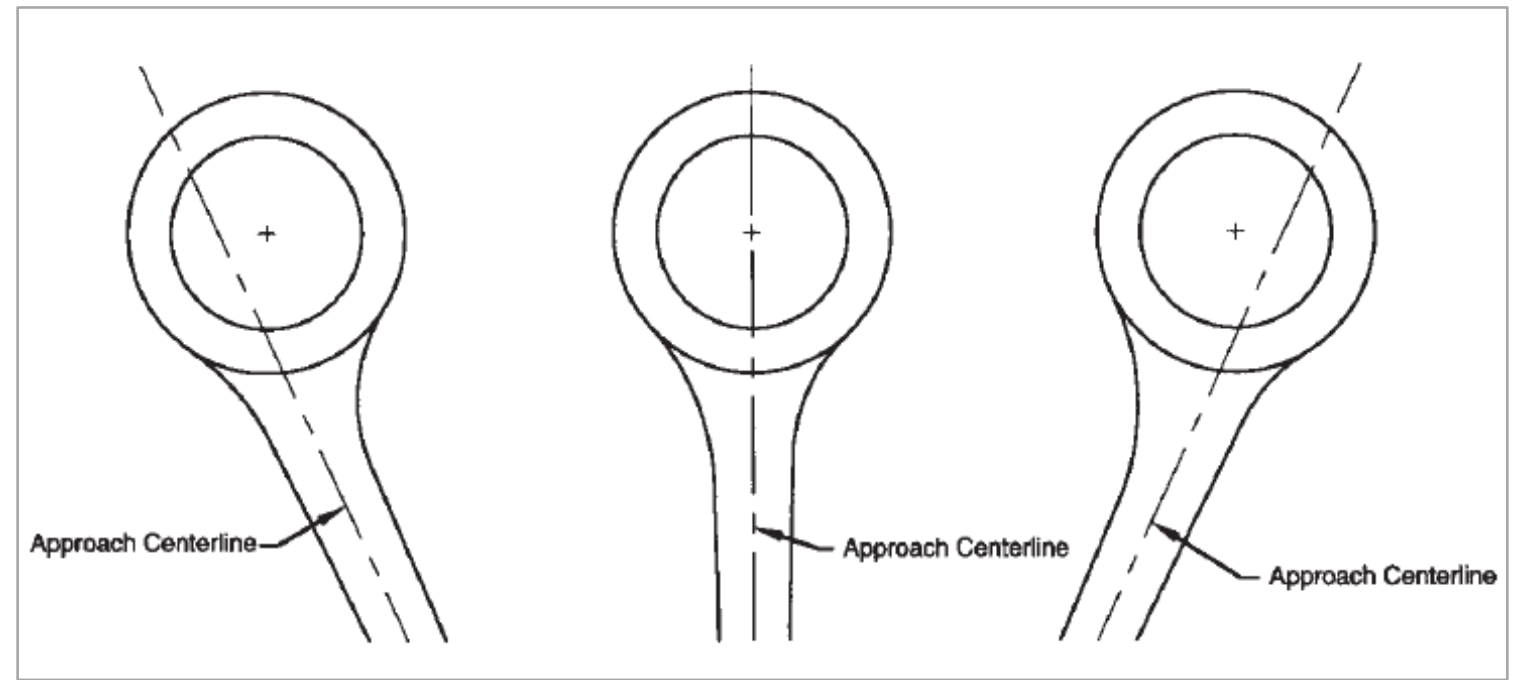

Figura 2. 15 Posiciones de los ejes de acceso respecto del centro de la glorieta.

Fuente: FHWA, 2000. 
Al desplazar el eje del acceso hacia la izquierda respecto al centro, se mejoran las condiciones en la entrada. Esto se debe a que se fuerza la curvatura de la trayectoria de entrada y, en consecuencia, la capacidad para provocar más deflexión en el perfil de velocidades. De igual forma, se mejoran las condiciones de la salida ya que se minimiza la curvatura y, por tanto, se facilita la maniobra. En estos casos, se debe comprobar que las velocidades resultantes de salida no son demasiado elevadas si existe un paso de peatones situado aguas abajo.

La solución con el eje del acceso pasando por el centro de la glorieta es aceptable. El último caso, con el eje situado a la derecha del centro, es poco recomendable.

La selección del vehículo patrón se realiza en base a los tipos de vías que confluyen en la calzada anular, los datos de tráfico y a los usos del suelo del entorno. El acomodo de los vehículos con mayor longitud tiene un impacto directo sobre el tamaño de la glorieta. Aunque en una fase posterior hay que comprobar el área barrida del vehículo patrón, en esta fase es importante no condicionar la solución imponiendo unos valores mínimos a determinados parámetros geométricos (dimensiones de las calzadas e isleta central y radios de giro en los accesos). En las guías de diseño se encuentran normalizadas las dimensiones mínimas de la isleta central y la anchura de la calzada anular para permitir el paso de vehículos de diferente longitud.

En lo que se refiere al acomodo de los usuarios no motorizados, se debe tener en cuenta si hay que realizar provisiones para peatones y ciclistas. Básicamente, se deben considerar las necesidades de cruce limitando las velocidades y las dimensiones mínimas para las isletas (zona de refugio).

En base a estos datos y a la normativa, el proyectista utiliza su propia experiencia para realizar la asignación inicial de los parámetros geométricos. Puesto que la técnica de diseño en el método convencional se basa en la prueba y error, el número de iteraciones depende de la calidad de la asignación inicial. En este sentido, las dimensiones de las calzadas tienen una menor incertidumbre respecto a otros parámetros como pueden ser las coordenadas del centro de la glorieta, cuya posición es desconocida y difícil de determinar de antemano. 
Para finalizar esta fase, se dibuja la solución y se realiza el estudio de capacidad (apartado 2.2.4.2). Éste ha de realizarse carril por carril asegurando que se obtiene un balance adecuado entre la demanda y la formación de colas de tráfico. En caso necesario se modifica la asignación de parámetros geométricos iniciales.

\section{$\underline{\text { Fase } 1}$}

En esta fase hay que realizar varias comprobaciones en un proceso de naturaleza iterativa que finaliza con la propuesta de la geometría en planta. Para ello, los parámetros geométricos iniciales se modifican hasta que se satisfacen una serie de requisitos funcionales y de seguridad:

- El área barrida por el vehículo patrón. Es necesario comprobar que el diseño de la glorieta permite el paso y giro no forzado del vehículo más grande que tiene una probabilidad razonable de utilizarla (vehículo patrón). Si se ha realizado una adecuada asignación inicial, lo normal es que no haya que realizar muchos cambios en la geometría. No obstante, se debe comprobar que la geometría final permite el paso del vehículo patrón. Para esto se pueden utilizar diferentes herramientas informáticas que se han desarrollado para dibujar la huella generada por un vehículo.

- La moderación de las velocidades y su consistencia. Es el principal condicionante para validar la geometría en planta (NCHRP, 2010; AUSTROADS, 2011). En todas las normativas no se aborda su análisis de la misma manera. La tendencia actual es modelar las trayectorias de los vehículos más rápidos comprobando los valores máximos de la velocidad y la consistencia de acuerdo a unos indicadores. Para realizar este trabajo no se han desarrollado herramientas que permitan realizar este cálculo de una forma completamente automatizada.

- El guiado. En glorietas multicarril, se debe tener en cuenta que la geometría favorezca un correcto guiado de los vehículos en las entradas y las salidas hacia la calzada anular para evitar el solape de las distintas trayectorias. Para 
considerar este apartado suele ser suficiente con una buena asignación de los valores de los radios exteriores e interiores en las entradas y las salidas.

- Compatibilidad del diseño con los usuarios no motorizados. Se deben considerar las necesidades de peatones y/o ciclistas para que presenten unas condiciones de seguridad adecuadas en los casos en que sea previsible su presencia en el flujo circulatorio. Aunque no siempre es posible compatibilizar las necesidades de otros modos a posteriori, suele bastar con imponer un valor mínimo al valor de la isleta deflectora (zona de refugio) y limitar las velocidades en la calzada anular y en los accesos.

Los objetivos del trazado en planta se analizan con mayor detalle en el apartado 2.2.4.

\section{Fase 2}

En la segunda fase, se realiza la definición de las inclinaciones longitudinales y transversales.

En general, para las alineaciones verticales en la calzada anular se adoptan valores moderados $(<3 \%)$ forzando en su caso las rasantes de los accesos. Si no resultara factible y hubiera que adoptar valores extremos, puede ser conveniente plantear otra alternativa para la solución del cruce.

Existen varias soluciones para definir el estado de peraltes en la calzada anular. En países como España y Francia suele adoptarse constante y hacia el exterior para facilitar las condiciones de drenaje. Con esta disposición se obtienen ventajas adicionales. Por un lado, se mejoran las condiciones de visibilidad de la isleta central que se encuentra más elevada. Por otro lado, se facilita la conexión con los accesos ya que las transiciones del peralte se pueden realizar de forma más sencilla. Además, el signo resultante del peralte en las entradas y salidas resulta favorable para compensar la aceleración. 
En Reino Unido y EEUU, es común definir una limatesa dentro del anillo, lo que significa que la calzada anular queda a dos aguas. Este cambio de pendiente transversal puede ser crítico para los vehículos de mayor longitud y, de forma general, es más perjudicial que la alternativa anterior.

Una tercera solución consiste en definir un peralte variable de forma que la glorieta queda embebida en un plano (la rasante de la glorieta es una sinusoide). Esta alternativa presenta varios inconvenientes: el agua debe recorrer distancias más largas, existe variación de peraltes en la calzada anular y se empeoran las condiciones para la conexión con los accesos.

Una vez se ha definido el trazado en planta y alzado, se debe comprobar las condiciones de drenaje ajustando el estado de peraltes en caso necesario. A continuación, se puede iniciar la definición de la sección transversal, aunque este proceso es más gradual y se desarrolla a lo largo de todo el proceso de diseño.

El elemento fundamental de la sección transversal es la calzada, cuyas dimensiones se han deducido del estudio de capacidad y su posterior ajuste. En cuanto a los arcenes, las bermas y los acerados sus valores suelen depender del tipo de vía y de las especificaciones de los responsables de la gestión de la red. En base a los estudios de tráfico, geológicos y climáticos se deciden las secciones de firme y los elementos de drenaje (superficiales y profundos). La definición de la sección transversal se finaliza en la siguiente etapa.

\section{$\underline{\text { Fase } 3}$}

En la tercera fase, se realizan una serie de estudios con una influencia muy importante en la seguridad vial y que permiten definir la señalización e iluminación, realizar el estudio de visibilidad y disponer los elementos de carácter estético.

La señalización es uno de los factores con más incidencia en la frecuencia de accidentes. Los criterios para definirla dependen de las especificaciones de los 
responsables de la gestión de la red y se establecen en base al modo de funcionamiento que, como se ha comentado, para glorietas multicarril no es igual en todos los países.

Hawkins (2011) expone que es recomendable tener en cuenta la señalización durante el proceso de diseño y no sólo en la última fase de la redacción. La señalización debe reforzar los principios básicos de diseño mediante mensajes consistentes. Las bases de una buena señalización para el autor son: establecer las expectativas de los conductores, situar a los usuarios en el carril adecuado, identificar la prioridad y direccionar el movimiento de peatones y ciclistas. Los objetivos pueden diferenciarse por zonas:

- En las aproximaciones: situar a los conductores en el carril adecuado, advertir de la presencia de la glorieta y facilitar el tránsito de peatones.

- En las entradas: establecer el sistema de prioridad y la dirección de viaje.

- En la calzada anular: definir los tipos de movimientos y facilitar la salida.

- En las salidas: confirmar el destino deseado y establecer los itinerarios peatonales.

Avgoustis (2008) analiza las principales consideraciones sobre la señalización horizontal en glorietas comparando el estado de la práctica de Holanda, Reino Unido y Nueva Zelanda. El autor expone que es recomendable utilizar señalización horizontal en la calzada anular. El sistema recomendado es el denominado método "alberta" y que consiste en prolongar la línea central de separación de carriles a través de las salidas (Fig.2.16). En los accesos recomienda que se utilicen las flechas de carril para asistir al conductor a seleccionar el carril correcto.

Los sistemas de contención son elementos cuya función es mitigar las consecuencias de un vehículo que pierde el control y sale de la vía. Están muy relacionados con el diseño de las márgenes. En las isletas no deben situarse objetos que puedan representar un obstáculo. 


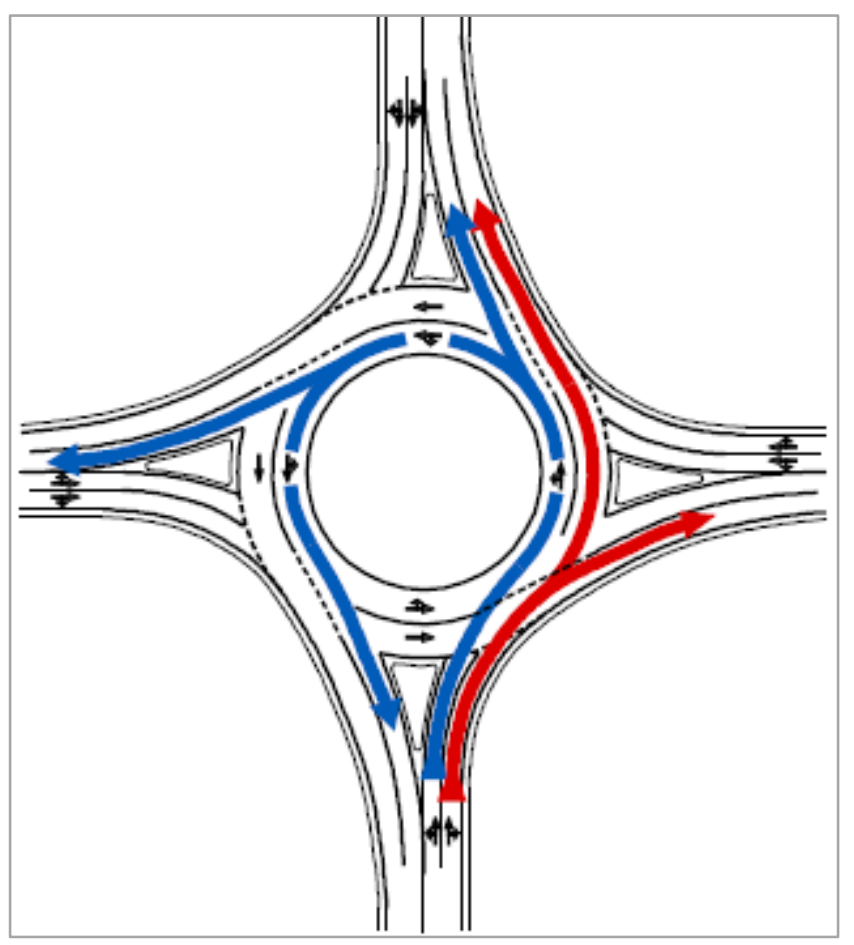

Figura 2. 16 Método "alberta" de señalización horizontal. Fuente: MF, 2012.

En cuanto a la iluminación, en general e independientemente del tipo de ambiente, es recomendable iluminar la glorieta. Aunque los costes suelen limitar la adopción de iluminación.

Urraca (2009) analiza las soluciones luminotécnicas para el diseño de glorietas. El autor propone dos sistemas fundamentales (Fig.2.17): iluminación periférica e iluminación central (con proyectores convencionales o proyectores asimétricos). Cada sistema presenta ventajas e inconvenientes. La iluminación de la glorieta debe extenderse a los accesos.

La glorieta representa una obstrucción física a la trayectoria del tráfico, luego es muy importante que exista una adecuada visibilidad. Desde cada acceso se deben valorar tres situaciones. La primera, de aproximación, establece un despeje necesario para poder percibir la glorieta con suficiente antelación. Se suele fijar desde un punto situado en el acceso a una distancia antes de la marca de detención igual a la necesaria para detenerse sin rebasarla. La segunda, de inserción, se refiere a un área mínima visible de la calzada anular y el acceso anterior desde un observador situado en la entrada. De esta forma el 
conductor puede elegir un hueco en la circulación para realizar la incorporación al anillo. La tercera, se refiere a la visibilidad de los pasos de peatones situados en el propio acceso antes de llegar a la calzada anular y en la siguiente salida.
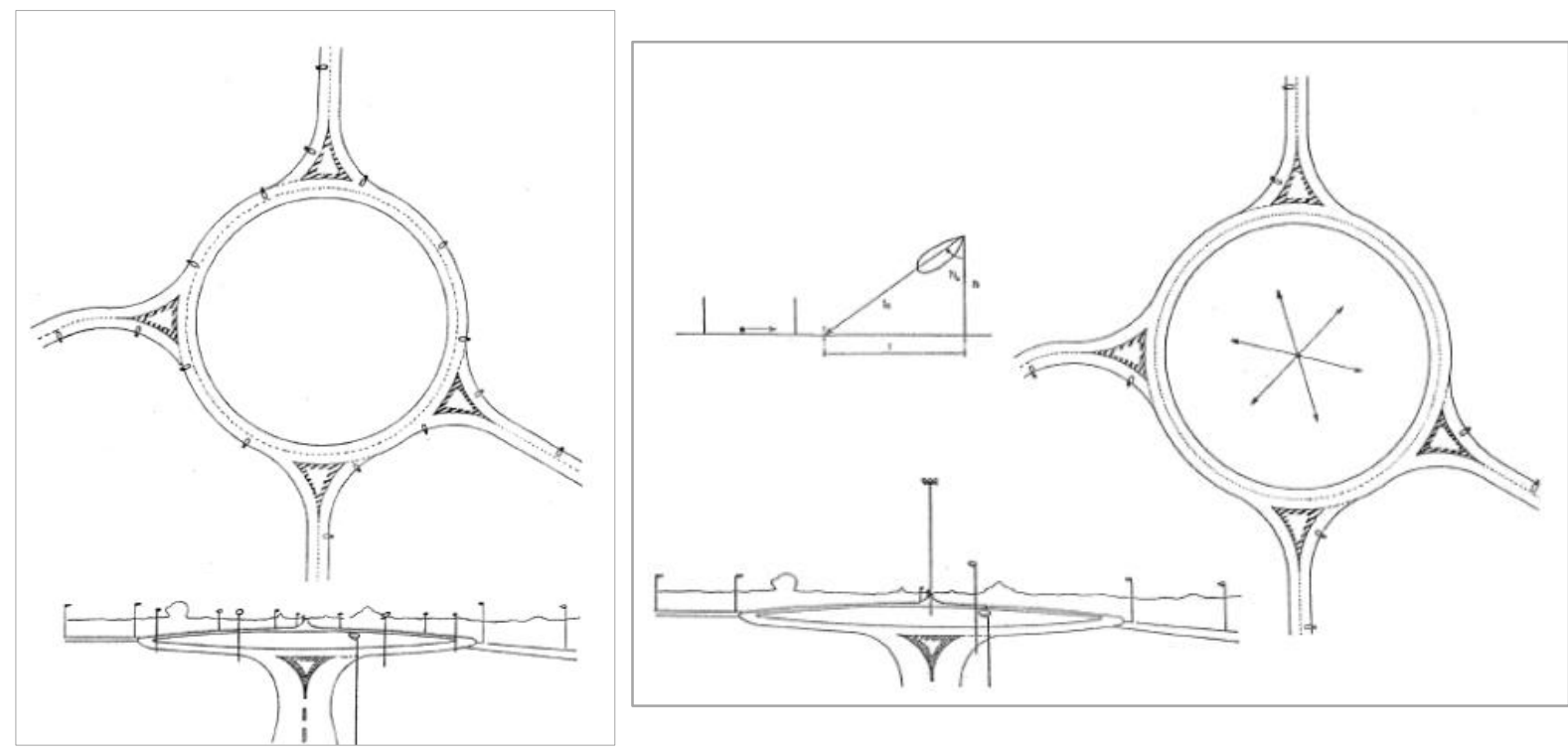

Figura 2.17 Iluminación en glorietas: periférica (izquierda) y central (derecha).

Fuente: Urraca, 2009.

Los elementos de carácter estético asociados a una glorieta están muy relacionados con las condiciones de visibilidad, el tipo de entorno y las velocidades que se van a desarrollar. El estudio de visibilidad resulta fundamental para las condiciones de seguridad de la intersección.

El área de la isleta central es muy proclive a la implantación de elementos de carácter estético y vegetación. Es deseable que se defina mediante una zona elevada ya que se mejoran las condiciones de reconocimiento de la intersección. Además se pueden obtener otras ventajas: se oculta las perspectiva del lado opuesto evitando confusiones y se ayuda a orientar a los conductores hacia el sentido de circulación correcto (MOPU, 1989).

Pero hay que tener en cuenta que un vehículo fuera de control puede rebasar este área. Por este motivo, el Departamento de Transportes del Estado de Wisconsin (EEUU) recomienda una elevación mínima de 1m y máxima de 1,8m y que, en cualquier caso, 
no se superen las pendientes de 6H:1V (WisDOT, 2008). Además, hay que considerar la conveniencia de no implantar objetos fijos.

Los accesos y el perímetro de la calzada anular también pueden aprovecharse para implantar vegetación, aunque se deben evitar árboles y otros elementos que puedan comprometer la seguridad ante una eventual salida de la calzada. Como en el caso de la isleta, estos elementos pueden ayudar a las condiciones de visibilidad y a definir los itinerarios ciclistas.

\subsubsection{Aspectos de construcción y explotación.}

La construcción de una glorieta está muy condicionada por los desvíos de tráfico. Se deben valorar tres situaciones: sin desvíos de tráfico, desvíos parciales y desvío total de la circulación mediante itinerarios alternativos.

El caso ideal es cuando la glorieta representa una nueva intersección que permite realizar la construcción sin afectar al tráfico existente. Ello repercute en los tiempos de ejecución, en la seguridad y en el coste.

El desvío total o parcial dependerá de las condiciones particulares y en cualquier caso será conveniente minimizar su diseño.

Atkinson (2014) analiza las condiciones del proceso constructivo en glorietas. En el caso de los desvíos parciales especifica que se incrementa el tiempo de viaje y que hay que considerar el paso de los servicios de emergencia y la posibilidad de rutas alternativas. Para el caso de un desvío total de la circulación o sin desvíos, el autor propone siete fases para el proceso constructivo: instalar la iluminación y la señalización, construir los límites exteriores, construir las superficies de las aproximaciones, construir las isletas deflectoras, replantear y construir la isleta central y, por último, extender las capas de firme. 
En cualquier caso, hay que tener especial precaución con la señalización, las condiciones de seguridad vial y las rutas para los usuarios no motorizados (peatones y ciclistas).

Como en otras tipologías de intersección, en las glorietas debe proponerse un plan de mantenimiento. Las principales actividades se centran en el cuidado de las especies vegetales (seleccionar aquéllas que requieran un mantenimiento periódico) y las actividades para la conservación del firme.

2.2.3.8 Ventajas e inconvenientes de las glorietas

Berruezo (2009) resumen las ventajas e inconvenientes de las glorietas en los siguientes puntos:

\section{Ventajas}

1. Moderación de la velocidad.

2. Aumento de la seguridad.

3. Reducción de los tiempos de espera.

4. Aumento de la capacidad en relación con cualquier otra intersección a nivel.

5. Economía de suelo. Maximización de la relación capacidad/superficie.

6. Solución razonable para el cruce de dos o más vías.

7. Posibilidad de ampliar el número de vías que acceden siempre que el tamaño del diámetro exterior sea suficientemente amplio. Posibilidad de sustitución por enlaces.

8. Sencillez de funcionamiento.

9. Sencillez de señalización.

10. Disminución de ruidos.

11. Economía de construcción y explotación.

12. Caracterización e identificación del espacio.

13. Disminución del impacto ambiental.

14. Posibilidades arquitectónicas. 


\section{Inconvenientes}

1. Pérdida de la prioridad.

2. Falta de jerarquía en las vías que acceden a ellas. No deben proyectarse en intersecciones fuertemente desequilibradas en términos de IMD (intensidad media diaria).

3. Se coordinan mal con los semáforos aguas abajo en el sentido del tráfico y un poco mejor, pero tampoco muy bien, con los situados aguas arriba.

4. En zonas urbanas y periurbanas pueden presentarse problemas con los transportes públicos (autobuses).

\subsubsection{Consideraciones de diseño}

\subsubsection{Introducción}

En el proceso de diseño se debe fijar el valor de los parámetros de diseño de acuerdo a diferentes objetivos relacionados con el funcionamiento de la circulación, la seguridad y el coste.

El trazado en planta debe satisfacer cinco requerimientos (Kuhlow, 2011): la capacidad, el acomodo de vehículos de mayor longitud, la seguridad, el acomodo de los usuarios no motorizados y el guiado. En este apartado se analiza de forma independiente cada uno de los objetivos del trazado en planta.

\subsubsection{Capacidad}

\subsection{Introducción}

El término de capacidad hace referencia a la máxima intensidad horaria de personas o vehículos que atraviesan un carril o una sección de la vía en un período de tiempo y bajo unas condiciones preestablecidas de tráfico (HCM, 2010). 
Un objetivo básico del trazado de glorietas es proporcionar capacidad a la intersección. En este apartado, se realiza una descripción general de los estudios de capacidad en glorietas, los métodos que se han desarrollado para su cálculo y la influencia de este condicionante en la definición del trazado en planta.

Si se desea un estudio más amplio de los métodos de capacidad puede consultarse el texto publicado por Rodegerdts y Robinson (2004).

\subsection{Consideraciones generales}

En las glorietas, la calzada anular no se comporta como una serie de tramos de trenzado sino que los vehículos entran directamente a ella cuando consideran que existe un hueco suficiente. Luego existe una interrupción del flujo en las entradas que significa pérdida de tiempo debido a la forma de la regulación de la prioridad.

Debido a este modo de funcionamiento, los investigadores abandonaron el método de trenzado que venían utilizando para estudiar la capacidad de las primeras intersecciones giratorias y desarrollaron nuevos modelos. Estos se basan en descomponer la glorieta en simples intersecciones en $\mathrm{T}^{7}$ en correspondencia con cada una de las entradas.

Con este nuevo planteamiento, son de aplicación las teorías de las intersecciones reguladas por prioridad aunque, a diferencia de éstas, no se puede hablar del concepto de capacidad global de la intersección. La distribución de tráficos es la que determina la capacidad global de una glorieta, y puesto que puede existir un amplio espectro de distribuciones, se concluye que es más correcto hablar de capacidad para cada una de las entradas.

Por tanto, el objetivo de los métodos de capacidad en glorietas es buscar expresiones que relacionen el tráfico en la calzada anular y el máximo que podría incorporarse en una entrada.

\footnotetext{
${ }^{7}$ Las intersección en T es un tipo de nudo a nivel en el que dos de los tres tramos que concurren en la intersección son más importantes que el otro.
} 
El dato de partida básico es el tráfico. Es necesario determinar las intensidades horarias en todos los movimientos, la composición del tráfico y la prognosis hasta el año horizonte, teniendo en cuenta las variaciones estacionales e incluso diarias.

Para determinar las intensidades se puede partir de una matriz origen-destino, u otra técnica, de forma que se pueda estimar un diagrama de flujos para cada acceso y se estime: intensidad de tráfico en la entrada, intensidad de tráfico en la salida e intensidad de tráfico en el anillo circulando delante de la entrada.

La relación entre el flujo de entrada y el que circula por la calzada anular es inversa puesto que, a medida que aumenta el tráfico en el anillo, es más difícil para los vehículos situados en la entrada incorporarse al flujo circulatorio.

La influencia del flujo en la salida del acceso se suele omitir en los cálculos aunque algunos autores recomiendan incluir esta intensidad para mejorar las predicciones.

Al igual que sucede en los estudios de tráfico aplicados a otros elementos viarios, se suele convertir los diferentes vehículos que componen la corriente de tráfico a un número equivalente de vehículos ligeros. La norma de EE.UU de diseño (NCHRP, 2010) especifica, a modo de ejemplo, la siguiente equivalencia: un vehículo pesado es igual a dos vehículos ligeros y una bicicleta es igual a 0,5 vehículos ligeros.

Los factores que condicionan la capacidad de un acceso son (Akcelik, 2008): el tráfico en los otros accesos, la interacción entre todos ellos, el comportamiento de los conductores y la geometría. Otros factores que hay que tener en cuenta son la presencia de peatones y la señalización.

Los modelos internacionales desarrollados para evaluar la capacidad toman en mayor o menor grado cada uno de estos factores. En los siguientes epígrafes se realiza una descripción general de estos métodos y que se refieren en esta investigación como: modelos basados en la geometría, modelos basados en la geometría y el comportamiento de los conductores y, en tercer lugar, herramientas de simulación. 
Por último, hay que tener en cuenta que el concepto de capacidad por sí mismo no describe el funcionamiento de la intersección. Para este objetivo, se pueden utilizar varios conceptos (Rodergedts, 2011):

- Grado de saturación. Es la relación entre volumen y capacidad. El valor deseable es inferior a 0,85 (AUSTROADS 1993, Brown 1995). Si el grado de saturación supera este valor puede deteriorarse rápidamente el funcionamiento en la glorieta. No todos los emplazamientos soportan de igual forma una intersección saturada por lo que debe considerarse el contexto de la localización.

- Demora. Este concepto está formado por un retraso asociado a las maniobras de acoplamiento a una cola (la deceleración, el tiempo en cola y la aceleración) y el asociado a las características geométricas. Como sucede con la capacidad, se han desarrollado métodos analíticos y empíricos para su cálculo.

- Otras medidas: colas, medidas medioambientales (emisiones y consumo de fuel), etc.

En el caso de glorietas, el Manual de Capacidad $^{8}$ (HCM) utiliza el concepto de demora por cola para establecer el nivel de servicio ${ }^{9}$. Siguiendo la formulación que propone esta publicación, referida a escenarios con un grado de saturación inferior a la unidad, se puede calcular la demora y asignar el nivel de servicio entre seis posibles. Al objeto de uniformizar es habitual codificar los niveles de servicio mediante una letra, iniciando la clasificación en A (servicio óptimo) hasta F (servicio pésimo).

\footnotetext{
8 El Manual de Capacidad, Highway Capacity Manual, es el texto de referencia a nivel mundial para evaluar la capacidad y los niveles de servicio. En este texto se especifican un conjunto de técnicas y criterios de análisis que abarcan todos los tipos de infraestructuras viarias y que tienen en cuenta las particularidades de vehículos, peatones y ciclistas, tanto en circulación continua como interrumpida.

${ }^{9}$ El nivel de servicio se define como el modo en el que los conductores y usuarios perciben las condiciones de funcionamiento de una circulación de vehículos.
} 


\subsection{Modelos basados en la geometría de la intersección}

Los modelos empíricos de cálculo de capacidad en glorietas basados en la geometría tienen su origen en Reino Unido a finales de los años setenta. Están asentados en un número elevado de observaciones de glorietas existentes en períodos de sobresaturación. Con la información obtenida, se lleva a cabo un ajuste estadístico de los datos mediante técnicas de regresión lineal o exponencial, y se fijan relaciones entre la capacidad, el tráfico y las características geométricas.

Se han desarrollado varios modelos a nivel mundial. El procedimiento más contrastado fue elaborado por el británico Kimber (1980), profesional perteneciente a la administración del Transportation Research Laboratory (TRL) de Londres.

A continuación, se ofrecen algunos datos que dan idea de la magnitud de este estudio (Kennedy, 2008): grabación superior a 11.000 minutos y observación de más de 500.000 vehículos en un amplio espectro de diseños geométricos y condiciones de circulación. El coste aproximado fue de 11 millones de dólares. Este trabajo se ha demostrado consistente con investigaciones realizadas en años posteriores (Crown y Johnson, 2005).

Las medidas experimentales que se concluyeron indican una relación lineal entre la capacidad de la entrada y el flujo anular, dependiendo dicha relación de la geometría de la glorieta.

Los parámetros geométricos estadísticamente significativos para el estudio de la capacidad se han representado en la Fig.2.18 y son: la anchura de la entrada, la anchura de la aproximación, la longitud del abocinamiento en la entrada, el diámetro exterior, el ángulo de entrada y el radio de aproximación.

Las relaciones empíricas deducidas entre la capacidad y cada uno de estos seis parámetros se han representado en la Fig.2.19. Como se puede observar, y a excepción del ángulo de entrada, todos presentan una relación creciente con la capacidad. Los 
parámetros con mayor influencia son: la anchura de la entrada, la anchura de la aproximación y la longitud del abocinamiento en la entrada.

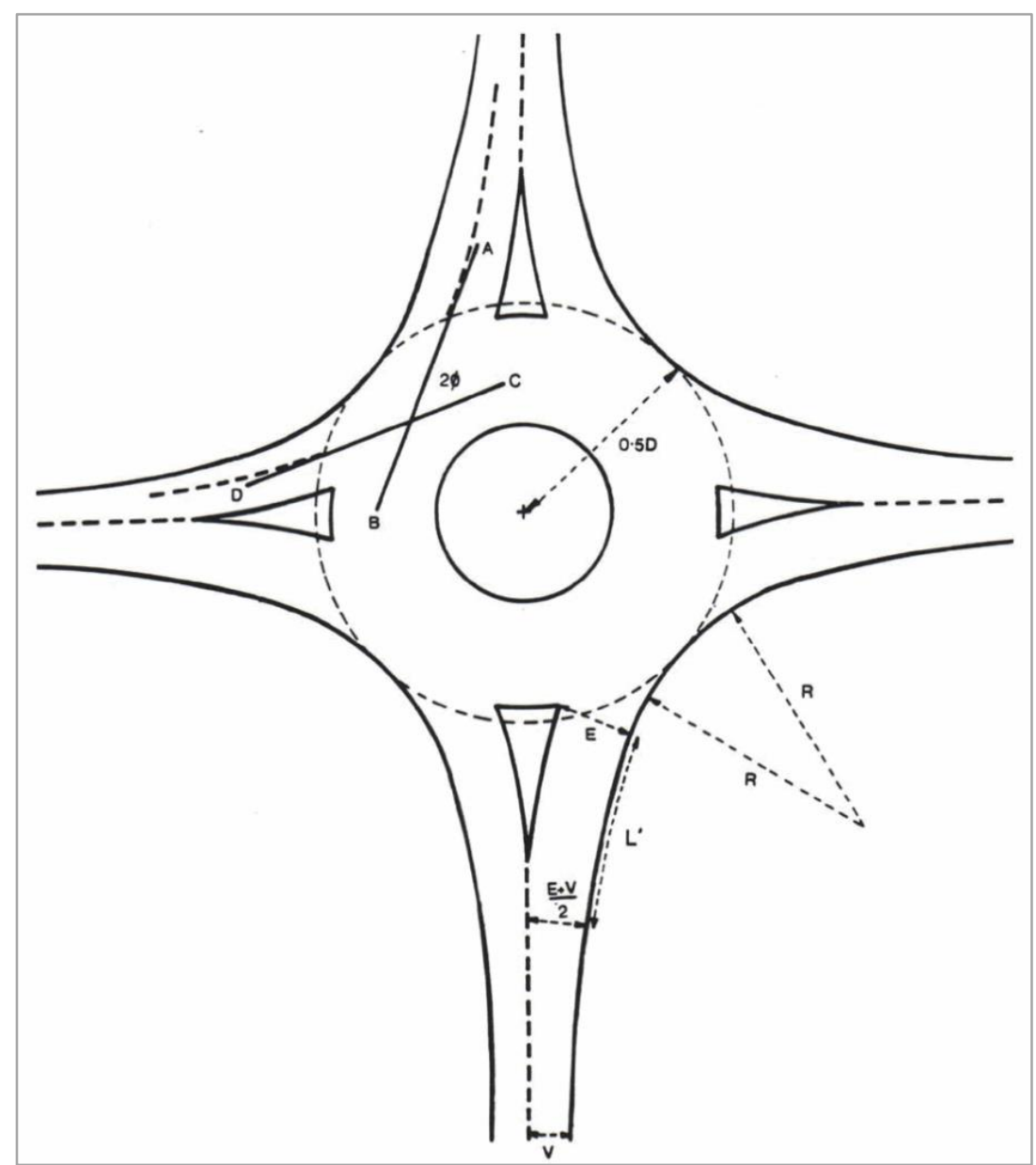

Figura 2. 18 Parámetros geométricos con mayor incidencia en la capacidad. Fuente: Kimber, 1980.

Los softwares comerciales ARCADY y RODEL tienen sus bases en la formulación empírica de Kimber.

Varios países europeos han adoptado modelos similares al de Kimber. En Alemania, la preferencia fue inicialmente utilizar un modelo de regresión lineal basado en la geometría aunque, en la actualidad, se ha abandonado por una formulación basada en la aceptación del hueco (segundo tipo de los modelos que se van a presentar).

En Francia, el cálculo sigue el modelo inglés pero con algunas variaciones que tienen que ver fundamentalmente con la consideración del denominado "tráfico molesto", y 
que se refiere al flujo que abandona la calzada anular por el mismo acceso en el que se está calculando la capacidad. En España, se ha adoptado de igual forma un modelo similar al de Reino Unido.

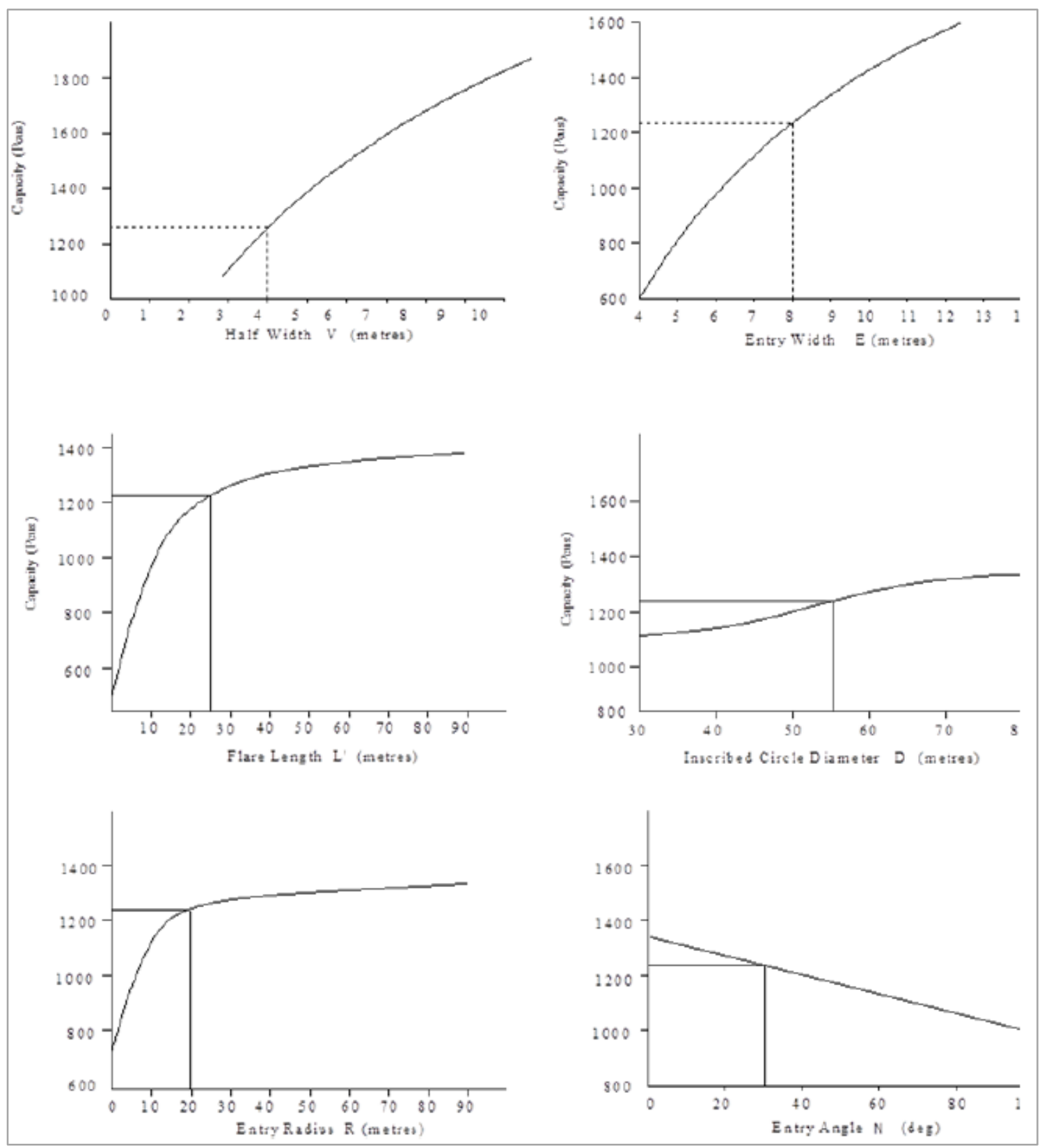

Figura 2.19 Relaciones entre capacidad y parámetros geométricos. Fuente: Kimber, 1980.

2.2.4.2.4 Modelos basados en la geometría y el comportamiento del conductor (aceptación del hueco) 
Este tipo de modelos están basados en la teoría de aceptación del hueco: un usuario situado en una entrada accederá a la calzada anular si considera que existe un hueco suficiente. Por tanto, debe valorar la seguridad de aprovechar un hueco corto y peligroso para entrar frente al beneficio de minimizar la demora en la maniobra.

La teoría de aceptación del hueco contempla dos conceptos básicos: el tamaño de los huecos en la corriente prioritaria y su distribución, y la utilidad de los huecos por los conductores.

El grado de utilidad de los huecos por los conductores se puede evaluar mediante dos variables: el intervalo crítico y el intervalo entre vehículos sucesivos.

El intervalo crítico es una variable aleatoria medida en unidades de tiempo y que representa el intervalo mínimo (o hueco entre vehículos) que debe existir entre dos vehículos que circulan por la calzada anular para que un vehículo que espera decida incorporarse.

El intervalo entre vehículos sucesivos se define como el tiempo que transcurre entre la incorporación de un vehículo desde un acceso y la incorporación del siguiente, aprovechando un mismo hueco, y de manera que ambos vehículos se encuentren inicialmente en cola esperando dicho hueco.

Existen básicamente dos grandes grupos de metodologías para la estimación del intervalo crítico y del intervalo entre vehículos sucesivos.

En el primero, se realiza una estimación conjunta de los tiempos mediante un análisis de regresión (número de vehículos que utilizan el mismo intervalo frente al tamaño del intervalo). Se necesitan condiciones de saturación.

En el segundo, se calculan los valores medios esperados de los tiempos de forma probabilística pudiendo aplicarse en condiciones no saturadas. Conceptualmente puede ser análogo al método anterior, si se ajusta una distribución de probabilidades a una muestra de datos. 
En cualquier caso, para evaluar la capacidad se asume lo siguiente (Gallelli y Vaiana, 2008):

- Valores constantes para el intervalo crítico e intervalo entre vehículos sucesivos.

- Distribución exponencial de los huecos dentro de la corriente de circulación.

- Valores constantes para las intensidades.

El cálculo de capacidad está muy influenciado por los valores del intervalo crítico e intervalo entre vehículos sucesivos, por lo que es muy recomendable calibrarlos para adaptarlos a las condiciones locales (Trueblood, 2011).

Diferentes Administraciones han calibrado los principales parámetros de la teoría de aceptación del hueco para adaptarla a las condiciones de circulación de sus territorios. Para realizar el cálculo se proponen diferentes expresiones de naturaleza empírica.

En Alemania, los estudios se iniciaron en los años setenta con los trabajos desarrollados por Siegloh y Harders (Luttinen, 2003). Estos métodos se han ido mejorando con el tiempo, adoptándose en la normativa vigente la formulación propuesta en el trabajo de Brilon y Wu (2008). Para facilitar los cálculos se ha desarrollado el software KREISEL.

En Estados Unidos, el Highway Capacity Manual sigue el modelo de Harders en el caso general, transformado a un modelo de regresión exponencial en la normativa de glorietas (NCHRP, 2010). En este texto se proponen unos umbrales para los valores de la utilidad de los huecos. La metodología que plantea el HCM se ha plasmado en el software Highway Capacity Software.

Australia presenta una gran tradición en este tipo de modelos. Los estudios se iniciaron en los años sesenta con la formulación propuesta por Tanner (1967). La normativa australiana (AUSTROADS, 1993) se basa en la formulación de Troutbeck (1989) y posteriores modificaciones. Akcelik, autor de numerosas publicaciones sobre glorietas, plantea un modelo similar al de la normativa con algunas modificaciones recogidas en Akcelik (2004). Este mismo autor ha desarrollado el software comercial SIDRA. 
Los modelos de aceptación del hueco captan en mayor o menor grado la geometría de la intersección. En referencia a los modelos analizados:

- Los modelos de EEUU y Alemania incluyen como datos de partida el número de carriles y las dimensiones de las calzadas en los accesos y en el anillo.

- El modelo de Australia de Akcelik, además del número de carriles y sus dimensiones, considera el diámetro exterior, el radio de entrada, y el ángulo en la trayectoria de entrada.

\subsection{Herramientas de simulación de tráfico}

Mediante los paquetes de simulación de tráfico es posible evaluar la capacidad de una glorieta y visualizar su funcionamiento.

Estas herramientas permiten modelar escenarios complejos teniendo en cuenta la interacción con el resto de la red. Se recomienda utilizar microsimulación en las siguientes situaciones (Ambadipudi, 2008): proximidad de otras intersecciones, tráfico compuesto con diferentes tipos de vehículos, pendientes en los accesos, interacción aguas abajo con confluencias-bifurcaciones y, por último, cuando se desea comparar el efecto de la aplicación de diferentes tratamientos en el diseño de la glorieta.

Para poder utilizar estas herramientas es necesario introducir muchos datos relacionado con la geometría de la red, el comportamiento de los conductores y del tráfico. Además es necesario realizar una buena calibración que permita adaptar el modelo a las condiciones reales.

Al igual que en los procedimientos presentados con anterioridad, se han desarrollado a nivel mundial numerosas aplicaciones informáticas (Rodergedts, 2011): AIMSUN (España), CORSIM (Estados Unidos), INTEGRATION (Estados Unidos y Canadá), PARAMICS (Reino Unido), SimTraffic (Estados Unidos) y VISSIM (Alemania). 


\subsection{Comparación de los modelos de cálculo de capacidad.}

En primer lugar, hay que tener en cuenta que todos los procedimientos para estimar la capacidad de una glorieta realizan suposiciones que entrañan un riesgo en los cálculos. El proyectista debe conocer estos riesgos y usar las herramientas informáticas de forma adecuada.

Los modelos basados en la geometría y en el comportamiento de los conductoresgeometría basan el estudio de capacidad en intensidades de tráfico (estudio macroscópico). El principal input es la intensidad en la entrada y en la calzada anular, y todos los modelos predicen la capacidad total de la entrada.

Si se desea mejorar la estimación, se puede realizar un estudio carril por carril (Chard, 1997). Algunas de las aplicaciones informáticas presentadas permiten este tipo de análisis. El ejemplo más representativo es el modelo de Australia plasmado en SIDRA.

Puesto que estos procedimientos no permiten el estudio de la interacción de la glorieta con el resto de elementos de la red, puede ser necesario utilizar una herramienta de microsimulación. En este caso se tienen en cuenta los vehículos y los conductores de forma individual (estudio microscópico).

En todos los casos hay que tener en cuenta las implicaciones culturales y sociales del país donde se va a desarrollar el proyecto. En los métodos basados en la geometría, los ajustes que fundamentan el método pueden resultar inválidos cuando se exportan a las condiciones de tráfico y culturales de otro país. De igual forma sucede para las variables de los métodos basados en el comportamiento del conductor. En las herramientas de simulación, es obligatorio calibrar los parámetros de acuerdo a la red de estudio y presentan un esfuerzo computacional mayor.

A continuación, se resumen algunas de las principales conclusiones extraídas de investigaciones cuyo objeto fue comparar las tres metodologías presentadas: 
- Para McCulloch (2008), los resultados obtenidos según los modelos basados en la geometría y en el comportamiento de los conductores-geometría pueden ser muy diferentes.

- Gallelli et al., (2007) y Capiluppi et al., (2006) recomiendan utilizar los modelos basados únicamente en la geometría. Los autores advierten que para poder utilizarlos deben basarse en un número importante de mediciones en glorietas existentes en condiciones sobresaturadas (esto resulta indiferente en los modelos basados en el comportamiento de los conductores-geometría). Además, puede resultar difícil la exportación de los criterios a otros países.

- Butch (2008) concluye que existen mayores riesgos de cálculo en los modelos basados en la aceptación del hueco.

- Gallelli y Vaiana (2008) ponen de manifiesto las limitaciones de los modelos basados en el comportamiento de los conductores-geometría, lo que implica que pueda resultar difícil su aplicación en la práctica.

- Scott (2008) expone que los modelos de simulación pueden ser costosos de construir por lo que en situaciones con intersecciones aisladas y bajas intensidades de tráfico los resultados son similares a los obtenidos utilizando los métodos analíticos.

- Rodergedts (2011) expone que se han obtenido buenos resultados en glorietas de un carril mediante los métodos basados en el comportamiento de los conductores-geometría. No obstante, para el autor no existe un método mejor que otro, sino que el éxito depende mucho de la calidad de los datos de partida y su calibración.

- Stanek (2011) recomienda calibrar las condiciones locales, chequear el cálculo mediante varios procedimientos y realizar un análisis de sensibilidad en un margen del $10 \%$ sobre los datos considerados. Para uso conservativo usar el método del HCM 2010. 
- Salamati (2011) concluye que el método del HCM no da buenos resultados para glorietas de tres carriles.

En cuanto a la comparativa de las capacidades estimadas y las observadas en campo, Persaud et al., (2005) concluyen que todos los métodos realizan predicciones superiores a las observadas.

\subsubsection{Necesidades de área barrida del vehículo patrón}

Un objetivo básico del trazado en planta de glorietas es compatibilizar el diseño con las necesidades de área barrida de los vehículos de mayor longitud.

En primer lugar, hay que seleccionar un vehículo patrón (fase preliminar). Se debe considerar el vehículo más grande que tiene una probabilidad razonable de utilizar la glorieta, pues el diseño final debe permitir el paso y giro no forzado de todos los vehículos.

Para realizar esta selección hay que tener en cuenta los tipos de vías que confluyen en el anillo, los datos de tráfico y los usos del suelo del entorno. Si procede, la elección se debe ajustar a las especificaciones sobre dimensiones que, por tipología de vehículo, suelen recoger el Código de Circulación o algún texto similar. No obstante, las guías de diseño especifican el tipo de vehículo a tener en cuenta en el proyecto.

Los vehículos de mayor longitud tienen un impacto directo sobre el diseño, tanto en planta como en alzado.

En planta, puede ser necesario un espacio extra para facilitar el paso por la glorieta. Para esto, se pueden diseñar unas zonas contiguas a los carriles en los accesos y a la isleta central (gorjal) situadas fuera de la circulación normal, pero que pueden ser utilizadas por los vehículos más grandes en caso necesario (Fig.2.20). 


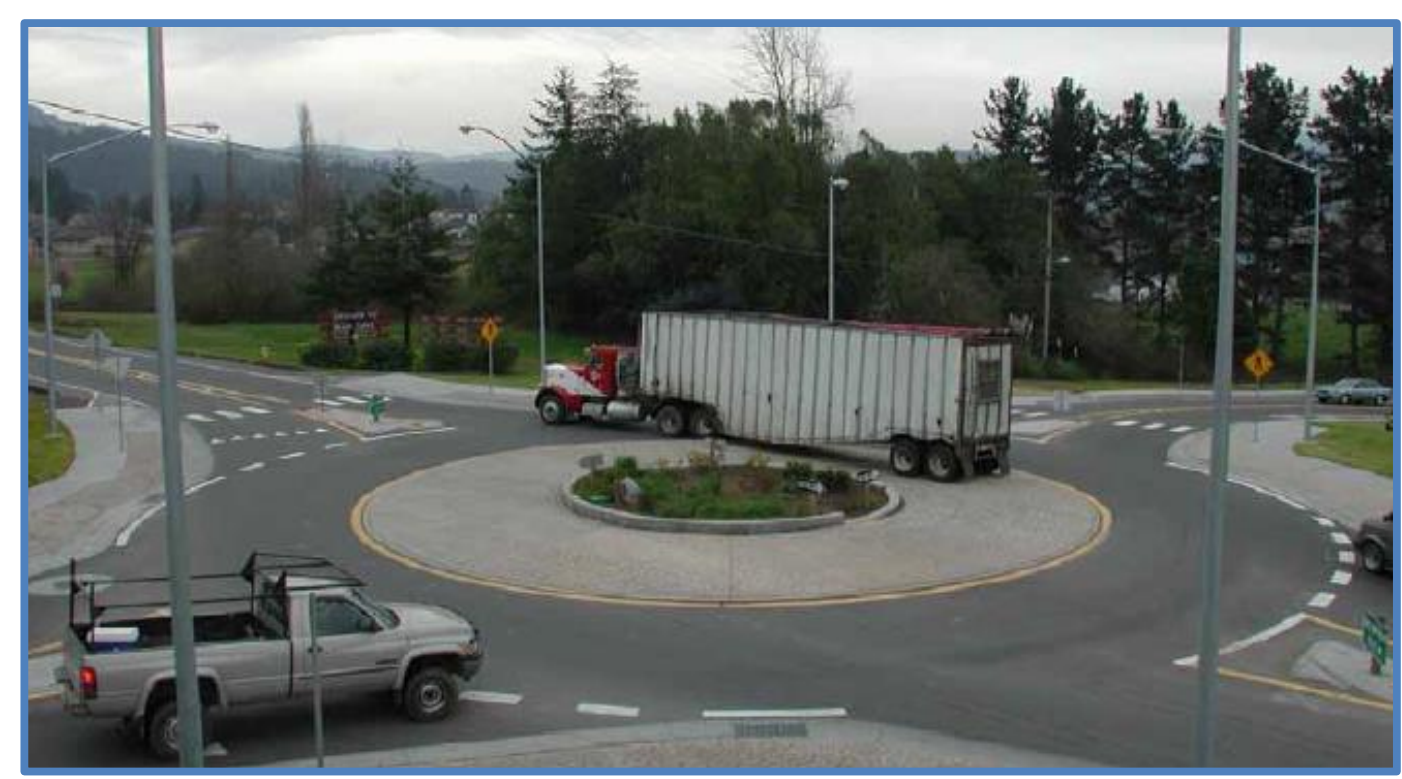

Figura 2. 20 Gorjal para el paso de los vehículos de mayor longitud.

Fuente: Weinberger, 2005.

En glorietas de un carril la problemática de paso de los vehículos de mayor longitud es más importante que en glorietas multicarril. Es común que los camiones ocupen la calzada completa de los accesos para realizar la maniobra.

Ritchie y Butch (2011) analizaron las condiciones de paso de los vehículos de mayor longitud en glorietas multicarril de EEUU mediante la definición de tres escenarios:

- Los vehículos ocupan más de un carril cuando realizan la maniobra.

- Los vehículos permanecen en su carril en la entrada y ocupan otros carriles en la calzada anular y en la salida.

- Los vehículos permanecen en su carril en la trayectoria completa.

Los autores analizaron la distribución de escenarios en glorietas existentes situadas en diferentes Estados. Los resultados mostraron que el primer caso es el más generalizado. En menor proporción se identificó el segundo escenario y con muy bajas probabilidades al tercero.

Para realizar las comprobaciones de paso y necesidades de área barrida de los vehículos de mayor longitud se han desarrollado diferentes aplicaciones informáticas 
(AUTOTURN, AUTOTRACK, VPATH,...). En general, el manejo de estos programas se realiza en un entorno de CAD y para poder realizar el cálculo hay que seleccionar un vehículo patrón y definir el trazado de la trayectoria. El software genera de forma automática el área barrida.

En las guías de diseño está normalizado el tamaño mínimo de la glorieta necesario para admitir el paso de diferentes vehículos patrón. Estos valores son muy útiles para orientar al proyectista para fijar el tamaño de los elementos. Hay que tener en cuenta que suelen asumir ciertas simplificaciones por lo que resulta siempre recomendable comprobar las condiciones de paso mediante alguna aplicación informática.

Gingrich (2008) estudió la influencia del alzado y pendientes transversales en el paso de los vehículos de mayor longitud por glorietas. Las alineaciones verticales deben ser compatibles con las exigencias que impone la longitud y distancia hasta el suelo de la caja del vehículo (Fig.2.21). Este aspecto debe tenerse en cuenta cuando se diseña el gorjal y, según el autor, necesita ser mejor regulado en las normativas de diseño.

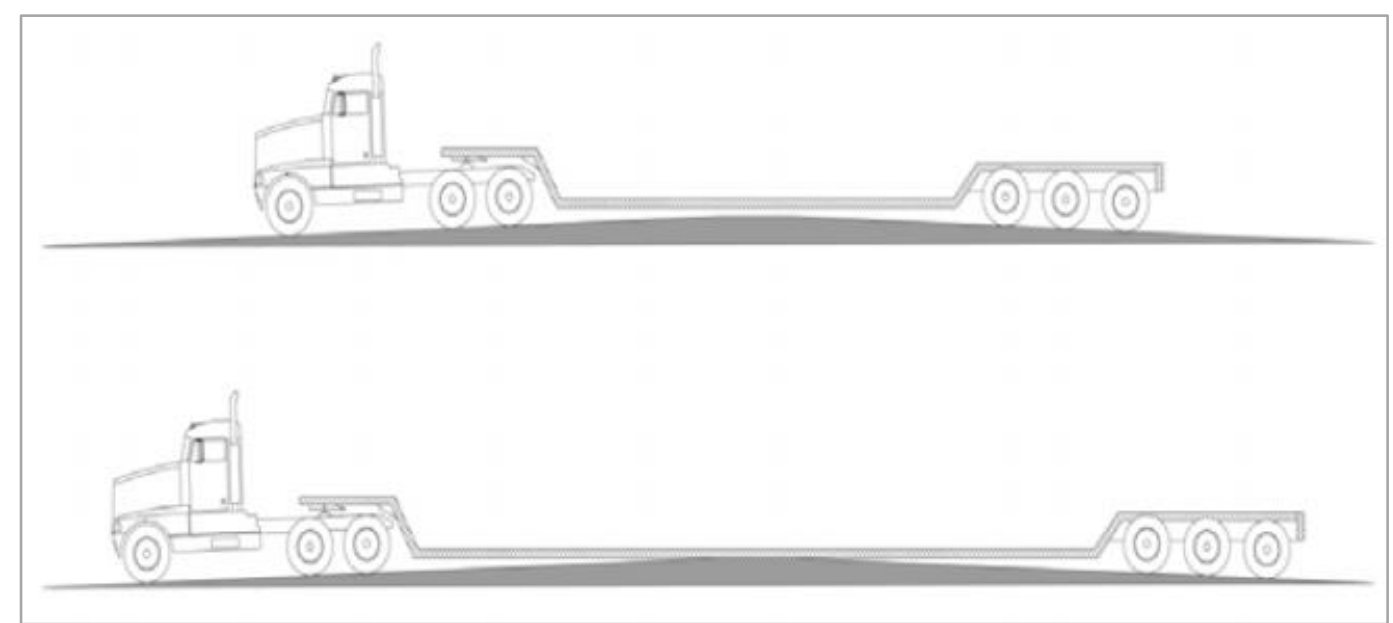

Figura 2. 21 Condicionante en alzado del paso de los vehículos de mayor longitud. Fuente: Gingrich, 2008.

En cuanto a las pendientes transversales, en esta investigación se analizaron las condiciones del peralte en la calzada anular en relación a la aceleración que sufre el conductor y la caja del vehículo. El conductor recibe más aceleración que el tráiler en diseños con peralte a dos aguas y al contrario cuando el peralte es hacia la isleta central. El escenario más desfavorable, y que define la máxima diferencia de aceleración, se 
produce cuando la caja del vehículo circula sobre el gorjal. El autor concluye que son necesarias más investigaciones para determinar todos estos efectos con mayor detalle.

Los vehículos pesados (y sobre todos los articulados) pueden volcar o perder su carga al pasar por algunas glorietas (MF, 2012). Sawers (2011) analizó las condiciones de vuelco en una investigación. Las causas principales según el autor son: una velocidad excesiva, el tropiezo con los bordillos, el cambio en el radio de la calzada circular, la carga del vehículo, el fallo mecánico y la climatología. El autor recomienda que en el diseño se tengan en cuenta los siguientes apartados: promover una adecuada deceleración en la entrada, asegurar una buena visibilidad de la calzada anular y minimizar los cambios en la pendiente transversal.

En cuanto a la capacidad, Lee y Dahl (2011) exponen que los modelos de cálculo actuales no tienen en cuenta de forma específica los volúmenes de vehículos pesados. Este aspecto es importante ya que los camiones presentan un comportamiento diferente a la hora de insertarse en el hueco del flujo circulatorio y su velocidad de maniobra varía respecto a los turismos.

\subsubsection{Seguridad}

\subsection{Introducción}

En este apartado se analiza la relación entre seguridad y el trazado en planta de glorietas. El estudio se ha dividido en varios apartados y se pretenden alcanzar los siguientes objetivos:

- Revisar las principales investigaciones sobre siniestralidad en glorietas.

- Definir los tipos de accidentes en glorietas y analizar su frecuencia.

- Identificar las características geométricas más recurrentes en la generación de accidentes.

- Presentar los principales modelos de predicción de accidentes.

- Analizar los criterios desarrollados para evaluar la seguridad de un diseño. 


\subsection{Aspectos generales}

Las intersecciones son un punto crítico dentro del sistema viario. En ellas se produce el cruce de dos o más vías, y los vehículos y resto de modos deben ser guiados a través de la geometría del nudo de forma que las interacciones entre ellos se realicen en condiciones de seguridad.

El comportamiento de las glorietas en cuanto a facilitar estos movimientos con máxima seguridad es notable. Numerosos estudios a nivel internacional han constatado una clara reducción de la siniestralidad y la severidad de los accidentes en comparación con las intersecciones convencionales. En el caso de peatones y ciclistas esta reducción es menos importante e incluso desfavorable.

Las razones que motivan un incremento de la seguridad en las glorietas son una consecuencia de sus propias características de funcionamiento (Hicks, 2005):

- Reducción del número de puntos de conflicto en comparación con las intersecciones convencionales.

- Modificación del tipo de accidente (las trayectorias no se cruzan sino que convergen y divergen).

- Eliminación de los giros a izquierdas.

- Moderación de las velocidades, lo que permite aumentar los tiempos de reacción de los conductores.

- Los peatones cruzan de forma escalonada las corrientes de tráfico de entrada y salida a la glorieta y se reducen el número de puntos de conflicto.

\subsection{Siniestralidad}

Los accidentes en glorietas pueden ser provocados por múltiples factores, relacionados con el fallo que se produce en la interacción entre usuario, vehículo y carretera. Aproximadamente el $30 \%$ de los sucesos son atribuidos parcial, o completamente, a la carretera y el entorno (Lenters, 2005). 
El estudio de los registros de accidentes ayuda a detectar los factores que inciden en la frecuencia de accidentes y en su severidad, y de forma general, a identificar el comportamiento de la intersección frente al condicionante de seguridad. A continuación, se relacionan las principales conclusiones de los estudios consultados:

- Las investigaciones internacionales mostradas en la Tabla 2.1 coinciden en sus conclusiones que la sustitución de una intersección convencional por una glorieta favorece la seguridad reduciendo el porcentaje de accidentes.

\begin{tabular}{|l|c|c|}
\hline \multirow{2}{*}{\multicolumn{1}{|c|}{ País - referencia }} & \multicolumn{1}{c|}{$\begin{array}{c}\text { Total de } \\
\text { accidentes }\end{array}$} & $\begin{array}{c}\text { Accidentes con } \\
\text { heridos o fatales }\end{array}$ \\
\cline { 2 - 3 } & \multicolumn{2}{|c|}{$\%$ reducción } \\
\hline Reino Unido - Lanani (1975) & 31 & 52 \\
\hline Australia - AUSTROADS (1993) & -- & 74 \\
\hline Francia - Guichet (1997) & -- & $57-78$ \\
\hline EEUU - Persaud et al., (2001) & 40 & 80 \\
\hline Bélgica - Antoine (2005) & -- & $42-48$ \\
\hline EEUU - NCHRP (2007a) & 35 & 76 \\
\hline
\end{tabular}

Tabla 2. 1 Porcentaje de reducción del número de accidentes en varios países.

- Antoine (2005) realizó un estudio sobre 122 intersecciones en Bélgica y determinó un gran impacto del tipo de entorno en los resultados. En ámbitos interurbanos la reducción de la siniestralidad fue del 50\%, en periurbanos esta reducción alcanzó el 46\%, mientras que en intersecciones urbanas fue sólo del $15 \%$.

- Kennedy et al., (2005) evaluaron el impacto de la accidentalidad por modos. El estudio se basó en el análisis de 1.162 glorietas de Reino Unido y los resultados alcanzados se resumen en las Fig. 2.22 y 2.23. De estos gráficos se deduce que el mayor porcentaje de accidentes se concentra en turismos. Peatones, ciclistas y motocicletas son los modos más sensibles a la severidad. Los autores también concluyeron que las glorietas con mayor número de accesos presentan mayor siniestralidad. 


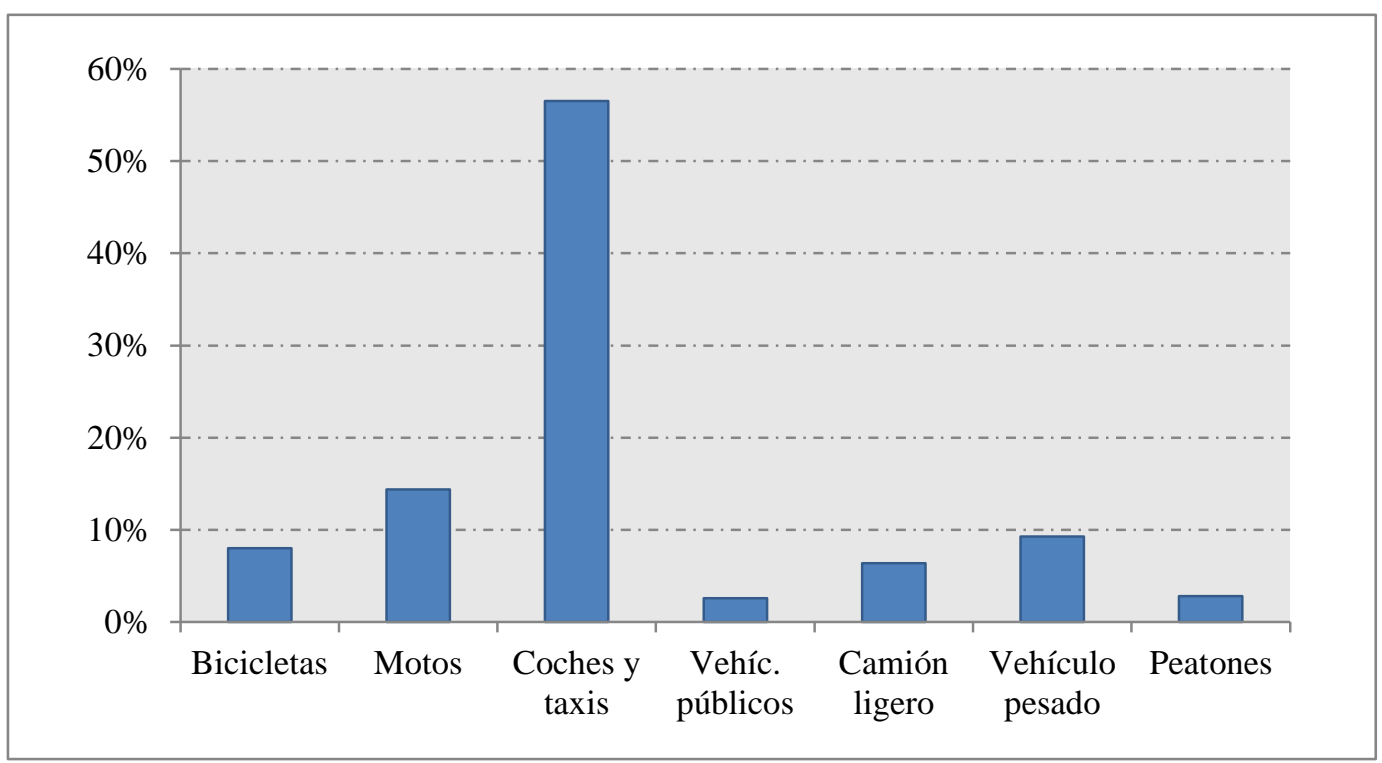

Figura 2. 22 Distribución del número de accidentes por modos.

Fuente: Kennedy et al., 2005.

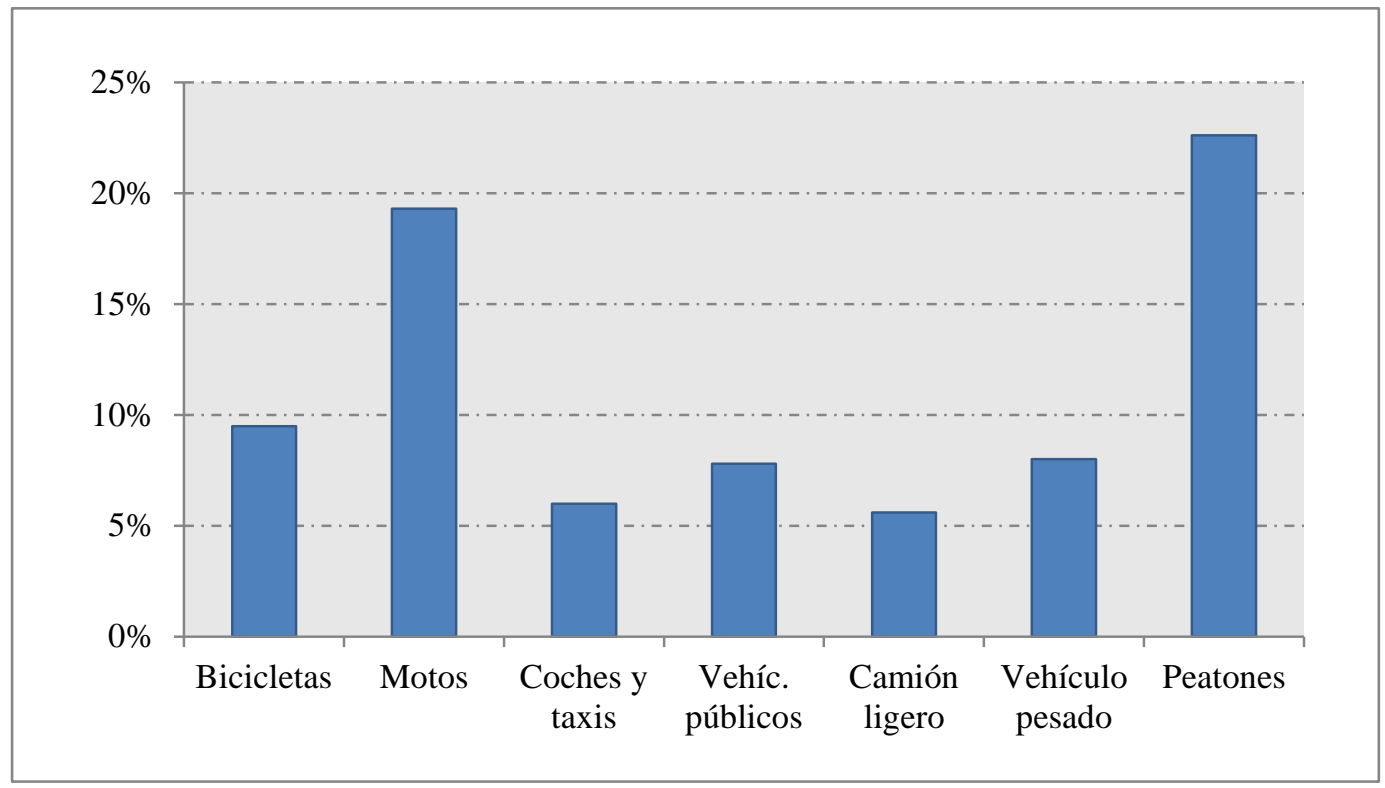

Figura 2. 23 Porcentaje de accidentes fatales por modos.

Fuente: Kennedy et al., 2005.

- Turner et al., (2006) obtuvieron resultados similares en la distribución de los accidentes por modos, aunque registraron una mayor proporción para peatones y ciclistas. La distribución de su estudio fue: $67 \%$ para los vehículos a motor, $25 \%$ en ciclistas y $8 \%$ para peatones. 
- Daniels et al., (2008) analizaron la evolución de la accidentalidad en 90 glorietas en la región de Flanders (Bélgica) en las que se vieron incluido ciclistas. Los resultados muestran un incremento general del número de accidentes severos sin tener en cuenta el tipo de glorieta. El autor concluye que funcionan peor que las intersecciones convencionales.

- En el informe preparado por cincuenta auditores de seguridad de Nueva Zelanda (Transfund NZ, 2002) se relacionaron las causas más comunes de accidentalidad en glorietas y se obtuvo la siguiente distribución (en porcentaje):

$\begin{array}{ll}15 \% & \text { señalización vertical } \\ 9 \% & \text { señalización horizontal } \\ 7 \% & \text { ciclistas } \\ 7 \% & \text { deflexión inadecuada de las velocidades } \\ 6 \% & \text { trazado de los límites de la intersección } \\ 6 \% & \text { configuración de carriles } \\ 6 \% & \text { peatones } \\ 6 \% & \text { visibilidad } \\ 6 \% & \text { líneas de visibilidad } \\ 5 \% & \text { emplazamiento de obstáculos } \\ 5 \% & \text { iluminación }\end{array}$

- Gbologah (2014) analizó la relación entre iluminación, seguridad y coste en glorietas de tres y cuatro carriles del Estado de Minnesota (EE.UU). Los datos de partida sobre accidentalidad fueron recogidos durante el período entre 2003 a 2010. El estudio considera tres niveles de iluminación en las glorietas existentes: sin iluminación, parcial y completa. En el análisis de los datos se compararon las secciones en glorietas con y sin iluminación concluyendo que las intersecciones iluminadas tenían una reducción del 60-65\% en accidentes nocturnos. Según nivel de iluminación, los resultados mostraron una reducción de 49-60\% en caso de iluminación parcial y $72 \%$ en condiciones de completa iluminación. 


\subsection{Tipología de Accidente}

Los investigadores han propuesto diferentes clasificaciones para definir los tipos de conflictos que pueden producirse en una glorieta. Kennedy et.al (2005) los clasifica en los siguientes (Fig.2.24):

Tipo 1. Accidentes en los que interviene un vehículo de forma aislada. Son debidos a la pérdida del control del vehículo. Se pueden localizar en la entrada, en la salida o en la calzada anular.

Tipo 2. Accidentes localizados en la aproximación. Se distinguen dos tipos: colisión trasera y choque lateral en las glorietas de más de un carril.

Tipo 3. Accidentes en la entrada. El fallo se produce entre el vehículo que pretende acceder y el que se encuentra circulando por la calzada anular con una colisión en ángulo.

Tipo 4. Otros tipos. En este grupo se incluyen el resto de accidentes. Su naturaleza puede ser variada (accidentes en la salida, accidentes con choque lateral en el anillo, accidentes con peatones y ciclistas,...).

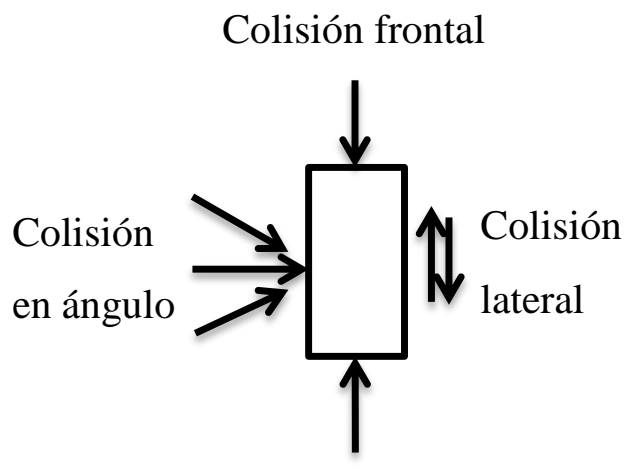

Colisión trasera

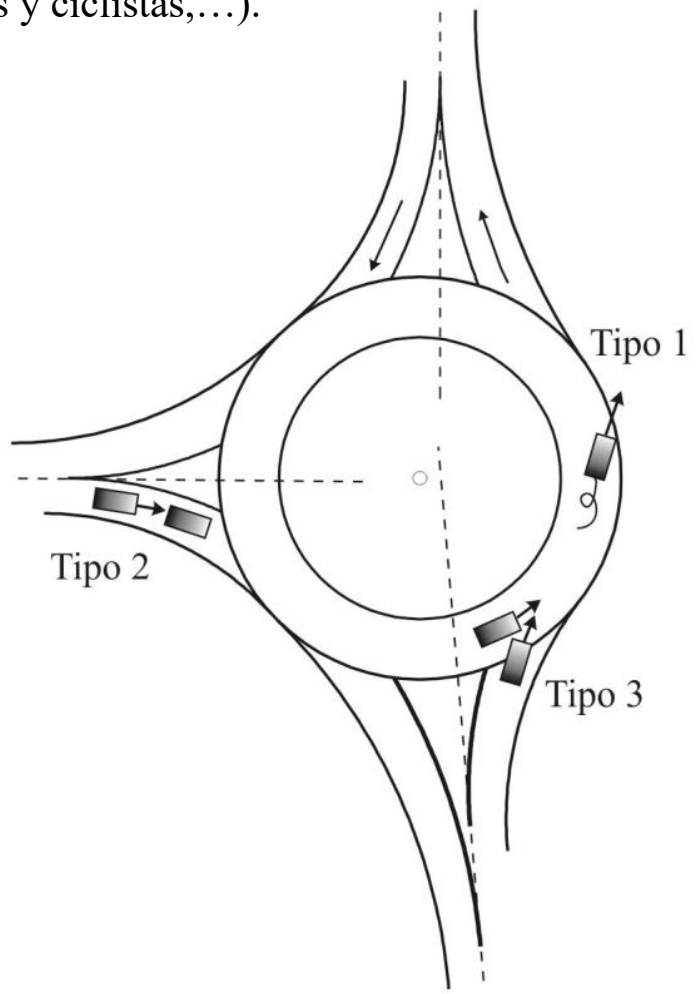

Figura 2. 24 Tipos de colisión (izquierda) y accidentes (derecha) en glorietas. 
Kennedy et.al (2005) relacionaron el tipo de accidente con la tipología de glorieta. En tamaños bajos y medianos, el tipo de accidente predominante es el accidente en la entrada (tipo 3), mientras que en las glorietas de tamaño mayor, con más de un carril en la entrada, los tipos de conflicto más frecuentes son los localizados en la aproximación (tipo 2) y en los que interviene un vehículo de forma aislada (tipo 1).

La tendencia en los estudios internacionales muestra que los siniestros localizados en la entrada (tipo 3) y de un vehículo de forma aislada (tipo 1), presentan una frecuencia más alta. En la Fig.2.25 se representan los resultados de las investigaciones consultadas.

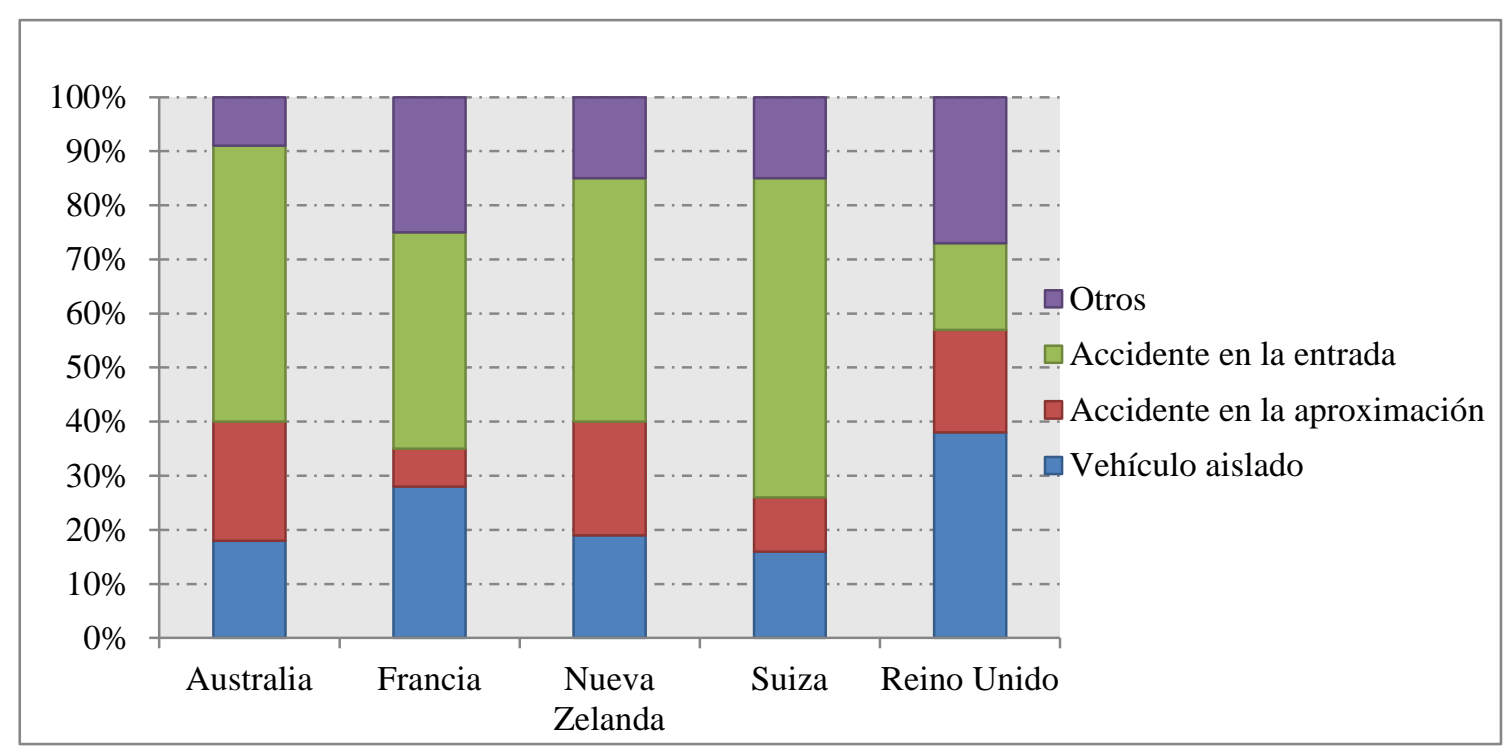

Figura 2.25 Tipología de accidente en varios países.

Fuentes: Arndt, 1998 (Australia); Guichet, 1997 (Francia); Harper y Dunn, 2003 (Nueva Zelanda); Spacek, 2004 (Suiza); Maycock y Hall, (1984) (Reino Unido).

En comparación con las intersecciones convencionales, la instalación de una glorieta modifica el tipo de accidente. El accidente en ángulo es potencialmente el tipo de siniestro más peligroso (Isebrands, 2011). En las intersecciones convencionales no semaforizadas de EE.UU representan un 84\% del total de siniestros (NCHRP, 2003).

En las glorietas, debido al funcionamiento mediante una calzada anular se eliminan los giros a izquierdas. En los accidentes en ángulo (tipo 3), se reduce la severidad debido a la deflexión de las velocidades en las entradas. Sin embargo, en las glorietas se tiende a aumentar el tipo de conflicto con alcance por la parte trasera y el choque lateral (tipo 2) (NCHRP, 2007a). 


\subsection{Geometría y accidentalidad}

Existe una relación estadística probada entre elementos geométricos y seguridad vial (Ritchie, 2005). Los investigadores han llevado a cabo diferentes estudios cuyo objetivo ha sido identificar los parámetros geométricos con mayor incidencia en la generación de accidentes. A continuación, se presentan las investigaciones más relevantes.

\section{Maycock y Hall (1984)}

En los años ochenta, Maycock y Hall (1984) llevaron a cabo un amplio estudio sobre la relación entre geometría y siniestralidad.

Los autores analizaron 84 glorietas de Reino Unido durante un período de cuatro años y concluyeron mediante correlaciones estadísticas que los parámetros de diseño con mayor influencia en la seguridad son (Fig.2.26):

$\Rightarrow$ Curvatura de la trayectoria en la entrada $(\mathrm{Ce})$.

Se refiere al inverso del radio de la trayectoria en la entrada. Este parámetro determina la deflexión de velocidades (deceleración del vehículo) y se ha convertido en un parámetro de referencia para evaluar la seguridad de un diseño. Si el acceso se produce de forma tangencial, el vehículo tenderá a alcanzar el punto de conflicto con la corriente que circula por la calzada anular a una velocidad excesiva, aumentando el riesgo y la severidad del accidente (Fig.2.27).

Los autores encontraron que el aumento de las velocidades es un factor importante que aumenta la probabilidad del tipo de accidente de un vehículo (tipo 1). Para los accidentes en la entrada (tipo 3), la repercusión es aún más importante. Estos mismos resultados han sido contrastados en otras investigaciones (Arndt, 1991; Robinson, 1998; Turner y Roozenburg, 2007). 


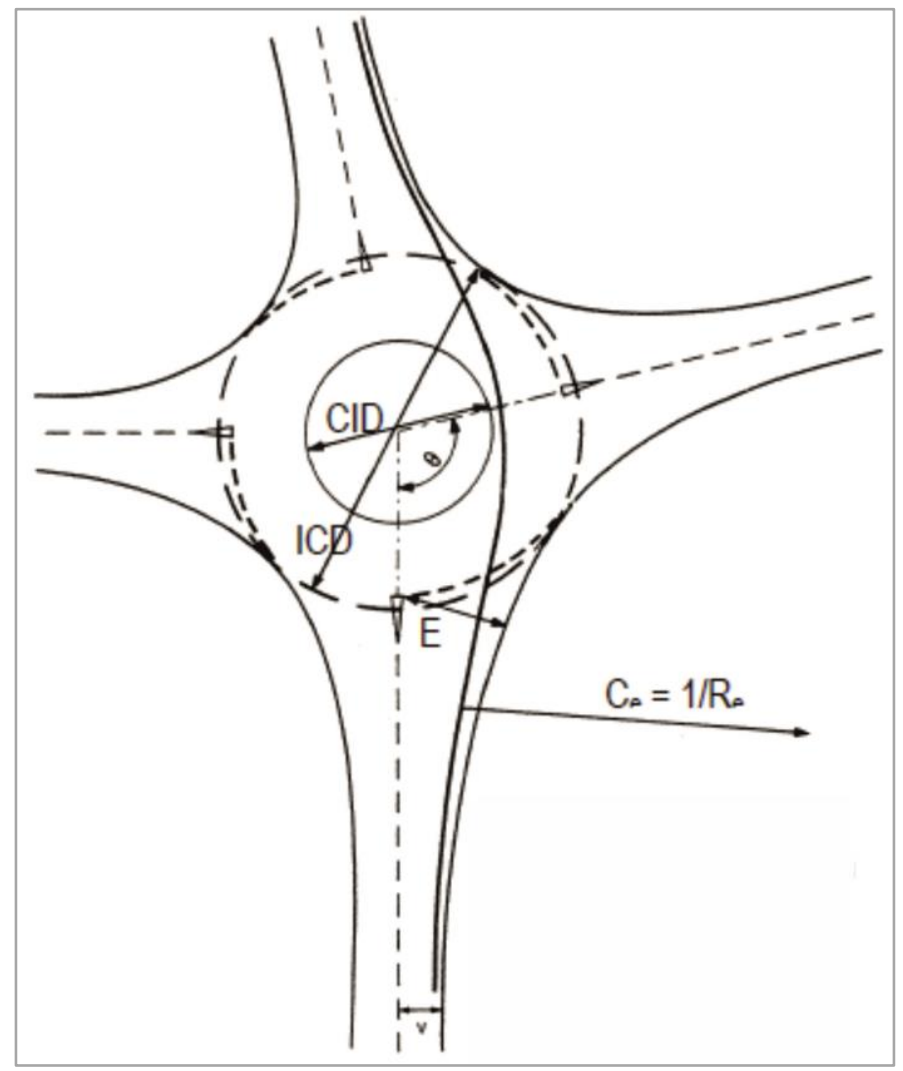

Figura 2. 26 Parámetros geométricos con una mayor influencia en la seguridad. Fuente: Maycock y Hall, 1984.

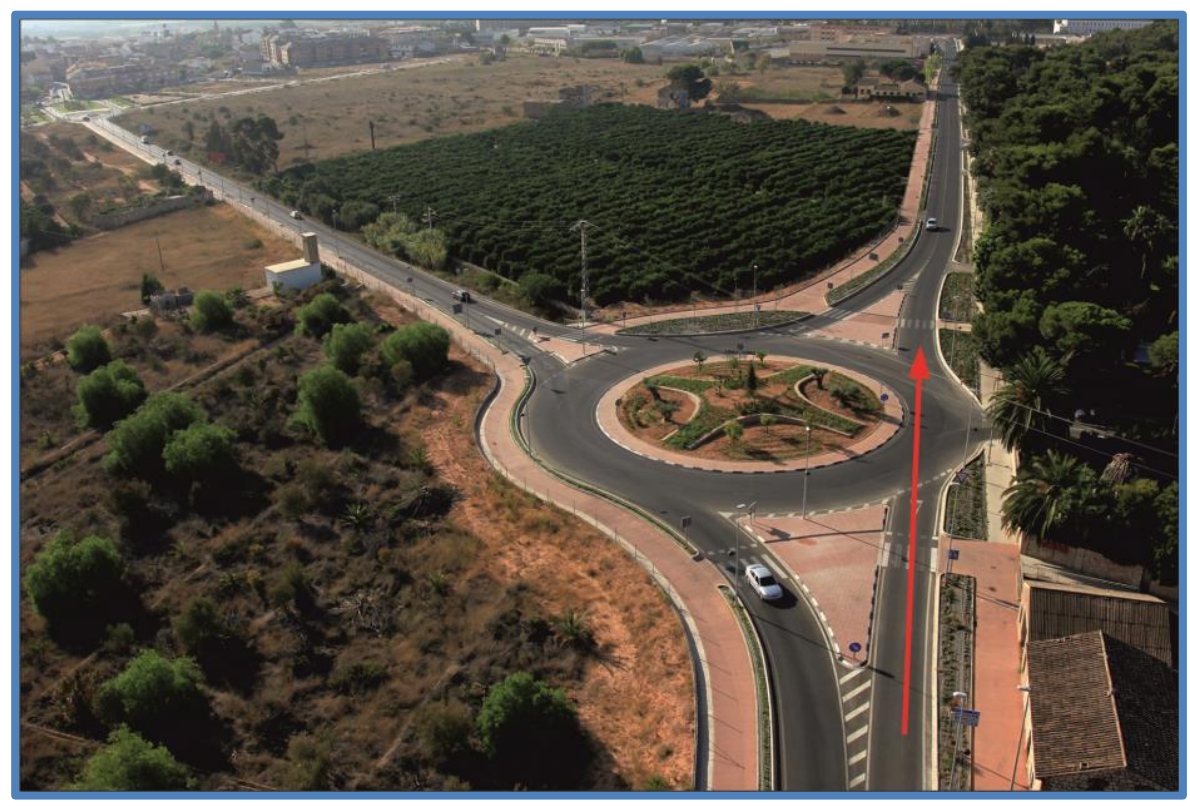

Figura 2. 27 Curvatura inadecuada en la entrada.

Fuente: Diputación de Valencia (www.dival.es) 
$\Rightarrow$ Anchura de la entrada (E).

Maycock y Hall (1984) exponen que con el aumento de la anchura de la entrada se incrementa la probabilidad de los accidentes en la entrada (tipo 3) y del vehículo aislado (tipo 1), pero decrece el accidente en la aproximación (tipo 2). Como establece Crown (1992), variando una de las características geométricas se puede reducir la probabilidad de que suceda un tipo de accidente, pero puede aumentar el riesgo de fallo en otro tipo.

$\Rightarrow$ Tamaño del diámetro exterior y de la isleta central (ICD y CID).

Determinan la tipología de glorieta e influyen en la cantidad de deflexión que se puede provocar en el perfil de las velocidades.

Otras variables geométricas con efecto en la seguridad fueron:

$\Rightarrow$ Ángulo entre accesos $(\Theta)$.

Al aumentar este ángulo se reduce la frecuencia de accidentes. Accesos equiespaciados son por tanto los más seguros.

$\Rightarrow$ Curvatura en la aproximación.

Se refiere al borde exterior de la curva de entrada y que junto con la isleta deflectora determina el guiado de los vehículos.

$\Rightarrow$ Anchura de la aproximación (v).

Presenta menor influencia en la frecuencia de accidentes.

Los resultados obtenidos en esta investigación han sido la base para la redacción de diferentes capítulos de la norma de diseño de Reino Unido de glorietas.

\section{$\underline{\text { Arndt y Troubeck (1995) }}$}

En Australia, Arndt y Troubeck (1995) establecieron que los resultados del estudio realizado por Maycock y Hall (1984) no podían aplicarse a las condiciones australianas. 
Su investigación se basa en el análisis exhaustivo en un período de cinco años de 100 glorietas seleccionadas aleatoriamente.

Para los autores, la relación entre la siniestralidad y el trazado en planta tiene que ver con las velocidades de las diferentes trayectorias permitidas por la geometría. Por ello, proponen las siguientes limitaciones:

1. Las diferencias de velocidad entre las corrientes en conflicto no deben ser superiores a $35 \mathrm{~km} / \mathrm{h}$. Esto permite reducir los accidentes en la entrada (tipo 3) y su severidad.

2. La velocidad de entrada a la glorieta no debe ser superior a $60 \mathrm{~km} / \mathrm{h}$. Esto permite minimizar el tipo de accidente en la aproximación (tipo 2).

Estos criterios se han implementado en las normas de Australia de diseño geométrico y son una clara referencia de la aplicación del concepto de consistencia en el diseño de glorietas. La consistencia se analiza con mayor profundidad en el apartado 2.2.5.

\section{Otros estudios de interés}

Las investigaciones de Maycock y Hall (1984) y Arndt y Troubeck (1995) pueden considerarse los trabajos fundamentales sobre geometría y accidentalidad. Existen otras publicaciones de interés que merece la pena destacar:

$\Rightarrow$ Lenters (2005) expone que a través de la geometría se obtiene una gran oportunidad de optimizar la seguridad. El autor resume las principales cuestiones que abordan los auditores de seguridad en relación con el diseño en glorietas de EE.UU. Destaca cinco apartados fundamentales:

- Curvatura de la trayectoria en la entrada. Justifica los mismos resultados que Maycock y Hall (1984).

- Anchura en la entrada. 
Justifica los mismos resultados que Maycock y Hall (1984), aunque destaca que los efectos son más pronunciados en glorietas multicarril. En esta tipología, los peatones deben aumentar la longitud de cruce lo cual resulta desfavorable para su seguridad.

- Guiado de los vehículos en glorietas multicarril.

Según el estudio intervienen la posición y el tamaño de la glorieta, y el trazado de las isletas deflectoras y la curva de aproximación. El autor explica que este factor es importante para evitar que se solapen las distintas trayectorias y que se produzcan accidentes por choque lateral. Además, influye en otros objetivos de la planta (la deflexión de velocidades y el acomodo del vehículo patrón). Este autor propone incrementar el radio del borde exterior para minimizar los accidentes.

- Reconocimiento de la isleta central y trazado de la isleta deflectora.

Según el autor, la consecuencia de falta de visibilidad de la isleta central puede ser la pérdida de control del vehículo. Afecta de forma más importante a motoristas. El trazado adecuado de la isleta deflectora asegura una buena deflexión de las velocidades. Kennedy et.al (2005) argumenta que la probabilidad del accidente de un vehículo (tipo 1) está relacionada con este factor.

- Estudio de Visibilidad.

Según el autor, la configuración de la aproximación, en planta y alzado, debe ser tal que se garanticen las distancias de visibilidad. Montella et. al (2012) pone de manifiesto la importancia de la visibilidad en la seguridad de la intersección.

$\Rightarrow$ Ritchie (2005) alcanza conclusiones similares y establece tres factores geométricos importantes para la seguridad: el diseño de la entrada, la velocidad de la trayectoria más rápida y la consistencia de velocidades. En cuanto a los factores no geométricos: la señalización, el estudio de las márgenes y la iluminación. 
$\Rightarrow$ Montella (2011) realizó un estudio sobre 15 glorietas urbanas en Italia, relacionando la probabilidad de fallo con las características geométricas. El autor detectó que en el $60 \%$ de los sucesos al menos un parámetro geométrico fue el factor desencadenante del accidente. Los factores geométricos más representativos fueron (Fig.2.28):

- Radio de la trayectoria en la entrada.

El autor expone valores excesivos como causa del fallo. Este factor es indicativo de altas velocidades en las entradas.

- Radio de la deflexión.

El radio de la deflexión se refiere al arco que dibuja la trayectoria alrededor de la isleta central. El autor expone valores excesivos como causa del fallo. Este factor es indicativo de altas velocidades en la calzada anular.

- Ángulo de desviación.

El ángulo de desviación se refiere al ángulo formado por dos líneas proyectadas desde las entradas (tangentes a los bordes interiores en el punto de intersección con el círculo inscrito) entre dos accesos situados en lados opuestos. El autor expone valores excesivos como causa del fallo. Este factor es indicativo de deficiencias en la deflexión de las velocidades.

$\Rightarrow$ Para Kennedy et.al (2005) las variables que afectan a la seguridad son: la curvatura de la trayectoria de entrada, la anchura de la entrada y de aproximación, el diámetro exterior, la isleta central, la proporción de motos en la circulación, el ángulo con la próxima pata, la curvatura de la aproximación y la visibilidad. 


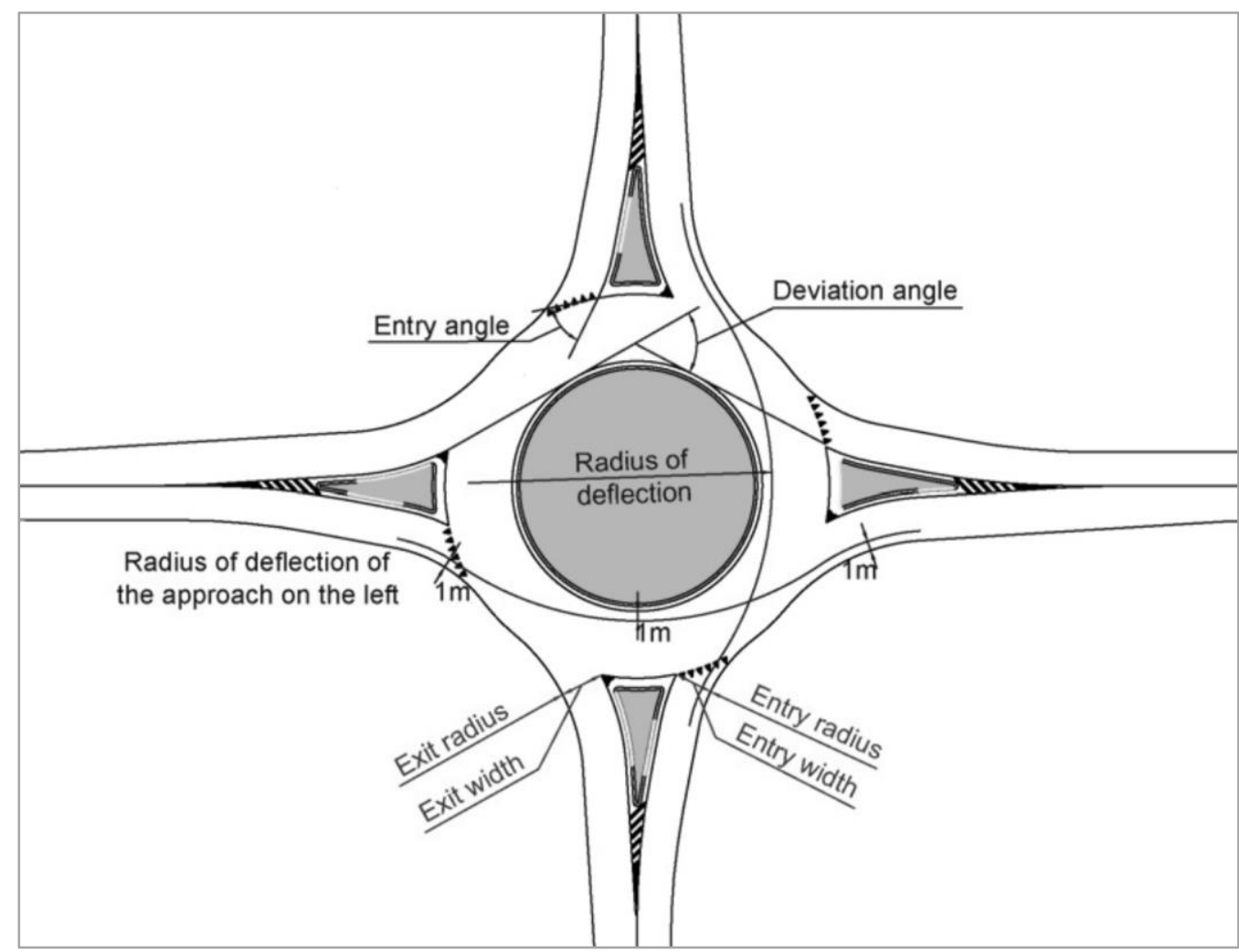

Figura 2. 28 Parámetros geométricos relacionados con la siniestralidad.

Fuente: Montella, 2011.

$\Rightarrow$ Ridding (2014) expone la necesidad de mejorar las provisiones para los modos más vulnerables (peatones, ciclistas, motocicletas, niños, ancianos y personas con discapacidad visual y movilidad reducida). El autor concluye que los factores geométricos con más incidencia en la accidentalidad son:

- Tamaño de los elementos.

En las glorietas de mayores dimensiones se aumenta la probabilidad de accidentes. Se debería disminuir el número de carriles en las entradas y salidas en la medida de lo posible.

- Número de accesos.

La intersección aumenta la complejidad de funcionamiento cuando existen un número importante de accesos. Esto hace que los vehículos centren su atención en el tráfico rodado disminuyéndola sobre el resto del entorno. Según el autor la probabilidad de accidentes aumenta. 
- Velocidad.

Resulta crítico promover la deflexión para controlar las velocidades y disminuir la probabilidad de accidente.

$\Rightarrow$ Campbell et al., (2011) resumieron las principales conclusiones de un estudio llevado por la Agencia de Transportes de Nueva Zelanda sobre las condiciones de seguridad en glorietas de más de un carril. Según el autor, la seguridad de los peatones está relacionada con la instalación de provisiones y un adecuado control de las velocidades. Esta opción es preferible frente a semaforizar la glorieta.

$\Rightarrow$ O’brien (2011) analiza las condiciones de los ciclistas para glorietas de Australia y nueva Zelanda y concluye que el 70-90\% de los accidentes son porque los vehículos no ceden el paso en la entrada. La causa puede ser un trazado que no favorece la moderación de las velocidades. El autor propone como solución separar los tráficos de ciclistas y peatones.

\subsection{Modelos de predicción de accidentes}

Con el objetivo de evaluar la seguridad, los investigadores han desarrollado expresiones matemáticas que permiten estimar el número de accidentes en la fase de diseño.

El cálculo de estas ecuaciones no resulta sencillo. En primer lugar, es necesario recopilar los registros de accidentes y las causas que los han generado. En segundo lugar, hay que determinar mediante un estudio estadístico los factores con más correlación con la probabilidad de accidente. Por último, se propone una expresión que contiene las variables con más peso. El resultado suele ser el número de accidentes totales por año, diferenciando o no este número por tipo de accidente. A continuación, se describen los principales modelos desarrollados por los investigadores.

Maycock y Hall (1984) proponen un modelo de predicción de accidentes ajustado mediante técnicas de regresión lineal. Los parámetros de entrada son: el tráfico (coches, peatones y ciclistas), la anchura de la entrada, la curvatura de la trayectoria de entrada, 
la curva y la acnhura de aproximación y ángulo entre accesos. La respuesta del modelo es el total de accidentes anuales por acceso y particularizados por tipo de accidente.

En el trabajo de Arndt y Troubeck (1995) el resultado es el número de accidentes anuales por acceso y por tipo de accidente. Los modelos que proponen los autores están basados en técnicas de regresión lineal múltiple con variables independientes que tienen que ver con el comportamiento de los conductores en lugar de características geométricas (Kennedy et al., 2005). Los parámetros de entrada son: el tráfico, la geometría de la glorieta, el radio de las trayectorias y los coeficientes de fricción. Las expresiones de los diferentes modelos varían para cada tipo de accidente y presentan la particularidad de incluir como variables las velocidades y su consistencia. Las ecuaciones que proponen los autores se han incluido en la normativa de Australia y en el software de diseño de glorietas ARNDT.

Brude y Larsson (1999) trabajaron sobre una muestra de 650 glorietas en Suecia, desarrollando un modelo que tiene como variables el número de accesos y carriles, y la máxima limitación de velocidad. El resultado es el ratio de accidentes (número de siniestros por millón de vehículos). En Francia, se propone un modelo basado únicamente en la intensidad de tráfico y que proporciona el número de accidentes con lesiones (SETRA, 1998b).

El modelo en Estados Unidos fue desarrollado en el documento NCHRP (2007a) en base a un extensivo análisis e incluye como variables independientes: las intensidades de tráfico, el número de accesos y el número de carriles. El resultado es el número de accidentes por año. También se intentó establecer un modelo basado en la velocidad pero debido a los efectos de las puntas de tráfico la regresión resultó inadecuada. Este documento no incluye muchas variables que podrían permitir al diseñador evaluar la seguridad (Lyon et al., 2014).

Debido a la ausencia de datos sobre accidentes y a las pequeñas variaciones en las características geométricas que existen en los diseños, los investigadores han propuesto en los últimos años evaluar la seguridad de forma indirecta a través de la velocidad y la distancia de visibilidad. 
Angelastro (2010) en base a los datos recopilados en 26 glorietas define seis modelos estadísticamente significativos mediante técnicas de regresión lineal y que permiten relacionar distancia de visibilidad con la velocidad (3 modelos) y el ratio de accidentes (3 modelos). La única variable independiente es la distancia de visibilidad. Otra conclusión que alcanza el autor es que proporcionar más distancia de visibilidad de la necesaria induce a velocidades más elevadas reduciendo la seguridad de la intersección. De forma similar Zirkel et al., (2013) establecieron relaciones entre la velocidad, la distancia de visibilidad y la seguridad, aunque expone que son necesarias futuras investigaciones para confirmar los resultados.

La velocidad es un factor que contribuye habitualmente a la accidentalidad, aunque sólo un modesto número de estudios han evaluado la relación entre velocidad y seguridad (NCHRP, 2008; Isebrands et al., 2015). Chen et al., (2011) justificaron esta relación y establecieron que la velocidad puede ser utilizada de forma indirecta para evaluar la seguridad de las glorietas. Los autores proponen una relación que permite calcular la velocidad en base al tamaño de la glorieta y la anchura de la entrada.

En un trabajo posterior, Chen et al., (2013) desarrollaron un modelo en dos etapas sobre una muestra de 139 accesos de glorietas de EE.UU. En la primera, se obtiene las velocidades de operación. En la segunda, se propone una ecuación para estimar los accidentes por año basada en las intensidades de tráfico y en la velocidad. Los autores exponen lo prometedor de los resultados debido a la dificultad que representa incluir las características geométricas dentro de las ecuaciones.

En resumen, los modelos de predicción de accidentes son un prometedor estimador de la seguridad en glorietas, aunque sus ecuaciones están sujetas a las condiciones locales lo que les confiere una complejidad importante. Los primeros modelos desarrollados se basan en las características geométricas y en las condiciones del tráfico. Las investigaciones más recientes proponen evaluar la seguridad mediante métodos indirectos basados en el cálculo de las velocidades y las distancias de visibilidad. 


\subsection{Criterios para evaluar la seguridad de un diseño}

Los criterios para evaluar la seguridad de un diseño vienen recogidos en las normas de diseño y están basados en las conclusiones obtenidas de las investigaciones presentadas en el apartado 2.2.4.4.5.

Existe consenso internacional en fijar el control de la velocidad como el factor fundamental para proporcionar unas condiciones óptimas de seguridad a un diseño geométrico. Los criterios que se especifican en las normas para el estudio del control de la velocidad han evolucionado.

Las versiones más tradicionales se basan en la experiencia con glorietas existentes, y consisten en un conjunto de reglas sobre los rangos admisibles de ciertas dimensiones y ángulos para que la seguridad sea aceptable (Ramos et al., 2010). Los principales indicadores geométricos utilizados son (Montella et al., 2012): el radio de la trayectoria de entrada, el radio de la deflexión y el ángulo de desviación.

El radio de la trayectoria de entrada es una medida de la deflexión impuesta en la entrada y su influencia en la seguridad se ha contrastado en diferentes investigaciones. Para determinar este radio se debe modelar la trayectoria que se supone más rápida guardando una serie de resguardos con los límites exteriores e interiores de la glorieta.

En la Fig.2.29 se muestra el esquema de cálculo del radio de la trayectoria de entrada de la normativa de Reino Unido (HA, 2007) y que posteriormente fue incluido en las Recomendaciones sobre Glorietas de España (MOPU, 1989). Se propone que el valor del radio de la trayectoria de entrada no exceda de 100m con el objetivo de moderar la velocidad de los vehículos en el movimiento de entrada. 


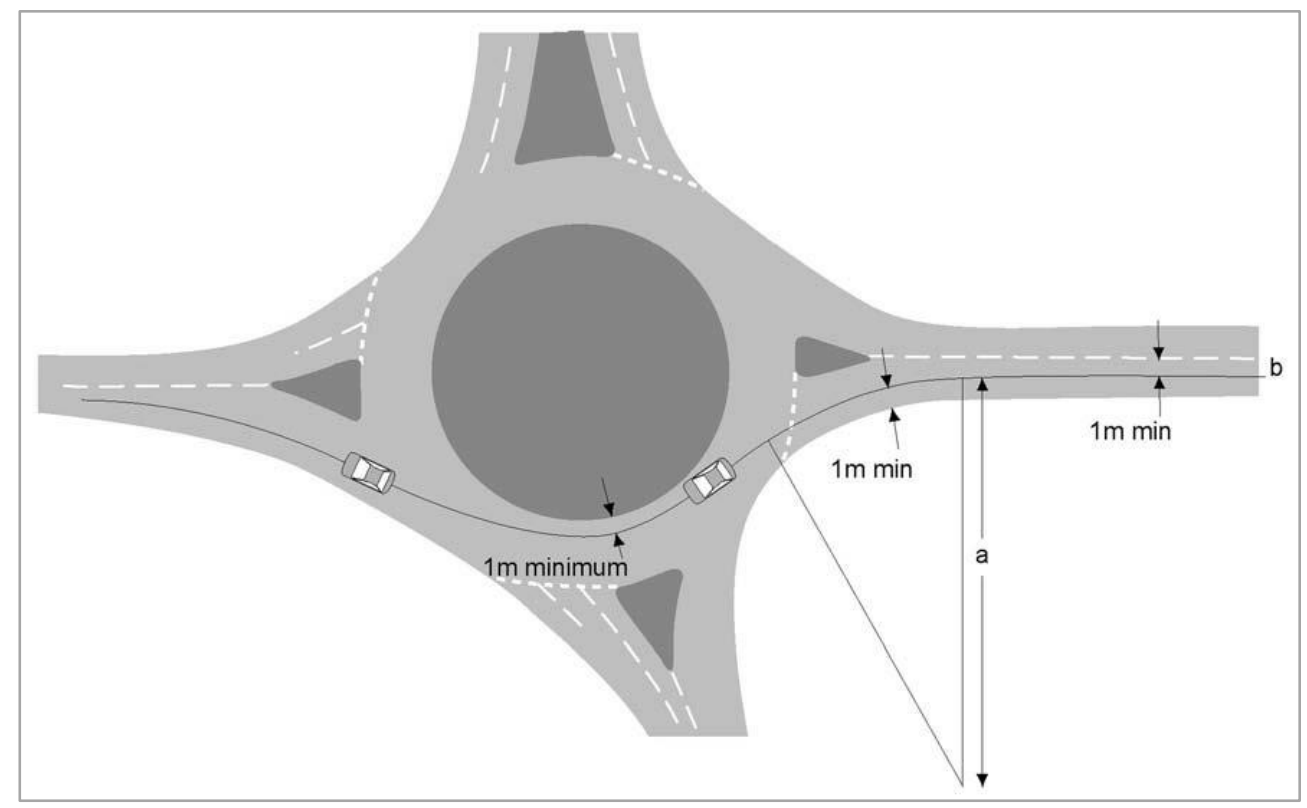

Figura 2. 29 Cálculo del radio de la trayectoria de entrada. Fuente: HA, 2007.

Aunque no se propone ningún método para modelar la trayectoria, se recomienda que el inicio de su trazado se localice $50 \mathrm{~m}$ antes de la marca de "Ceda el Paso" y que el radio se determine sobre un arco que presente un desarrollo mínimo de 25m (Fig.2.30). En la Norma de EE.UU (NCHRP, 2010) se ha adoptado esta misma recomendación, aunque se especifica que con otros criterios se pueden obtener resultados igualmente satisfactorios.

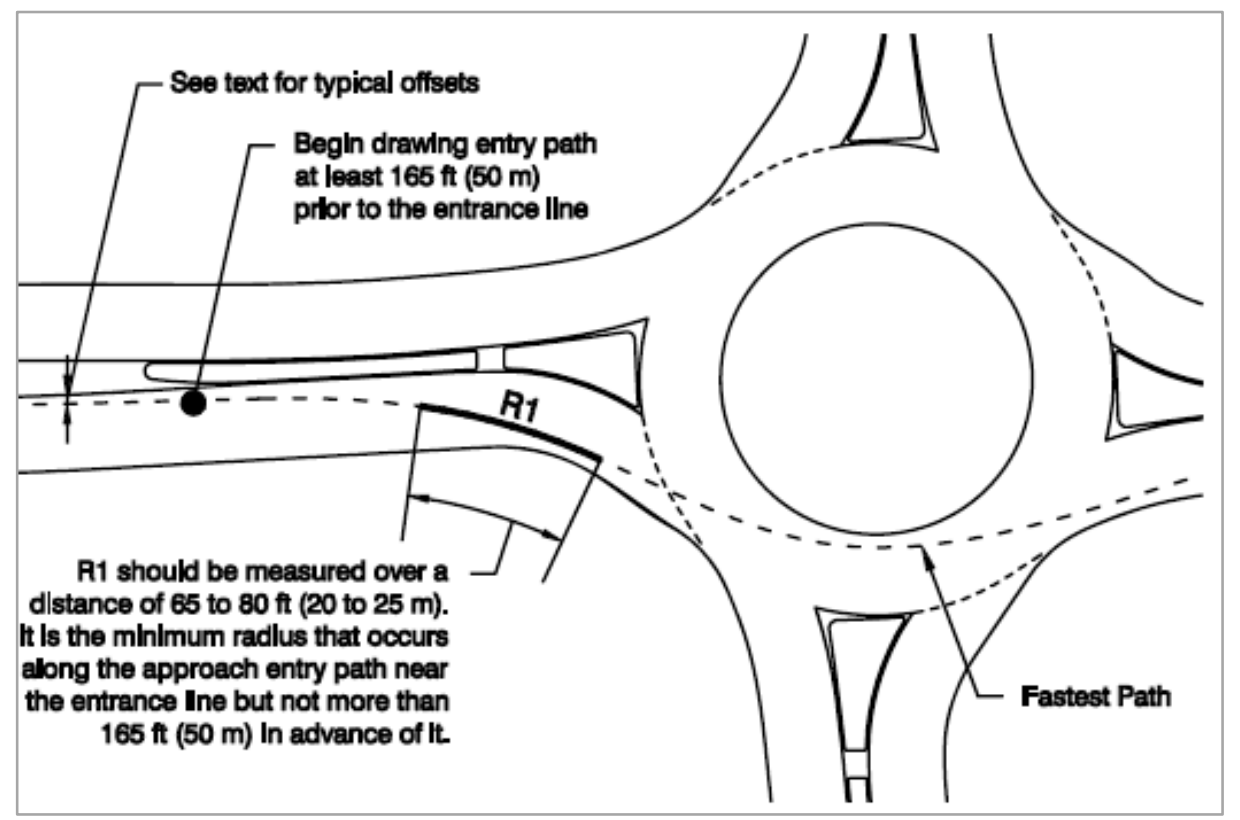

Figura 2.30 Recomendaciones para el cálculo de la trayectoria de entrada. Fuente: NCHRP, 2010. 
El radio de la deflexión se refiere al arco que define la trayectoria más rápida a su paso por la isleta central (Fig.2.31). Para la norma en Francia (SETRA, 1998a) es el parámetro determinante de las condiciones de seguridad y su efecto ha sido contrastado en el estudio de Montella (2011). El valor resultante no debe exceder de 100m con lo que se pretende limitar la velocidad de los vehículos en el movimiento de paso por la calzada anular. No se propone ningún procedimiento para estimar el trazado de la trayectoria.

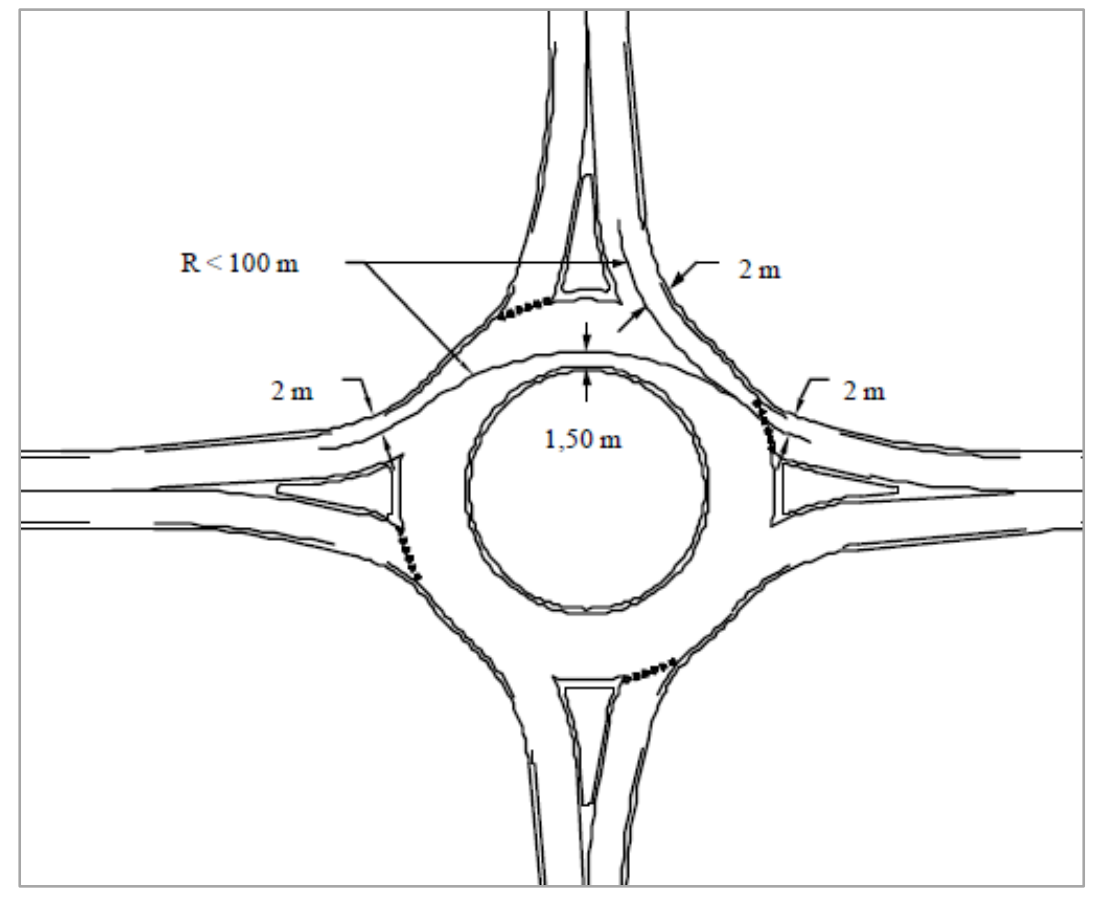

Figura 2.31 Cálculo del radio de la deflexión.

Fuente: SETRA, 1998a.

Por último, el ángulo de desviación se deduce exclusivamente de la geometría de la glorieta. Este parámetro se ha incluido en las Normas de Suiza e Italia (VSS, 1999; MIT, 2006) como indicador de la seguridad de un diseño. Se propone que el valor de este ángulo no supere $45^{\circ}$. Spacek (2004) en un estudio experimental muestra una correlación entre pequeños ángulos de desviación y altos ratios de accidentes.

Un enfoque más moderno consiste en modelar las trayectorias y estimar los perfiles de velocidad evaluando el valor de las velocidades máximas y la consistencia. Debido a la importancia de este concepto para la investigación, su estudio se realiza de forma detallada en el apartado 2.2.5. 


\subsubsection{Guiado}

En glorietas con más de un carril es necesario para validar la geometría en planta comprobar las trayectorias de los denominados movimientos naturales.

A diferencia de lo considerado para realizar el estudio del control de la velocidad, un movimiento natural está definido por una trayectoria sin ocupación de los carriles adyacentes. El vehículo permanece en su carril cuando realiza el paso por la geometría y la trayectoria está compuesta por radios de similar curvatura (no se admiten cambios instantáneos de velocidad o curvatura).

Cuando un vehículo se sale de su trayectoria natural ocupa el carril adyacente y puede provocar un conflicto debido al solape de las trayectorias. Este fenómeno ocurre con mayor frecuencia en las entradas e influye en la capacidad y la seguridad de la intersección.

En la Fig.2.32 se muestra un ejemplo de la problemática que supone el solape de las trayectorias naturales. A la izquierda, un diseño deficiente propicia que el vehículo situado en el carril más exterior de la entrada se dirija hacia el carril interior de la calzada anular interponiéndose en el movimiento natural del vehículo que estaba situado en el carril más interior. A la derecha, se ha aumentado el radio de entrada del borde derecho lo que permite mejorar el guiado de los vehículos evitando la interferencia de las trayectorias.
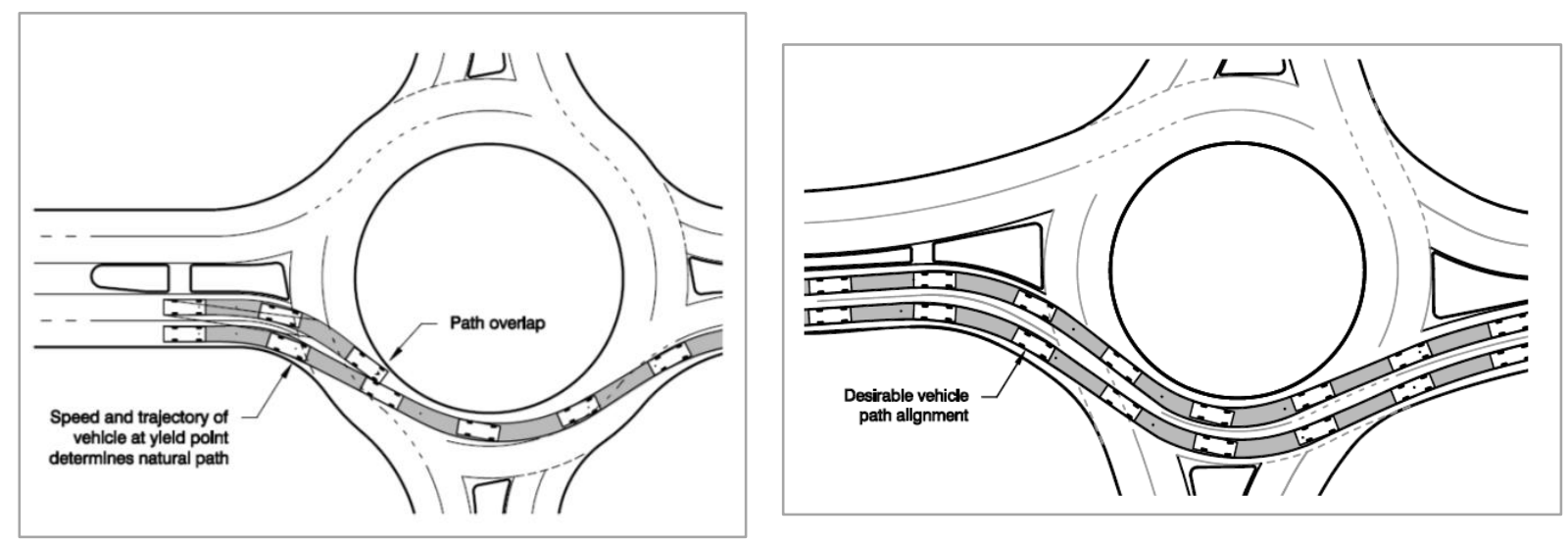

Figura 2. 32 Solape de trayectorias naturales en la entrada.

Fuente: NCHRP, 2010. 
Para Ritchie (2005), este fenómeno está relacionado con dos parámetros geométricos: ángulo de entrada importante y radio exterior de entrada reducido. Para la salida, se pueden realizar las mismas consideraciones. El autor propone un conjunto de soluciones para evitar el posible solape de las trayectorias naturales:

- Incrementar los radios exteriores en las entradas y las salidas.

- Modificar los ángulos de entrada y de salida.

- Desplazar la calzada anular.

- Modificar el trazado de la isleta deflectora.

- Modificar la señalización.

Arndt (1998) propone para mitigar el solape de las trayectorias naturales que los radios de los bordes exteriores en las entradas y salidas no sean inferiores al radio del diámetro exterior.

En cualquier caso, para permitir la continuidad de los movimientos sin interferencias entre vehículos es importante promover un diseño con trayectorias suaves, sin cambios bruscos en la velocidad.

\subsubsection{Usuarios no motorizados}

\subsection{Introducción}

Los modos que utilizan las glorietas se pueden agrupar en: vehículos, motocicletas, ciclistas y peatones. En este apartado se analiza la influencia en el diseño geométrico de la planta de las necesidades de los peatones y los ciclistas.

\subsection{Aspectos generales}

Los peatones y los ciclistas no necesitan un permiso especializado para circular. La interacción de estos modos con los vehículos motorizados puede ser problemática ya 
que resultan menos perceptibles para ellos. Las consecuencias de una colisión son mucho más graves.

Los principios generales que rigen el acomodo de los peatones y los ciclistas en las glorietas son (NCHRP, 2010): minimizar y simplificar los itinerarios, proporcionar acerados y carriles bici situados convenientemente, implantar pasos de peatonesciclistas por las calzadas de acceso y proporcionar en la isleta deflectora una zona de refugio que facilite la operación de cruce.

A favor de la seguridad, las glorietas promueven la deceleración del tráfico lo cual proporciona una serie de ventajas para peatones y ciclistas: disminuye la severidad de los accidentes, aumenta el tiempo para la toma decisiones y el tiempo de reacción. Además, debido al refugio que proporcionan las isletas deflectoras permite salvar las corrientes de tráfico de forma escalonada. Una adecuada visibilidad también es importante ya que los peatones y los ciclistas pueden sentirse muy incómodos a la hora de afrontar el paso por una glorieta.

\subsection{Peatones}

El acomodo para peatones se realiza en el perímetro de la intersección disponiendo acerados y pasos peatonales en las calzadas de los accesos.

El flujo de peatones presenta conflictos con los vehículos que entran y salen de la calzada anular. En la Fig.2.33 se han representado los puntos de conflicto para peatones en una intersección convencional y en una glorieta. Como sucedía con los vehículos a motor, las glorietas reducen considerablemente el número de puntos de conflicto (8 puntos) respecto a las intersecciones convencionales (16 puntos). 


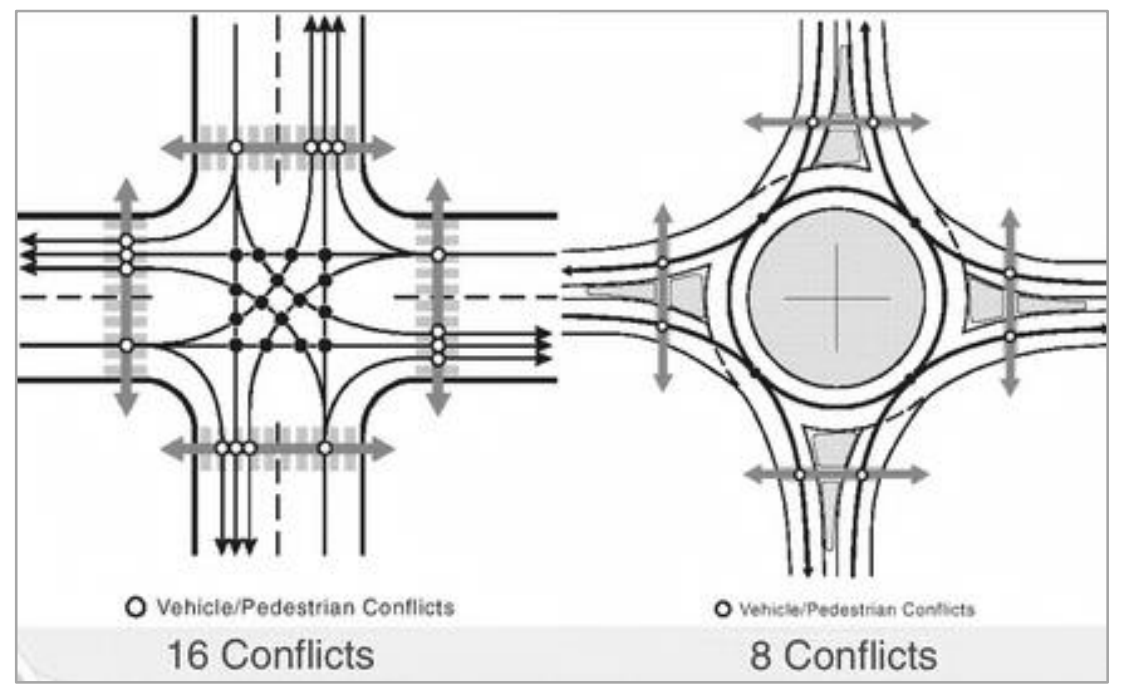

Figura 2. 33 Puntos de conflicto en peatones: intersección convencional vs glorieta. Fuente: FHWA, 2000.

En los itinerarios peatonales se debe permitir su circulación sin obstáculos. Los puntos de cruce se suelen fijar en un rango de entre 5 a $25 \mathrm{~m}$ medidos desde el borde del círculo inscrito hacia el exterior. Esto permite el almacenamiento de uno o varios vehículos. Para fijar la distancia hay que diferenciar si se está considerando la entrada o la salida de la glorieta. El acceso hacia la isleta central está prohibido.

En las entradas, se tiende a aproximar el paso de peatones a la señal de "Ceda el Paso" ya que esto favorece que los vehículos circulen a menor velocidad. En las salidas, aproximar demasiado el paso de peatones a la glorieta puede provocar que una eventual parada de los vehículos se refleje en la calzada anular penalizando el funcionamiento. En el lado contrario, una distancia excesiva es desaconsejable porque los vehículos están en proceso de aceleración y pueden alcanzar el paso de peatones a una velocidad excesiva.

En el diseño de los puntos de cruce hay que tener en cuenta los siguientes apartados (NCHRP, 2007b): existen suficientes oportunidades para realizar el cruce, son estas oportunidades detectadas y aprovechadas por los peatones, se dispone de un tiempo razonable para el cruce y el cruce se realiza sin riesgo. 
La regulación de la prioridad en los pasos de peatones depende fundamentalmente del entorno y de los tráficos, aunque también de la cultura de diseño del país. Inman (2008) define cuatro tipos: prioridad para el peatón, prioridad para el vehículo, prioridad regulada por el peatón (pulsador para peatones y semáforo para vehículos) y sistema inteligente de detección de peatones (semáforo para los vehículos). De forma general, y a falta de dispositivos de control de tráfico, se suele dar prioridad a los peatones en medios urbanos y al contrario en medios rurales.

Otros elementos utilizados para el acondicionamiento de los peatones son las vallas para delimitar los itinerarios y las mesetas elevadas para reducir la velocidad del tráfico en los pasos de peatones.

Las glorietas pueden resultar problemáticas para los usuarios de mayor edad, los niños y los que tienen una discapacidad visual o auditiva. Las personas de menor edad pueden tener problemas a la hora de juzgar el momento de realizar el cruce. Para el resto, hay que tener en cuenta que su paso es más lento.

Otro aspecto a considerar es que la naturaleza curvilínea del itinerario altera las señales audibles y táctiles en comparación con las intersecciones convencionales. Las personas con discapacidad visual pueden tener problemas para determinar si un vehículo está saliendo o entrando de la calzada anular. Este problema es más acusado en glorietas con más de un carril. La solución pasa por implementar señales auditivas, vibrotáctiles y realizar un tratado de las aceras e isletas para mejorar el guiado. Hughes (2008) recomienda prohibir el aparcamiento en el entorno de la glorieta y cuidar la vegetación que pueda obstaculizar la visual hacia los niños situados en los pasos de peatones.

Los estudios de capacidad deben tener en consideración las intensidades de peatones ya que pueden retrasar los flujos de entrada y salida de los vehículos. Cheu et al., (2011) analizaron los efectos de los flujos de peatones en la capacidad mediante microsimulación y concluyeron que con altas intensidades de tráfico la capacidad resulta muy afectada. El impacto es menor con altos volúmenes de tráfico en el anillo y disminuye poco si alejamos el cruce de la línea de ceda el paso. 


\subsection{Ciclistas}

El paso de ciclistas por las glorietas se puede realizar de varias formas: mezclado con el tráfico rodado, mediante carril bici anexo a las calzadas, con carril bici independiente (dos opciones, con prioridad para ciclistas o sin ella), y carril bici a diferente nivel. El tratamiento depende en gran medida del tamaño de la glorieta y de las intensidades de tráfico.

En miniglorietas y glorietas de un carril, los ciclistas experimentados pueden circular sin dificultad por la glorieta. En glorietas con más de un carril la complejidad de la intersección aumenta y pueden existir problemas en los procesos de selección de los carriles. No obstante, y puesto que un ciclista puede sentirse incómodo a la hora de afrontar el paso por la glorieta, es necesario disponer de rampas de acceso al acerado.

Los estudios han demostrado que hay que tener especial precaución con el tráfico de ciclistas en glorietas con una IMD superior a 10.000 veh/día y si las velocidades son superiores a $50 \mathrm{~km} / \mathrm{h}$. Según Brilon (2008), en ningún caso debe situarse el carril ciclista en la calzada anular colindando con el tráfico rodado. Las investigaciones sobre accidentalidad han demostrado el aumento de la frecuencia de accidentes para los ciclistas en glorietas. La solución más segura es diseñar itinerarios ciclistas por el exterior.

\subsection{Transporte colectivo}

Las paradas de transporte colectivo no se situarán en ningún caso en la calzada anular. Se deben situar en las entradas o en las salidas.

En las entradas, es recomendable situarlas antes del paso de peatones a una distancia mínima que no impida la visibilidad de los peatones que cruzan. En glorietas de un carril, para evitar que un vehículo ocupe la isleta cuando el autobús esté maniobrando para salir, se debe situar la parada más allá de ella. Una configuración interesante es prolongar la parada hasta la calzada anular (Fig.2.34). 


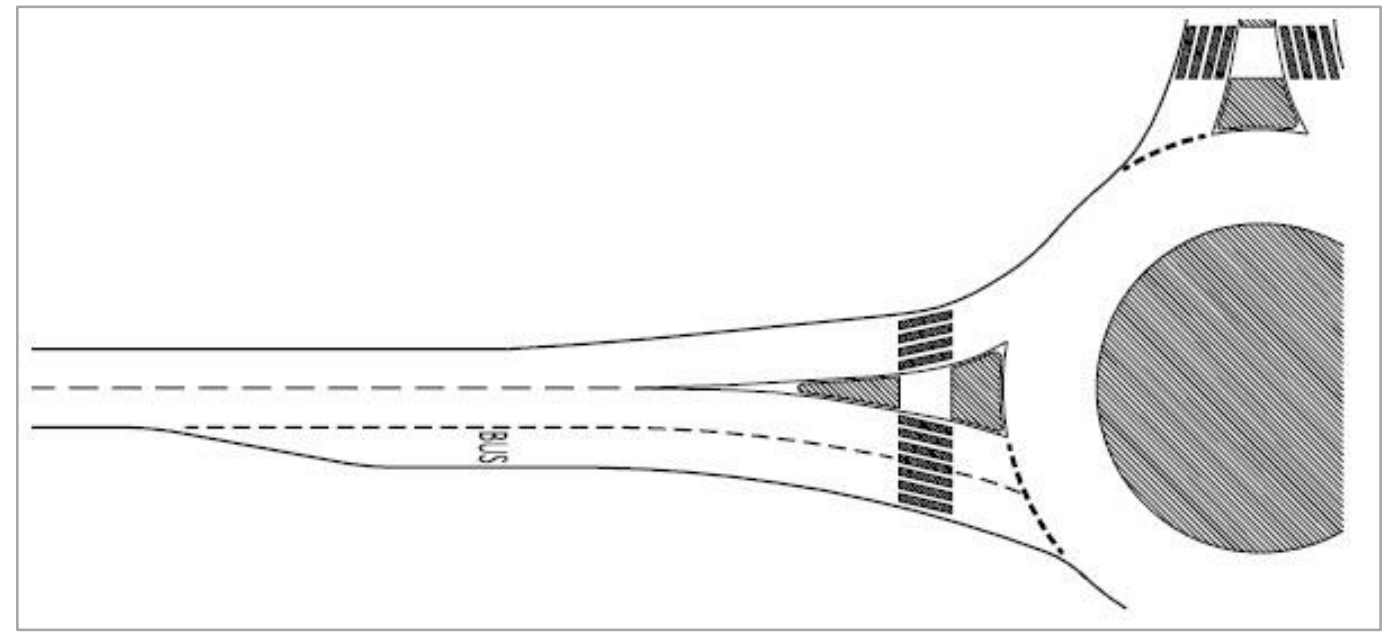

Figura 2. 34 Prolongación del carril bus en la entrada hacia una glorieta. Fuente: MF, 2012.

En las salidas, aunque la velocidad de los vehículos es mayor, se puede situar la parada más allá del paso de peatones sin que interfiera en el trazado.

\subsubsection{Consistencia}

\subsubsection{Consistencia del trazado de carreteras}

El concepto de consistencia del trazado surge en la década de los 70 en Estados Unidos y se puede definir como la capacidad de la geometría de la vía de satisfacer las expectativas del conductor.

Un trazado consistente implica que las características geométricas sean homogéneas y que se pueda realizar una conducción cómoda y libre de sorpresas. De esta forma, se minimiza la probabilidad de que el conductor efectúe maniobras inseguras y cometa errores.

Por tanto, la consistencia del trazado está muy relacionada con las condiciones de seguridad de la vía. Por este motivo, se han realizado muchos estudios cuyo objetivo ha sido intentar cuantificarla y traducirla a criterios de diseño. 
Existen diferentes procedimientos para evaluar la consistencia que pueden ser clasificados en los siguientes grupos (Castro et. al, 2008a):

- Métodos basados en las características del tráfico de vehículos. Estos métodos evalúan aspectos de la circulación tales como el análisis de las velocidades de operación, la estabilidad de los vehículos en curva o el ratio de accidentes.

- Métodos basados en las características geométricas, como son los criterios basados en índices de trazado.

- Métodos basados en el comportamiento de los conductores, por medio de índices como la demanda visual o la carga de trabajo.

En general, la aplicación de estos métodos permite obtener un indicador que asigna un valor cualitativo a la consistencia ("buena", “aceptable” o "mala"). A continuación, se presentan de forma resumida los principales métodos desarrollados para evaluar la consistencia.

\subsection{Criterios basados en las velocidades de operación.}

El método más común para evaluar la consistencia en carreteras se basa en el estudio de los perfiles de velocidad de la vía (Castro et. al, 2008b).

La velocidad de operación es la velocidad elegida por los conductores para circular sin restricciones de tráfico (AASTHO, 2001). Tradicionalmente se la relaciona con el percentil 85 de la distribución de velocidades ${ }^{10}$ de los turismos en condiciones de circulación libre (en solitario).

Esta velocidad se desarrollará una vez construida la carretera por lo que es desconocida en la fase de diseño. No obstante, se han realizado estudios que han permitido detectar las variables que afectan más a la velocidad de operación y modelos que permiten su cálculo con mayor o menor fiabilidad.

\footnotetext{
${ }^{10}$ La velocidad del percentil 85 de una distribución de velocidades es aquélla que sólo es sobrepasada por el $15 \%$ de los vehículos.
} 
Para realizar la evaluación de la consistencia mediante este criterio es necesario:

- Estimar las velocidades de operación de las alineaciones principales que componen el eje de trazado: rectas y curvas.

- Definir las tasas de aceleración y deceleración que tengan en cuenta la variación de la velocidad entre las rectas y las curvas.

- Construir el perfil de velocidades.

- Evaluar la consistencia.

Para la estimación de las velocidades de operación en curvas horizontales se han desarrollado muchos modelos, entre los que se pueden destacar los siguientes:

- Modelo de Krammes et al. (1995). Se basa en el cálculo del grado de curvatura $^{11}$, la longitud de la curva circular, el ángulo total girado y la velocidad en la recta anterior.

- Modelo de Fitzpatrick et al. (2000a). Depende de las características del trazado en alzado y el cálculo se basa en el valor del radio de la curva circular.

- Modelo de Castro et al. (2006). Calibrado para las carreteras de España, el cálculo se basa en el valor del radio de la curva circular.

- Modelo de Lamm et al. (2007). Se basa en el índice de cambio de curvatura (gon/km) para lo que se necesita deducir las longitudes de la curva circular y clotoides, y el radio de la curva circular.

Para determinar las velocidades de operación en rectas no se han desarrollado un número tan importante de modelos debido a que no hay ninguna variable tan influyente como lo es el radio de la curva para los modelos de curvas horizontales. En general, los investigadores proponen definir la velocidad de operación en recta como un valor constante: Krammes et al. (1995) sugieren 97,9 km/h y Hassan et al. (2000) recomiendan $102 \mathrm{~km} / \mathrm{h}$.

\footnotetext{
${ }^{11}$ Se entiende por grado de curvatura, al ángulo abarcado por un arco de círculo unidad de determinado desarrollo, habitualmente de $100 \mathrm{~m}$. El grado de curvatura es inversamente proporcional al radio.
} 
Las tasas de aceleración y deceleración han sido estimadas por diferentes autores. Krammes et al. (1995) y Ottesen y Krames (2000) proponen una tasa de aceleración/deceleración de $0,85 \mathrm{~m} / \mathrm{s}^{2}$.

La construcción del perfil de velocidades se realiza yuxtaponiendo las velocidades de los sucesivos elementos de trazado calculadas según los modelos individuales y ajustando el perfil resultante bajo ciertas hipótesis. Ottesen y Krames (2000), Fitzpatrick et al. (2000b) y Figueroa y Tarko (2007), entre otros, han propuesto modelos para estimar los perfiles de velocidad siguiendo esta metodología.

Otra forma de construir el perfil de velocidades es definir un perfil único desde el principio que no considere la discretización anterior, aunque en este caso la computación es más compleja y no se puede analizar el comportamiento individual de los elementos del trazado.

Por último, para evaluar la consistencia se han desarrollado diferentes métodos. El más conocido fue propuesto por Lamm et al. (1988) y se basa en dos criterios:

1. Consistencia del diseño. Se compara la velocidad de diseño ${ }^{12}\left(\mathrm{v}_{\mathrm{d}}\right)$ con la velocidad de operación en cada uno de los elementos de trazado.

En muchos casos, existe una disparidad manifiesta entre estos dos conceptos debido a que la velocidad de diseño establece una referencia mínima para el diseño que no se corresponde con la velocidad observada a la que circulan los usuarios (velocidad de operación). Un diseño será consistente si existe un ajuste razonable entre estas dos velocidades. Se propone la siguiente clasificación:

\footnotetext{
${ }^{12}$ Según MF, 2000:

La velocidad de diseño es la velocidad que permite definir las características geométricas mínimas de los elementos de trazado, en condiciones de comodidad y seguridad. Se corresponde con la menor velocidad específica de los elementos que constituyen el tramo.

La velocidad específica de un elemento de trazado es la máxima velocidad que puede mantenerse en un elemento de trazado considerado aisladamente, en condiciones de seguridad y comodidad, cuando encontrándose el pavimento húmedo y los neumáticos en buen estado, las condiciones meteorológicas, del tráfico y legales son tales que no imponen limitaciones a la velocidad.
} 


\begin{tabular}{|c|c|c|}
\hline \multicolumn{3}{|c|}{ Consistencia del diseño } \\
\hline Buena & Aceptable & Mala \\
\hline$\left(v_{85 i}-v_{d}\right) \leq 10$ & $10<\left(v_{85 i}-v_{d}\right) \leq 20$ & $20<\left(v_{85 i}-v_{d}\right)$ \\
\hline
\end{tabular}

Tabla 2. 2 Criterio de consistencia del diseño de una vía.

Fuente: Lamm et al. 1988

2. Consistencia en la velocidad de operación. Se comparan las velocidades de operación entre elementos geométricos consecutivos.

El diseño será consistente si las características geométricas mantienen una cierta homogeneidad que eviten saltos en las velocidades de circulación conforme los usuarios avanzan por la vía. Se propone la siguiente clasificación:

\begin{tabular}{|c|c|c|}
\hline \multicolumn{3}{|c|}{ Consistencia en la velocidad de operación } \\
\hline Buena & Aceptable & Mala \\
\hline$\left(v_{85(i)}-v_{85(i+1)}\right) \leq 10$ & $10<\left(v_{85(i)}-v_{85(i+1)}\right) \leq 20$ & $20<\left(v_{85(i)}-v_{85(i+1)}\right)$ \\
\hline
\end{tabular}

Tabla 2. 3 Criterio de consistencia en la velocidad de operación de una vía. Fuente: Lamm et al. 1988

El software IHSDM (Interactive Highway Safety Design Model) (FHWA, 2004) es una aplicación informática desarrollada en EE.UU que permite evaluar diferentes aspectos de la seguridad vial de los diseños geométricos. Uno de sus módulos está dedicado a la consistencia. El cálculo se realiza en base a la estimación del perfil de velocidades y la aplicación de los criterios de consistencia de Lamm et al. (1988).

Existen un número importante de investigaciones a nivel internacional que han relacionado la frecuencia de accidentes con la consistencia del trazado. En los trabajos de Warren (1982), TRB (1984), Garber y Gadiraju (1989) y Voigt (1996), se establece una relación directa entre las variaciones de velocidad y la accidentalidad observando que cuanto mayor es el salto de las velocidades mayor es la frecuencia de accidentes. 


\subsection{Criterio basado en índices de trazado}

Los índices de trazado son unos parámetros que permiten medir de forma cuantitativa determinadas características de la geometría tanto en planta como en alzado.

Se puede analizar la consistencia de una carretera observando la variación de los índices de trazado. Los criterios de evaluación habituales presentan el objetivo de medir su variación a lo largo de sucesivos elementos de trazado, la frecuencia de cambio o la diferencia para un elemento entre su valor y el valor promedio del tramo.

Se han definido muchos índices de trazado. Fitzpatrick et al. (2000b) los resume en los siguientes:

- Trazado en planta: CCR (tasa de cambio de la curvatura), GC (grado de curvatura), CL:RL (relación entre la longitud del radio y la del tramo), AVGR (radio promedio en el tramo) y AVGT (longitud promedio de las rectas en el tramo).

- Trazado en alzado: VCCR (cambio de curvatura vertical en el tramo), Tcv (tasa promedio de curvatura vertical en el tramo) y $\Delta H$ (diferencias de altura promedio).

No existen criterios fijos que permitan evaluar la consistencia mediante los índices de trazado, aunque sí se han utilizado en el desarrollo de modelos mixtos como el propuesto por Polus y Dagan (1987) que definen un procedimiento basado en las características del tráfico y en índices de trazado.

\subsection{Criterios basados en la carga de trabajo del conductor}

Durante el proceso de circulación por una vía, el conductor está de forma continuada procesando información visual, tomando decisiones y gestionando las maniobras de los diferentes movimientos que realiza. La carga de trabajo del conductor se refiere al porcentaje de tiempo que dedica a las tareas relacionadas con la conducción. 
La evaluación de la consistencia según este criterio se basa en la medición de la carga de trabajo que transmite un diseño geométrico a un conductor. Si es baja podría provocar distracción y si es alta podría generar algún imprevisto, por lo que la situación ideal es una carga de trabajo media.

El cálculo de los parámetros que caracterizan la carga de trabajo es complejo debido al número de factores que intervienen: condición física y psicológica de los conductores, condición del vehículo, características de la vía y climatología, entre otros. Los parámetros más utilizados son la "demanda visual" y la "carga de trabajo" aunque es necesario desarrollar más estudios que permitan conocerlos menor.

\subsubsection{Consistencia en glorietas}

En los últimos años, el concepto de consistencia se ha aplicado al diseño de glorietas y ha servido para definir una serie de criterios que permiten evaluar la seguridad de un trazado geométrico.

En las normas de diseño de EE.UU (NCHRP, 2010), de Australia (QDMR, 2006; AUSTROADS, 2011) y, recientemente, de España (MF, 2012) se ha incluido la comprobación de la consistencia como un objetivo del trazado en planta.

En general, los métodos recogidos en las normas se basan en la estimación de las velocidades de operación de las diferentes trayectorias y en el análisis de los saltos de velocidad. Se proponen dos criterios para evaluar la consistencia (Easa and Mehmood, 2004):

1. Consistencia en la velocidad de operación. Se comparan las velocidades de operación entre los elementos geométricos consecutivos que componen una misma trayectoria.

2. Consistencia en los puntos de conflicto. Se comparan las velocidades de operación en los puntos de conflicto de trayectorias diferentes. 
Por tanto, un diseño será consistente si la geometría promueve velocidades homogéneas en el conjunto de las trayectorias de los vehículos.

A continuación, se realiza una descripción más detallada de cómo definir las trayectorias y las velocidades, y de los métodos propuestos en las normas de diseño para evaluar la consistencia.

\subsection{Trayectorias más rápidas en glorietas}

Para poder aplicar los métodos de evaluación de la consistencia de velocidades en glorietas es necesario modelar las trayectorias de los vehículos. Estas en general se refieren al centro del vehículo.

Debido a que la referencia es el vehículo con la máxima velocidad de paso por la intersección, el proyectista debe buscar el trazado con las menores curvaturas posibles que pueda intercalarse dentro de los límites que define la geometría (guardando un cierto resguardo con los bordes).

Esto implica que la composición de la trayectoria entre un acceso y el opuesto presente las siguientes características:

○ En la calzada de aproximación, el vehículo tenderá a acercarse al eje de la vía.

○ En la entrada, la trayectoria buscará el borde exterior de la curva de aproximación.

- En la calzada anular, el vehículo tenderá a aproximarse a la isleta central.

○ En la salida, la trayectoria buscará la curva exterior de salida.

- En el acceso de salida, el vehículo tenderá a acercarse de nuevo al eje de la vía.

En el caso entre una entrada y salida consecutiva:

○ En la calzada de aproximación, el vehículo tenderá a acercarse al eje de la vía. 
- En la entrada, la trayectoria buscará el borde exterior de la curva de aproximación.

○ En el acceso de salida, el vehículo tenderá a acercarse de nuevo al eje de la vía.

En glorietas con más de un carril, hay que tener en cuenta que un vehículo puede mantenerse en su carril durante la maniobra o, bien, ocupar total o parcialmente toda la anchura de las calzadas. El caso más desfavorable, y es el que se suele adoptar, se define cuando la trayectoria se realiza ignorando las marcas viales. Esto provoca que conseguir el objetivo de la deflexión de velocidades resulte más complejo en las glorietas multicarril.

Los resguardos sirven de referencia para modelar las trayectorias y son unas distancias mínimas con los límites exteriores e interiores de la glorieta. Se debe fijar siempre un valor para los resguardos debido a que hay que considerar la anchura del vehículo que realiza el movimiento.

El valor de los resguardos viene normalizado en las guías de diseño. En las normativas de EE.UU (NCHRP, 2010) y Australia (QDMR, 2006; AUSTROADS, 2011), se fija una distancia de $1 \mathrm{~m}$ si el borde de la calzada está materializado con pintura y $1,5 \mathrm{~m}$ en caso contrario; la normativa de Francia (SETRA, 1998a), fija 2m en todos los casos; y, las normativas de Reino Unido (HA, 2007) y España (MF, 2012), establecen 1m en todos los casos.

Las trayectorias son ejes geométricos similares a los ejes viarios. En general se suele suponer que están compuestos por una o varias alineaciones circulares, dependiendo del tipo de movimiento:

- En los giros a derechas, las trayectorias suelen estar compuestas por una o dos alineaciones circulares consecutivas del mismo signo.

- En los movimientos de paso, haciendo una trayectoria aproximadamente recta, suelen estar compuestas por tres arcos circulares consecutivos. El signo de la alineación intermedia es diferente al de las otras dos. 
- En los giros a izquierdas, con una variación del acimut de más de $90^{\circ}$, por tres arcos de manera similar al movimiento de paso.

Debido a que las patas pueden adoptar cualquier configuración, esta clasificación puede ser imprecisa y no siempre podrá componerse el movimiento de la manera que se ha descrito.

En un estudio realizado por Chan (2012) se investiga la posibilidad de estandarizar la geometría de la trayectoria de entrada. La metodología incluye pruebas experimentales con un semi-trailer atravesando diferentes configuraciones de glorietas y analizando las trayectorias resultantes. Se concluye que la geometría y el trazado de la trayectoria están relacionados, siendo la composición geométrica de la trayectoria de entrada una clotoide seguida de una recta de pequeña longitud. Las limitaciones del estudio son: la geometría de la entrada se limitó mediante conos por lo que no se conoce si el comportamiento del conductor sería el mismo en un caso real, las pruebas fueron realizadas por un único conductor, y por último, no se contabilizaron las velocidades, lo cual puede tener impacto sobre la definición de la clotoide y de la recta.

Mussone et al., 2011 introduce un método para analizar las velocidades y las trayectorias basado en el procesamiento de imágenes. Aunque la investigación se centró en la metodología y no en el trazado de la trayectoria y su relación con la geometría.

Teniendo en cuenta estas premisas generales, se han desarrollado varios métodos para modelar las trayectorias y que se describen a continuación.

En primer lugar, se pueden utilizar plantillas y realizar varios tanteos a mano hasta que se alcance una solución satisfactoria. Debido a la aparición de los softwares de trazado este método se ha abandonado.

La normativa de EE.UU (NCHRP, 2010) propone los esquemas representados en la Fig.2.35 para modelar las trayectorias. 

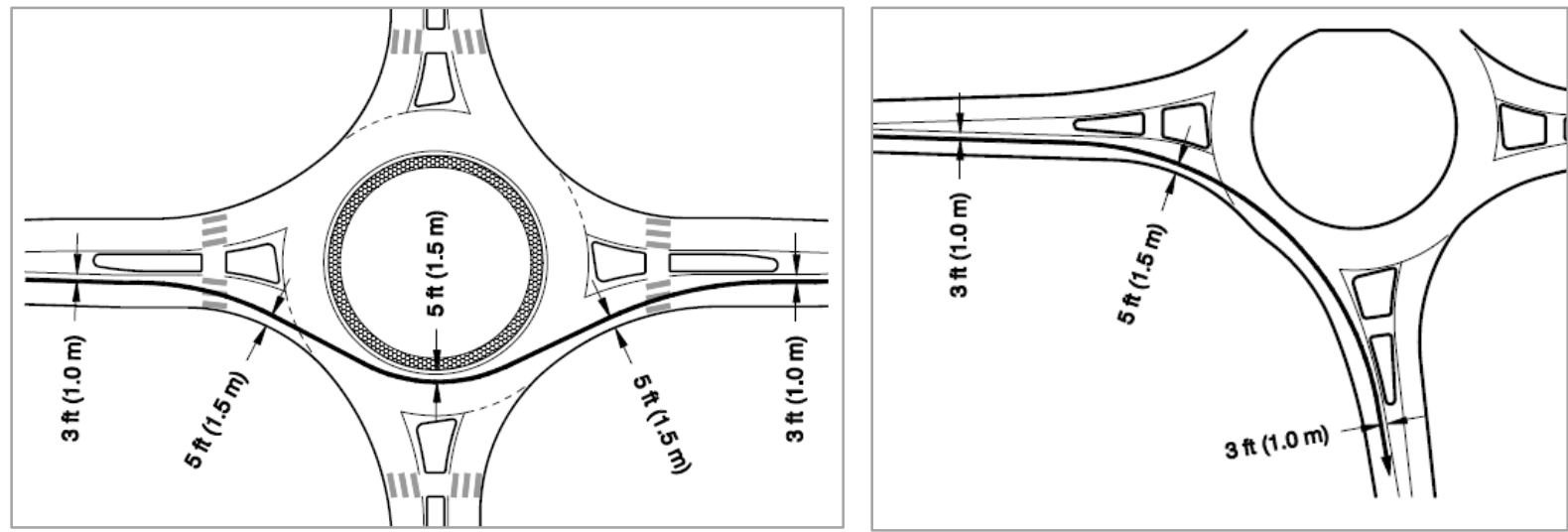

Figura 2.35 Trayectorias según el método de la norma de EE.UU.

Fuente: NCHRP, 2010.

Esta norma no define ninguna metodología para crear las trayectorias aunque propone el uso del sistema de cálculo recogido en la norma de glorietas del Estado de Wisconsin (WisDOT, 2008).

En este texto se describe una técnica para crear trayectorias en CAD (AutoCad y MicroStation) de forma que se facilita la tarea durante los tanteos. Mediante la selección de diferentes puntos de paso el programa va ofreciendo de forma automática un trazado para la trayectoria, que obtiene resolviendo unos problemas de tangencias (Fig.2.36). Posteriormente, hay que realizar correcciones para asegurar que el trazado respeta los resguardos mínimos. Este procedimiento puede ayudar al proyectista en la tarea del encaje de las trayectorias pero sigue siendo un trabajo manual y laborioso.

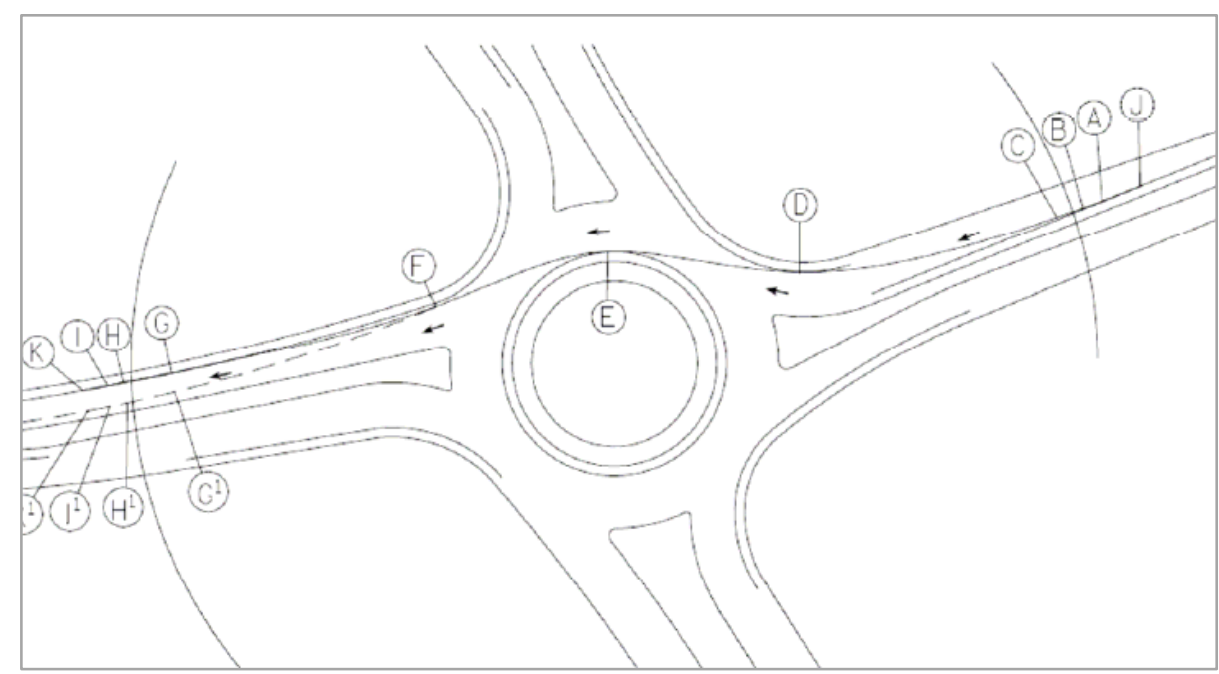

Figura 2.36 Trayectorias según el método de la norma de Wisconsin (EE.UU). Fuente: WisDOT (2008). 
La normativa de glorietas del Estado de Idaho en EE.UU (ACHD, 2011) introduce un método que permite definir las trayectorias en dos etapas. En primer lugar, el procedimiento determina el tipo de salida que se define de acuerdo al número de carriles en la entrada y la geometría de la salida. En segundo lugar, en base al tipo de salida se selecciona un procedimiento entre tres posibles. Mediante varias construcciones geométricas sencillas es posible calcular las trayectorias para los tres procedimientos. En la Fig. 2.37 se muestra una imagen de la construcción de una trayectoria entre un acceso y el opuesto. Este método presenta la ventaja de ser un procedimiento que puede automatizarse. El inconveniente es que no permite calcular las trayectorias con determinadas configuraciones de las patas de acceso.

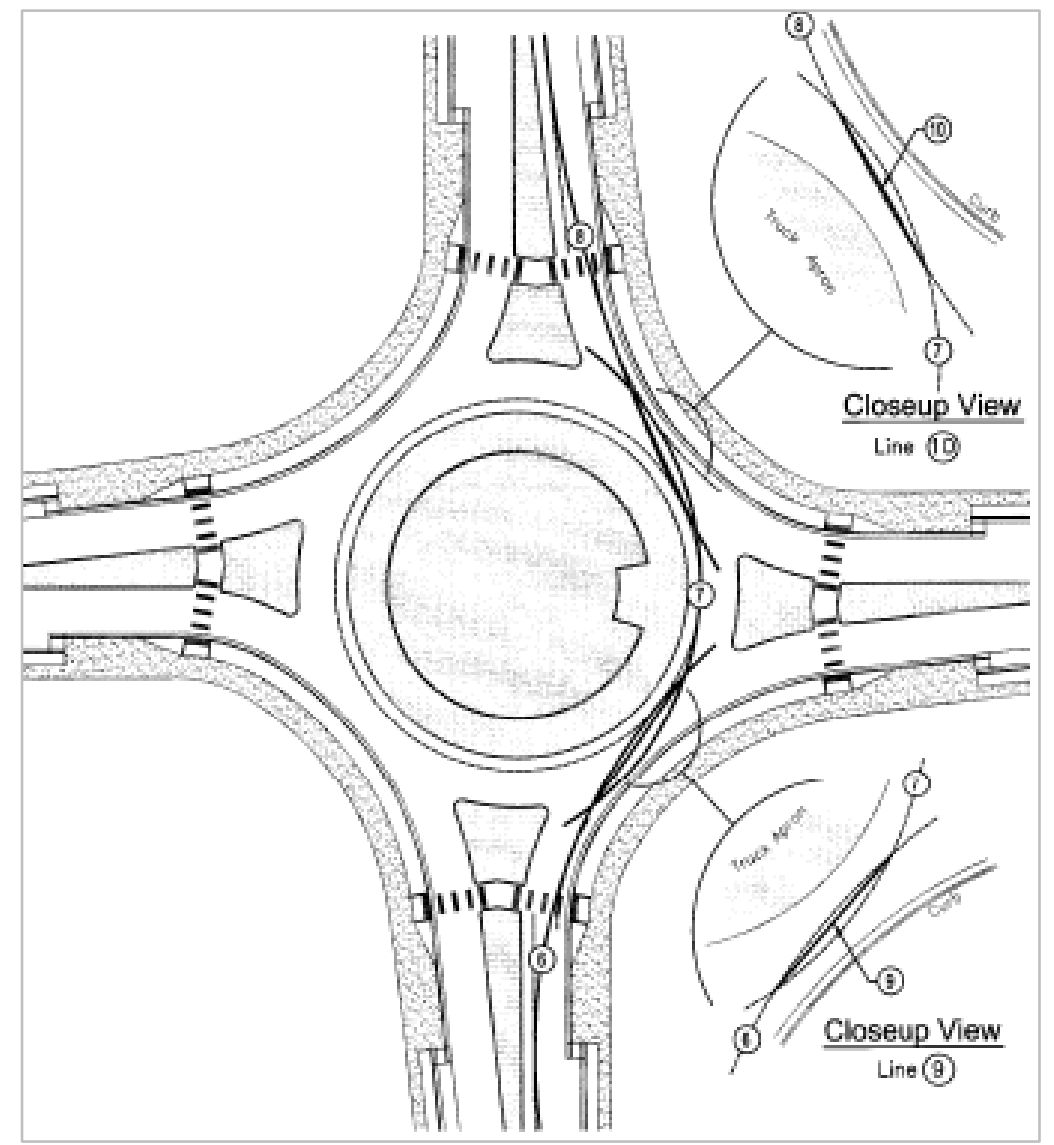

Figura 2. 37 Trayectorias según el método de la norma de Idaho (EE.UU). Fuente: ACHD, 2011.

Por último, el software ARNDT incluido en el método de Australia (QDMR, 2006; AUSTROADS, 2011) permite realizar un estudio de seguridad de la intersección. El programa requiere como entrada la geometría, las velocidades en la aproximación y las 
intensidades de tráfico. Siguiendo la metodología que se adjunta en la norma, es posible calcular las trayectorias más rápidas de forma automática (Fig.2.38). El inconveniente es que no es posible establecer la trayectoria entre una entrada y la salida consecutiva.
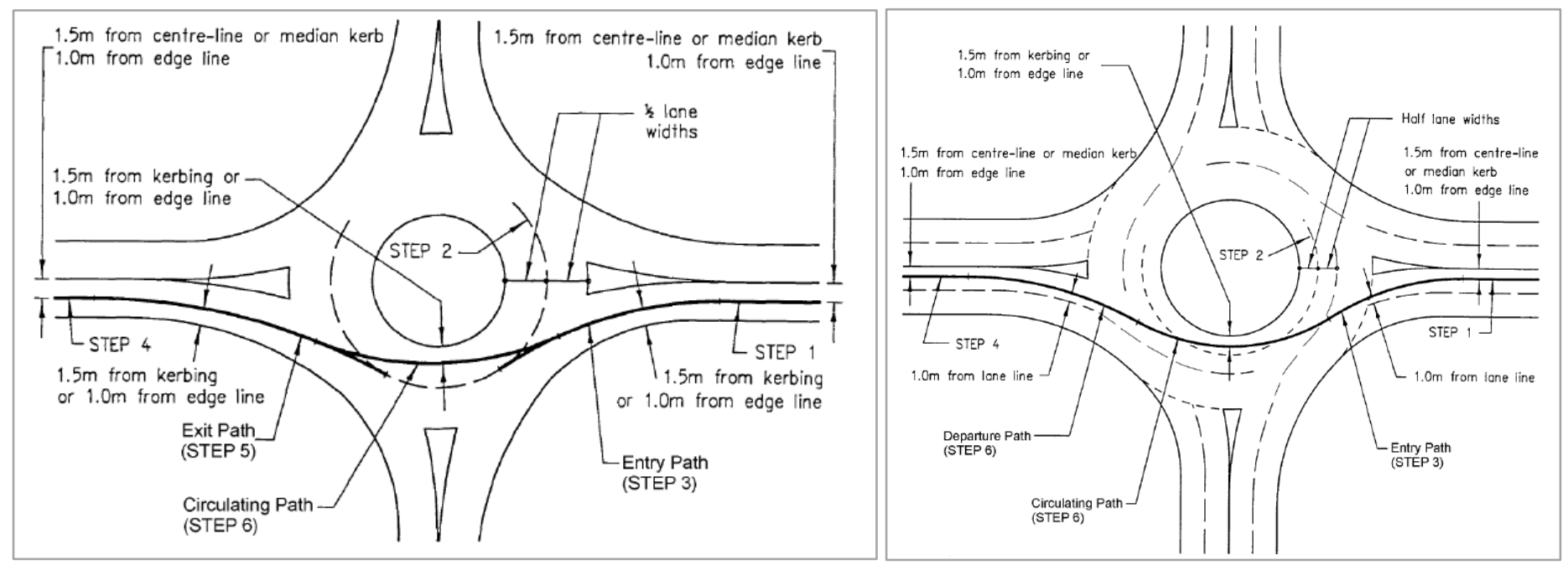

Figura 2.38 Trayectorias según la normativa de Australia. Fuente: QDMR, 2006.

En la norma de España de Nudos (MF, 2012) no se propone ningún método para modelar las trayectorias.

En resumen, se puede concluir que no existe en la actualidad ninguna metodología que permita definir todas las trayectorias de una manera automatizada cualquiera que sea la posición de los accesos.

\subsection{Cálculo de las velocidades}

El último paso necesario antes de evaluar la consistencia es el cálculo de las velocidades. El punto de partida es el valor de los radios de las curvas que componen las diferentes trayectorias.

En la Norma de EE.UU (NCHRP, 2010) se proponen cuatro formulaciones. Las dos primeras se basan en las ecuaciones incluidas en la norma de trazado (AASTHO, 2004), 
y propone una relación entre radio, velocidad y peralte que permite obtener el percentil 85 del perfil de velocidades.

$$
\begin{array}{ll}
V=3,4415 R^{0,3861} & \text { para peralte }+0,02 \\
V=3,4614 R^{0,3673} & \text { para peralte de }-0,02
\end{array}
$$

donde $R$ representa al radio de la trayectoria en pies y $V$ la velocidad en millas por hora.

En la tercera, puede estimarse la velocidad en la entrada considerando una distancia de deceleración. La expresión es:

$$
V_{1}=\frac{1}{1,47} \sqrt{\left(1,47 V_{2}\right)^{2}+2 a_{12} d_{12}}
$$

siendo:

$\mathrm{V}_{1}=$ velocidad de entrada en millas por hora.

$\mathrm{V}_{2}=$ velocidad del radio definido en la calzada anular en millas por hora.

$\mathrm{a}_{12}=$ deceleración entre el punto de interés del radio de entrada (no especifica ninguno) y el punto medio del radio definido en la calzada anular (segundo radio). Se asume un valor de $-4,2 \mathrm{ft} / \mathrm{s}^{2}$.

$\mathrm{d}_{12}=$ distancia entre el punto de interés del radio de entrada y el punto medio del radio definido en la calzada anular en pies.

La velocidad en la entrada será el mínimo valor calculado por las expresiones (2-1), (22) y (2-3).

La cuarta ecuación es idéntica a la tercera pero considerando una aceleración dentro de la expresión (se propone $6,9 \mathrm{ft} / \mathrm{s}^{2}$ ) y permite estimar la velocidad en la salida.

Inman et al., 2003 en su investigación sobre las trayectorias y las velocidades en glorietas expone que, atendiendo a los datos observados, el punto de deceleración en el arco de entrada se sitúa un poco antes del punto de inflexión con el siguiente arco, aunque sugiere investigaciones adicionales para justificar estos fenómenos. Además, obtiene un ratio entre la velocidad de entrada y la del segundo arco de 1,3:1 en interurbanas y 1,4:1 en urbanas. Arndt y Troubeck (1995) sugiere que esta diferencia se sitúe en 1,25:1. 
El cálculo de velocidades en la Norma de Australia se basa en el gráfico representado en la Fig.2.39 y que es aplicable para turismos. El procedimiento se inicia proyectando una vertical desde el valor del radio calculado hasta la intersección con la curva de velocidad libre (velocidad que el conductor elige en condiciones de flujo sin restricciones). La proyección horizontal de este punto intersección es el percentil 85 de velocidades buscado.

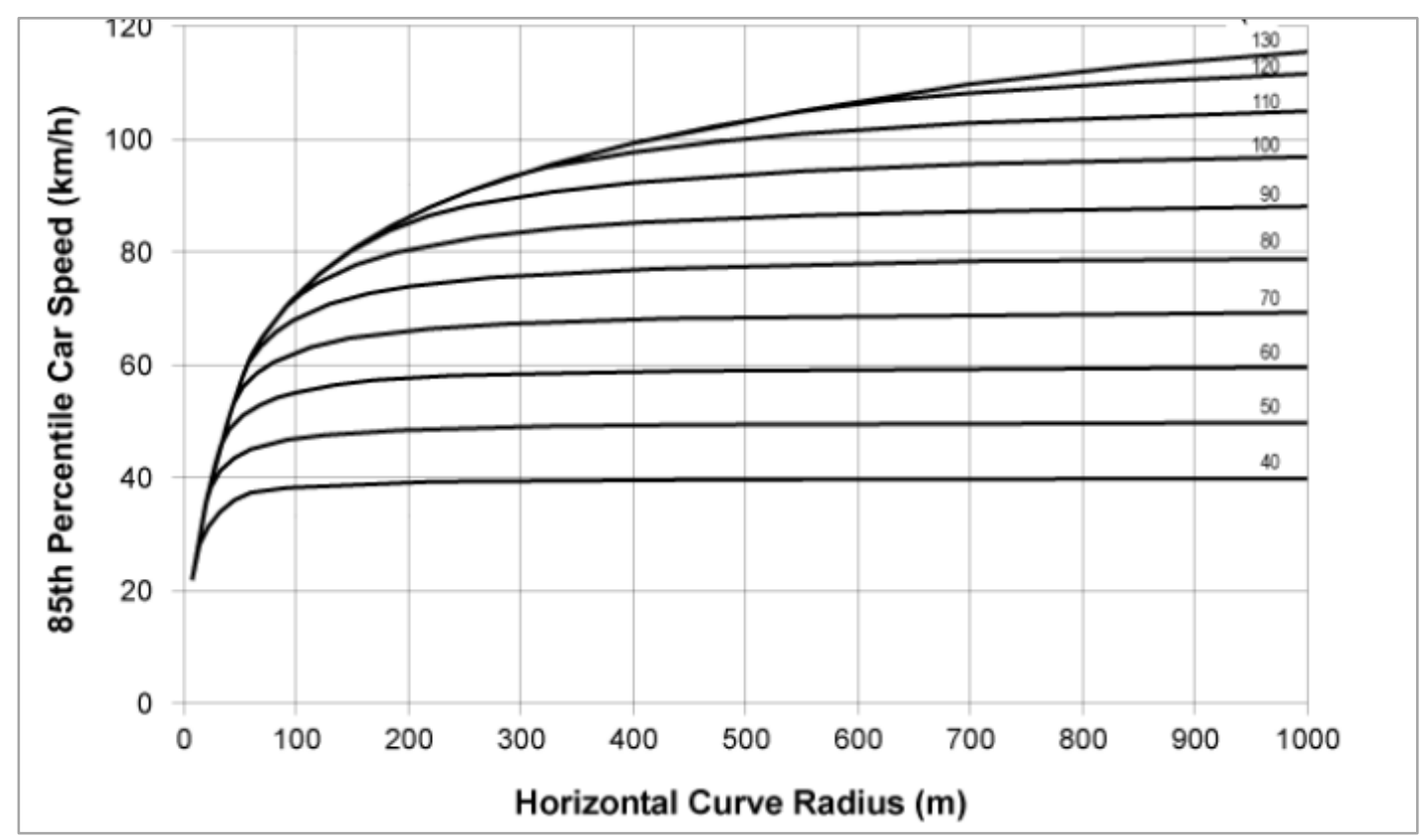

Figura 2. 39 Relación entre velocidades y los radios horizontales. Fuente: QDMR, 2006.

\subsection{Criterios de consistencia de velocidades en las normas de diseño}

En el apartado 2.2.4.4.7 se analizaron los criterios tradicionales para evaluar la seguridad de un diseño. El enfoque más moderno que han adoptado las principales normas de diseño consiste en modelar las trayectorias de paso y analizar los perfiles de velocidad. Se han propuesto fundamentalmente dos métodos basados en este principio.

El método de EE.UU (NCHRP, 2010) se basa en el cálculo de las trayectorias de los vehículos más rápidos para todas las aproximaciones y para todos los movimientos. Posteriormente, se tienen que comprobar para cada acceso que las velocidades asociadas 
a los cinco arcos críticos mostrados en las Fig. 2.40 no superan unos determinados valores umbrales.

La norma establece limitaciones al valor de estos radios. Además, se debe revisar la consistencia de velocidades entre los arcos pertenecientes a una misma trayectoria y en los puntos de conflicto de trayectorias diferentes limitando ambos indicadores según los datos recogidos en la Tabla 2.5 que se muestra al final del apartado.

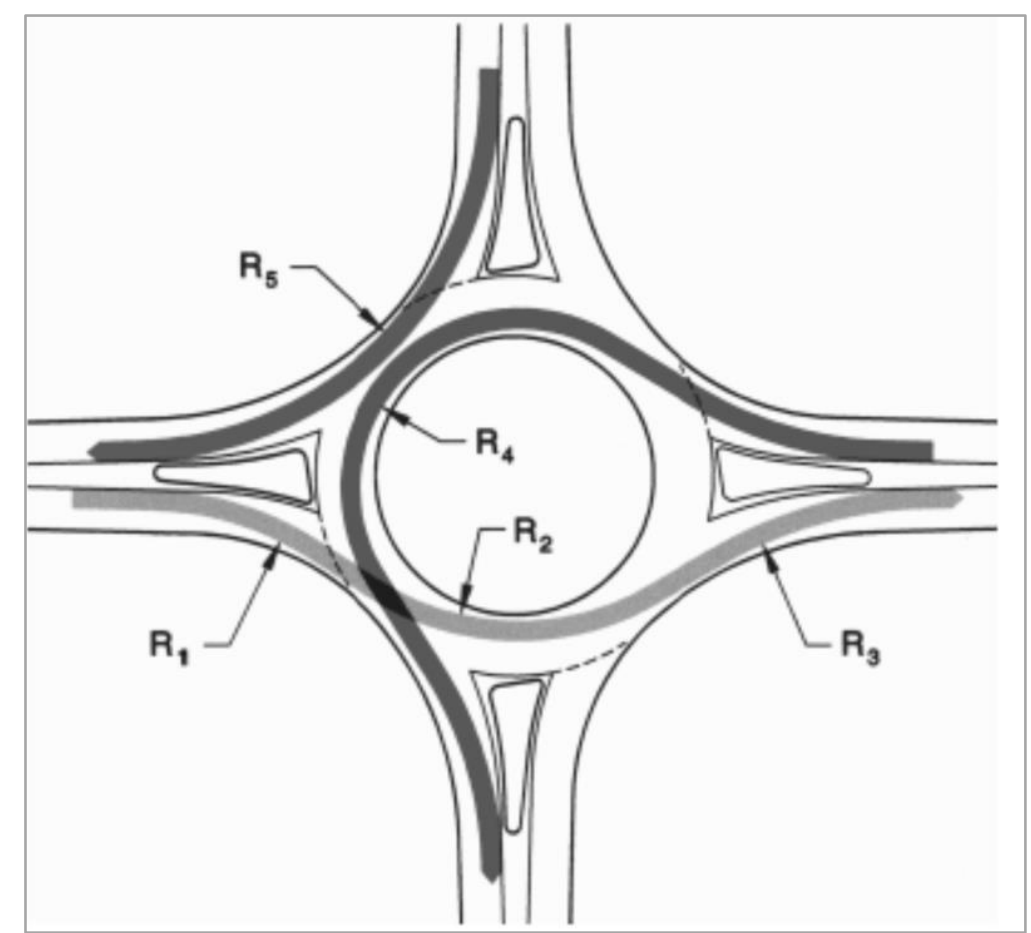

Figura 2. 40 Radios críticos en el método de evaluación de la consistencia de EE.UU. Fuente: NCHRP (2010).

Los resultados de las investigaciones con casos reales de Inman et al., (2003) y Gallelli et al., (2014) validan el procedimiento definido por el método de EE.UU. Bastos y Maia (2006) han adoptado una metodología muy parecida para el caso portugués.

En España, la nueva Guía de Nudos (MF, 2012) ha incluido un procedimiento similar basado en el mismo gráfico mostrado en la Fig.2.40, pero con diferentes criterios de consistencia (Tabla 2.4). La velocidad en la calzada anular se limita a $50 \mathrm{~km} / \mathrm{h}$. 


\begin{tabular}{|c|c|c|c|}
\hline Radio & \multicolumn{2}{|c|}{ Tipo de entorno } & Condición \\
\hline $\mathrm{R}_{3}$ & \multicolumn{2}{|c|}{ Urbano } & $\begin{array}{c}\mathrm{V}_{3}<45 \mathrm{~km} / \mathrm{h} \mathrm{o} \\
\text { alternativamente, } \\
\mathrm{V}_{2}<30 \mathrm{~km} / \mathrm{h}\end{array}$ \\
\hline \multirow{4}{*}{$\mathrm{R}_{1}$ y $\mathrm{R}_{2}$} & \multirow[b]{2}{*}{ Urbano } & 1 carril & $\mathrm{V}_{1}<\mathrm{V}_{2}+20 \mathrm{~km} / \mathrm{h}$ \\
\hline & & 2 carriles & $\begin{array}{c}\mathrm{V}_{1}<\mathrm{V}_{2}+20 \mathrm{~km} / \mathrm{h} \mathrm{y} \\
\mathrm{V}_{1}>\mathrm{V}_{2}-10 \mathrm{~km} / \mathrm{h}\end{array}$ \\
\hline & \multirow[b]{2}{*}{ Interurbano } & 1 carril & $\mathrm{V}_{1}<\mathrm{V}_{2}+15 \mathrm{~km} / \mathrm{h}$ \\
\hline & & 2 carriles & $\begin{array}{c}\mathrm{V}_{1}<\mathrm{V}_{2}+15 \mathrm{~km} / \mathrm{h} \mathrm{y} \\
\mathrm{V}_{1}>\mathrm{V}_{2}-10 \mathrm{~km} / \mathrm{h}\end{array}$ \\
\hline \multirow{2}{*}{$\mathrm{R}_{3}$ y $\mathrm{R}_{2}$} & \multicolumn{2}{|c|}{ Urbano } & $\mathrm{V}_{3}>\mathrm{V}_{2}-5 \mathrm{~km} / \mathrm{h}$ \\
\hline & \multicolumn{2}{|c|}{ Interurbano } & $\mathrm{V}_{3}>\mathrm{V}_{2}$ \\
\hline $\mathrm{R}_{1}$ y $\mathrm{R}_{4}$ & \multicolumn{2}{|c|}{ Cualquiera } & $\mathrm{V}_{1}<\mathrm{V}_{4}+30 \mathrm{~km} / \mathrm{h}$ \\
\hline $\mathrm{R}_{5} \mathrm{y} \mathrm{R}_{4}$ & \multicolumn{2}{|c|}{ Cualquiera } & $\mathrm{V}_{5}<\mathrm{V}_{4}+20 \mathrm{~km} / \mathrm{h}$ \\
\hline $\mathrm{R}_{2} \mathrm{y} \mathrm{R}_{4}$ & \multicolumn{2}{|c|}{ Cualquiera } & $\begin{array}{c}\mathrm{R}_{2}<1,6^{*} \mathrm{R}_{4} \\
\mathrm{~V}_{2}<\mathrm{V}_{4}+20 \mathrm{~km} / \mathrm{h}\end{array}$ \\
\hline
\end{tabular}

Tabla 2. 4 Criterios de consistencia para el diseño de glorietas en España. Fuente: MF, 2012; MF, 2016.

El método incluido en las Normas de Australia (QDMR, 2006, AUSTROADS, 2011) se basa en el modelado de las trayectorias de los vehículos más rápidos aunque se excluye de este cálculo el movimiento entre una entrada y una salida consecutiva. Posteriormente, hay que comprobar el radio de entrada de la trayectoria, el radio de la deflexión y la consistencia de velocidades de acuerdo de los indicadores que se recogen en la Tabla 2.5.

A continuación, y a modo de resumen, se incluyen los criterios para el control de las velocidades que se exponen en las diferentes normas según los criterios tradicionales descritos con anterioridad (apartado 2.2.4.4.7) y el enfoque más moderno que se acaba de presentar (Tabla 2.5). 


\begin{tabular}{|c|c|c|c|c|c|c|c|}
\hline & $\begin{array}{l}\text { Reino } \\
\text { Unido }\end{array}$ & España & Francia & Suiza & Italia & USA & Australia \\
\hline & HA, 2007 & MOPU, 1989 & SETRA, 1998 & VSS,1999 & MIT,2006 & NCHRP, 2010 & QDMR, 2006 \\
\hline \multicolumn{8}{|l|}{ Paráme tros geométricos } \\
\hline Radio de la trayectoria de entrada $(m)$ & $<100$ & $<100$ & -- & -- & -- & -- & -- \\
\hline Radio de la deflexión $(\mathrm{m})$ & -- & -- & $<100$ & -- & -- & -- & $<100$ \\
\hline Ángulo de desviación(grados) & -- & -- & -- & $>45$ & $>45$ & - & - \\
\hline \multicolumn{8}{|l|}{ Velocidades } \\
\hline \multicolumn{8}{|l|}{ Máxima veloc. en la entrada } \\
\hline $\operatorname{Min}(\mathrm{km} / \mathrm{h})$ & -- & -- & -- & -- & -- & 32 & -- \\
\hline $\operatorname{Max}(\mathrm{km} / \mathrm{h})$ & - & -- & -- & -- & -- & 40 & 60 \\
\hline \multicolumn{8}{|l|}{ Consistencia de velocidades } \\
\hline \multicolumn{8}{|l|}{ Velocidad relativa $(\mathrm{km} / \mathrm{h})$ entre: } \\
\hline elementos geométricos consecutivos & -- & -- & -- & -- & -- & $15-25$ & $<20$ \\
\hline corrientes de tráfico en conflicto & -- & -- & -- & -- & -- & $15-25$ & $<35$ \\
\hline
\end{tabular}

Tabla 2. 5 Criterios para el control de velocidades en las normas de diseño.

En una investigación reciente, Arndt (2008) considera que estos métodos tienen el problema de exigir una enorme carga de trabajo al proyectista. Por este motivo, propone evaluar el control de la velocidad en base a dos parámetros: el máximo radio de entrada y el mínimo diámetro de la isleta central. El autor presenta tabulados el valor que hay que asignar a estos parámetros dependiendo de la velocidad de aproximación y el número de carriles. El inconveniente de este método es que para obtener estos valores se parte de unas condiciones ideales, como es el caso por ejemplo de accesos situados a $90^{\circ}$, lo cual no siempre ocurre en la práctica.

\subsection{APLICACIONES INFORMÁTICAS DE DISEÑO}

\subsubsection{Introducción}

Los avances de la tecnología han permitido mejorar las técnicas de trazado. En este apartado se presentan las principales herramientas informáticas de diseño de glorietas y cómo las utilizan los proyectistas para realizar este trabajo. Se pueden dividir en dos grupos principales: programas integrados de trazado de obras lineales y programas específicos de diseño de glorietas. 


\subsubsection{Programas integrados de trazado de obras lineales}

Mediante los programas de trazado de obras lineales es posible definir todos los elementos geométricos necesarios para la realización de un proyecto de una carretera. Se componen de una serie de módulos que permiten fundamentalmente la gestión de la topografía, la definición interactiva de todos los elementos geométricos, la obtención de las mediciones y la generación de los planos.

La definición de la geometría en planta de una glorieta se puede realizar utilizando los programas de trazado de obras lineales. Para ello, cada autor selecciona una herramienta informática y define una serie de ejes de trazado que junto al valor de las anchuras de las calzadas permiten generar los planos de replanteo ${ }^{13}$ del proyecto.

Si se desea un nivel adecuado de precisión, es necesario definir muchos ejes de trazado. El proyectista decide en cuántos ejes apoyarse y donde situarlos. En la Fig. 2.41 se muestra un ejemplo de la distribución realizada para el proyecto de la glorieta de un enlace.

Por lo general, el proceso de diseño se inicia proponiendo un centro y un tamaño para el anillo y, posteriormente, se realiza el encaje de los accesos. Por tanto, el primer reto importante al que se enfrenta el proyectista es situar y dimensionar la calzada anular.

Para definir la calzada anular se puede utilizar un único eje que puede situarse en el borde interior o en el borde más exterior. En el ejemplo de la Fig. 2.41 se ha definido por el borde exterior ya que así se facilita la definición de las alineaciones tangentes a los accesos y a la calzada anular.

13

En la planta de replanteo, los ejes que definen el trazado en planta se inscriben en el plano topográfico, el cual debe contener la información de todos los elementos que están presentes en el área de estudio. En cada eje, se suele destacar el tipo de alineación (recta, clotoide o círculo) y algún dato de interés (longitud, parámetro o radio). Además se establece una rotulación con su situación respecto al origen. También suele representarse las bases de replanteo utilizadas para realizar el levantamiento topográfico y los límites de expropiación. 


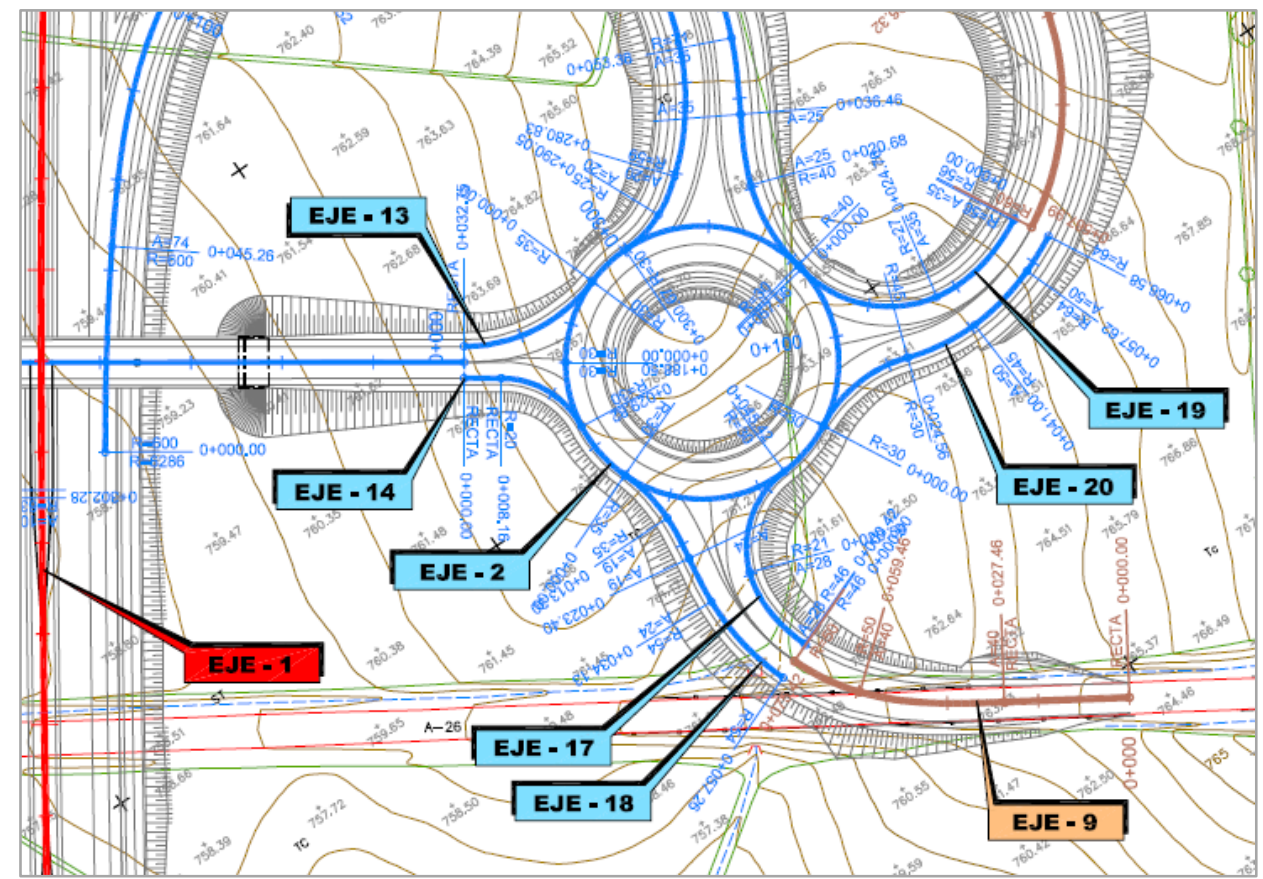

Figura 2. 41 Trazado en planta de una glorieta.

Fuente: Información pública: "Proyecto de Construcción Autovía A-32 Linares-Albacete. N322 de Córdoba a Valencia. Tramo: L.P Jaén - Reolid”. Ministerio de Fomento (España).

La composición geométrica de los ejes auxiliares que definen los accesos puede ser muy variable y determinan la morfología de la isleta deflectora. Conforme a las especificaciones de las principales normativas de diseño, es común definir los bordes de las entradas y las salidas mediante uno o varios arcos circulares.

Los ejes auxiliares suelen establecerse en la banda blanca exterior de pintura de la entrada (o salida) ya que cuando se hace por la banda blanca interior, disposición que se ha utilizado mucho en la práctica, queda una parte de la calzada del acceso sin definir, justo a partir del cruce del eje con el borde exterior de la calzada anular.

Un factor que puede condicionar el diseño es la disposición de las entradas y las salidas consecutivas. Los radios de los bordes exteriores de las entradas y salidas deben ser suficientemente grandes para permitir el giro de los vehículos de mayor longitud. A veces, entre una entrada y salida consecutiva puede interesar adoptar un único arco circular. Si el radio de este arco es muy reducido puede ser necesaria la modificación de la posición del anillo o de su tamaño. En el ejemplo de la Fig. 2.41 se puede observar 
que, para la entrada y la salida consecutiva del acceso situado al este, se ha hecho coincidir el punto de tangencia del arco exterior de la entrada con el punto de tangencia del arco exterior de la salida y con el borde exterior de la calzada anular.

Una vez se ha finalizado la definición de la calzada anular y de los accesos, se debe analizar la respuesta de la geometría frente a las necesidades del trazado en planta en un proceso de naturaleza iterativa. Para ello es necesario utilizar otras aplicaciones informáticas y modelar las trayectorias de los vehículos mediante la definición de nuevos ejes de trazado. Si no se satisfacen las condiciones funcionales y de seguridad se modifica el trazado hasta que se alcancen los objetivos.

La ventaja de este método es que es posible obtener con mucha precisión la definición de la geometría en planta y generar fácilmente los planos constructivos. No obstante, presenta algunos aspectos que pueden ser mejorados:

- El proceso de trazado es muy laborioso, por lo que es necesario emplear mucho tiempo en generar las diferentes soluciones geométricas.

- El modelado de las trayectorias de los vehículos suele ser un proceso manual, laborioso e impreciso.

- Puede ser necesario utilizar otras aplicaciones informáticas para comprobar los objetivos del trazado en planta.

- Es recomendable que el proyectista posea mucha experiencia para orientar el valor de los parámetros geométricos y alcanzar una solución adecuada sin emplear mucho tiempo.

Como consecuencia, la cantidad de iteraciones que se lleva a cabo antes de adoptar una solución final es limitada. 


\subsubsection{Programas específicos de diseño de glorietas}

Con el objetivo de superar las limitaciones de los programas integrados de obras lineales, se han desarrollado aplicaciones informáticas que permiten mejorar las técnicas de trazado en glorietas.

Ramos et. al, 2010 presentan un enfoque informatizado del trazado en planta de glorietas mediante una aplicación denominada TORUS. Este programa permite la definición interactiva de la geometría en un entorno de CAD y la comprobación dinámica de los objetivos del trazado. De esta forma, el proyectista puede fácilmente realizar el diseño geométrico y analizar cómo puede afectar un cambio en el trazado a los objetivos, por lo que dispone de un mayor tiempo para considerar opciones y aplicar su buen juicio.

A pesar de ser una herramienta muy útil para generar soluciones, presentan algunos aspectos que pueden ser mejorados:

- El trabajo sigue siendo manual y está sujeto al criterio del proyectista, que decide el valor de los parámetros de diseño de acuerdo a su experiencia y las recomendaciones de la norma aplicable.

- En la comprobación de la seguridad del diseño, no se puede realizar para todos los casos posibles el cálculo de las trayectorias y, por tanto, la evaluación de la consistencia.

- No se aportan criterios para decidir la mejor situación de la calzada anular ni tampoco información sobre el sentido en el cual se deben modificar los parámetros de diseño (los objetivos son contrapuestos) en las iteraciones manuales.

El software de glorietas ARDNT ha sido desarrollado por el Departamento de Transportes del Gobierno de Queensland en Australia y permite obtener la geometría y las trayectorias de forma automática introduciendo el valor de los parámetros geométricos. Además permite prever el ratio de accidentes y los costes asociados de acuerdo a la formulación incluida en la normativa de ese país. La ventaja de este método 
es que permite identificar aspectos problemáticos para la seguridad vial de un diseño. Presenta las mismas limitaciones que el programa TORUS y, además, no es posible realizar el resto de las comprobaciones de los objetivos del trazado en planta.

\subsection{NORMATIVAS DE DISEÑO}

\subsubsection{Introducción}

En este apartado se describen de forma detallada los parámetros geométricos y el resto de elementos que permiten definir la geometría en planta de una glorieta. El estudio se realiza sobre la base que establecen las principales normas de diseño, resumiendo los valores recomendados en éstas para los diferentes elementos.

\subsubsection{Las normas de diseño de referencia}

Para realizar un buen diseño es fundamental apoyarse en una buena norma de trazado.

Para completar esta investigación se han revisado las principales normas redactadas a nivel mundial y que están representadas por los textos publicados en Reino Unido, Francia, Australia, Estados Unidos y España.

En Reino Unido, la guía de diseño es el denominado TD 16 (la codificación se completa con el año de la publicación). En lo que se refiere a las intersecciones en glorieta se han publicado los siguientes documentos (Kennedy, 2008):

- Normativa de diseño: TD 16/07 (versiones anteriores TD 16/84 y TD 16/93).

- Otras normativas: TD 78/97 (señalización), TD 51/03 (carriles segregados y deflexión), TD 50/04(glorietas semaforizadas), TD 86/03(trazado en grandes intersecciones) y $T D$ 54/07(miniglorietas). 
En Francia, se han publicado diferentes normativas de diseño. A continuación se presenta la cronología de publicaciones (Guichet, 2008):

- Normativa de diseño: Aménegement des Carrefours Interurbains (Ministère de l'Equipement, des Transports et du Logement en 1998) y Carrefours Urbain (CETUR en 1999). A efectos de este apartado se tendrá en cuenta la versión traducida al inglés por el SETRA (Service D'études Techniques Des Routes Et Autoroutes) de título The Design of Interurban Intersections on Major Roads.

- Versiones anteriores de la normativa: Carrefours giratories (Ministere de L’Urbanisme en 1984) (1984) y Conception Des Carrefours a Sens Giratoire implantes en milieu Urbain (CETUR en 1988).

- Se han publicado asimismo otras disposiciones que tratan aspectos parciales: iluminación en glorietas, miniglorietas, glorietas y tranvías, y semaforización.

En Australia, existen dos publicaciones de referencia. Por un lado, el texto publicado en el estado de Queensland en el año 2006 (QDMR, 2006). La redacción de este documento se basa en versiones anteriores, en la norma de glorietas publicada por AUSTROADS en 1993 y en los trabajos de investigación del Sr. Owen Arndt. Con un contenido muy similar se ha publicado en el año 2011 el segundo documento de referencia, la nueva normativa de glorietas de AUSTROADS (AUSTROADS, 2011).

En Estados Unidos, con una historia más reciente, se han publicado las siguientes normas (Rodergedts, 2008):

- Normativa de diseño: NCHRP (Report 672): Roundabouts: An informal Guide (2010).

- Versión anterior de la normativa: Roundabouts: An informal Guide (2000).

- Otras disposiciones de interés: NCHRP (Report 572): Roundabouts in the United States (2007). Entre 2001 y 2007 muchos estados publican sus propias guías de diseño.

Por último, en España hasta hace unos años se utilizaban las "Recomendaciones sobre glorietas”, publicadas por el antiguo MOPU en el año 1989 (MOPU, 1989). Esta 
publicación sigue las especificaciones de la normativa de Reino Unido de la época. En la nueva norma de nudos publicada recientemente (MF, 2012), aunque no se realiza un tratamiento específico, se incluyen nuevas especificaciones relativas a glorietas en diferentes capítulos que actualizan los criterios del texto de 1989. Algunas Comunidades Autónomas han publicado sus propias guías de diseño, como es el caso de la Comunidad de Madrid (De la Hoz y Pozueta, 1995).

El número de capítulos, el contenido y la extensión que componen cada una de las normas de diseño es variable, aunque en todas ellas se podría establecer una estructura aproximadamente similar:

- Bloque 1, apartado introductorio (principios de diseño, tipología de glorietas, características generales, etc).

- Bloque 2, consideraciones generales sobre los aspectos a tener en cuenta en el diseño (capacidad, seguridad, usuarios no motorizados, etc).

- Bloque 3, diseño geométrico: planta (parámetros geométricos, barrido del vehículo patrón, solape de trayectorias, control de la velocidad, etc) y alzado.

- Bloque 4, sección trasversal y otros (iluminación, señalización, etc).

Kennedy (2007) realizó un estudio comparativo de los criterios y especificaciones de las principales normas de diseño a nivel mundial. De forma general, la autora concluyó para las normas de referencia de esta investigación: la normativa del Reino Unido se centra fundamentalmente en aspectos relacionados con la capacidad lo que conlleva diseños con glorietas de importantes dimensiones; en Francia (Alemania y Holanda), el diseño se focaliza en aspectos de seguridad que da lugar a glorietas con dimensiones más restringidas; y en Australia, la seguridad representa un factor clave, aunque se le da mucha importancia a la capacidad lo que la hace más similar al texto del Reino Unido. 


\subsubsection{Diámetro exterior (diámetro del círculo inscrito)}

El diámetro exterior se refiere al diámetro del borde exterior que define la calzada anular. En la elección de su valor se establecen dos objetivos fundamentales: acomodoguiado de los vehículos más largos y promover la deflexión de las velocidades.

El trazado es recomendable que se realice mediante formas circulares, sin ángulos. Esto es debido a que, en las formas ovaladas, los vehículos aumentan la velocidad en los tramos de menor curvatura (MOPU 1989). Alphand et al., (1991) obtuvo en un estudio de accidentes sobre glorietas francesas un considerable aumento del número de accidentes en aquéllas con formas ovaladas.

No obstante, la mejora en la calidad de los diseños en los últimos años ha permitido implantar formas no circulares con éxito en casos, por ejemplo, de accesos muy separados.

El valor del diámetro exterior determina las dimensiones de la glorieta. Los tamaños medios y grandes facilitan el trazado de las entradas de los accesos. Aunque debe buscarse un equilibrio debido a que, con diámetros muy grandes, puede aumentar en exceso la velocidad de circulación y provocar movimientos peligrosos de los vehículos (Grant y Nicholson, 2003). Las normas de diseño realizan recomendaciones sobre este valor de acuerdo al vehículo patrón considerado.

En la Tabla 2.6 se presentan los valores del diámetro exterior para las normativas de referencia. Para su cálculo se parte de cuatro accesos situados perpendicularmente, un valor adecuado para la isleta central y la selección de un vehículo patrón. Estas condiciones ideales no suelen encontrarse en la práctica por lo que es recomendable realizar la comprobación del área barrida del vehículo patrón mediante alguna aplicación informática. 


\begin{tabular}{|l|c|c|c|c|c|c|c|}
\hline \multirow{2}{*}{ Norma } & \multicolumn{3}{|c|}{ Un carril } & \multicolumn{3}{c|}{ Dos carriles } & $\begin{array}{c}\text { Veh. } \\
\text { Tipo }\end{array}$ \\
\cline { 2 - 9 } & Mín(m) & Máx(m) & Rec.(m) & Mín(m) & Máx(m) & Rec.(m) & Long.(m) \\
\hline MOPU, 1989 & 28 & 36 & -- & -- & -- & -- & 15,5 \\
\hline SETRA, 1998 & 24 & -- & $30-50^{*}$ & -- & -- & 50 & -- \\
\hline QDMR, 2006 & 10 & 200 & -- & 15 & 200 & -- & -- \\
\hline HA, 2007 & 28 & 100 & -- & 28 & 100 & -- & 15,5 \\
\hline NCHRP, 2010 & 32 & -- & $36-43$ & 46 & -- & $49-55$ & 16,7 \\
\hline MF, 2012 & 28 & -- & $30-40^{* *}$ & 35 & -- & $45-55^{* * *}$ & -- \\
\hline
\end{tabular}

* 24-30 m para carreteras secundarias

** 35-45 m para glorietas interurbanas

*** 55-60 m para glorietas interurbanas

Tabla 2. 6 Valores del diámetro exterior en las principales normas de diseño.

Como se desprende de los valores recogidos en esta tabla, se propone que el diámetro exterior de la glorieta no sea excesivo. Debe ser suficiente para acomodar a los vehículos más grandes y para limitar las trayectorias. En glorietas de un carril, suelen adoptarse valores de entre 25 a 50m. En glorietas de dos o más carriles, el mínimo suele ser algo mayor y el máximo no debería superar los 100m.

Brude y Larson (1999) concluyeron que los diámetros mayores de 50m incrementan el ratio de accidentes. Sugieren que entre 20 y 50m se encuentra el óptimo.

Para completar la definición de este parámetro geométrico es necesario establecer además su posición física en el espacio mediante unas coordenadas.

Las coordenadas del centro dependen de cada caso particular y necesitan ser fijadas mediante tanteos condicionando mucho el encaje de la geometría. El diseñador debe decidir su valor en función de los objetivos de guiado y deflexión, teniendo especial cuidado con el trazado de las entradas y salidas consecutivas. Además hay que tener en cuenta el espacio disponible y las condiciones orográficas.

Bastos y Maia (2006) proponen una dibujo auxiliar para orientar la búsqueda y que consiste en la construcción de un polígono tal y como se muestra en la Fig. 2.42. Como 
se puede observar, el área resultante se ha formado alargando los ejes de las alineaciones de los accesos que tienen que ser alineaciones rectas.

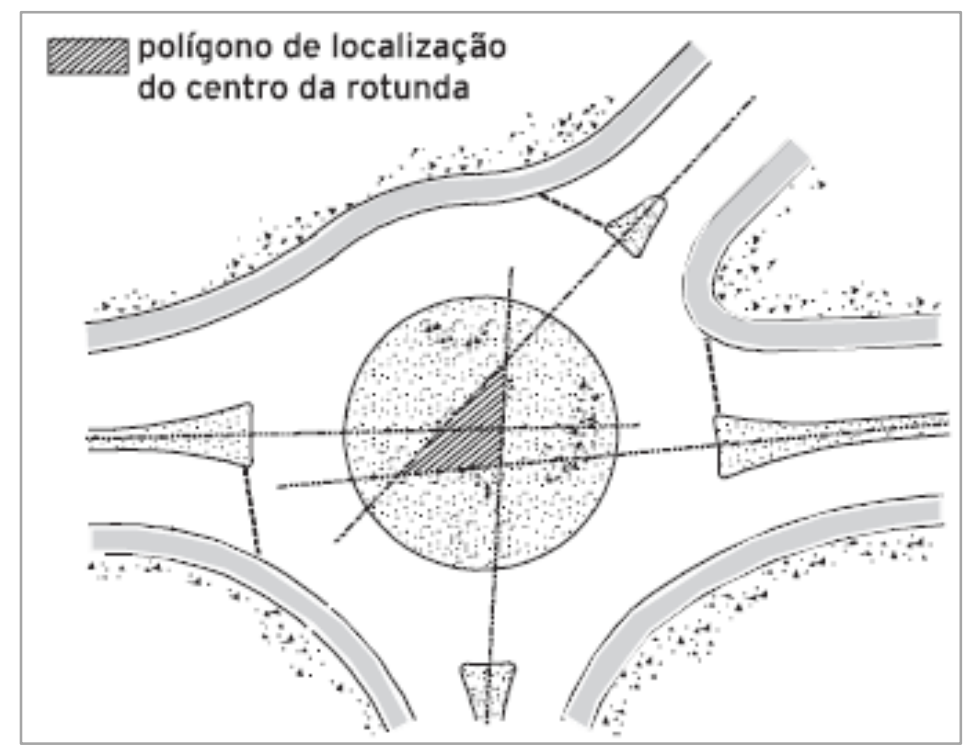

Figura 2. 42 Polígono de localización del centro de la glorieta. Fuente: Bastos y Maia, 2006.

\subsubsection{Anchura de la calzada anular}

La anchura de la calzada anular depende de varios factores, siendo los más importantes:

- Número de carriles en las entradas. Depende del estudio de capacidad realizado en la fase previa. La configuración más común es establecer uno o dos carriles concéntricos a la isleta central en continuidad con las entradas.

- Necesidades del vehículo patrón. El movimiento crítico suele ser el giro a izquierdas. Las normas establecen una serie de distancias mínimas respecto de los borde de calzada para realizar la comprobación del vehículo patrón.

En glorietas de un carril un aumento excesivo de la anchura de la calzada anular puede inducir a los vehículos a circular de forma paralela y aumentar el riesgo de accidente. En general, el número de accidentes crece con el tamaño de la calzada anular.

Todas las normas proponen que el valor de la anchura sea constante aunque se admiten configuraciones como la mostrada en la Fig.2.43, en la que se disponen reducciones en 
la anchura de la calzada anular para facilitar la coordinación con los carriles de los accesos.

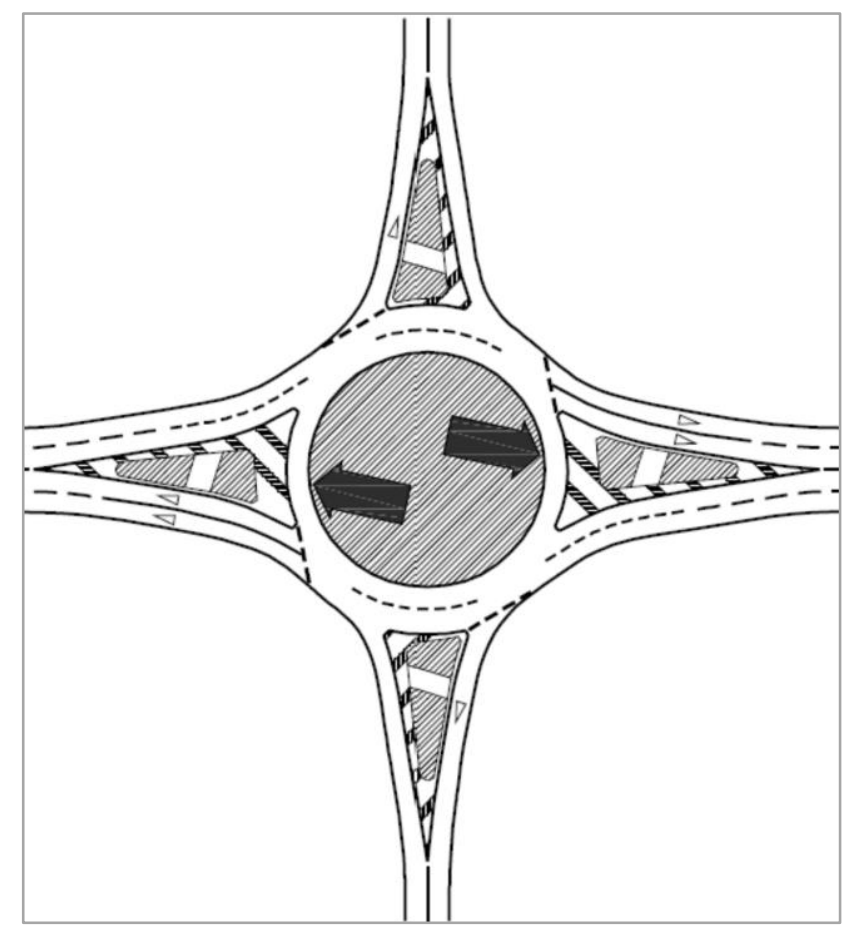

Figura 2.43 Anchura variable de la calzada anular. Fuente: MF, 2012.

En la Tabla 2.7 se presentan los valores de la anchura de la calzada anular para las normas de referencia.

\begin{tabular}{|l|c|c|c|c|c|c|}
\hline \multirow{2}{*}{\multicolumn{1}{|c|}{ Norma }} & \multicolumn{4}{|c|}{ Un carril } & \multicolumn{3}{c|}{ Dos carriles } \\
\cline { 2 - 8 } & Mín(m) & $\operatorname{Máx(m)}$ & Rec.(m) & Mín(m) & Máx(m) & Rec.(m) \\
\hline MOPU, 1989 & $1 \times$ Ae & $1,2 \times$ Ae $(<15)$ & -- & -- & -- & -- \\
\hline SETRA, 1998 & 6 & $1,2 \times$ Ae & 7 & 6 & 9 & 8,5 \\
\hline QDMR, 2006 & 5 & 12,6 & -- & 7,4 & 14,3 & -- \\
\hline HA, 2007 & $1 \times \mathrm{Ae}$ & $1,2 \times \mathrm{Ae}(<15)$ & $7,2-15$ & $1 \times \mathrm{Ae}$ & $1,2 \times \mathrm{Ae}$ & $10,8-15$ \\
\hline NCHRP, 2010 & $1 \times \mathrm{Ae}$ & $1,2 \times \mathrm{Ae}$ & $4,8-6,1$ & -- & -- & $8,5-9,8$ \\
\hline
\end{tabular}

Ae=máxima anchura de entrada.

Tabla 2. 7 Anchura de la calzada anular en las principales normas de diseño.

Por tanto, de acuerdo a las normas, en glorietas de un carril la anchura de la calzada anular debe ser como mínimo el valor de la anchura de la entrada más grande, y como máximo un $20 \%$ más de este valor. Los valores habituales suelen estar entre 5 y $7 \mathrm{~m}$. En 
glorieta de dos carriles, se debe buscar el mínimo posible de acuerdo a los objetivos del trazado, con unos valores que oscilan entre 4 a $5 \mathrm{~m}$ por carril. Según la norma de trazado de España (MF, 2016), únicamente se utilizarán glorietas con calzadas anulares de uno o dos carriles.

El tipo de accidente localizado en la salida (tipo 4) aumentan con el incremento de la anchura de la calzada anular (NCHRP, 2010). La normativa de Australia recomienda que en situaciones en las que se necesite aumentar la deflexión de las velocidades sin aumentar el diámetro de la glorieta es preferible reducir la anchura de la calzada anular (QDMR, 2006).

\subsubsection{Isleta central}

La isleta central representa el obstáculo en el centro de la glorieta alrededor del cual circulan los vehículos y que provoca la curvatura en las trayectorias de paso.

Existe una relación directa entre el diámetro exterior, la anchura de la calzada anular y la isleta central. Con anillos e isletas circulares sólo es necesario definir dos parámetros ya que, a partir de ellos, se puede deducir el tercero.

En general, se recomienda que su forma sea circular aunque puede ser necesario modificar su morfología para acondicionar las trayectorias de los vehículos. Jurisich y Asmus (2011) justifican mediante la exposición de un caso real la modificación de la morfología de una isleta circular a una elíptica al objeto de reducir las velocidades de los vehículos. En la Fig.2.44 se puede observar a la izquierda el estado original y a la derecha el estado reformado. 

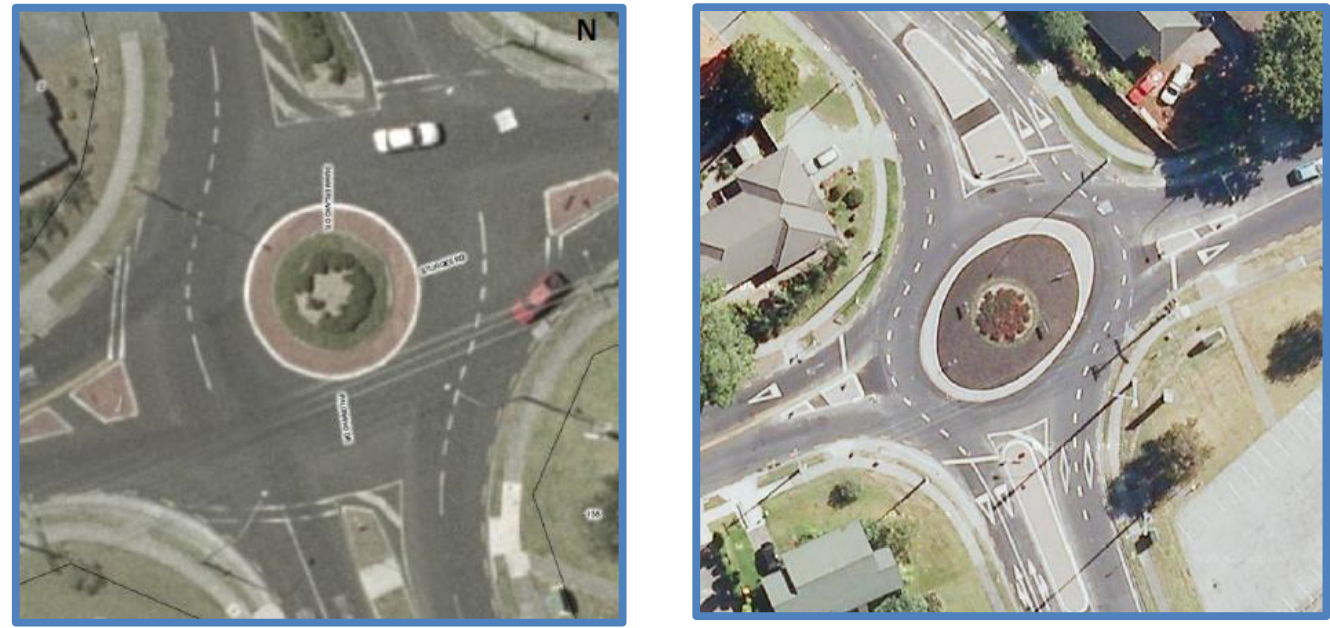

Figura 2. 44 Modificación de la forma de la isleta para promover la deflexión. Fuente: Jurisich y Asmus, 2011.

La isleta central presenta algunas particularidades de diseño. Suele elevarse para mejorar la percepción de la glorieta y se aprovecha para implementar instalaciones de carácter estético. El acceso al interior está prohibido.

Con el objetivo de minimizar el tamaño de la glorieta, se puede habilitar en el exterior de la isleta central una zona transitable denominada gorjal (Fig.2.45). Este espacio adicional sólo es utilizado por los vehículos más grandes que lo necesiten para la maniobra. Para delimitarlo, y desanimar al resto de vehículos de su utilización, suele tener un tratamiento diferente. Los métodos habituales son: señalización, tratamiento de la superficie del firme o ambos.

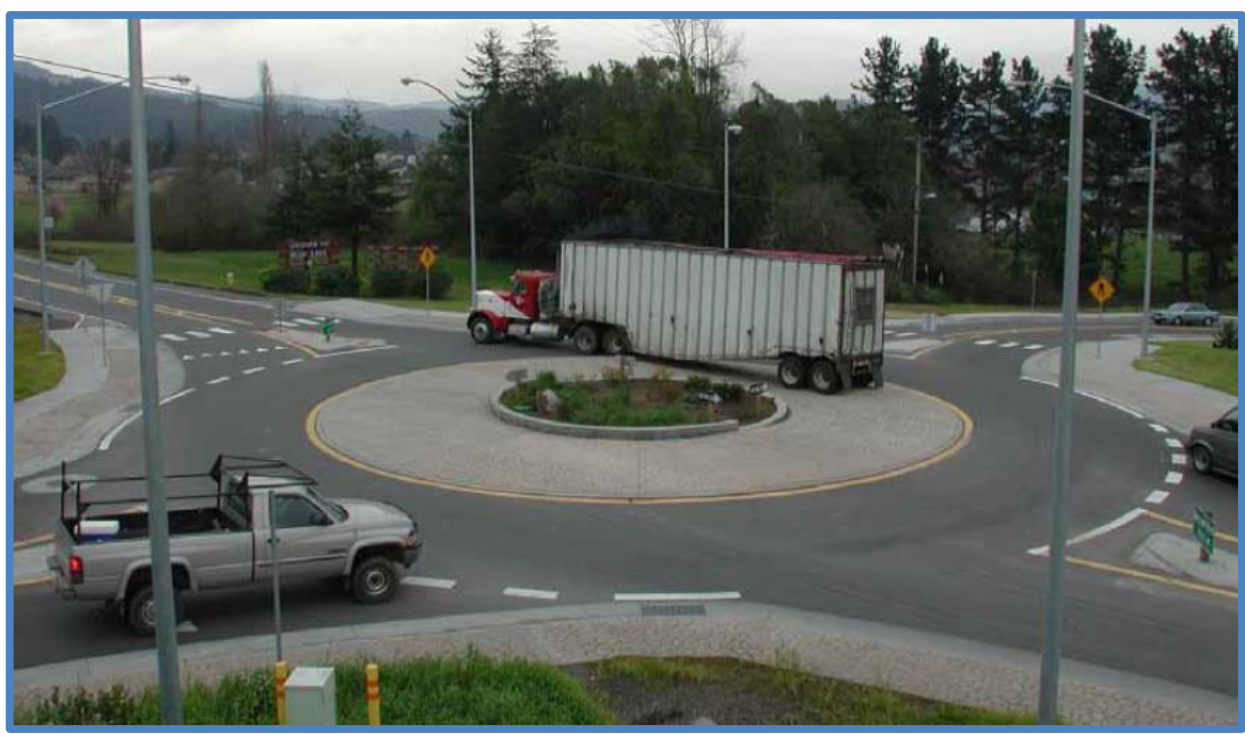

Figura 2. 45 Glorieta con gorjal.

Fuente: Weinberger, 2005. 


\subsubsection{Entradas}

El diseño de la entrada es muy importante para la seguridad ya que controla el movimiento de los vehículos que acceden a la glorieta, y por tanto, la velocidad de entrada.

Para definir su geometría es necesario definir tres parámetros que se relacionan entre sí: anchura, borde exterior y borde interior.

\subsubsection{Anchura}

La anchura de entrada es un factor clave en la capacidad. Debe ajustarse al mínimo estricto que permita acomodar el paso del vehículo patrón ya que una anchura moderada favorece la adecuada deflexión de velocidades y, por tanto, la seguridad.

Los valores de referencia especificados en las diferentes normas se han representado en el Tabla 2.8.

\begin{tabular}{|l|c|c|c|c|c|c|}
\hline \multirow{2}{*}{\multicolumn{1}{|c|}{ Norma }} & \multicolumn{3}{c|}{ Un carril } & \multicolumn{3}{c|}{ Dos carriles } \\
\cline { 2 - 8 } & Mín(m) & Máx(m) & Rec.(m) & Mín(m) & Máx(m) & Rec.(m) \\
\hline MOPU, 1989 & 2,5 & -- & -- & -- & -- & -- \\
\hline SETRA, 1998 & 2,2 & -- & 4 & 6 & -- & 7 \\
\hline QDMR, 2006 & 3,4 & $4-5$ & -- & 6,8 & 8 & -- \\
\hline HA, 2007 & 3 & 4,5 & 4,5 & 6 & 7 & -- \\
\hline NCHRP, 2010 & 4,2 & 5,5 & 4,6 & -- & -- & $7,3-9,1$ \\
\hline
\end{tabular}

Tabla 2.8 Anchura de entrada en las principales normas de diseño.

La frecuencia de los conflictos entre los vehículos que acceden a la intersección y los que circulan por la calzada anular (tipo 3) aumenta con el incremento del valor de la anchura de entrada (NCHRP, 2010). 
En casos con dificultad para conseguir una adecuada moderación de las velocidades, es preferible limitar el valor de la anchura en la entrada proporcionando áreas reservadas en las márgenes para su exclusiva ocupación por los vehículos de mayor longitud (QDMR, 2006).

Otra posibilidad que se recoge en las normas es realizar un aumento gradual de la anchura hasta llegar a la señal de "Ceda el Paso". Esto permite un aumento de la capacidad considerable (Kimber, 1980) sin un efecto directo en la seguridad (NCHRP, 2010). Los carriles segregados para el giro directo también pueden considerarse en el diseño.

En resumen, la anchura de la entrada es un parámetro clave en la capacidad, aunque su valor debe limitarse para no perjudicar el objetivo de la deflexión de las velocidades. En glorietas de un carril, los valores recomendados suelen estar entre 4 y $5 \mathrm{~m}$ (menores valores para glorietas de ámbito local). En glorietas de dos carriles, la anchura de cada carril suele estar comprendido entre 3 y $4 \mathrm{~m}$.

\subsubsection{Bordes exterior e interior (radio exterior e interior de entrada)}

El borde exterior presenta dos funciones principales: guiado de los vehículos hacia la glorieta y propiciar la deceleración de los vehículos en la entrada.

Para definir su geometría es habitual, principalmente en glorietas de un carril, trazar un arco tangente entre el borde derecho de la calzada de aproximación y el círculo inscrito tal y como se ha representado en la Fig.2.46. Este tipo de construcción favorece el guiado de los vehículos (Kennedy, 2005). De forma general, es la construcción recomendada en todas las normas.

Aunque el trazado de la entrada en glorietas multicarril siguiendo este método puede resultar más complejo, McCulloch (2011) recomienda utilizar esta misma configuración desplazando la alineación del eje del acceso hacia la izquierda respecto del centro del anillo. 
Para definir el borde interior se procede de forma análoga realizando un círculo tangente a la isleta central. Este elemento, junto con el borde interior en la salida, define la isleta deflectora.

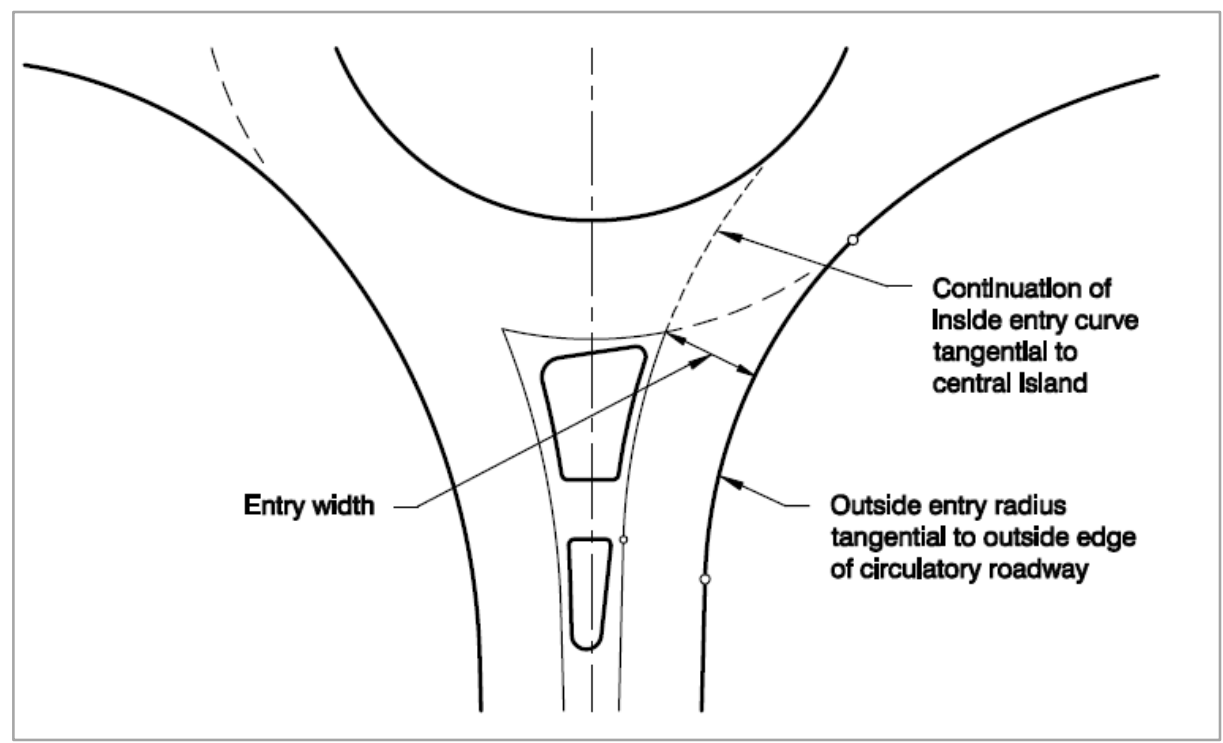

Figura 2. 46 Trazado de la entrada. Fuente: NCHRP, 2010.

Para la Norma de Australia (QDMR 2006) este parámetro es el más importante en el diseño de la planta de una glorieta. Su efecto es muy importante para la seguridad ya que al permitir moderar las velocidades permite reducir los tipos de accidentes por alcance (tipo 2) y el que se produce entre los vehículos que entran y los que circulan por la calzada anular (tipo 3 ).

En glorietas de uno y dos carriles los valores recomendados por las normativas de referencia se han representado en la Tabla 2.9.

\begin{tabular}{|l|c|c|c|c|c|c|}
\hline \multirow{2}{*}{ Norma } & \multicolumn{3}{|c|}{ Un carril } & \multicolumn{3}{c|}{ Dos carriles } \\
\cline { 2 - 7 } & Mín(m) & Máx(m) & Rec.(m) & Mín(m) & Máx(m) & Rec.(m) \\
\hline MOPU, 1989 & 6 & 100 & -- & 6 & 100 & -- \\
\hline SETRA, 1998 & $>\mathrm{R}_{\mathrm{g}}$ & -- & $10-15$ & $>\mathrm{R}_{\mathrm{g}}$ & -- & -- \\
\hline QDMR, 2006 & $>\mathrm{R}_{\mathrm{g}}$ & -- & -- & $>\mathrm{R}_{\mathrm{g}}$ & -- & -- \\
\hline HA, 2007 & 6 & 100 & -- & 6 & 100 & -- \\
\hline NCHRP, 2010 & -- & -- & $15-30$ & 20 & -- & -- \\
\hline
\end{tabular}

$\mathrm{R}_{\mathrm{g}}=$ radio del círculo inscrito

Tabla 2.9 Radio exterior de entrada en las principales normas de diseño. 
Una disposición que proponen las normas de Australia (QDMR, 2006; AUSTROADS, 2011) en entornos de altas velocidades de circulación es intercalar curvas sucesivas de diferente radio antes del borde exterior de entrada. De esta forma, se obliga a los vehículos a recorrer nuevas alineaciones circulares que aumentan la deflexión en el perfil de las velocidades y permiten escalonarla (ver apartado 2.4.9).

En definitiva, el trazado de la curva de aproximación es un parámetro muy importante en la consecución de una adecuada deflexión de las velocidades. Debe permitir el guiado de los vehículos de forma adecuada y hay que limitar su valor para no propiciar velocidades excesivas en la entrada. Su valor depende del tamaño de la glorieta. En glorietas de un carril, se puede aceptar un rango de valores de entre 15 y 30m. En glorieta de dos carriles, los valores recomendados son más difíciles de cuantificar, aunque se puede establecer un mínimo de $20 \mathrm{~m}$.

\subsubsection{Salidas}

El radio exterior de salida debe promover una salida fácil de la calzada anular por lo que, de forma general, presenta valores superiores a su homólogo en la entrada. Esto permite minimizar la probabilidad de accidentes y la congestión de los tráficos (NCHRP, 2010).

Su trazado está condicionado por la presencia de los pasos de peatones situados aguas abajo, por lo que los radios muy amplios pueden resultar contraproducentes por inducir elevadas velocidades en los vehículos.

Como sucedía en el caso de las entradas, para su definición es necesario fijar tres valores: anchura, borde exterior y borde interior.

La construcción recomendada es mediante formas circulares tal y como se muestra en la Fig. 2.47. 


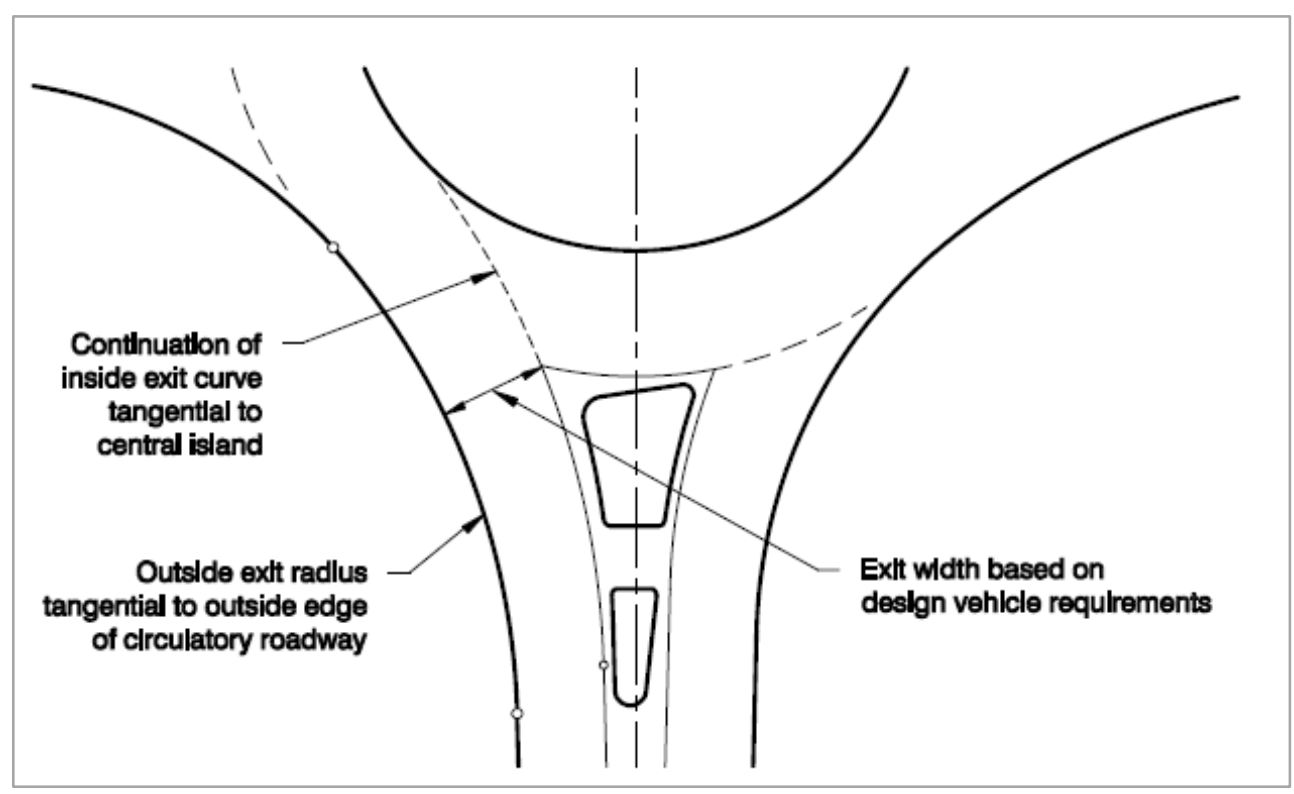

Figura 2. 47 Trazado de las salidas.

Fuente: NCHRP, 2010.

\subsubsection{Anchura}

Los valores recomendados en las normativas de referencia para la anchura de salida se han resumido en la Tabla 2.10 .

\begin{tabular}{|l|c|c|c|c|c|c|}
\hline \multirow{2}{*}{ Norma } & \multicolumn{3}{c|}{ Un carril } & \multicolumn{3}{c|}{ Dos carriles } \\
\cline { 2 - 7 } & Mín(m) & Máx(m) & Rec.(m) & Mín(m) & Máx(m) & Rec.(m) \\
\hline MOPU, 1989 & 6 & -- & -- & -- & -- & -- \\
\hline SETRA, 1998 & -- & -- & $4-5$ & -- & -- & 7 \\
\hline QDMR, 2006 & 4 & 5 & & 6,8 & 8 & \\
\hline HA, 2007 & -- & -- & $7-7,5$ & -- & -- & $10-11$ \\
\hline NCHRP, 2010 & -- & -- & -- & -- & -- & -- \\
\hline
\end{tabular}

Tabla 2. 10 Anchura de salida en las principales normas de diseño.

\subsubsection{Curva de salida (radio de salida)}

Para el tipo de construcción a aplicar en la curva de salida se pueden realizar las mismas consideraciones que para el caso de la entrada. 
Los valores recomendados en las normas de referencia se resumen en la Tabla 2.11.

\begin{tabular}{|l|c|c|c|c|c|c|}
\hline \multirow{2}{*}{\multicolumn{1}{|c|}{ Norma }} & \multicolumn{3}{c|}{ Un carril } & \multicolumn{3}{c|}{ Dos carriles } \\
\cline { 2 - 8 } & Mín(m) & Máx(m) & Rec.(m) & Mín(m) & Máx(m) & Rec.(m) \\
\hline MOPU, 1989 & 20 & -- & -- & -- & -- & -- \\
\hline SETRA, 1998 & $15 \mathrm{y}>\mathrm{R}$ & 30 & -- & $15 \mathrm{y}>\mathrm{R}$ & 30 & -- \\
\hline QDMR, 2006 & $>\mathrm{R}$ & -- & -- & $>\mathrm{R}$ & -- & -- \\
\hline HA, 2007 & 20 & 100 & 40 & -- & -- & -- \\
\hline NCHRP, 2010 & 15 & -- & $30-60$ & 15 & -- & $30-60$ \\
\hline
\end{tabular}

Tabla 2.11 Radio de salida en las principales normas de diseño.

En definitiva, en el diseño de la salida suelen adoptarse valores superiores respecto a su homólogo en la entrada. Por este motivo, hay que comprobar las velocidades de los vehículos principalmente en proyectos con presencia de pasos de peatones. En glorietas de un carril, la anchura se define en un rango de entre 4 y 7,5m (menores valores en glorietas de ámbito local), mientras que el radio puede establecerse a partir de los $15 \mathrm{~m}$ y hasta los 100m. En glorietas de dos carriles, la anchura puede fijarse entre 7 y $11 \mathrm{~m}$.

\subsubsection{Isletas deflectoras}

La isleta deflectora es una zona que no debe ser pisada por los vehículos y se define a través de las bandas interiores de entrada y salida para cada acceso. Presenta las siguientes funciones: guiado de los vehículos en la maniobra de salida, asistencia al control de las velocidades, refugio en los pasos de peatones, separación de los tráficos de entrada y salida, y espacio para la implantación de la señalización vertical.

La tipología de la isleta deflectora determina el trazado de las entradas y salidas. Según el Borrador de la Instrucción de Glorietas de la Generalitat de Catalunya (GC, 2006) las isletas en glorietas se clasifican de acuerdo a tres tipos: 
- Tipo 1. Mediante formas curvadas. Es la tipología recomendada y que se ha presentado en los apartados 2.4.6 y 2.4.7.

- Tipo 2. Triangulares. El trazado del borde exterior en la entrada se compone de una recta intermedia y dos alineaciones curvas: una tangente a la alineación de acceso y a la recta intermedia, y otra, tangente a la recta intermedia y el diámetro exterior. Para el borde interior se procede de forma análoga realizando la tangencia con el eje de la alineación del acceso y con la isleta central.

Esta tipología sigue los criterios de diseño de la norma de Francia (SETRA, 1998a) y permite obtener un espacio adicional para el refugio de peatones en comparación con el Tipo 1 tal y como se muestra en la Fig.2.48.

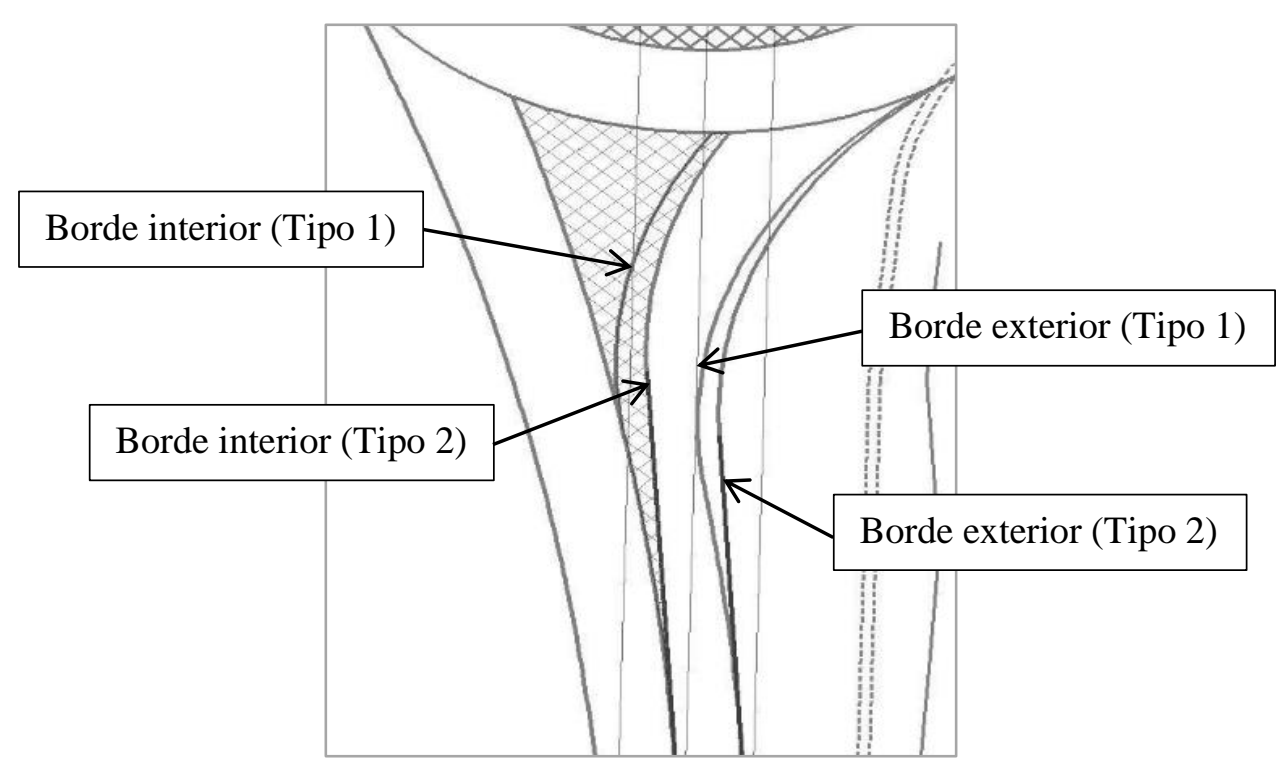

Figura 2. 48 Construcción para conseguir espacio adicional en isletas.

Fuente: McCulloch, 2008.

- Tipo 3. Con mediana central. El trazado mediante formas curvadas se complementa mediante la formación de una mediana que permite alargar la longitud de la isleta deflectora. Para su definición se procede de forma análoga a la descrita para el Tipo 1. Esta configuración puede ser recomendable en entornos de altas velocidades y en medios urbanos.

Las tres tipologías presentadas se han representado en la Fig.2.49. 


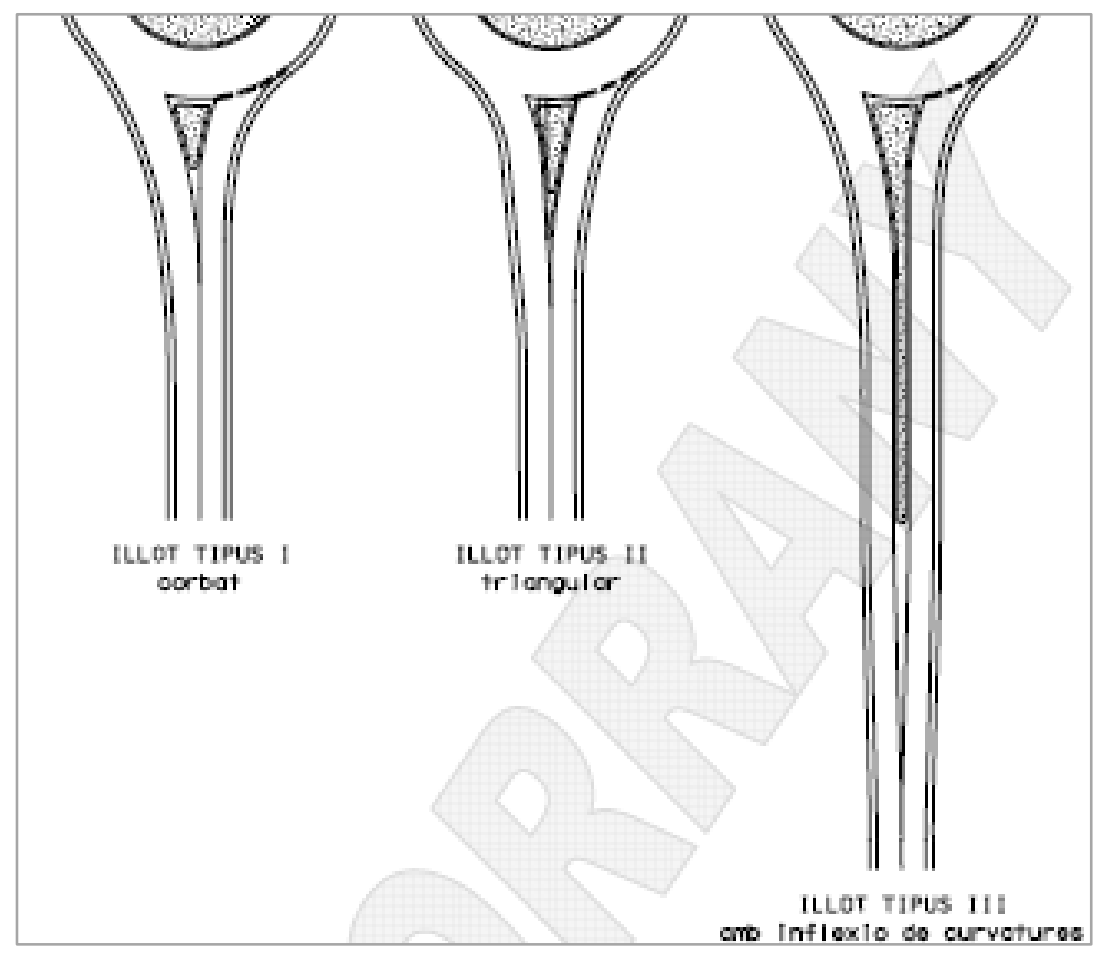

Figura 2. 49 Tipología de isletas deflectoras.

Fuente: GC, 2006.

Los valores recomendados por las normas de referencia se muestran en la Tabla 2.12.

\begin{tabular}{|l|c|c|c|c|c|c|}
\hline \multirow{2}{*}{ Norma } & \multicolumn{3}{c|}{ Un carril } & \multicolumn{3}{c|}{ Dos carriles } \\
\cline { 2 - 7 } & Mín(m) & Máx(m) & Rec.(m) & Mín(m) & Máx(m) & Rec.(m) \\
\hline MOPU, 1989 & 20 & 50 & -- & 20 & 50 & -- \\
\hline SETRA, 1998 & -- & -- & D/2 & -- & -- & D/2 \\
\hline QDMR, 2006 & -- & -- & 60 & -- & -- & 60 \\
\hline HA, 2007 & 20 & 50 & -- & 20 & 50 & -- \\
\hline NCHRP, 2010 & 15 & -- & $30-45$ & 15 & -- & $30-45$ \\
\hline
\end{tabular}

Tabla 2. 12 Longitud de las isletas deflectoras según las principales normas de diseño.

Por tanto, los valores recomendados oscilan entre $20 \mathrm{~m}$ y $60 \mathrm{~m}$. 


\subsubsection{Otros elementos de diseño}

\subsubsection{Carriles modificados en las entradas}

Como se ha comentado, una buena práctica para promover la moderación de las velocidades en la entrada es intercalar una serie de curvas sucesivas de valor decreciente y signo contrario.

En la Fig.2.50 se muestra el ejemplo incluido en las normas de Australia (QDMR, 2006; AUSTROADS, 2011), país donde se ha desarrollado esta solución. El trazado de la entrada se ha definido mediante una alineación circular a izquierdas de radio $200 \mathrm{~m}$ $(\mathrm{v}=90 \mathrm{~km} / \mathrm{h})$, una alineación circular a derechas de radio $100 \mathrm{~m}(\mathrm{v}=74 \mathrm{~km} / \mathrm{h}) \mathrm{y}$, por último, una alineación circular a izquierdas de $45 \mathrm{~m}$ de radio ( $=59 \mathrm{~km} / \mathrm{h}$ ). Téngase en cuenta que en este país la circulación en la calzada anular es horaria.

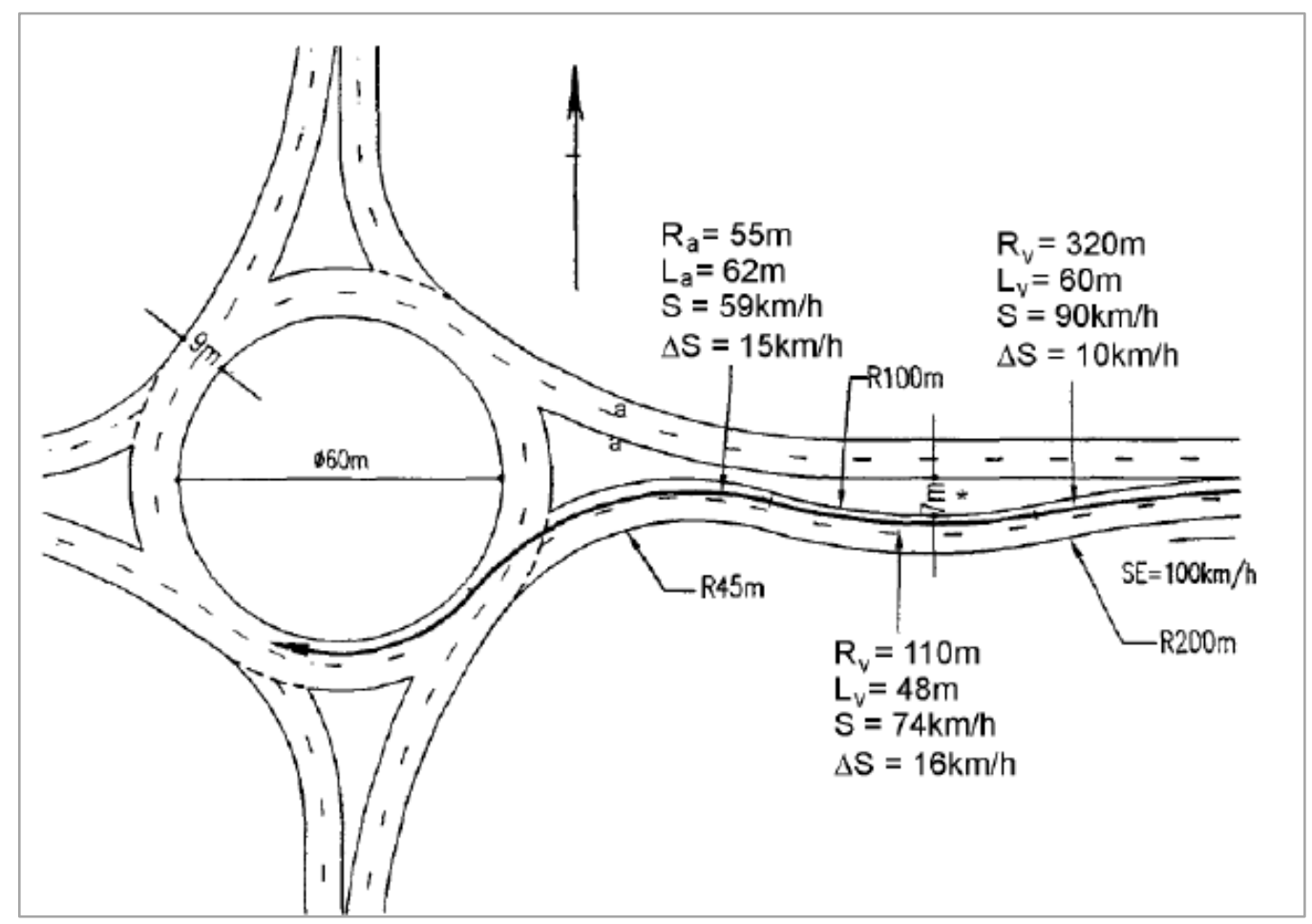

Figura 2. 50 Curvas sucesivas en el carril de entrada a una glorieta. Fuente: QDMR, 2006. 


\subsubsection{Abocinamiento del carril de entrada}

Con el objetivo de mejorar las condiciones de capacidad puede aumentarse la anchura de la entrada de los accesos. Es una técnica recomendada en las normas de diseño debido a su eficacia en la mejora de la capacidad de la entrada. Se puede realizar de dos formas. En la primera, la anchura se genera de manera gradual en una determinada longitud tal y como se muestra en la Fig.2.51. En la segunda, se realiza una duplicación del carril de entrada insertando un carril de cambio de velocidad (Fig.2.52).

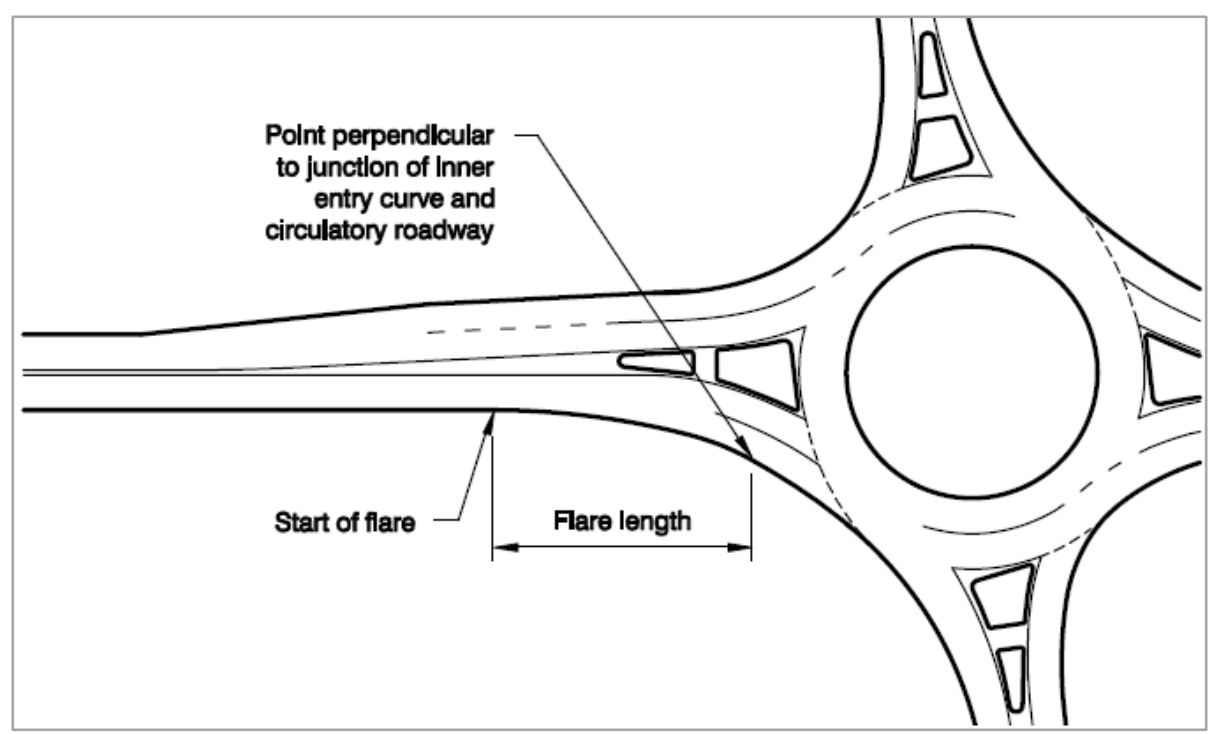

Figura 2. 51 Abocinamiento de la entrada de forma gradual.

Fuente: NCHRP, 2010.

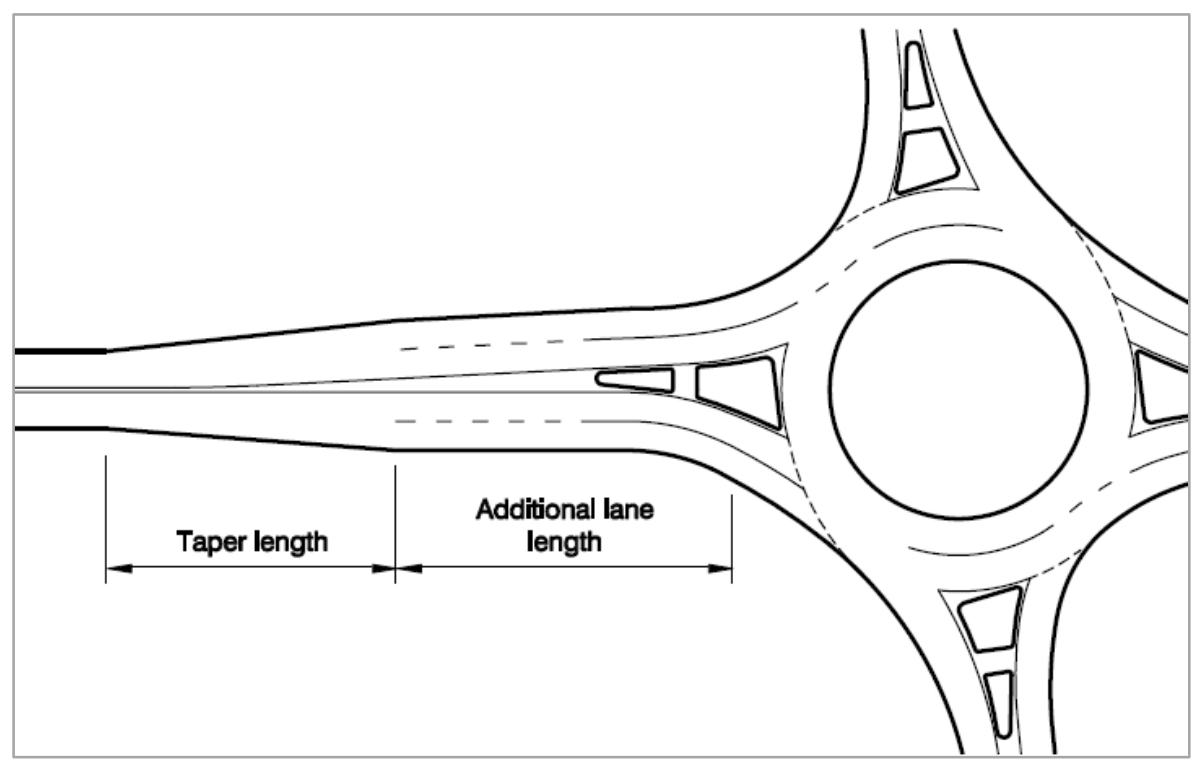

Figura 2. 52 Duplicación del carril de entrada mediante carril de cambio de velocidad. Fuente: NCHRP, 2010. 


\subsubsection{Carriles segregados de giro directo}

Se puede plantear la separación del giro directo entre una entrada y la salida consecutiva mediante un carril adyacente a la glorieta. Los objetivos son: facilitar el flujo de giro a la derecha (o a la izquierda en países con circulación por la izquierda), mejorar la capacidad y minimizar el número de puntos de conflicto.

Tracz (2011) propone una clasificación de estos carriles según varios criterios. El primero, se basa en la forma en la que se materializa el carril en el inicio (divergencia directa, carril de cambio de velocidad y carril con cuña de velocidad). El segundo, es similar al primer criterio pero considera el tipo de conexión en el final del carril. El tercer criterio tiene que ver con la posición del carril respecto a la calzada anular con tres tipos: pasa directamente por el anillo, con separación mediante una isleta e independiente a la calzada anular. La autora recomienda analizar las velocidades y el espacio requerido para el paso de vehículos. La vida útil de la glorieta puede extenderse debido al aumento de la capacidad.

En la norma de Trazado de España (MF, 2016) se establece que los carriles segregados para girar a la derecha se deben justificar exhaustivamente y se proyectarán bajo las siguientes condiciones:

- En la hora de proyecto del año horizonte realice dicha maniobra más del cincuenta por ciento (> $50 \%$ ) de los vehículos de esa entrada o sea superior su número a trescientos vehículos (> 300 veh).

- La entrada disponga, al menos, de dos carriles (incluidos los adicionales) y se destine uno al giro segregado.

- Inexistencia de conexiones o accesos a lo largo del carril segregado.

\subsubsection{Angulo de entrada}

Para analizar el efecto de la visibilidad hacia la izquierda (o hacia la derecha con circulación por la izquierda) algunas normas proponen el cálculo del ángulo de entrada definido con anterioridad. 
En las Recomendaciones sobre glorietas de España se indica que (MOPU, 1989): los ángulos pequeños obligan a los conductores a mirar hacia atrás, propiciando velocidades elevadas en la entrada; los ángulos demasiado grandes también afectan al funcionamiento, pues favorecen los conflictos en forma de cruce.

Los valores típicos recomendados por la Norma de España (MOPU, 1989) y Reino Unido (HA, 2007) para el ángulo de entrada se encuentran entre 20 y $40^{\circ}$, con un óptimo de $25^{\circ}$. En la norma de Trazado de España (MF, 2016) se recomienda que este ángulo esté comprendido entre $45^{\circ}$ y $67^{\circ}$.

\subsubsection{Influencia de los parámetros de diseño en la capacidad y la seguridad.}

A modo de resumen, se presenta en la Tabla 2.13 la influencia de los elementos de diseño descritos en las condiciones de capacidad y seguridad.

\begin{tabular}{|l|c|c|}
\hline \multicolumn{1}{|c|}{ Elemento de diseño } & Seguridad & Capacidad \\
\hline Diámetro exterior grande & Menos seguro & Mejor \\
\hline Aumento de la anchura de la calzada anular & Menos seguro & Mejor \\
\hline Aumento de la anchura de entrada & Menos seguro & Aumenta \\
\hline Radio del borde exterior de entrada grande & Menos seguro & Mejor \\
\hline Importante ángulo entre accesos & Más seguro & Disminuye \\
\hline Bajo ángulo de entrada & Pobre visibilidad & Mejor \\
\hline Aumento gradual de la anchura en la entrada & Neutro & Mejor \\
\hline
\end{tabular}

Tabla 2. 13 Influencia de los elementos de diseño en la capacidad y la seguridad. Fuente: Khulow, 2011.

Como se observa, los elementos de diseño influyen de manera diferente en los objetivos del trazado en planta. Esta interacción entre los parámetros de diseño provoca que el encaje geométrico se convierta en una tarea compleja y que necesariamente deba analizarse desde una perspectiva global. 


\subsection{ProcedimiEnTos HeURísticos DE OPTIMIZACIÓN}

\subsubsection{Introducción}

En este apartado se presentan una serie de técnicas que se han desarrollado para permitir la búsqueda de una buena solución (no necesariamente la óptima) a problemas difíciles de un modo sencillo y rápido, analizando la posibilidad de aplicarlas en el proceso de definición del trazado de una glorieta.

El estudio se ha dividido en cuatro apartados. En primer lugar, se describirá brevemente la disciplina de la Investigación de Operaciones y la metodología que propone ésta para definir un modelo de optimización. A continuación, se realiza una revisión de las herramientas de programación matemática que permiten resolver los modelos de optimización y las principales aplicaciones llevadas a cabo hasta la fecha actual en el diseño de vías y glorietas. Por último, se realiza un análisis general de las características y el funcionamiento de los algoritmos evolutivos.

\subsubsection{La Investigación de Operaciones.}

La Investigación de Operaciones (IO) es una rama de las matemáticas que se ocupa de la aplicación de métodos científicos en los procesos de toma de decisiones. El objetivo de esta disciplina es encontrar la mejor solución posible para un problema determinado.

El origen de la IO se sitúa en el período que comprende la Segunda Guerra Mundial cuando los servicios militares del bando aliado experimentaron una urgente necesidad de posicionar de forma óptima los recursos armamentísticos.

El progreso de las posiciones teóricas y los computadores en los años siguientes hicieron que esta disciplina se extendiera a otros ámbitos del conocimiento, como son la industria, la economía y la ingeniería entre otros. El desarrollo de la Investigación de Operaciones sigue vigente en nuestros días como es, por ejemplo, en el área de la Inteligencia Artificial. 
Según sea el objetivo que se persiga, los problemas que aborda la IO se pueden clasificar en modelos de optimización o de predicción (Merino, 2013). En los primeros, el objetivo es maximizar o minimizar una cantidad sujeta a una serie de restricciones. En los segundos, el objetivo es predecir sucesos dadas ciertas circunstancias. En la presente investigación se desarrolla un modelo de optimización.

La metodología general que contempla la IO para definir un modelo de optimización puede resumirse en los siguientes puntos (Hillier y Lieberman, 2010):

1. Definición del problema. Identificación de los elementos clave, los objetivos y las condiciones del problema. Es necesario extraer toda la información relevante.

2. Formulación del modelo matemático. Definición del problema mediante un lenguaje algebraico de una manera sintetizada, simplificando la realidad y extrayendo los componentes fundamentales para su resolución. Las conclusiones obtenidas en el modelo serán aceptadas como válidas para el sistema al que representa.

El modelo matemático está conformado por las variables de decisión, la función objetivo y el sistema de restricciones. Las variables de decisión son cantidades numéricas cuyos valores son determinados por la solución del modelo de optimización. La medida del desempeño adecuado para las variables se realiza a través de la función objetivo. El sistema de restricciones impone condiciones que deben cumplir las variables. Es necesario analizar el tamaño y la estructura del problema e identificar la herramienta de programación matemática para el cálculo.

3. Resolución mediante técnicas de programación matemática. Consiste en determinar los valores de las variables que hacen máxima o mínima, según la definición que se haya realizado, la función objetivo cumpliendo con el sistema de restricciones. Se pueden emplear diferentes técnicas de programación matemática para su resolución.

4. Verificación, validación y modificación. Definición de experimentos que evalúen la compatibilidad del modelo y sus simplificaciones con la realidad. Se modifica el modelo si es necesario. 
5. Análisis de resultados. Se estudia la robustez de la solución y se realiza un análisis de sensibilidad.

6. Implementación y desarrollo. En el último estadio se redacta la documentación relativa al funcionamiento del modelo y se expone para su posterior uso.

\subsubsection{Herramientas de programación matemática.}

La resolución de un problema de optimización requiere el uso de una herramienta de programación matemática. Se han desarrollado muchos algoritmos, que pueden clasificarse en dos grandes grupos: métodos exactos y métodos aproximados.

En los métodos exactos, se realiza una búsqueda exhaustiva entre un conjunto de soluciones posibles. Este tipo de métodos si bien alcanzan la solución óptima de forma global, presentan varios inconvenientes. En primer lugar, para muchos problemas de interés no se han desarrollado algoritmos exactos. En segundo lugar, la velocidad de cálculo limita el número de variables que se pueden considerar. Ello da lugar a que, aunque se consiga definir el problema, puede que sea inabordable computacionalmente. Por último, presentan una elevada rigidez derivada de su dependencia con la forma de definir el problema, de tal forma que si se modifican las condiciones se tiene que diseñar un nuevo algoritmo y demostrar que se alcanza la solución óptima.

Cuando el número de variables es muy elevado, la función objetivo presenta mucho ruido y discontinuidades, puede ser conveniente buscar una solución aproximada, que se acerque al óptimo, si con ello se reducen los tiempos y la complejidad de los cálculos y se mejora la convergencia. Las técnicas heurísticas-metaheurísticas ${ }^{14}$ permiten realizar búsquedas bajo estas condiciones de manera eficiente.

\footnotetext{
${ }^{14}$ Existe una diferencia sutil entre el término heurística y metaheurística. El primero, hace referencia a procedimientos simples que se supone que obtendrán una buena solución (no necesariamente la óptima) a problemas difíciles de un modo sencillo y rápido. El segundo, hace referencia a un procedimiento iterativo que guía y que modifica las operaciones de una heurística subordinada para producir eficientemente soluciones de alta calidad.
} 
En los procedimientos heurísticos se explora el espacio de soluciones en base a la experiencia adquirida en el proceso de búsqueda. Yepes (2002) clasifica estas técnicas en tres subgrupos:

- Búsqueda secuencial por entornos. El proceso de búsqueda se realiza explorando el entorno de una solución de partida y analizando si se produce mejora con el movimiento discreto realizado en este entorno. A este subgrupo pertenecen entre otros la búsqueda tabú (Glover, 1983), la técnica del recocido (Kirkpatrick et al., 1983) y el algoritmo del solterón (Hu et al., 1995).

- Métodos basados en poblaciones. Se procede generando una familia inicial, que representa un conjunto de soluciones potenciales al problema, la cual va evolucionando para acercarse a la solución del problema. A este grupo pertenecen, entre otros, los algoritmos genéticos (Holland, 1962a; Holland, 1962b), los algoritmos meméticos (Moscato, 1989) y la búsqueda dispersa (Glover et al., 2002).

- Redes neuronales. Presentan un funcionamiento inspirado en las redes neuronales biológicas.

\subsubsection{Aplicaciones en el diseño de carreteras}

La IO ha sido empleada por los investigadores dedicados a la mejora de las técnicas de trazado en ingeniería de carreteras.

La mayoría de los investigadores plantean el problema de diseño de una carretera como un problema de optimización en el cual el objetivo es la minimización del coste de la obra, adoptando como variables de decisión los vértices de la poligonal que permite definir el trazado. El problema presentará diferentes restricciones que tienen que ver con la propia geometría, el drenaje, medioambiente,...etc. 
La optimización del trazado se ha realizado de manera independiente para la planta y el alzado, o de manera simultánea. Kim et al. 2003 analizan las principales investigaciones realizadas sobre la optimización del trazado de acuerdo a la técnica de programación matemática utilizada (Tabla 2.14). Los autores concluyen que los algoritmos genéticos constituyen una buena herramienta para resolver el problema de optimización.

\begin{tabular}{|c|c|c|}
\hline $\begin{array}{l}\text { Objetivo de la } \\
\text { optimización }\end{array}$ & Técnica de resolución & Referencias \\
\hline \multirow{14}{*}{$\begin{array}{l}\text { Optimización del } \\
\text { trazado en planta }\end{array}$} & \multirow{5}{*}{ Cálculo de variaciones } & Howard et al. (1968) \\
\hline & & Shaw y Howard (1981) \\
\hline & & Shaw y Howard (1982) \\
\hline & & Thomson y Sykes (1988) \\
\hline & & Wan (1995) \\
\hline & \multirow{6}{*}{ Optimización en redes } & OECD (1973) \\
\hline & & Turner y Miles (1971) \\
\hline & & Athanassoulis y Calogero (1973) \\
\hline & & Parker (1977) \\
\hline & & Trietsch (1987a) \\
\hline & & Trietsch (1987b) \\
\hline & \multirow{2}{*}{ Programación dinámica } & Nicholson et al. (1973) \\
\hline & & Hogan (1973) \\
\hline & Algoritmos genéticos & Jong (1998) \\
\hline \multirow{8}{*}{$\begin{array}{l}\text { Optimización del } \\
\text { trazado en alzado }\end{array}$} & Búsqueda enumerativa & Easa (1988) \\
\hline & \multirow{4}{*}{ Programación dinámica } & Fwa (1989) \\
\hline & & Puy (1973) \\
\hline & & Murchland (1973) \\
\hline & & Goh et al. (1988) \\
\hline & \multirow{2}{*}{ Programación lineal } & ReVelle et al. (1997) \\
\hline & & Chapra y Canale (1988) \\
\hline & Algoritmos genéticos & Jong (1998) \\
\hline \multirow{7}{*}{$\begin{array}{l}\text { Optimización } \\
\text { simultánea de } \\
\text { planta y alzado }\end{array}$} & \multirow{2}{*}{ Programación dinámica } & Nicholson et al. (1973) \\
\hline & & Hogan (1973) \\
\hline & \multirow{2}{*}{ Optimización bi-etapa } & Parker (1977) \\
\hline & & Trietsch (1987a) \\
\hline & \multirow{3}{*}{ Algoritmos genéticos } & Jong (1998) \\
\hline & & Jha (2000) \\
\hline & & Kim (2001) \\
\hline
\end{tabular}

Tabla 2. 14 Investigaciones sobre la optimización del trazado de carreteras. Fuente: Kim et al., 2003. 
En lo que se refiere al diseño de glorietas, no se han desarrollado un número tan importante de investigaciones.

Easa and Mehmood (2004) proponen un modelo que permite optimizar la geometría en planta mediante un algoritmo de programación lineal (método exacto). Los datos de partida del modelo son (Fig.2.53): la posición de la glorieta, las alineaciones de los accesos (perpendiculares entre sí) y el rango de variación de las variables geométricas (anchuras de las calzadas y diámetro de la glorieta).

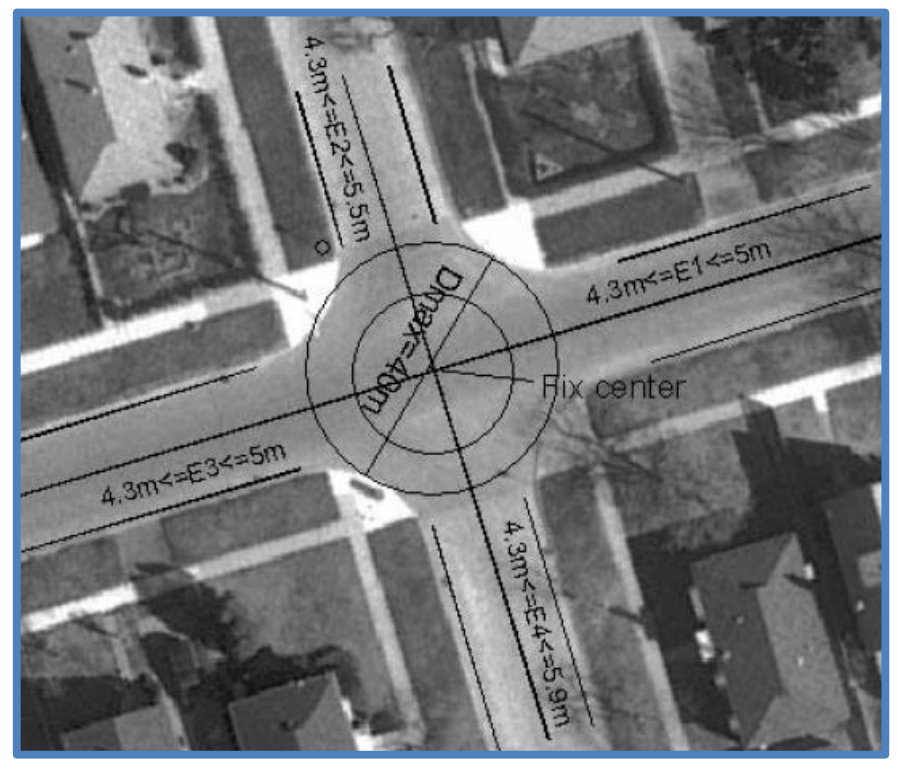

Figura 2. 53 Datos de partida. Modelo de Easa and Mehmood (2004). Fuente: Easa and Mehmood, 2004.

La función objetivo evalúa la consistencia de las velocidades mediante dos indicadores que se definen como el sumatorio de las diferencias de velocidad entre elementos geométricos consecutivos de una misma trayectoria y el sumatorio de las diferencias de velocidad en los puntos de conflicto. Como restricciones se impone que las velocidades resultantes sean inferiores a la velocidad de diseño y que las diferencias de velocidad no superen a un máximo prefijado.

Para poder aplicar la función objetivo, los autores desarrollaron diferentes expresiones mediante las cuales es posible calcular el valor de los radios de las diferentes trayectorias. En la Fig.2.54 se muestra el esquema de cálculo del radio de la trayectoria 
entre un acceso y el opuesto. A partir de los radios de las trayectorias se calculan las velocidades de todos los movimientos.

Cuando se ejecuta el modelo se tiene como resultado el conjunto de trayectorias óptimas que minimizan las diferencias de velocidad y el valor de los parámetros de diseño que permiten dibujar la geometría. Los bordes interiores y exteriores en las entradas y salidas se obtienen a partir de las trayectorias mediante líneas paralelas.

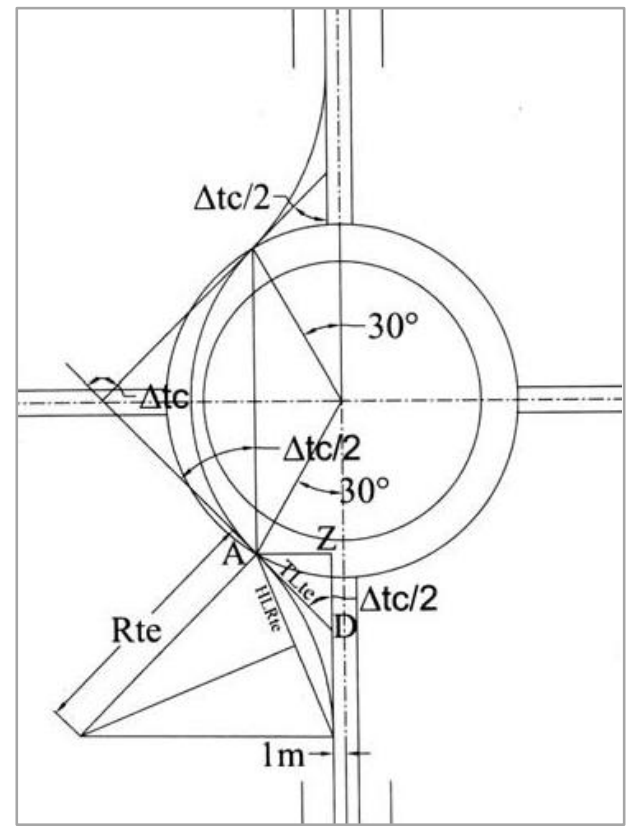

Figura 2. 54 Cálculo de trayectorias. Modelo de Easa and Mehmood (2004). Fuente: Easa and Mehmood (2004).

Aunque se consigue obtener el óptimo global, este trabajo sólo es aplicable en un caso muy sencillo que, en muchas ocasiones, no se da en la práctica: cuatro accesos situados de forma perpendicular. Además, se parte de una posición fija del centro de la glorieta y no se tiene control sobre la geometría de las isletas deflectoras (importante para el acomodo de peatones).

En un segundo trabajo, Mehmood and Easa (2006) proponen una ampliación del modelo incluyendo como nuevo objetivo la capacidad (minimizar colas y retrasos). Para ello se realiza una optimización multiobjetivo que se resuelve mediante técnicas de programación lineal. Este modelo presenta las mismas limitaciones que el primer trabajo. 


\subsubsection{Los algoritmos genéticos}

\subsubsection{Introducción}

Con el objetivo de superar las limitaciones de los métodos tradicionales para resolver los problemas de optimización, en esta investigación se propone el empleo de un algoritmo genético (AG) para realizar la búsqueda del diseño de una glorieta empleando un modelo de optimización. En esta sección se describe de forma resumida en qué consisten estos algoritmos y, con mayor detalle, algunos aspectos específicos de los AGs: la codificación, el sistema de restricciones, los operadores y los parámetros de funcionamiento.

\subsubsection{Descripción general}

Los AGs son un método de optimización heurística basada en una búsqueda al azar de las soluciones. Constituyen una poderosa herramienta para la optimización de problemas complejos, cuyas funciones objetivo tienen demasiadas variables, ruido o discontinuidades, que hacen que las técnicas de optimización clásicas mediante métodos exactos no se pueden aplicar o sean poco eficientes. Estos algoritmos fueron desarrollados por John Holland (Holland, 1975).

Los AGs emulan el comportamiento de la selección natural. Los individuos son soluciones potenciales del problema planteado, y están codificados en unos cromosomas. Cada individuo tiene al menos un cromosoma y cada cromosoma se representa como una cadena numérica donde cada número es un gen, y su posición codifica una variable del problema. El conjunto de individuos conforman la población. Mediante la función objetivo es posible evaluar la calidad de cada individuo (Fig.2.55). 


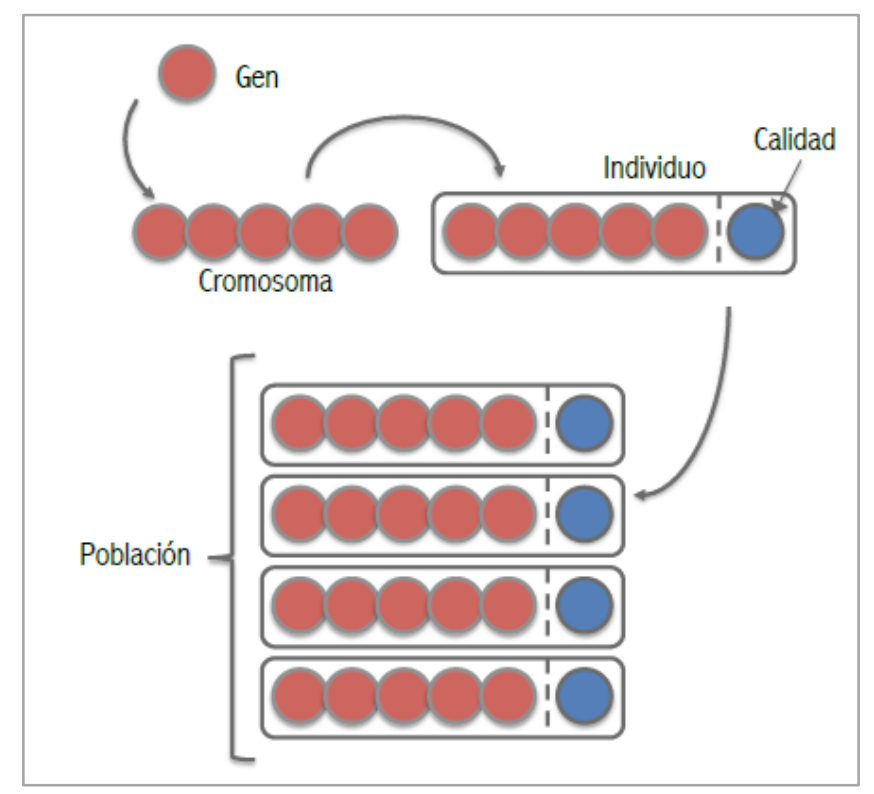

Figura 2. 55 Estructura de la población de un algoritmo genético. Fuente: Caamaño, 2010.

La estructura general de un AG se muestra en la Fig. 2.56. Dada una población inicial, los individuos con mejor valoración en la función objetivo tienen mayor probabilidad de reproducirse (a través de los operadores de selección, cruce y mutación) y pasar a las siguientes generaciones ${ }^{15}$. La población evoluciona a través de las sucesivas generaciones para intentar converger hacia el óptimo global. Las iteraciones continúan mientras se computan mejoras en el valor de la función objetivo de los individuos, aunque también se establece un número mínimo de generaciones para evitar que la solución quede atrapada en un mínimo local. De esta forma se garantiza una buena exploración del espacio de búsqueda.

\footnotetext{
${ }^{15}$ Cada iteración en el proceso de cálculo es denominada generación.
} 


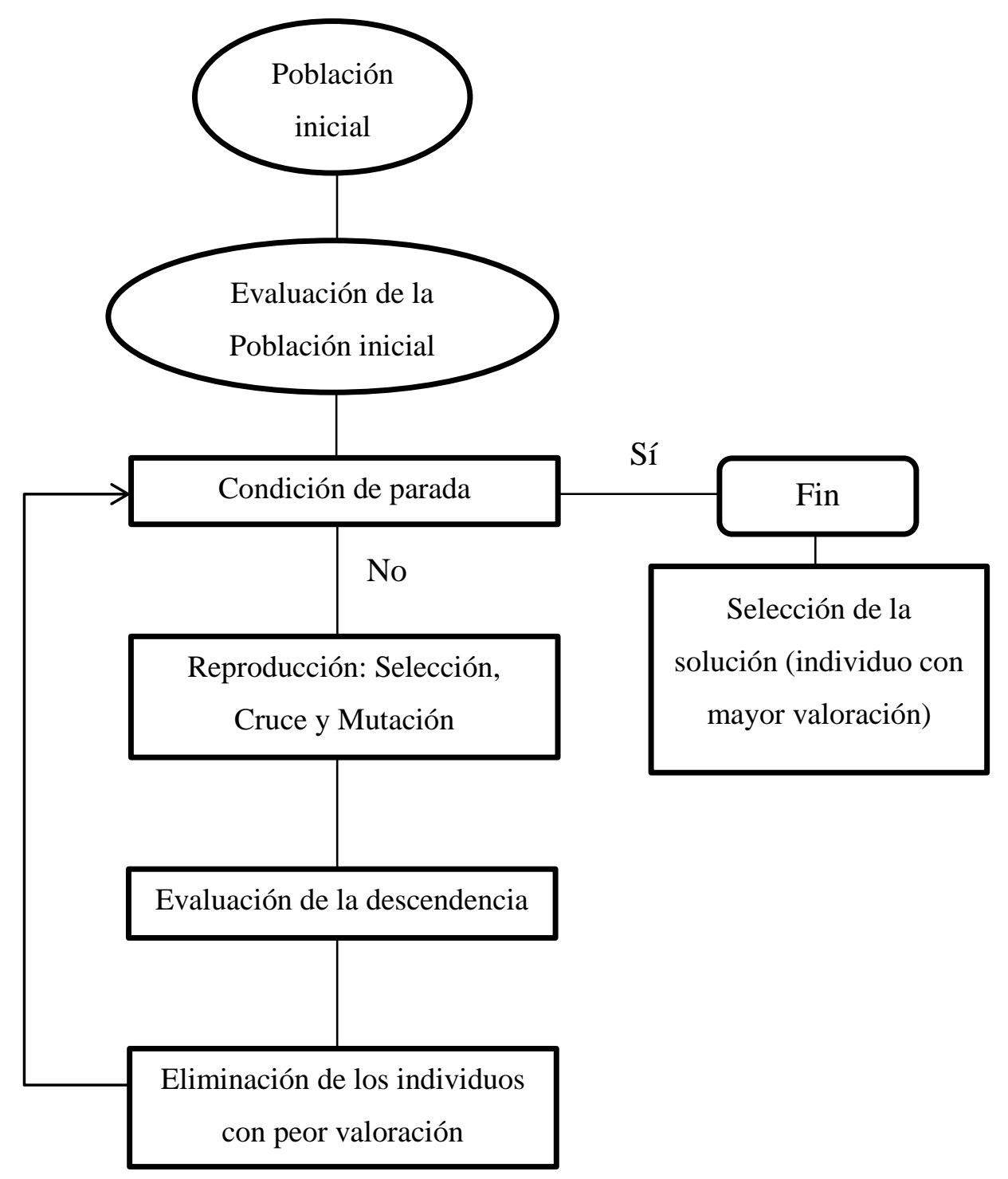

Figura 2.56 Esquema básico de un algoritmo genético.

\subsubsection{Codificación}

La elaboración de un algoritmo genético para la resolución de un problema específico requiere el empleo de una codificación de los individuos. En sus orígenes la codificación se llevaba a cabo empleado números binarios, si bien más recientemente es usual la codificación mediante números reales (Horby, 2003). La longitud de los cromosomas puede ser fija o puede definirse variable a lo largo de las generaciones (Bentley, 2002). 


\subsubsection{Sistema de restricciones}

En los AGs las restricciones se pueden tener en cuenta usando diferentes técnicas. Cuando un individuo viola una restricción, se puede proceder de diferentes maneras (Craenen et al. 2003): i) eliminando el individuo, ii) reparando el individuo para que llegue a ser factible, iii) aplicando operadores especializados de forma que se preserve la factibilidad o iv) imponiendo una penalización que empeore el valor de la función objetivo.

\subsubsection{Operadores}

En este apartado se realiza una breve descripción de los operadores genéticos. La literatura sobre los operadores en los AGs es muy extensa, por lo que si se desea ampliar la información se pueden consultar los textos de Goldberg (1989) y Davis (1991).

El operador de selección permite elegir los individuos que van a reproducirse. Los métodos más comunes son:

- Selección proporcional. Los individuos son seleccionados a partir de una ruleta de probabilidades que se establece en función del valor obtenido en la función objetivo o del ranking de soluciones. Así, los individuos con mayor aptitud tendrán más probabilidades de ser elegidos. Esta técnica fue propuesta originalmente por Holland (1975).

- Selección mediante torneo. La idea básica es realizar una selección de acuerdo a la comparación directa de los individuos que compiten entre sí, normalmente en parejas, en base a su aptitud. Este operador fue desarrollado por Wetzel (1983).

Mediante el operador de cruzamiento se realiza el intercambio de información entre cromosomas de parejas de individuos permitiendo que se amplíe la búsqueda a otros puntos del espacio de diseño. 
En el símil biológico, los cromosomas se alinean, se fraccionan y posteriormente se intercambian fragmentos. En los AGs se simula este comportamiento de forma que se debe seleccionar la localización y la longitud de material genético que se va a intercambiar. Los métodos más utilizados son:

- Cruza de un punto. Se escoge un punto de cruza en la cadena cromosómica de forma aleatoria. Las dos partes resultantes de cada individuo se intercambian tal y como se representa en la Fig.2.57. Esta técnica fue propuesta originalmente por Holland (1975).

- Cruza de dos puntos. Se procede de forma similar pero en este caso se realiza el intercambio seleccionando dos puntos de cruza Fig.2.57. Este operador fue desarrollado por De Jong (1975).
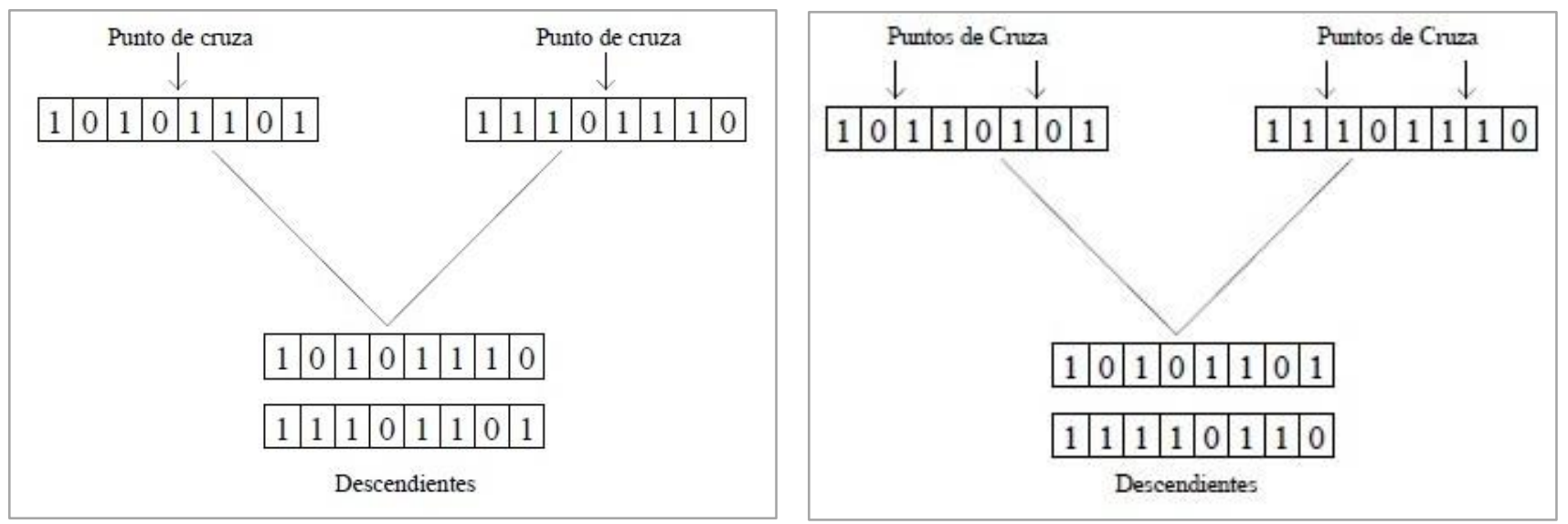

Figura 2.57 Cruza: un punto (a las izquierda) y dos puntos (a la derecha). Fuente: Coello, 2012.

Por último, mediante la mutación se permite la introducción de nuevo material genético en la población tal y como sucede en los sistemas biológicos. Mediante este operador se realiza la modificación de uno o varios genes seleccionados aleatoriamente. De igual forma se han desarrollado varios métodos para definir cómo realizar la mutación. 


\subsubsection{Parámetros}

Los parámetros más importantes para controlar un AG son:

- Tamaño de la población.

- Frecuencia de aplicación de los operadores en cada generación.

- Criterio de parada.

El tamaño de la población determina el número de individuos que se definen en la generación inicial y que generalmente se mantiene en las diferentes generaciones. Si se selecciona un número demasiado bajo, el algoritmo puede tener pocas oportunidades de exploración del espacio de búsqueda ya que existirá poca variabilidad genética. Si se selecciona un número demasiado elevado, se puede complicar la convergencia del algoritmo.

De modo orientativo, algunos valores recogidos en las principales investigaciones son: De Jong (1975) con un tamaño de entre 50 y 100; Grefenstette (1986) con un tamaño de entre 30 y 80; y, por último, Schaffer et al., (1989) con un tamaño de entre 20 y 40.

En cuanto a la frecuencia de aplicación del operador de cruce, mediante este valor se determina el número de veces que debe ser realizado el intercambio de información genética en cada generación. Si se define este concepto en términos de probabilidad, con un $0 \%$ la nueva generación presenta cromosomas que son una copia exacta de los progenitores mientras que con un $100 \%$ toda la descendencia se formaría por recombinación de la información genética de los padres. En las investigaciones citadas con anterioridad se recomiendan los siguientes valores: De Jong (1975) una probabilidad del 60\%; Grefenstette (1986) una probabilidad del 95\%; y, por último, Schaffer (1989) una probabilidad del 75-95\%.

Para la frecuencia de aplicación del operador de mutación se suelen adoptar valores muy inferiores (en las investigaciones citadas $<1 \%$ ).

En cuanto el criterio de parada, se puede establecer varias estrategias: 
- Fijar un número mínimo de generaciones.

- Tiempo máximo de resolución.

- Indicador del estado de la población. Se puede observar si no existe mejora en la función objetivo en un cierto número de generaciones o si se ha perdido diversidad dentro de la población.

También se puede recurrir a una condición mixta, por ejemplo, limitando el número máximo de generaciones y estableciendo algún indicador del estado de la población. 


\section{Capítulo 3. FORMulación del problema de OPTIMIZACIÓN}

\subsection{INTRODUCCIÓN}

En este capítulo se formula un modelo matemático de optimización que permite automatizar el procedimiento de diseño del trazado en planta de glorietas. Las técnicas para su resolución se describen en el siguiente capítulo.

El capítulo se ha dividido en dos apartados. En primer lugar, se presenta un resumen del problema que es objeto de estudio. A continuación, se reformula de manera conveniente para su análisis mediante la construcción de un modelo matemático.

\subsection{DEFINICIÓN DEL PROBLEMA}

El primer paso para poder formular el problema de optimización es comprender la problemática asociada a la definición del trazado en planta de una glorieta. A lo largo de las diferentes secciones incluidas en el capítulo 2 (Antecedentes) se han descrito las etapas del proceso de diseño de una glorieta y las principales consideraciones a tener en cuenta en el mismo. En el diagrama de la Fig.3.1 se resumen mediante un esquema estas etapas. 
RODEL, SIDRA, VISSIM, etc

PROGRAMAS

INTEGRADOS DE OBRAS LINEALES
PROGRAMAS

ESPECIFICOS DE DISENOO (TORUS)

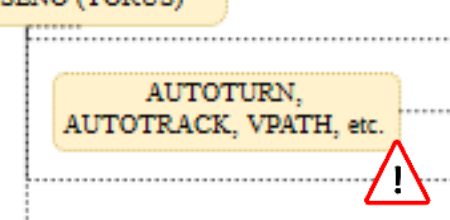

\section{ESTUDIO DE TRÁFICO}

$\downarrow$

CONFIGURACIÓN DE CARRILES

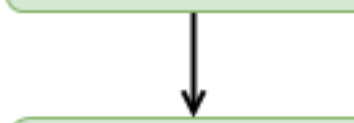

ASIGNACIÓN DE

PARÁMETROS

GEOMÉTRICOS INICIALES

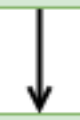

ESTUDIO DE CAPACIDAD

TRAZADO PRELIMIINAR Disposición de las patas de acceso.

Selección del vehículo tipo.

Posición y tamaío de la glorieta.

Necesidades de usuarios no motorizados.

Condiciones particulares del Proyecto.
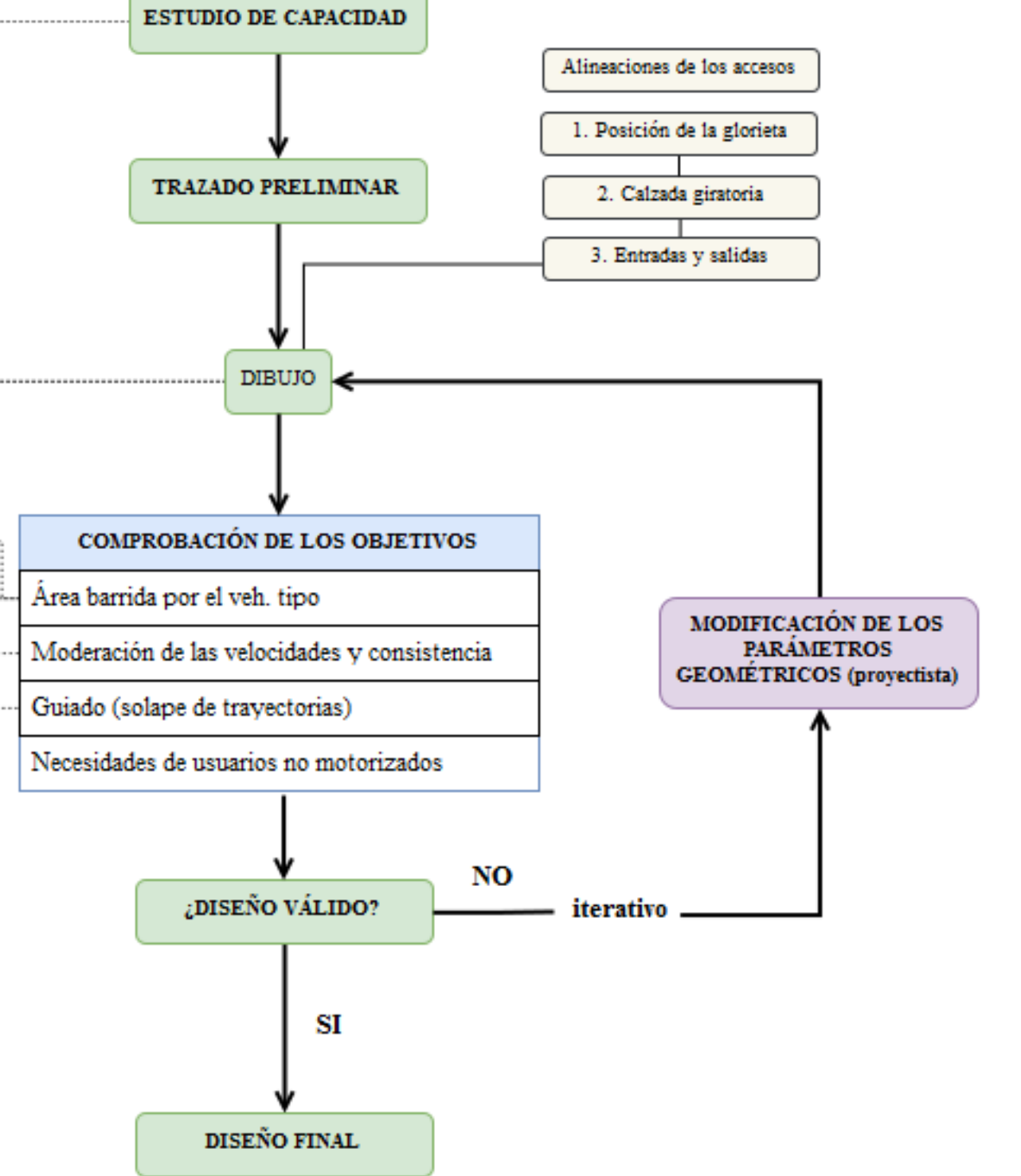

Figura 3. 1 Definición del problema. 


\subsection{MODELO MATEMÁtico}

Para implementar y automatizar el proceso de diseño de una glorieta es necesario construir un modelo matemático que represente la esencia del problema planteado. Se propone un modelo de optimización para llevar a cabo la búsqueda de una solución que satisfaga unos requisitos preestablecidos. Su resolución facilitará la toma de decisiones generando soluciones óptimas, o suficientemente cercanas al óptimo, dados unos objetivos iniciales.

La definición del modelo propuesto se ha realizado de forma escalonada captando diferentes aspectos del problema real, lo que ha permitido considerar unos datos de partida y la definición de las variables de decisión, de la función objetivo y de las restricciones.

En la Fig. 3.2 se identifican los principales elementos del modelo de optimización cuya descripción detallada se completa en los siguientes apartados. Las variables de decisión están representadas por unos parámetros geométricos, cuyos valores permiten llevar a cabo la construcción geométrica de una glorieta. Las necesidades del trazado en planta, a excepción del objetivo de la seguridad, se tratan como restricciones al problema. La calidad de las soluciones viene dada por la respuesta de la geometría frente al objetivo de la moderación de las velocidades y la consistencia (seguridad). Por tanto, para la construcción de la función objetivo es necesario modelar las trayectorias de los vehículos más rápidos y estimar las velocidades. 


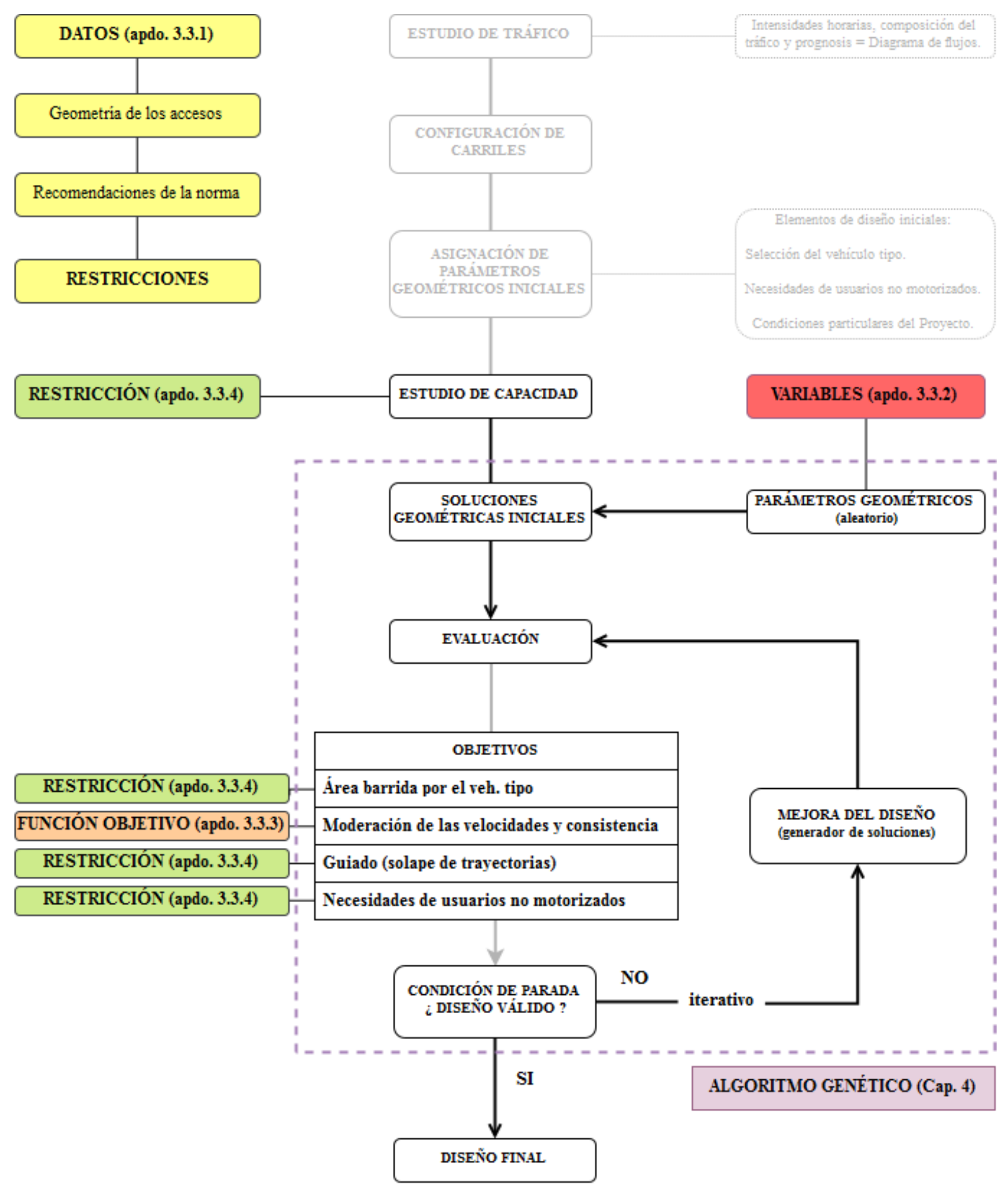

Figura 3. 2 Identificación de los elementos del problema de optimización. 


\subsubsection{Datos de partida}

Los datos de partida están conformados por aquéllos elementos que se mantienen sin modificaciones durante el proceso de búsqueda y por aquella información que sirve de base para la construcción del modelo de optimización.

La información básica de partida está relacionada con:

- La geometría de los $M$ accesos en la aproximación. Hay que considerar los siguientes elementos:

$s_{j}$ : alineaciones de las patas de acceso (rectas), con $j=1,2, \ldots M$.

$W A_{j}$ : anchura de las calzadas, $\operatorname{con} j=1,2, \ldots M$.

- Recomendaciones de la normativa de diseño aplicable.

La definición geométrica de una glorieta se apoya en una norma de diseño. En general ésta proporciona criterios contrastados de diseño que, para esta investigación, se centran en dos aspectos: permite deducir el rango de valores recomendados de las variables que definen la geometría y permite identificar los factores a considerar en el estudio de seguridad. En el primer caso, si se deducen valores recomendados para los parámetros geométricos es posible acotar el espacio de búsqueda, pues se introducen como una restricción al problema (apartado 3.3.4). En el segundo caso, las normas en general proporcionan unos valores sobre los resguardos a respetar en la definición de las trayectorias $\left(d_{1}, d_{2}\right.$, $\left.d_{3}, d_{4} \quad y \quad d_{5}\right)$ y que se definirán en el capítulo 5 , además de otros criterios relacionados con la consistencia y que son trasladados al problema como restricciones (apartado 3.3.4) o como componente de la función objetivo.

- Estudios preliminares. De forma similar a cómo se realiza en la práctica, es necesario completar una serie de estudios de forma previa al inicio del procedimiento. En particular, se deben analizar los tráficos y realizar una asignación de parámetros geométricos iniciales para poder evaluar la capacidad. 
Además se debe seleccionar el vehículo patrón e identificar las necesidades de los usuarios no motorizados si es previsible su presencia en el flujo circulatorio. Los estudios preliminares permiten definir una serie de restricciones $y$ considerar los objetivos del trazado en planta dentro del modelo.

\subsubsection{Variables de decisión}

Las variables de decisión son cantidades numéricas cuyos valores son determinados por la solución del modelo de optimización. En esta investigación se ha considerado que las variables de decisión están definidas por un conjunto de parámetros geométricos que permiten la definición completa de la geometría en planta de una glorieta y la evaluación de la función objetivo a partir de ésta.

Las variables elegidas son las siguientes:

$\Rightarrow$ Para la calzada anular:

- Diámetro exterior $\left(D_{I C}\right)$.

- Anchura de la calzada anular $\left(W_{C}\right)$.

- Coordenadas del centro $\left(X_{c}, Y_{c}\right)$.

$\Rightarrow$ En cada entrada $j$ :

- Longitud de la isleta deflectora $\left(L E_{j}\right) . \quad j=1,2, \ldots M$

- Anchura $\left(W E_{j}\right) . \quad j=1,2, \ldots M$

$\Rightarrow$ En cada salida $j$ :

- Longitud de la isleta deflectora $\left(L S_{j}\right) . \quad j=1,2, \ldots M$

- Anchura $\left(W S_{j}\right) . \quad j=1,2, \ldots M$

Estas variables se muestran gráficamente en la Fig.3.3 para el caso de una glorieta con tres accesos. En total se tienen 12 variables para una glorieta de tres patas, 16 variables para una glorieta de cuatro patas y 20 variables para una glorieta de cinco patas. 
Se ha desarrollado un procedimiento para la definición geométrica de una glorieta a partir de los valores de estas variables de decisión, tomando como datos de partida la anchura de la calzada de aproximación de cada pata y los ejes de las alineaciones de cada acceso. Este procedimiento se detalla en el apartado 5.1 y se denota como AX-1.

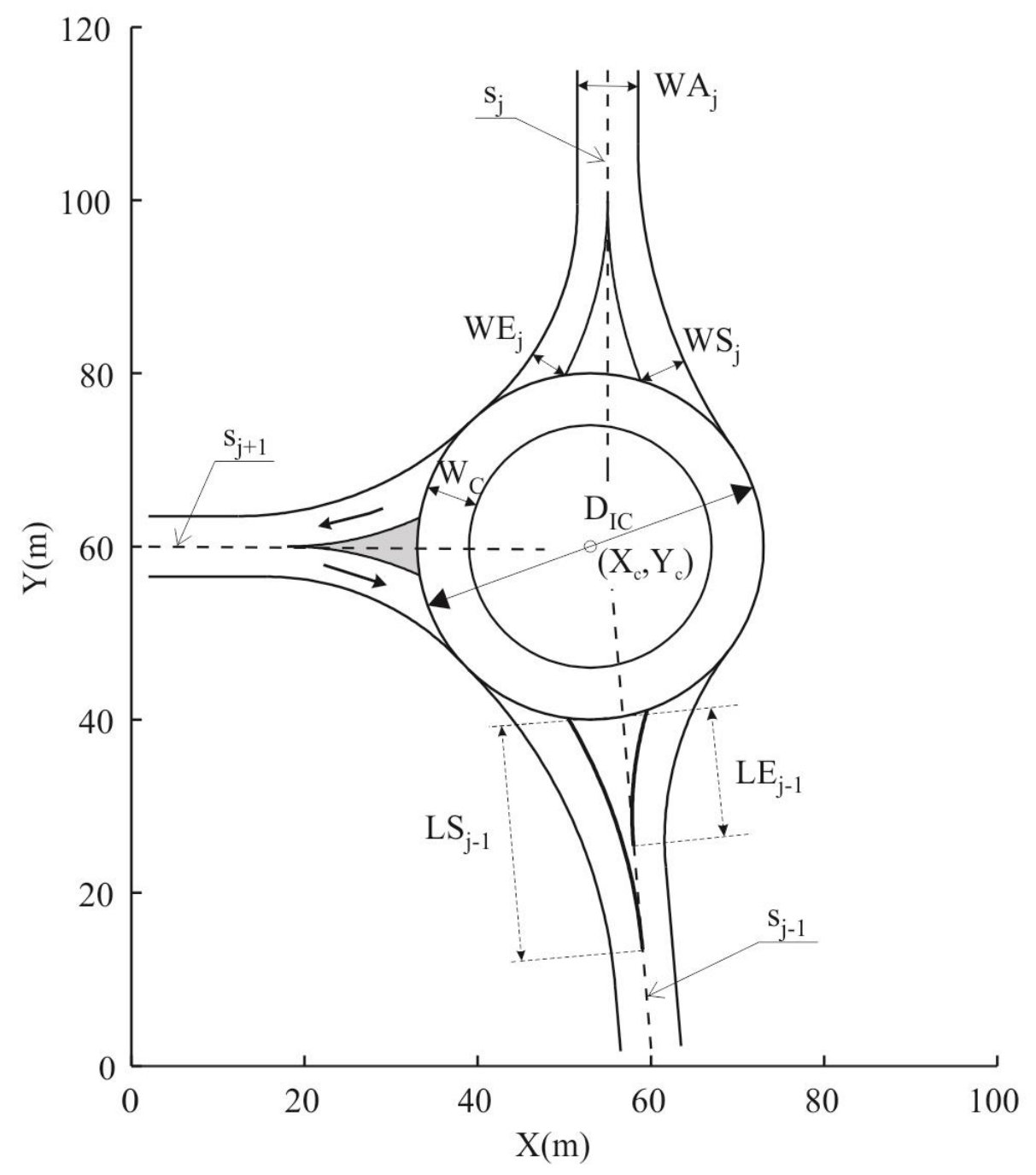

Figura 3. 3 Variables de decisión.

\subsubsection{Función objetivo}

Tal y como se ha comentado en el capítulo 2 (Antecedentes), un factor fundamental para la seguridad de un diseño es moderar las velocidades, principalmente en el movimiento de entrada, y facilitar la consistencia de velocidades entre los usuarios de la vía. Este aspecto ha sido recogido en las normas de referencia analizadas que además 
consideran la comprobación de este objetivo como el apartado con mayor influencia en la definición del trazado en planta de una glorieta.

Por este motivo, los objetivos del trazado relacionados con la operación del tráfico son tenidos en cuenta como restricciones al problema. De igual forma, la moderación de velocidades se va a imponer como una restricción al problema. Por tanto, la función objetivo a emplear en el problema de optimización se puede centrar en la evaluación de la consistencia de velocidades.

En glorietas, la consistencia de velocidades tiene dos componentes (Easa and Mehmood, 2004):

- Componente 1. Consistencia en los puntos de conflicto. Se comparan las velocidades de operación en los puntos de conflicto de trayectorias diferentes.

- Componente 2. Consistencia en la velocidad de operación. Se comparan las velocidades de operación entre los elementos geométricos consecutivos que componen una misma trayectoria.

Las dos componentes presentan un comportamiento homogéneo frente al estudio de la consistencia ya que cuando se mejora una de las dos, la otra no resulta perjudicada. Por este motivo, la función objetivo final $\boldsymbol{O F}$ se puede definir como la suma en valores absolutos de ambas componentes. Esta misma consideración ha sido realizada en Easa y Mehmood (2004) y en Mehmood y Easa (2006).

Como se ha comentado, el cálculo del valor de la función objetivo a partir de una geometría en planta de la glorieta (definida por las variables de decisión) requiere determinar las trayectorias y velocidades de los diferentes movimientos.

Para realizar esta tarea se ha desarrollado un algoritmo denominado AX-2 que permite realizar el trazado de forma automática de todas las trayectorias, cualquiera que sea la definición geométrica que establezcan los parámetros de diseño. 
Este procedimiento se ha desarrollado de forma específica para esta tesis y supera las limitaciones de los métodos existentes descritos en la sección 2.2.5.2.1. Se describe de manera detallada en el apartado 5.2 y asume, básicamente, que entre una entrada y una salida sólo pueden darse dos tipos de movimientos. El primero, denominado "movimiento directo", se compone de dos arcos circulares y entre ellos una recta de longitud variable (incluso nula). El segundo, denominado "movimiento con deflexión", se compone de tres arcos circulares con el intermedio de diferente signo.

Las componentes de la función objetivo se calculan en el procedimiento propuesto de la siguiente manera:

I. Componente $O F_{1}$, basada en las diferencias de velocidad en los puntos de conflicto.

Si se denota $N_{c p}$ como al número total de puntos de conflicto en la glorieta, y $\Delta V_{C, k} k=1, \ldots, N_{c p}$ la diferencia de velocidad en términos absolutos de las trayectorias en el punto de conflicto $k$, entonces la componente $O F_{1}$ se define como:

$$
O F_{1}=\sum_{k=1}^{N c p}\left|A V_{C, k}\right| / N_{c p}
$$

II. Componente $\mathrm{OF}_{2}$, basada en las diferencias de velocidad a lo largo de una misma trayectoria.

Para cada una de las trayectorias $N_{t r}$, se calculan las diferencias de velocidad en términos absolutos entre los diferentes radios que componen la trayectoria $m, \mathrm{y}$ se obtiene el valor promedio $\Delta V_{P, m} m=1, \ldots, N_{t r}$. La componente $O F_{2}$ se define como:

$$
O F_{2}=\sum_{m=1}^{N t r}\left|A V_{P, m}\right| / N_{t r}
$$

La función objetivo $O F$ se ha definido como la suma de $O F_{1}$ y $O F_{2}$. Luego:

$$
O F=O F_{1}+O F_{2}
$$

Cuanto menor sea el valor de $O F$, mejor será la consistencia del diseño. 
A modo de ejemplo, en la Fig.3.4 se ha representado la modelización de las trayectorias para el caso de una glorieta de tres accesos. En este ejemplo se pueden identificar las componentes de cada uno de los términos de la función objetivo. Como se observa, se producen seis conflictos entre las trayectorias de entrada y las que circulan por la calzada anular. Esto da lugar a que la componente 1 se defina como la media del valor absoluto de seis diferencias. Para cada trayectoria, se realiza la diferencia entre un radio y el siguiente. La componente 2 se define como la media del valor absoluto de estas diferencias.

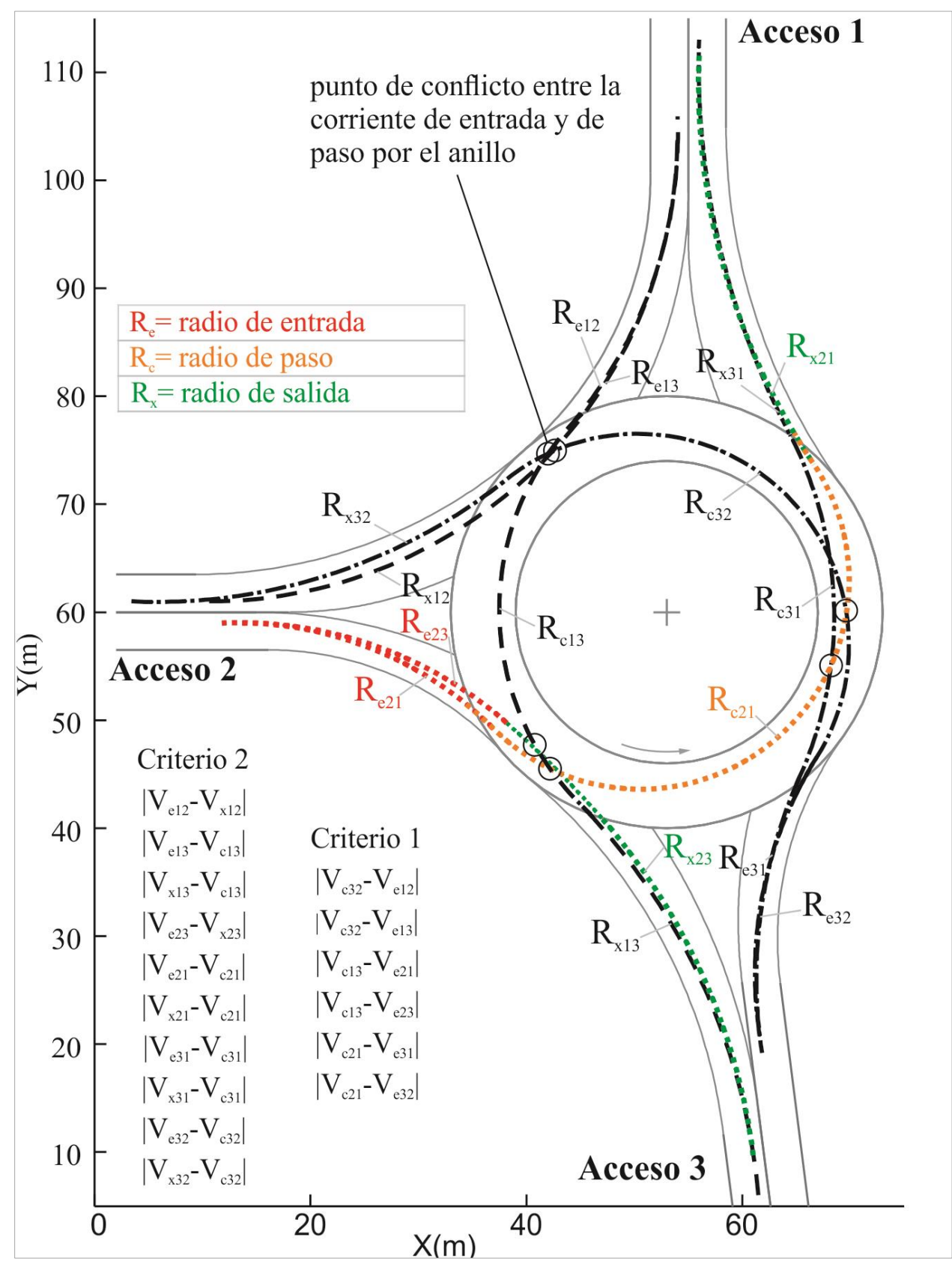

Figura 3. 4 Identificación de las componentes de la función objetivo. 


\subsubsection{Sistema de restricciones}

El sistema de restricciones define una serie de condiciones a las variables del problema de forma que es posible aproximar el modelo a la realidad del problema y a los objetivos que se desean alcanzar. Otra característica importante del sistema de restricciones es que permite acotar el espacio de búsqueda. Se han considerado seis condiciones que se analizan en detalle en los siguientes apartados.

3.3.4.1 Condición1. Limitaciones derivadas de las especificaciones de las normas de diseño.

La primera condición define una serie de limitaciones al valor de los parámetros geométricos para tener en cuenta las recomendaciones de la norma de diseño aplicable. En particular, esta restricción permite establecer un umbral máximo y mínimo a las siguientes variables de decisión: diámetro exterior $\left(D_{I C}\right)$, anchura de la calzada anular $\left(W_{C}\right)$, longitud de la isleta en las entradas $(L E)$, anchura en las entradas $(W E)$, longitud de la isleta en las salidas $(L S)$ y anchura en las salidas $(W S)$.

Otra condición se refiere a la región en la cual se puede ubicar el centro de la glorieta, cuyas coordenadas son variables de decisión del problema. Para acotar la búsqueda es conveniente establecer un área, que se ha denominado "región de centros factibles" (FCA), donde el centro de una glorieta que es candidata a ser solución del problema de optimización debe estar localizado. Esta región define una zona en la que pueden existir soluciones de glorietas con centro en ella cumpliendo con las limitaciones de la norma de diseño aplicable relativas a los elementos geométricos que definen la glorieta. De este modo, si el centro está fuera de esa zona, no es posible la construcción de ninguna glorieta para los valores de variación de las variables de decisión. Para definir la FCA se ha desarrollado un algoritmo auxiliar denominado AX-3 cuya descripción se puede consultar en el apartado 5.3. 


\subsubsection{Condición 2. Capacidad.}

El diseño geométrico de la glorieta debe proporcionar suficiente capacidad para garantizar un adecuado nivel de servicio. El estudio se realiza de forma previa y permite determinar el número de carriles en cada entrada y en la calzada anular, y en consecuencia, se pueden establecer unos rangos de valores recomendados para estos parámetros geométricos.

\subsubsection{Condición 3. Envolvente de giro del vehículo patrón}

El trazado en planta generado debe proporcionar unas anchuras de calzada tales que permitan inscribir en la superficie pavimentada la envolvente de giro del vehículo patrón (es decir, el área barrida por éste al efectuar la maniobra correspondiente de giro a la velocidad de referencia, incrementada en una determinada holgura). El vehículo patrón es definido en base a la normativa de referencia aplicable y al estudio de tráfico realizado en la fase preliminar. Aunque esta comprobación debe realizarse tras la definición de la geometría, se trata de un aspecto que puede considerarse desde el inicio de diseño condicionando los valores umbrales de determinadas variables de la geometría como son los radios de giro mínimos en los arcos que delimitan las entradassalidas y el tamaño mínimo de la calzada anular.

Por tanto, esta condición se puede considerar estableciendo unos valores mínimos para el diámetro exterior $\left(D_{I C}\right)$ y para la anchura de la calzada anular $\left(W_{C}\right)$. En las normas de diseño se suelen especificar los valores para el diámetro exterior mínimo y la anchura de calzada de acuerdo a unas hipótesis de paso o en función de la longitud del vehículo patrón.

En lo que se refiere al radio de giro mínimo de maniobra para el vehículo patrón, los arcos que delimitan las entradas-salidas no se han definido como variables de decisión por lo que para considerar esta restricción se define una condición para unas variables intermedias denominadas radio del bordes exterior de entrada $\left(R b_{e}\right)$ y radio del borde 
exterior de salida $\left(R b_{s}\right)$. Estas variables se derivan del procedimiento de cálculo de la geometría $(\mathrm{AX}-1)$.

\subsubsection{Condición 4. Solape de trayectorias naturales}

Se trata de un condicionante que se presenta en glorietas multicarril. En el modelo se introduce como una restricción, que consiste en que el valor de los radios de los bordes exteriores en las entradas $\left(R b_{e}\right)$ y en las salidas $\left(R b_{s}\right)$ sean mayores que el radio del círculo inscrito (Arndt, 1998).

\subsubsection{Condición 5. Velocidades máximas.}

Desde el punto de vista de la seguridad, las velocidades excesivas son uno de los principales factores en la generación de accidentes. El trazado en planta debe facilitar la moderación de las velocidades así que, para considerar este factor, se ha impuesto una serie de restricciones a las velocidades obtenidas en las trayectorias deducidas de una determinada solución geométrica. En concreto, se establecen condiciones relativas a las velocidades máximas en las entradas, en las salidas y en las de paso por la calzada anular.

Mediante estas limitaciones se puede satisfacer otro de los condicionantes del diseño en planta y que se refiere a la compatibilidad con otros modos. Por tanto, si existen pasos de peatones y ciclistas deben establecerse condiciones a las velocidades obtenidas.

Las velocidades son variables dependientes del valor de las variables de decisión y se tienen en cuenta en el procedimiento de cálculo de trayectorias y velocidades incluido en el apartado 5.2.

\subsubsection{Condición 6. Consistencia de velocidades.}


Como última restricción se impone un valor máximo a los indicadores de consistencia de velocidades en cada uno de los términos que componen la función objetivo. Esto significa que las diferencias de velocidad entre elementos de una misma trayectoria y entre las corrientes en conflicto no podrán superar un valor que debe fijarse de antemano.

\subsubsection{Formulación algebraica}

El problema matemático que se plantea consiste en buscar los valores de unos parámetros geométricos que permiten definir la geometría en planta de una glorieta (que son las variables de decisión) de forma que se satisfagan las condiciones descritas (restricciones geométricas y funcionales) y se maximice la consistencia de velocidades caracterizada mediante la función objetivo $O F$.

Por lo tanto, partiendo de los siguientes parámetros fijos y variables de decisión:

- Parámetros fijos:

$$
\begin{gathered}
s_{j}, W A_{\mathrm{j}}, d_{1}, d_{2}, d_{3}, d_{4} y d_{5} \\
j=1,2, \ldots, M
\end{gathered}
$$

donde $s_{j}$ y $W A_{\mathrm{j}}$ son el eje de la alineación y la anchura de la calzada de aproximación del acceso $j$ y $d_{1}, d_{2}, d_{3}, d_{4}$ y $d_{5}$ son los valores de los resguardos necesarios para poder modelar las trayectorias.

- Variables de decisión:

$$
\begin{gathered}
X_{c}, Y_{c}, D_{I C}, W_{C}, L E_{j}, W E_{j}, L S_{j} \mathrm{y} W S_{j} \\
j=1,2, \ldots M
\end{gathered}
$$

donde $X_{c}, Y_{c}, D_{I C}$ y $W_{C}$ son las coordenadas del centro, el diámetro exterior y la anchura de la calzada anular, $L E_{j}$ y $W E_{j}$ son la longitud de la isleta y la anchura de la entrada de la pata $j$ y $L S_{j}$ y $W S_{j}$ son la longitud de la isleta y la anchura de la salida de la pata $j$. 
El problema de optimización a resolver consiste en minimizar el valor de la función objetivo $O F$

$$
\min (\mathrm{OF}) \rightarrow \min \left(\sum_{\mathrm{k}=1}^{\mathrm{Ncp}}\left|A V_{\mathrm{C}, \mathrm{k}}\right| / \mathrm{N}_{\mathrm{cp}}+\sum_{\mathrm{m}=1}^{\mathrm{Ntr}}\left|A V_{\mathrm{P}, \mathrm{m}}\right| / \mathrm{N}_{\mathrm{tr}}\right)
$$

donde $N_{c p}$ es el número total de puntos de conflicto en la glorieta, $\Delta V_{C, k}$ la diferencia de velocidad en términos absolutos de las trayectorias en el punto de conflicto $k, N_{t r}$ es el número total de trayectorias y $\Delta V_{P, m}$ es el valor promedio de las diferencias de velocidad en términos absolutos entre los diferentes radios que componen la trayectoria $m$.

satisfaciendo las siguientes restricciones:

- condiciones 1,2 y 3

$$
\begin{gathered}
\gamma_{i} \geq \gamma_{i, \min } \quad y \quad \gamma_{i} \leq \gamma_{i, \max } \\
i=1, \ldots, N \\
i \neq X_{C}, Y_{C} \\
{\left[X_{C}, Y_{C}\right] \in F C A}
\end{gathered}
$$

donde $\gamma_{i, \min }$ y $\gamma_{i, \max }$ son los límites inferior y superior de la variable de decisión $\gamma_{i}, N$ es el número total de variables de decisión dependiente del número de accesos y $F C A$ es la región de centros factibles.

- condición 3

$$
\begin{gathered}
R g_{\min } \geq R b e_{j} \\
R g_{\min } \geq R b s_{j} \\
j=1,2, \ldots M
\end{gathered}
$$

donde $R g_{\min }$ es el radio de giro mínimo de maniobra del vehículo patrón y $R b e_{j}$ y $R b s_{j}$ son los radios de los bordes exteriores de entrada y salida respectivamente de la pata $j$. 
- condición 4

$$
\begin{aligned}
& R b e_{j} \geq \frac{D_{I C}}{2} \\
& R b s_{j} \geq \frac{D_{I C}}{2} \\
& j=1,2, \ldots M
\end{aligned}
$$

- condición 5

$$
\begin{aligned}
& V_{E, m} \leq V_{E, \max } \\
& V_{P, m} \leq V_{P, \max } \\
& V_{X, m} \leq V_{X, \max } \\
& m=1, \ldots, N_{t r}
\end{aligned}
$$

donde $V_{E, m}, V_{P, m}$ y $V_{X, m}$ representan las velocidades de entrada, de paso por la calzada anular y de salida de la trayectoria $m$, y $V_{E, \max } V_{P, \max }$ y $V_{X, \max }$ las velocidades máximas admisibles.

- condición 6

$$
\begin{aligned}
& A V_{C, k} \leq I c \\
& k=1, \ldots, N_{c p} \\
& A V_{P, m} \leq I c \\
& m=1, \ldots, N_{t r}
\end{aligned}
$$

donde $I_{C}$ representa el máximo valor admisible establecido para las diferencias de velocidad medidas en cualquiera de los dos criterios de la función objetivo. 


\section{CAPítULO 4. RESOLUCIÓN MEDIANTE TÉCNICAS DE PROGRAMACIÓN MATEMÁTICA}

\subsection{INTRODUCCIÓN}

En este capítulo se presenta un método para la resolución del problema de optimización planteado en el capítulo 3 basado en un algoritmo genético con codificación mediante números reales. En primer lugar se describe la estructura del algoritmo desarrollado. Se describe a continuación la codificación empleada para caracterizar a cada "individuo" o solución potencial del problema (es decir, la geometría de glorieta). Se detallan asimismo los operadores de mutación y de cruce empleados en el algoritmo y la manera en que el algoritmo afronta las restricciones del problema de optimización.

\subsection{ESTRUCTURA GENERAL DEL ALGORITMO}

La estructura general del algoritmo diseñado se muestra de forma esquemática en la Fig. 4.1 .

Cada individuo representa un diseño geométrico en planta de la glorieta, candidato a ser la solución al problema de optimización.

El algoritmo se inicia con la generación de forma aleatoria de un conjunto de $n_{p}$ individuos, que forman una población inicial $P$.

La calidad como solución al problema de cada uno de los individuos de la población inicial es posteriormente evaluada mediante la función objetivo establecida para el problema (apartado 3.3.3). La población inicial de $\mathrm{P}$ individuos (que son los padres de 
la siguiente generación) es posteriormente ordenada en función del valor obtenido de la función objetivo; esto facilita el proceso posterior de selección.

En la siguiente etapa se inicia un bucle para el cual se deben establecer unos criterios de parada. Normalmente las iteraciones continúan mientras se computan mejoras en el valor de la función objetivo de los individuos, aunque también se impone un criterio de detención basado en un número mínimo de generaciones $\left(n_{T}\right)$ para evitar que el algoritmo quede atrapado en un mínimo local.

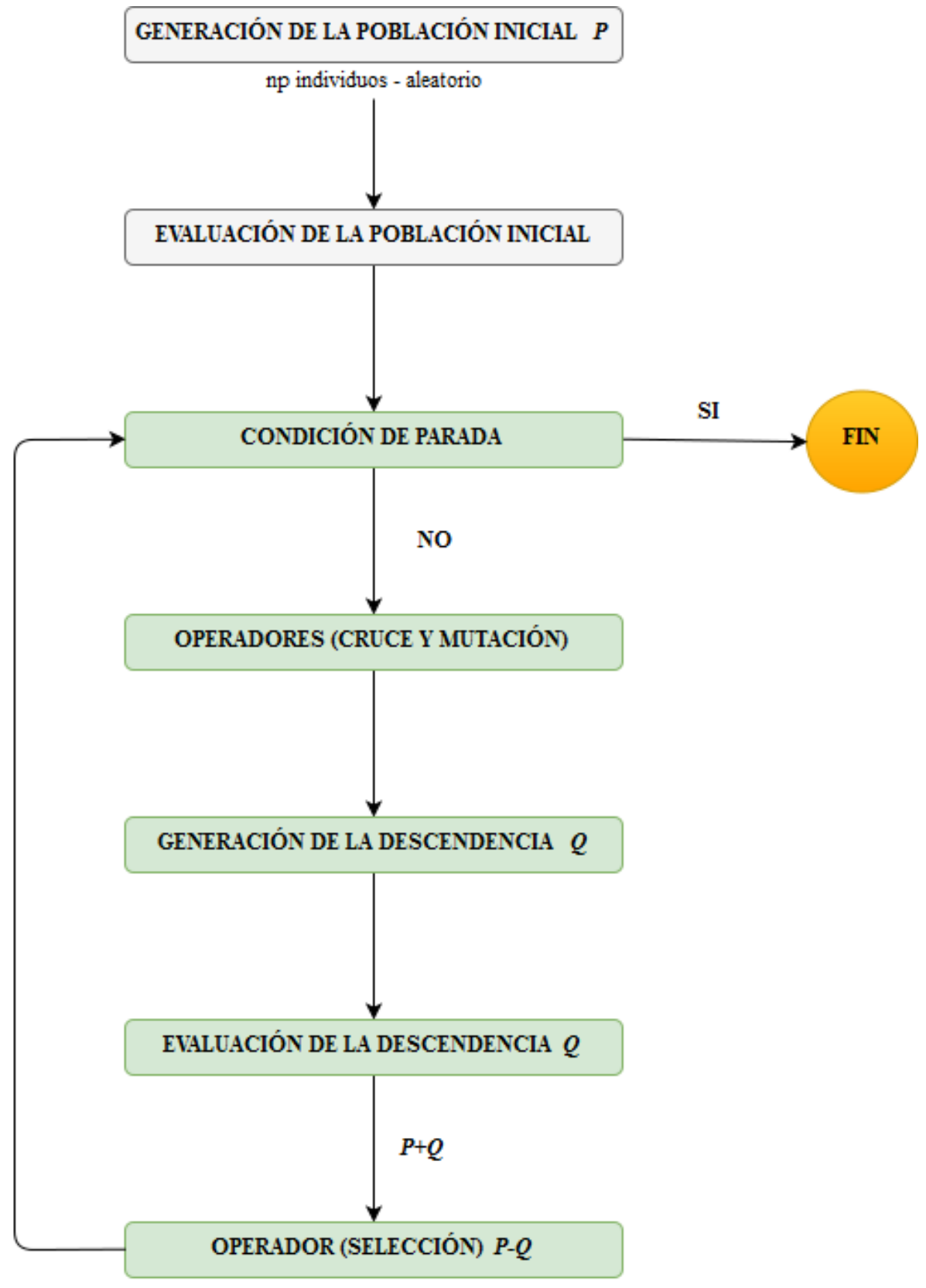

Figura 4. 1 Estructura del algoritmo genético 
En este bucle uno o dos padres son seleccionados de la población para su reproducción mediante la aplicación de unos operadores de cruce y mutación; en cada proceso de selección y reproducción se obtienen uno o dos individuos nuevos (que son hijos de esta población). Este proceso se repite tantas veces como se desee, resultando finalmente en una descendencia de $Q$ nuevos individuos (hijos) o posibles soluciones potenciales al problema, que son evaluados de acuerdo a la función objetivo. Finalizada la fase de reproducción, la descendencia $Q$ se une a la población inicial $P$ formando una población de tamaño $P+Q$. Para asegurar que la siguiente generación tiene el mismo número de individuos, se eliminan mediante un operador de selección un total de $Q$ individuos.

\subsection{CODIFICACIÓN}

La codificación que se ha empleado para las variables de decisión se ha basado en números reales. Las variables de decisión se introducen en un vector $\boldsymbol{S}$, cuya longitud depende del número de patas $M$. Puesto que se necesitan cuatro variables para definir la calzada anular $\left(X_{c}, Y_{c}, D_{I C}, W_{C}\right)$ y cuatro para cada acceso $(L E, W E, L S$ y $W S)$, la longitud del vector $S$ es $N=4(M+1)$ :

$S=\left[X_{C}, Y_{C}, D_{I C}, W_{C}, L E_{1}, W E_{1}, L S_{1}, W S_{1}, L E_{2}, W E_{2}, L S_{2}, W S_{2}, \ldots, L E_{M}, W E_{M}, L S_{M}, W S_{M}\right]$

En el algoritmo genético definido, $S$ es un cromosoma, y cada variable de decisión un gen. El conjunto de valores contenidos en $S$ definen un individuo, que representa una solución geométrica de la glorieta.

\subsection{Población INICIAL}

Los individuos que forman la población inicial son generados aleatoriamente en el espacio de búsqueda con el objetivo de conseguir variedad genética. El espacio de búsqueda queda definido por una región bidimensional (es el caso del centro de la 
glorieta, que deben encontrarse en la FCA) y por unos valores umbrales máximo y mínimo para el resto de variables de decisión.

Para generar un individuo, las coordenadas del centro de la glorieta son obtenidas en primer lugar aleatoriamente dentro de la denominada FCA y los valores del resto de variables se definen de forma aleatoria empleando una distribución de probabilidad uniforme entre los valores mínimos y máximos que establecen el sistema de restricciones (condiciones 1,2 y 3 del apartado 3.3.4).

El tamaño de la población $\left(n_{p}\right)$ se mantiene constante en todas las generaciones y debe ser establecido al comienzo del proceso. El tamaño influye de manera importante en la convergencia y, por tanto, en el tiempo de ejecución del algoritmo (ver apartado 4.7).

\subsection{CONSIDERACIÓN DEL SISTEMA DE RESTRICCIONES EN EL ALGORITMO}

\subsubsection{Introducción}

Para poder incluir el sistema de restricciones en el algoritmo genético se han utilizado diferentes estrategias: funciones de penalización, métodos de reparación y métodos de rechazo.

En general, se ha preferido utilizar los métodos que admiten un margen de error en el cumplimiento de la restricción y que actúan penalizando o reparando la solución. En los casos en los que la solución resulta completamente inútil si no se satisface la restricción se utiliza un método de rechazo. En los siguientes apartados se describe de manera detallada las estrategias consideradas en el algoritmo para tener en cuenta el sistema de restricciones definido en el apartado 3.3.4. 


\subsubsection{Funciones de penalización}

Las funciones de penalización fueron propuestas inicialmente por Courant (1943) y desarrolladas posteriormente en los trabajos de Carroll (1961) y Fiacco y McCormick (1966). Este tipo de estrategia se aplica en el caso de la condición 5 (velocidades máximas) y 6 (consistencia de velocidades) del sistema de restricciones.

En el caso de que los valores de las diferencias de velocidad $\Delta V_{C, k}$ correspondientes a la componente 1 de la función objetivo, o las diferencias de velocidad $\Delta V_{P, k}$ correspondientes a la componente 2 de la función objetivo, superen el valor fijado por el usuario $(I c)$, se aplica una función de penalización.

La función de penalización definida es similar a la estrategia propuesta por Homafair et al. (1994) que establece una penalización estática por niveles. Los parámetros de la función se tienen que fijar de acuerdo a las pruebas experimentales (Yeniay, 2005), que para la presente investigación han resultado los siguientes:

$\Rightarrow$ Si la violación se encuentra en un margen de hasta $5 \mathrm{~km} / \mathrm{h}$ sobre el valor fijado, se multiplica por dos la diferencia de velocidad correspondiente.

$\Rightarrow$ Si la violación se encuentra entre 5 y $10 \mathrm{~km} / \mathrm{h}$ sobre el valor fijado, se multiplica por tres la diferencia de velocidad correspondiente.

$\Rightarrow \mathrm{Si}$ la violación supera los $10 \mathrm{~km} / \mathrm{h}$ sobre el valor fijado, se multiplica por cinco la diferencia de velocidad correspondiente.

Esta función de penalización se aplica de igual forma en el caso de que se superen las limitaciones de velocidades máximas.

\subsubsection{Métodos de reparación}

Los métodos de reparación han sido muy utilizados en problemas de optimización y pueden encontrarse numerosas aplicaciones con éxito en la literatura científica (Michalewicz y Nazhiyath, 1995; Michalewicz y Xiao, 1995; Xiao et al., 1997). 
No se puede definir un procedimiento general para este tipo de estrategias debido a su dependencia con el tipo de problema y la codificación. En esta investigación se han definido dos técnicas de reparación.

En primer lugar, se ha utilizado en el desarrollo del algoritmo auxiliar de cálculo de la geometría y permite incluir la condición 3 (parcialmente) y la condición 4 referidas a los valores mínimos de los radios de los bordes exteriores en las entradas y las salidas. El estudio en detalle se puede consultar en el apartado 5.1 y el objetivo es generar una solución factible para compatibilizar la geometría con las maniobras de los vehículos de mayor longitud (vehículo patrón) y evitar el solape de las trayectorias naturales teniendo en cuenta la posibilidad de que existan accesos próximos y el trazado de una entrada interfiera en la salida de la pata contigua.

En segundo lugar, se ha definido un procedimiento que permite reparar las coordenadas del centro de la glorieta e incluirlas dentro de la FCA una vez se han aplicado los operadores de cruce y mutación y se ha generado la descendencia. Primero, se evalúa si el centro de la glorieta está dentro de la FCA. En el caso de localizarse fuera, se traza una línea entre dicho centro y el centroide de la FCA. El nuevo centro (reparado) se sitúa en la intersección de esta línea con el contorno de la FCA.

\subsubsection{Métodos de rechazo}

Este tipo de estrategia se ha considerado cuando la geometría de un descendiente resulta inútil por no satisfacer una determinada restricción y se procede por tanto a eliminar el individuo. Este caso se refiere a las condiciones 1 (normas de diseño), 2 (capacidad) y 3 (acomodo del vehículo patrón). 


\subsection{OPERADORES}

El algoritmo requiere la definición de unos operadores para llevar a cabo la selección de individuos para su reproducción y para decidir cuáles sobreviven al final de una generación, y de otros para la reproducción, que podrán ser de cruce o de mutación. El funcionamiento del algoritmo es altamente dependiente de los operadores. Se han empleado un operador de selección, tres de mutación y cuatro de cruce.

\subsubsection{Selección}

La selección de individuos tanto para la reproducción como para la supervivencia es llevada a cabo en el algoritmo empleando el método "torneo".

La idea original de este operador fue propuesta por Wetzel (1983). Partiendo de una población, la selección de un individuo se lleva a cabo mediante la comparación de un número predeterminado de ellos (en este caso dos) elegidos al azar en base al valor de una función objetivo.

En la selección para la reproducción deben elegirse uno o dos individuos, dependiendo del tipo de operador de reproducción. Para la reducción de la población $P+Q$ obtenida tras una generación hasta un tamaño de $n_{p}$ individuos, es necesario aplicar el operador un número de veces igual a $Q$ (los individuos seleccionados deben ser previamente eliminados de la población).

\subsubsection{Cruce}

\subsubsection{Cruce simple}

Esta técnica fue propuesta originalmente por Holland (1975). Mediante este operador se selecciona un punto de corte de la cadena cromosómica de los padres de forma 
aleatoria. Luego se intercambia cada parte de uno de los padres con la contraria del otro. Después de la aplicación, se obtienen dos hijos.

Si se considera $\mathbf{S}_{\mathrm{i}}=\left[q_{i 1}, q_{i 2}, \ldots, q_{i k}, \ldots, q_{i n}\right]$ y $\mathbf{S}_{\mathrm{j}}=\left[q_{j 1}, q_{j 2}, \ldots, q_{j k}, \ldots, q_{j n}\right]$ a los padres y $k=$ $\mathrm{r}_{\mathrm{d}}[1, n]$ el gen en el cual se produce la cruza, $\left(r_{d}\right.$ en una función de distribución discreta uniforme que genera un número aleatorio entero en el dominio definido por el intervalo $[1, n])$ la descendencia será:

$$
\begin{aligned}
& \mathbf{S}_{\mathbf{i}}^{\prime}=\left[q_{i 1}, q_{i 2}, \ldots, q_{i k}, q_{j(k+1)}, \ldots, q_{j n}\right] \\
& \mathbf{S}_{\mathbf{j}}^{\prime}=\left[q_{j 1}, q_{j 2}, \ldots, q_{j k}, q_{i(k+1)}, \ldots, q_{i n}\right]
\end{aligned}
$$

\subsubsection{Cruce de dos puntos}

Esta técnica fue propuesta originalmente por De Jong (1975). A diferencia del cruce de un punto, este operador rompe la cadena cromosómica de los padres en dos puntos generados de forma aleatoria en lugar de uno.

Si se considera $\mathbf{S}_{\mathrm{i}}=\left[q_{i 1}, q_{i 2}, \ldots, q_{i k}, \ldots, q_{i n}\right]$ y $\mathbf{S}_{\mathrm{j}}=\left[q_{j}, q_{j 2}, \ldots, q_{j k}, \ldots, q_{j n}\right]$ a los padres y $k=$ $\mathrm{r}_{\mathrm{d}}[1, n]$ y $l=\mathrm{r}_{\mathrm{d}}[1, n]$ los dos puntos aleatorios, siendo $k \neq l$ y $k<l$. La descendencia será:

$$
\begin{aligned}
& \mathbf{S}_{\mathbf{i}}^{\prime}=\left[q_{i 1}, q_{i 2}, \ldots, q_{i k}, q_{j(k+1)}, \ldots, q_{j l}, q_{i(l+1)}, \ldots, q_{i n}\right] \\
& \mathbf{S}_{\mathbf{j}}^{\prime}=\left[q_{j 1}, q_{j 2}, \ldots, q_{j k}, q_{i(k+1)}, \ldots, q_{i l}, q_{j(l+1)}, \ldots, q_{j n}\right]
\end{aligned}
$$

\subsubsection{Cruce aritmético}

Este operador genera la descendencia por una combinación lineal de dos padres.

Si se considera $\mathbf{S}_{\mathrm{i}}=\left[q_{i l}, q_{i 2}, \ldots, q_{i k}, \ldots, q_{i n}\right]$ y $\mathbf{S}_{\mathrm{j}}=\left[q_{j 1}, q_{j 2}, \ldots, q_{j k}, \ldots, q_{j n}\right]$ a los padres y $w$ $=\mathrm{r}_{\mathrm{c}}[0,1]$ ( $r_{c}$ es una función de distribución continua y uniforme que genera un número aleatorio en el intervalo [0,1]), la descendencia será: 


$$
\begin{aligned}
& \mathbf{S}_{\mathbf{i}}^{\prime}=w \mathbf{S}_{\mathbf{i}}+(1-w) \mathbf{S}_{\mathbf{j}} \\
& \mathbf{S}_{\mathbf{j}}^{\prime}=w \mathbf{S}_{\mathbf{j}}+(1-w) \mathbf{S}_{\mathbf{i}}
\end{aligned}
$$

\subsubsection{Cruce heurístico}

Este operador considera dos padres representados por $\mathbf{S}_{\mathrm{i}}$ y $\mathbf{S}_{\mathrm{j}}$ y que el valor de la función objetivo de $\mathbf{S}_{\mathrm{i}}$ es al menos tan buena como la de $\mathbf{S}_{\mathrm{j}}$. El operador genera un único descendiente mediante el desplazamiento de $\mathbf{S}_{\mathrm{i}}$ en la dirección $\mathbf{S}_{\mathrm{i}}-\mathbf{S}_{\mathrm{j}}$ de acuerdo a la siguiente expresión:

$$
\mathbf{S}^{\prime}=\mathbf{S}_{\mathbf{i}}+w\left(\mathbf{S}_{\mathbf{i}}-\mathbf{S}_{\mathbf{j}}\right)
$$

Donde $w=\mathrm{r}_{\mathrm{c}}[0,1]$

\subsubsection{Mutación}

\subsubsection{Mutación uniforme}

Se considera $\mathbf{S}=\left[q_{1}, q_{2}, \ldots, q_{n}\right]$ el cromosoma al que se le aplica la mutación en su gen $\mathrm{k}$, donde $k=\mathrm{r}_{\mathrm{d}}[1, n]$. Entonces $q_{k}$ es reemplazado por:

$$
q_{k}=r_{c}\left[g_{L, k}, g_{U, k}\right]
$$

donde $\mathrm{g}_{\mathrm{L}, \mathrm{k}} \mathrm{y} \mathrm{g}_{\mathrm{U}, \mathrm{k}}$ son los límites inferior y superior de la variable de decisión $k$.

\subsubsection{Mutación no uniforme}

Este operador fue introducido por Michalewicz (1996). Se considera a $\mathbf{S}=\left[q_{1}, q_{2}, \ldots, q_{n}\right]$ el cromosoma al que se le aplica la mutación en su gen $\mathrm{k}$, donde $k=\mathrm{r}_{\mathrm{d}}[1, n]$. En primer lugar, se genera un número binario de forma aleatoria $r_{d}[0,1]$. Entonces, el valor de $q_{k}$ se calcula mediante las siguientes ecuaciones: 
Si $r_{d}[0,1]=0$, entonces

$$
q_{k}=q_{k}-f\left(t, q_{k}-g_{L, k}\right)
$$

En caso contrario,

$$
q_{k}=q_{k}+f\left(t, g_{U, k}-q_{k}\right)
$$

La función $f(t, y)$ es:

$$
f(t, y)=y \cdot r_{c}[0,1] \cdot\left(1-\frac{t}{n_{T}}\right)^{\xi}
$$

donde $n_{T}$ es el número máximo de generaciones, $t$ el número de la generación actual, y $\xi$ un parámetro definido por el usuario que determina el grado de no uniformidad. Se ha definido un valor de 5 para este parámetro siguiendo las recomendaciones de Michalewicz (1996). Esta función ofrece un valor en el rango [0, y] de forma que la probabilidad de que $f(t, y)$ tienda a cero aumenta conforme $t$ se incrementa.

\subsubsection{Mutación no uniforme total}

Este operador aplica una mutación no uniforme a cada uno de los genes que componen el cromosoma S. El resultado es una descendencia completamente diferente a la del cromosoma original.

\subsection{Parámetros}

Los valores de los parámetros de funcionamiento del algoritmo se han establecido en base a las recomendaciones de la literatura científica y los resultados obtenidos en las pruebas experimentales.

Se deben fijar los siguientes parámetros: 
- Tamaño de la población.

- Condición de parada. En esta metodología la población evoluciona hasta que no se producen cambios significativos en el valor de la función objetivo. Además se fija un número mínimo de generaciones para garantizar una buena exploración y evitar que el algoritmo quede atrapado en un mínimo local.

- Cada uno de los operadores de reproducción definidos se aplican una vez, al menos, en cada generación.

\subsection{ESTRUCTURA DEL PROGRAMA DE ORDENADOR}

\subsubsection{Introducción}

El procedimiento se ha implementado en un programa de ordenador empleando el software MATLAB. En este apartado se describen por orden de ejecución los módulos principales de la aplicación informática desarrollada y la secuencia de operaciones del algoritmo en forma de pseudocódigo ${ }^{16}$.

\subsubsection{Módulo 1. Datos de partida}

Se deben introducir los siguientes datos de partida:

- El trazado de los accesos.

Los ejes de las alineaciones de los accesos (Datos.al) se pueden introducir de cuatro formas (Datos.forma):

Datos.forma $=1$. Definición interactiva en una ventana gráfica.

Datos.forma $=2$. Definición mediante coordenadas $(\mathrm{UTM})$ en una matriz contenida en un archivo .mat (propio de MATLAB).

Datos.forma $=3$. Definición mediante coordenadas $(\mathrm{UTM})$ en una hoja de cálculo.

\footnotetext{
${ }^{16}$ El pseudocódigo es utilizado en ciencias de la computación para describir cómo funciona un programa informático o algoritmo mediante un lenguaje compacto e informal.
} 
Datos.forma $=4$. Definición interactiva en una ventana gráfica con una imagen de Google Earth establecida como fondo.

- La geometría de la plataforma de los accesos.

Se refiere a la anchura de las calzadas en las aproximaciones (Datos.anC), el valor de los peraltes (bombeo) (Datos.per) y la anchura de mediana si existe (Datos.med).

- Condiciones de capacidad.

Se debe definir un valor mínimo para las siguientes variables de decisión: la anchura de la calzada en cada entrada y la anchura de la calzada anular (también si se considera el diámetro exterior y las longitudes de las isletas en las entradas). Los datos se integran dentro del vector DatosAG.gene_inf.

- Condiciones de paso del vehículo patrón.

Se debe fijar un valor mínimo para el diámetro exterior y la anchura de la calzada anular dentro del vector DatosAG.gene_inf. También hay que definir el radio mínimo de los bordes de los accesos en las entradas y salidas (Datos.radmin).

- Condición del solape de trayectorias en glorietas multicarril.

Se debe considerar un valor mínimo para los radios de los bordes de los accesos en las entradas y salidas (Datos.radmin).

- Cálculo de las trayectorias.

Valor para los resguardos (Datos.Res) de forma que se puedan modelar las trayectorias de los vehículos.

- Moderación de las velocidades (compatibilidad con los usuarios no motorizados).

Limitaciones de velocidad en las entradas (Datos.limvelent), en las salidas (Datos.limvelsal) y en la calzada anular (Datos.limvelpas). 
- Criterio de consistencia de velocidades.

Se debe fijar un valor máximo a los indicadores de consistencia de velocidades en cada uno de los términos que componen la función objetivo (Datos.Ic).

- Parámetros del algoritmo genético.

- El tamaño de la población (DatosAG.pob_tam).

- Número de hijos de la descendencia (número de veces que se aplican los siete operadores) (DatosAG.uujj). Por tanto, si aplico una vez los operadores se obtienen diez hijos (uno por cada operador de mutación y en el cruce heurístico y dos por cada operador de cruce), si aplico dos veces los siete operadores se obtienen veinte hijos y así sucesivamente.

- Número mínimo y máximo de iteraciones (DatosAG.num_generacion).

- Parámetro de la mutación no uniforme (DatosAG.coef_def).

- Operador de selección mediante torneo: tamaño del torneo (DatosAG.tam_tor).

Todos los datos de partida se agrupan dentro de dos estructuras ${ }^{17}$ (Datos y DatosAG).

\subsubsection{Módulo 2. Cálculos básicos}

En este primer apartado, se realizan una serie de cálculos básicos que servirán de base para los módulos siguientes. Los objetivos son numerar los accesos, representarlos gráficamente, calcular el ángulo entre ellos y las bisectrices y trazar los bordes exteriores de las calzadas de aproximación y la mediana (si existe). Además se determinan los valores máximos y mínimos de las variables de decisión (parámetros geométricos) de acuerdo a las restricciones establecidas, las recomendaciones de la norma y el criterio del proyectista (DatosAG.gene_sup y DatosAG.gene_inf). Si existen varias condiciones para un mismo factor se considera el valor más restrictivo.

\footnotetext{
${ }^{17}$ En MATLAB, las estructuras permiten agrupar datos de tipo diferente (caracteres, números, matrices, ...) bajo un mismo nombre. La codificación se realiza de la siguiente manera: nombre de la estructura.dato.
} 


\subsubsection{Módulo 3. Región de centros factibles (FCA)}

Definición del contorno cerrado que permite delimitar la FCA. La estructura de esta función se trata de forma particularizada en el apartado 5.3.

\subsubsection{Módulo 4. Algoritmo Genético}

En este apartado se realiza el proceso de búsqueda. Se siguen las siguientes operaciones:

- Generación de la familia inicial y evaluación de la calidad de los individuos.

De forma aleatoria, y siguiendo una distribución uniforme, se generan los valores de las variables de decisión (parámetros geométricos) del individuo según los umbrales definidos en DatosAG.gene_sup y DatosAG.gene_inf. Para los centros se generan pares de coordenadas X e Y contenidas en el área FCA. A continuación, se aplica el submódulo de evaluación de la función objetivo y se obtiene la calidad del mismo. Si resultase no factible se elimina y se genera uno nuevo. El procedimiento es iterativo hasta que se alcanza el tamaño de la población prefijado. Por último, se ordena la población resultante de acuerdo al valor de la función objetivo.

El submódulo de evaluación de la función objetivo consta de las siguientes etapas:

- Definición de la geometría según el procedimiento AX-1. Si no se satisfacen los requerimientos geométricos se desecha el individuo y se genera uno nuevo.

- Cálculo de las trayectorias según el procedimiento AX-2.

- Cálculo de las velocidades según el procedimiento descrito en AX-2. Aplicación de la función de penalización si se superan las limitaciones de velocidad.

- Análisis de la consistencia y cálculo del valor de la función objetivo. Se aplica la función de penalización en caso necesario. 
- Bucle principal del algoritmo genético.

- Se genera la descendencia a partir de la aplicación de los operadores de cruce y mutación un número de veces igual a Datos.uujj. Debido a la particularidad que representan las variables que definen la posición de la calzada anular, se aplica en caso necesario la reparación de las coordenadas del centro.

- Cálculo del valor de la función objetivo para los hijos. Se aplica el submódulo de evaluación de la función objetivo y se obtiene la calidad de la descendencia. En caso de que exista alguna incompatibilidad se penaliza la solución o se elimina.

- Se unen los padres con la descendencia y se aplica el operador de selección (torneo), que devuelve el tamaño de la población al inicial prefijado.

- El procedimiento se repite conforme a los criterios de convergencia establecidos en los datos de partida.

\subsubsection{Módulo 5. Resultados}

En este último bloque, se extraen los datos de interés de la mejor solución obtenida:

- Evolución del valor de la función objetivo de la mejor solución de cada generación.

- Representación de la solución geométrica.

- Región de centros factibles.

- Representación de las trayectorias y el haz de soluciones para cada movimiento.

- Tabla de las velocidades resultantes para todos los movimientos. 


\subsubsection{Estructura del programa}

Los diferentes módulos de cálculo se integran en un programa de ordenador cuya estructura se presenta en este apartado en forma de pseudocódigo. La descripción de la aplicación informática se completa en el capítulo siguiente con la definición de los algoritmos que permiten el establecimiento de la geometría, la evaluación de la función objetivo y la definición de la FCA.

Programa: Optimización del diseño en planta de glorietas mediante un AG

1. LEER Datos;

//Entrada: datos de partida//

2. LEER DatosAG; //Entrada: parámetros del algoritmo//

3. FUNCIÓN cálculos básicos;

4. FUNCIÓN región de centros factibles (FCA);

//ver apartado 5.3//

5. ITERACIÓN desde 1 hasta el tamaño de la población hacer

6.

MIENTRAS contador es 0

7.

FUNCIÓN generación aleatoria de valores de las variables de decisión

8.

FUNCIÓN evaluación de la calidad

//ver apartado 5.1 y $5.2 / /$

9.

CONDICIONAL si el individuo es factible entonces

10. contador es 1

11.

FIN CONDICIONAL

12. FIN MIENTRAS

13. FIN ITERACIÓN

14. ITERACIÓN desde 1 hasta que se satisfacen los criterios de convergencia hacer

15. ITERACIÓN desde $\mathbf{1}$ hasta el número de veces que se repite cada operador hacer

16.

17. FUNCIÓN selección de los padres;

18.

FUNCIÓN generación de la descendencia (uno o dos hijos);

19. FIN ITERACIÓN

20.

FUNCIÓN reparación de los centros;

FUNCIÓN evaluación de la calidad;

//ver apartado 5.1 y $5.2 / /$

21.

FUNCIÓN Selección por torneo de supervivientes para la siguiente generación;

\section{FIN ITERACIÓN}

23. FUNCIÓN solución final //Salida: mejor solución y representación// FIN 


\section{CAPÍTULO 5. ALGORITMOS AUXILIARES}

\subsection{INTRODUCCIÓN}

En este capítulo se presentan tres algoritmos auxiliares que ha sido necesario desarrollar para alcanzar el objetivo general de esta tesis.

El primero, permite construir de forma automatizada la geometría de una glorieta a partir de los valores de unos parámetros geométricos, que representan las variables de decisión del problema.

El segundo tiene como objetivo obtener el trazado de las trayectorias de todos los movimientos posibles desde cada entrada a partir de una determinada geometría de la glorieta. A partir de estos algoritmos es posible estimar las velocidades y evaluar la función objetivo.

El tercero, se ha desarrollado para establecer los umbrales de variación de las coordenadas del centro de la glorieta mediante la creación de una región convexa. Esta región define una zona en la que pueden existir soluciones de glorietas con centro en ella; si el centro está fuera de esa zona, no es posible la construcción de ninguna glorieta para los valores de variación de las variables de decisión.

\subsection{DEFINICIÓN AUTOMÁTICA DE LA GEOMETRÍA (AX-1)}

Los datos de partida para poder aplicar el procedimiento son los ejes de las alineaciones de acceso y la anchura de las calzadas de estos ejes. Mediante la asignación del valor de cuatros parámetros geométricos que definen la calzada anular (diámetro exterior, anchura de la calzada anular y coordenadas del centro) y de otros cuatro que definen cada acceso (longitud de la isleta en la entrada, anchura en la entrada, longitud de la 
isleta en la salida y anchura en la salida), es posible construir de forma automática la geometría de la glorieta.

Básicamente, las etapas a seguir son las siguientes:

1. Dibujo de la calzada anular. Esta tarea se realiza de forma directa a partir de las coordenadas del centro de la glorieta, el diámetro exterior y la anchura de la calzada anular.

2. Dibujo de los accesos. Para esto se propone aplicar la denominada "construcción básica" (apartado 5.2.1). Si existe interferencia en el trazado de accesos contiguos puede ser necesario aplicar el método de reparación descrito en el apartado 5.2.2.

3. Validación de la solución geométrica.

Los tres pasos de construcción de la geometría se integran dentro de un algoritmo de cálculo que se describe en el apartado 5.2.3.

\subsubsection{Construcción básica de la geometría de un acceso}

En una pata $j$ definida por su eje $s_{j}$ y la anchura de la calzada en la aproximación $W A_{j}$ es posible definir la geometría de la entrada mediante las siguientes operaciones (Fig.5.1):

- Determinación del punto $P_{j, 1}$ mediante la intersección de la alineación $s_{j}$ con el círculo inscrito.

- Determinación del punto $P_{j, 2}$ localizado a una distancia $L E_{j}$ desde el punto $P_{j, 1}$ y a lo largo de la alineación $s_{j}$.

- Cálculo de la circunferencia tangente al eje $s_{j}$ por el punto $P_{j, 2}$ y a la circunferencia que define la isleta central. La intersección de esta circunferencia con el círculo inscrito determina el punto $P_{j, 3}$. El arco comprendido entre los puntos $P_{j, 2} \quad$ y $P_{j, 3}$ define el límite interior de la calzada en la entrada. 
- Definición de una línea que une los puntos $P_{j, 4}$, que es el centro del arco determinado en la operación anterior, y $P_{j, 3}$. Cálculo del punto $P_{j, 5}$ localizado a una distancia $W E_{j}$ desde el punto $P_{j, 3}$. Mediante esta construcción se fija la anchura de la entrada.

- Definición de la línea $s_{j, e}$ paralela a $s_{j}$ en una distancia $W A_{j} / 2$. A continuación se traza una circunferencia tangente a $s_{j, e}$ y al círculo inscrito, pasando por el punto $P_{j, 5}$. Esta circunferencia define el borde exterior de la calzada en la entrada.

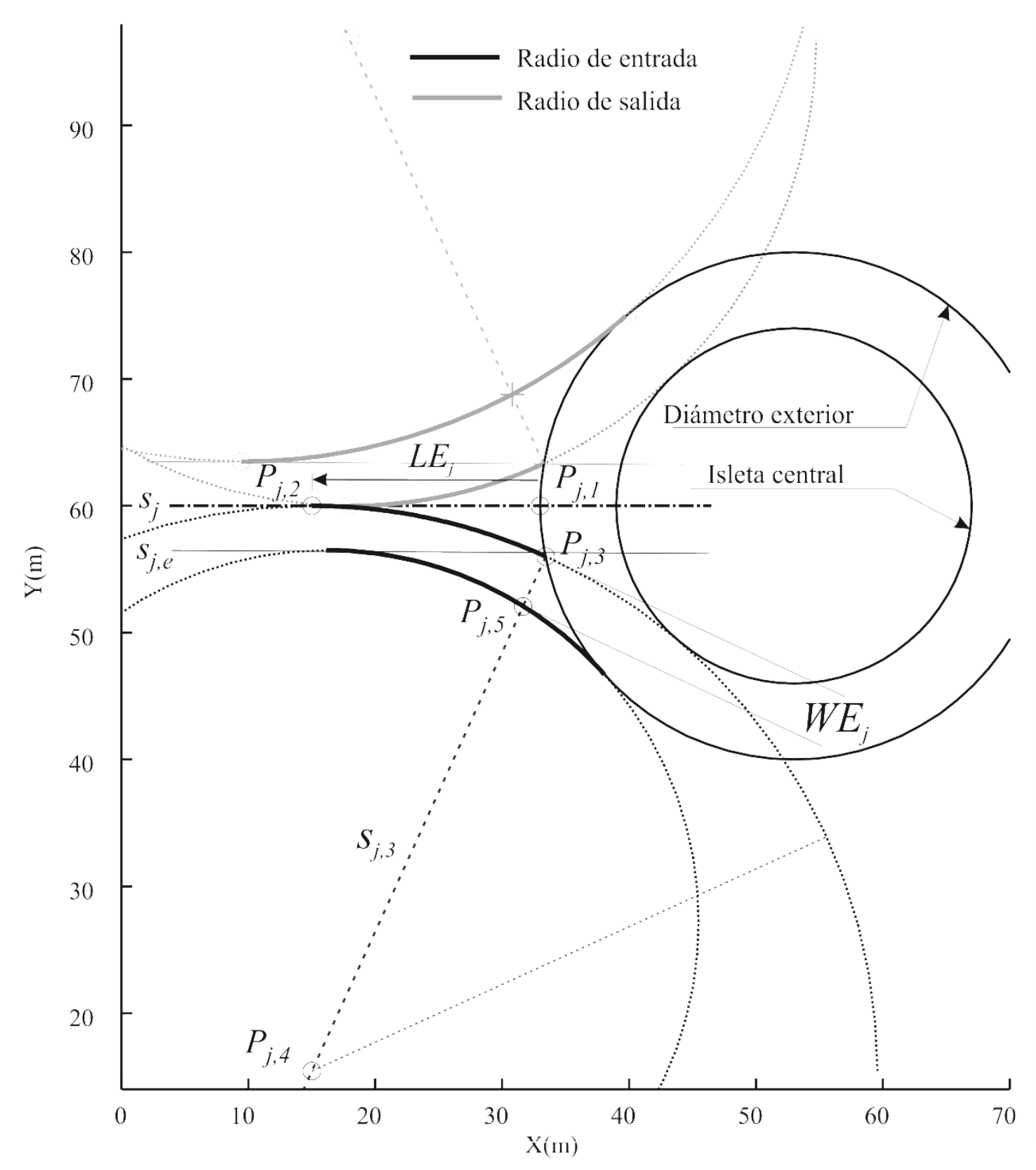

Figura 5. 1 Construcción geométrica de un acceso. 
Para definir la geometría de la salida se procede de forma análoga considerando $W S_{j}$ y $L S_{j}$ en lugar de $W E_{j}$ and $L E_{j .}$. El procedimiento se repite para cada una de las $j$ patas.

En el caso de que exista una mediana central en el acceso, se sustituye la alineación $s_{j}$ por dos nuevas alineaciones que definan los límites derecho (en el carril de entrada) e izquierdo (en el carril de salida) de la mediana y se aplica de igual forma el procedimiento.

\subsubsection{Construcción alternativa de la geometría de accesos próximos}

En el procedimiento básico que se acaba de presentar, la geometría de los accesos se construye de manera independiente. Si dos accesos están próximos puede ocurrir que el trazado de una entrada interfiera con el de la salida en la pata contigua. El resultado es una solución no factible.

Para evitarlo, se propone un método de reparación denominado "construcción alternativa" que se basa en adoptar un arco común para la geometría de los bordes exteriores en la entrada y la salida. Esta operación es habitual en la práctica profesional cuando se presentan estos casos.

El arco común entre una entrada y una salida se define mediante una circunferencia tangente a los bordes de las calzadas (de entrada y de salida consecutiva) y al círculo inscrito. El radio del arco resultante se ha denominado radio común.

En la Fig.5.2 se muestra, a modo de ejemplo, el cálculo del radio común realizado para una glorieta de 4 accesos en la que se han obtenido tres arcos de 6, 20 y $60 \mathrm{~m}$. 


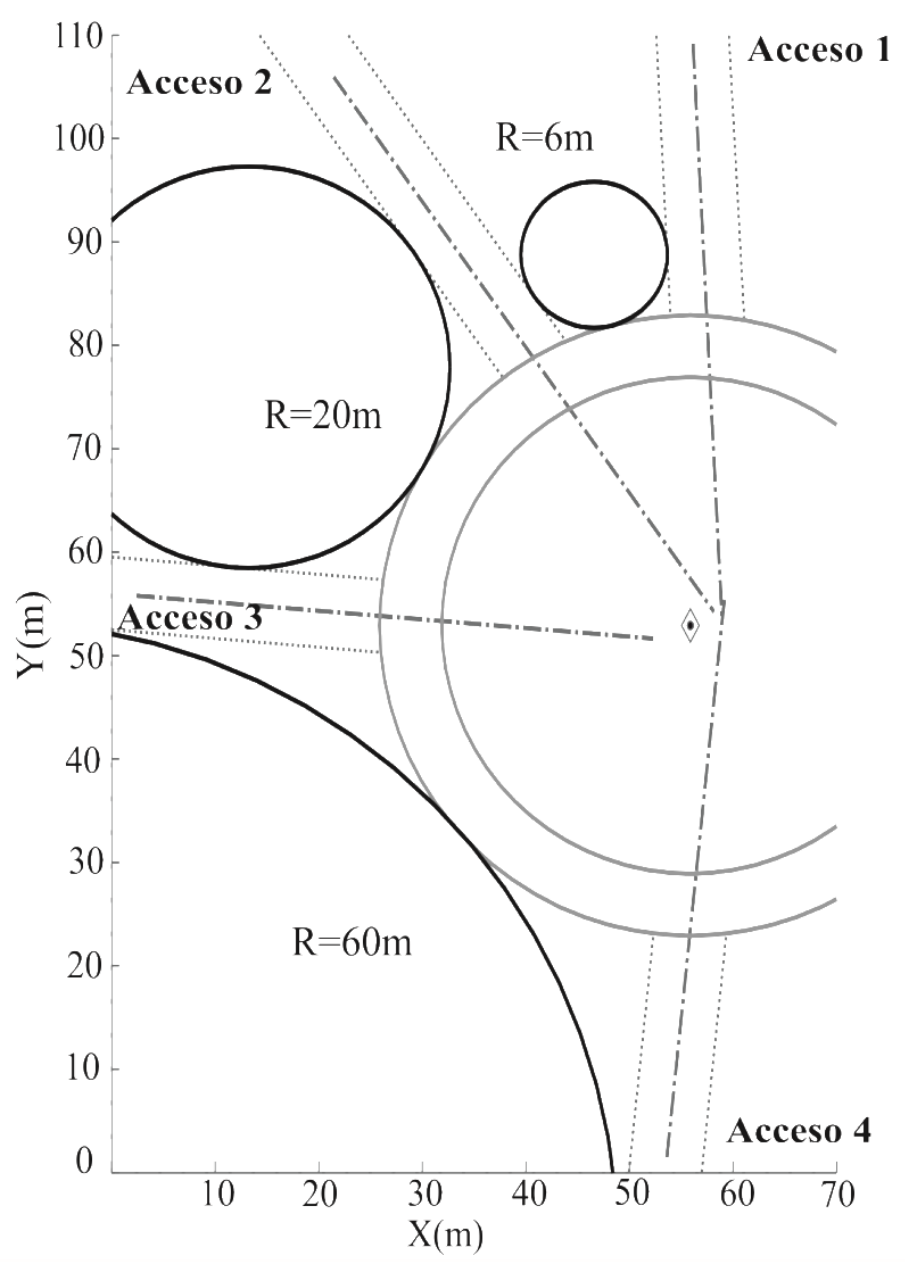

Figura 5. 2 Construcción del arco común entra las entradas y las salidas consecutivas.

En la construcción básica la geometría del acceso se define a partir del borde interior y de la anchura de calzada. En la construcción alternativa se procede de forma inversa, es decir, que partiendo del borde exterior y de la anchura de calzada se determina el borde interior y, a partir de éste, la longitud de la isleta. Por lo tanto a partir del arco común y de la anchura de la calzada en la entrada, es posible definir la geometría de una entrada mediante las siguientes operaciones (Fig. 5.3):

- Determinación del punto $P_{j, 1}$ mediante la intersección de la alineación $s_{j}$ con el círculo inscrito.

- Definición de una línea que une los puntos $P_{j, 6}$, que es el centro del radio común calculado, y $P_{j, 1}$. Sobre esta línea, y tomando como origen el centro del arco común $P_{j, 6}$, se calcula el punto $P_{j, 7}$ a una distancia igual al valor del radio común 
más la anchura de calzada en la entrada $W E_{j}$. Mediante esta construcción se fija la anchura de la entrada.

- Se determina el arco interior de entrada mediante una circunferencia tangente a la alineación de acceso $s_{j}$ y a la isleta central, pasando por $P_{j, 7}$. El punto de tangencia con $s_{j}\left(P_{j, 8}\right)$ permite calcular la longitud de la isleta deflectora $L E_{j}$. Este valor no coincidirá con el parámetro asignado para la isleta en los datos de partida.

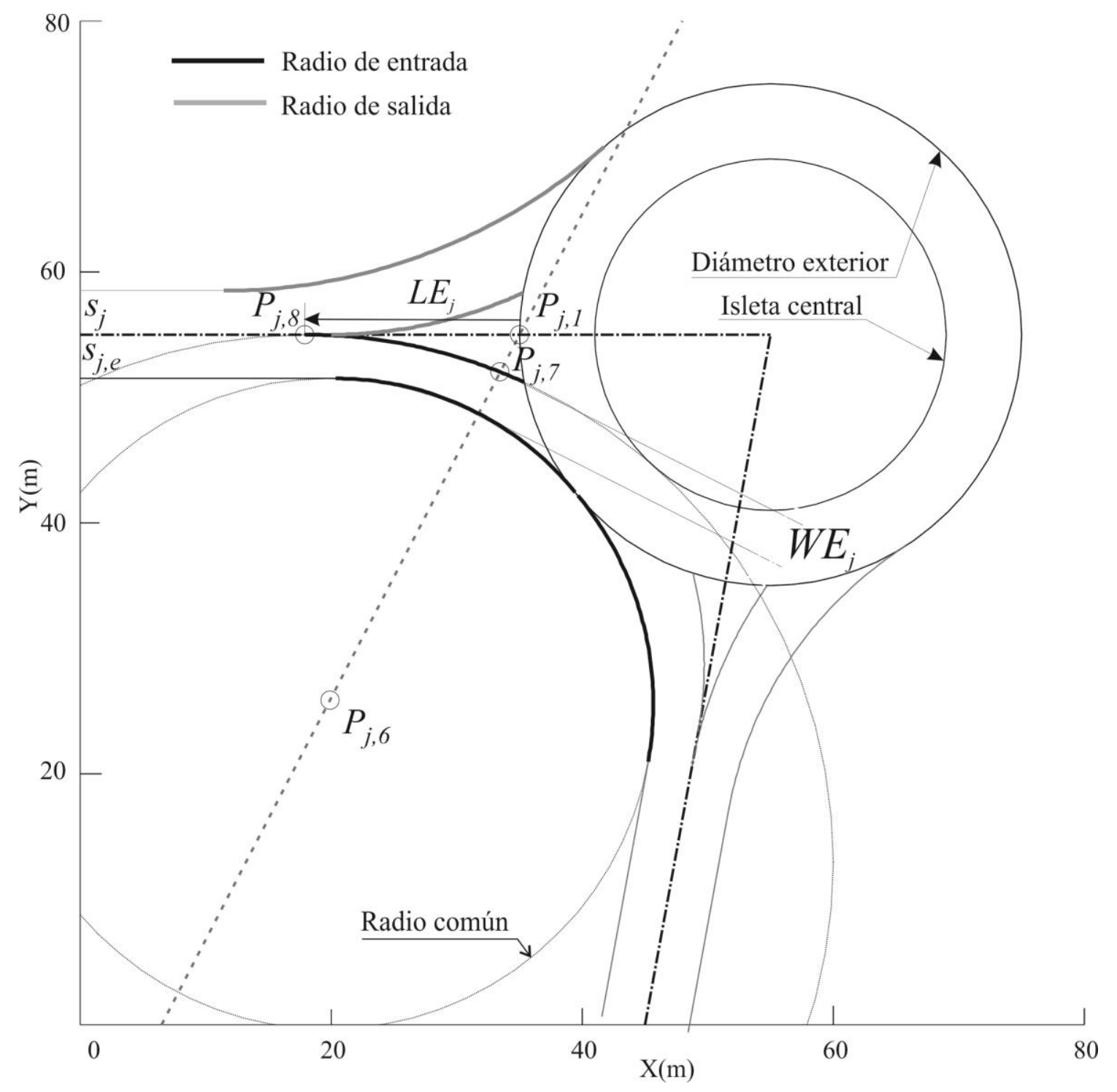

Figura 5. 3 Construcción alternativa en una entrada y una salida consecutiva.

Para la salida consecutiva se procede de manera análoga. 


\subsubsection{Estructura del programa}

\section{Etapa 1. Datos de partida.}

Los datos de partida son el número (Datos.na), el trazado (Datos.al) y la anchura de las calzadas (Datos.anC) de los accesos, los valores de los parámetros geométricos que se adoptan como variables de decisión (Datos.var $=\left[X_{c}, Y_{c}, D_{I C}, W_{C}, L E_{j}, W E_{j}, L S_{j}\right.$ y $W S_{j}$ ] con $j=1, \ldots M)$, el radio de giro mínimo del vehículo patrón (condición 3) (Datos. $R g_{\min }$ ), el radio de giro mínimo establecido para evitar el solape (condición 4)(Datos.tn= $\left.D_{I C} / 2\right)$ y el radio máximo (Datos.radmax) para aplicar la denominada construcción alternativa cuyo significado se explica en la etapa siguiente. Todos los datos de partida se agrupan dentro de la estructura Datos.

\section{Etapa 2. Revisión de las condiciones de accesos próximos.}

Se aplica el procedimiento descrito en el apartado 5.1.2 a todos los accesos y se compara el valor obtenido del radio común con un umbral máximo (Datos.radmax).

El valor del umbral máximo se establece por el usuario, si es posible en base a las especificaciones de la norma aplicable, y representa hasta qué punto el radio común es una solución adecuada para definir el trazado de una entrada y una salida consecutiva. Si el radio común calculado en un determinado acceso es menor al umbral máximo prefijado entonces la entrada y salida se define conforme a la construcción alternativa, y se modifican los valores de las longitudes de isleta consideradas en los datos de partida. Si el radio común es mayor que el umbral máximo, se pasa a la siguiente etapa.

\section{Etapa 3. Definición de la geometría.}

Se aplica el procedimiento descrito en el apartado 5.1.1 a todos los accesos teniendo como resultado la definición geométrica de las entradas y las salidas.

\section{Etapa 4. Validación de la solución.}

Para validar la solución se realizan una serie de comprobaciones que, en caso de cumplirse, tienen como resultado una solución factible (almacenada en Res.Geometria):

- No existe interferencia entre el radio de una entrada y el de una salida consecutiva. Para analizar la interferencia, se comprueba que no exista solape 
entre los puntos de tangencia con el círculo inscrito de los radios de los bordes exteriores de entrada y de la salida consecutiva.

- Las longitudes de las isletas deflectoras satisfacen las longitudes mínimas. Esto es necesario ya que cuando se aplica la construcción alternativa no se controla esta longitud (se deduce del cálculo).

- Los radios de los bordes exteriores de entrada y de salida $\left(R b_{e}\right.$ y $\left.R b_{s}\right)$ son superiores al umbral mínimo definido por las condiciones 3 y 4 (Datos.radmin se define como el menor valor de Datos. $\operatorname{Rg}_{\min }$ y Datos.tn=DIC 2 ).

La estructura del programa escrita en pseudocódigo se muestra en la página siguiente:

Programa: Cálculo automático de la geometría (AX-1)

1. LEER Datos;

//Entrada: datos de partida y parámetros geométricos//

2. FUNCIÓN cálculo del radio común entre cada entrada y salida;

//etapa 2 //

3. ITERACIÓN desde 1 hasta el número de accesos hacer

4. CONDICIONAL si el radio común es menor que el valor máximo prefijado entonces

5.

FUNCIÓN modificar el valor de las variables;

6. en otro caso

7. mantener los valores originales de las variables;

8. FIN CONDICIONAL

9. FIN ITERACIÓN

10. FUNCIÓN cálculo de la geometría de todos los accesos //etapa 3 //

11. ITERACIÓN desde 1 hasta el número de accesos hacer //etapa 4 //

12. CONDICIONAL si

13.

14.

15.

16.

17.

18.

19.

20. no existe interferencia entre $R b_{e}$ y $R b_{s}$ $L E>L E_{\min }$ $L S>L S_{\min }$ $R b_{e}>$ Datos.radmin $R b_{s}>$ Datos.radmin entonces la geometría es válida; //Salida: definición geométrica// en otro caso

21. FIN CONDICIONAL

22. FIN ITERACIÓN

23. FIN 


\subsection{CÁLCULO DE TRAYECTORIAS Y VELOCIDADES (AX-2)}

\subsubsection{Datos básicos e hipótesis de partida}

\subsubsection{Geometría de la glorieta}

El dato básico de partida para la definición de las trayectorias y las velocidades es la geometría de la glorieta. Las alineaciones curvas que definen las entradas y salidas, y la posición de la isleta central condicionarán en gran medida la definición de las trayectorias seguidas por los vehículos que deberán respetar unos resguardos mínimos.

\subsubsection{Resguardos $\left(\mathrm{d}_{1}, \mathrm{~d}_{2}, \mathrm{~d}_{3}, \mathrm{~d}_{4} \mathrm{y} \mathrm{d}_{5}\right)$}

Siguiendo las recomendaciones de la normativa internacional, el barrido del vehículo a lo largo de la trayectoria de paso debe respetar una serie de resguardos respecto a la geometría en diferentes partes de la glorieta.

En base a esto, se han posicionado los siguientes resguardos (Fig.5.4):

$\mathrm{d}_{1}$. Resguardo respecto del eje de trazado del acceso en la aproximación (o mediana si existe) y el borde interior de la calzada de entrada.

$\mathrm{d}_{2}$. Resguardo respecto del borde exterior de la calzada de entrada.

$d_{3}$. Resguardo respecto de la isleta central o el gorjal si existe.

$\mathrm{d}_{4}$. Resguardo respecto del borde exterior de la calzada de salida.

$\mathrm{d}_{5}$. Resguardo respecto del eje de trazado del acceso en la salida (o mediana si existe) y el borde interior de la calzada de salida.

En el procedimiento propuesto las distancias $\mathrm{d}_{1}, \mathrm{~d}_{2}, \mathrm{~d}_{3}, \mathrm{~d}_{4} \mathrm{y} \mathrm{d}_{5}$ pueden ser seleccionadas de acuerdo a la normativa que se esté considerando en el diseño. Por defecto, se consideran las siguientes distancias: 
$\Rightarrow$ En los accesos con doble sentido de circulación el resguardo es de $1 \mathrm{~m}$ respecto de la marca vial de separación de sentidos. En los accesos con medianas la distancia dependerá de si se han definido arcenes interiores, acerados o bordillos.

$\Rightarrow$ Si se definen arcenes mayores a $0,5 \mathrm{~m}$, el resguardo es de $1 \mathrm{~m}$.

$\Rightarrow$ Si se definen arcenes menores a $0,5 \mathrm{~m}$, el resguardo mantendrá $1,5 \mathrm{~m}$ respecto del límite exterior del arcén.

$\Rightarrow$ Donde se definan acerados o bordillos, el resguardo será de $1,5 \mathrm{~m}$.

Para cada posible trayectoria entre una entrada y una salida se pueden establecer los valores de estos resguardos, y a partir de ellos se pueden definir cinco elementos geométricos auxiliares denominados $O_{i}, i=1, \ldots, 5$ y que se encuentran desplazados respecto de los límites de la geometría una distancia $d_{i}, i=1, \ldots, 5$.

Estos elementos auxiliares son utilizados para la construcción de la trayectoria correspondiente y determinan su factibilidad: una trayectoria es factible cuando se sitúa dentro de los límites definidos por los elementos $O_{i}, i=1, \ldots, 5$ y es no factible en caso contrario.

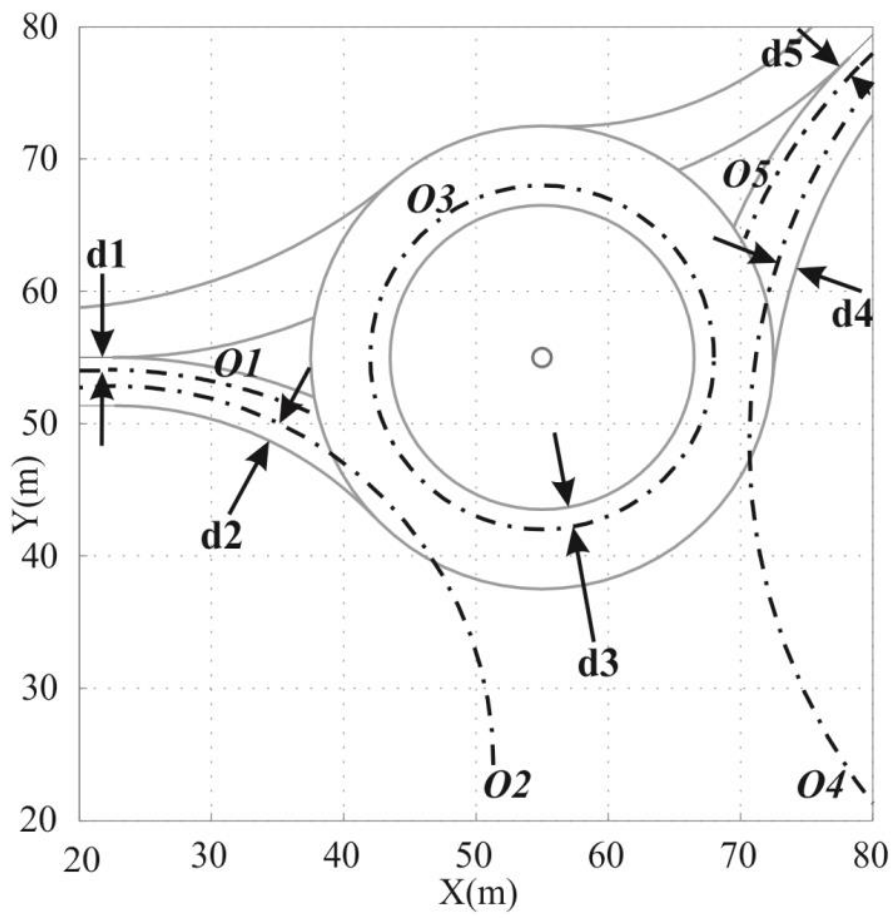

Figura 5. 4 Resguardos. 


\subsubsection{Tipos de trayectorias}

La clasificación habitual de los tipos de movimientos que pueden darse en una glorieta fue descrita en el apartado 2.2.3.4. Se definieron tres tipos de movimiento que, aproximadamente, se correspondían con: un giro a la derecha, un movimiento recto y un giro a la izquierda.

Puesto que el modelo propuesto admite cualquier posición de las patas, esta clasificación puede ser imprecisa. Por este motivo, y a efectos de este procedimiento, se propone una nueva clasificación basada en dos tipos de movimientos.

El primero, se ha denominado "trayectoria con deflexión" (Fig.5.5). La principal característica es que la presencia de la isleta central provoca una curvatura en la trayectoria del vehículo a su paso por la glorieta definiendo dos puntos de inflexión. El movimiento se compone de tres arcos circulares sucesivos de diferente signo, cuyos radios se han nombrado radio de entrada, radio de paso y radio de salida.

El segundo, se ha denominado "trayectoria directa" (Fig.5.5) y se realiza sin oposición de la isleta central y sin definir ningún punto de inflexión. La composición del movimiento es de un arco de entrada y un arco de salida con una recta intermedia de longitud variable (incluso cero).
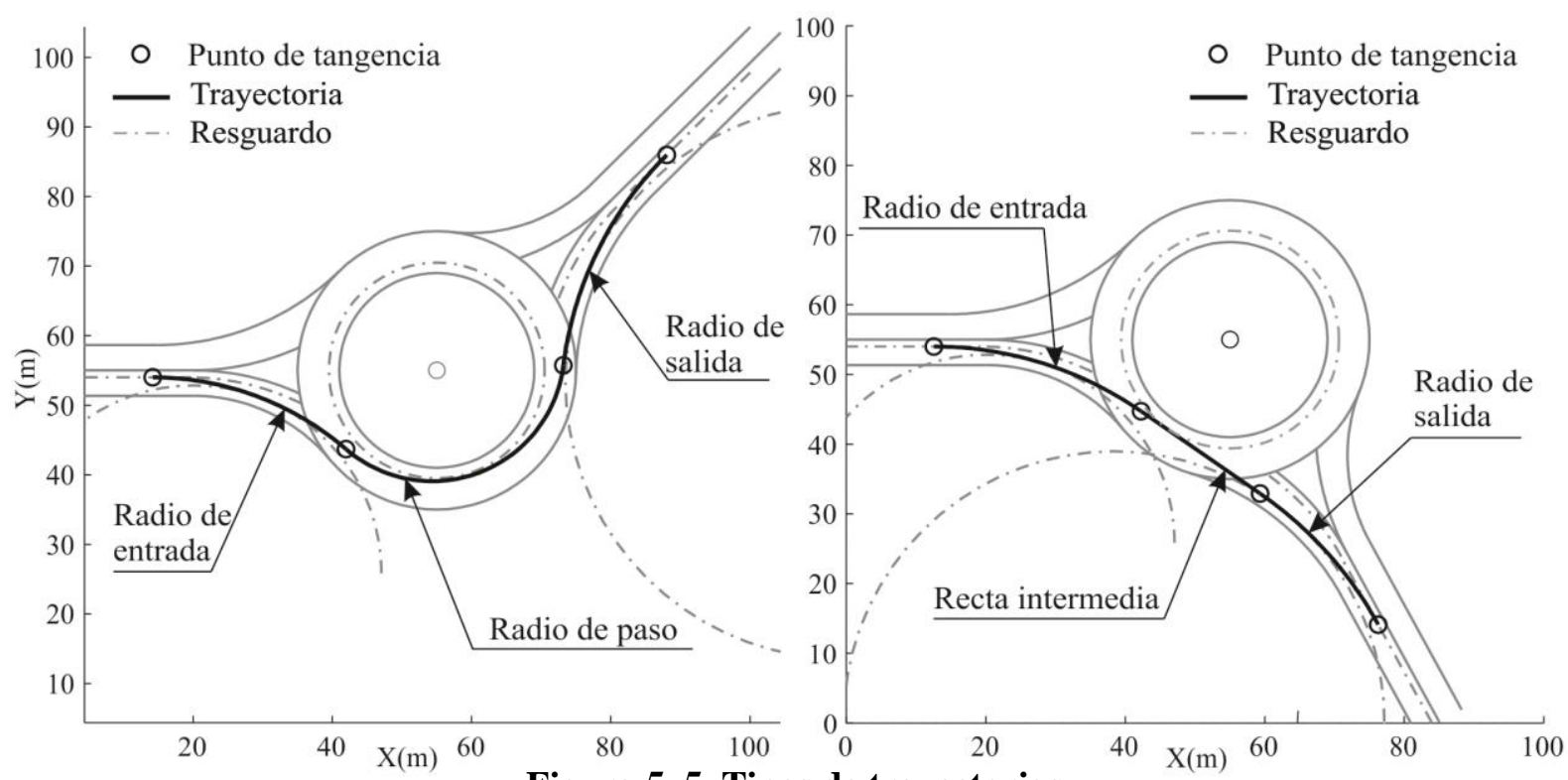

Figura 5. 5 Tipos de trayectorias. 


\subsubsection{Generación de una trayectoria}

El cálculo de la trayectoria entre una entrada y una salida se realiza definiendo una serie de alineaciones rectas y curvas circulares tangentes entre sí que se apoyan en los resguardos definidos en el apartado anterior y en un conjunto de puntos.

Para definir una trayectoria directa se parte de un punto en la entrada, denominado $P_{e}, \mathrm{y}$ de otro punto en la salida, denominado $P_{s}$. En el caso de la trayectoria con deflexión es necesario definir además un punto situado en la calzada anular y que se ha denominado $P_{c}$. La definición de $P_{e}, P_{s}, P_{c}$ se realiza en el apartado 5.3.3. La construcción geométrica de cada tipo de trayectoria se describe a continuación.

\subsubsection{Metodología para la trayectoria directa}

Para calcular una trayectoria directa entre una entrada y una salida se tienen que seguir los siguientes pasos (Fig.5.6):

- Dibujo de una línea $S$ entre los puntos $P_{e}$ y $P_{s}$.

- Si la línea $S$ intersecta con $O_{3}$, no es posible construir la trayectoria directa y se para el procedimiento.

- Cálculo del radio de entrada: círculo tangente a $O_{1}, O_{2}$ y $S$. El punto de tangencia en $S$ se ha denominado $T_{e}$.

- Cálculo del radio de salida: círculo tangente a $O_{4}, O_{5}$ y $S$. El punto de tangencia en $S$ se ha denominado $T_{s}$. 


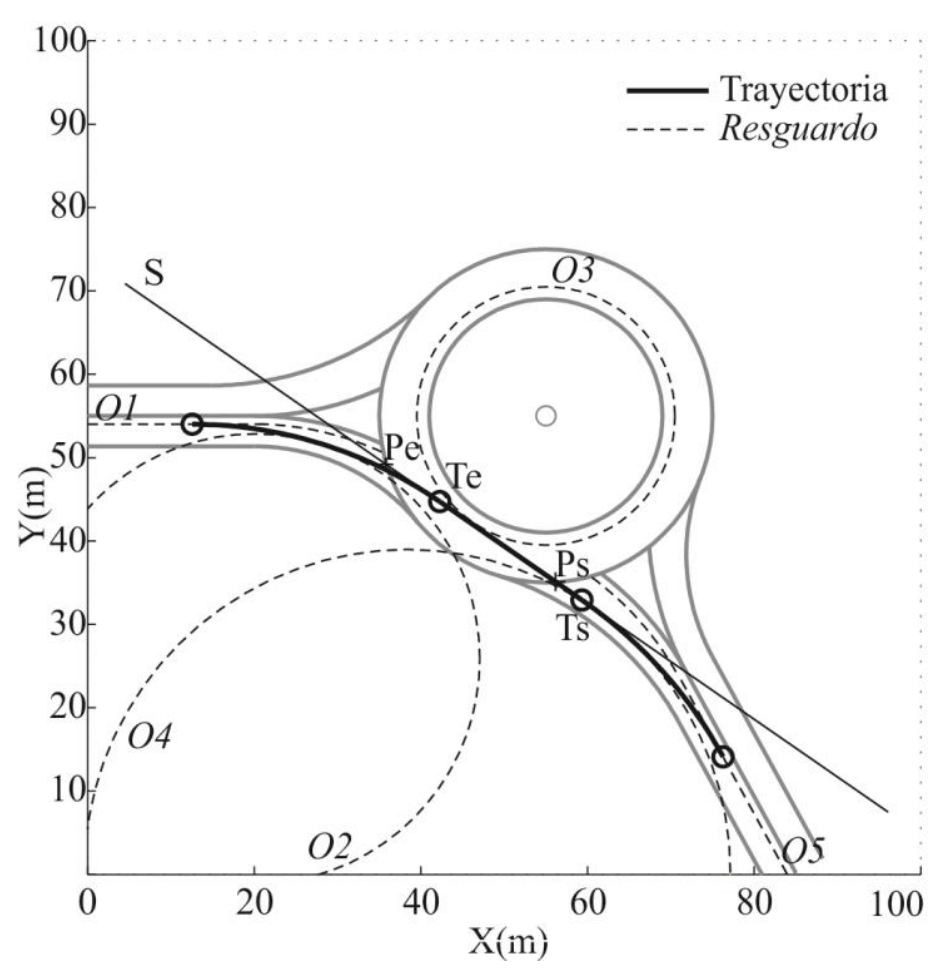

Figura 5. 6 Cálculo de la trayectoria directa.

- Si se produce la intersección de los arcos de entrada y de salida, se debe redefinir el arco de salida mediante la siguiente construcción: círculo tangente a $O_{5}$ y $S$ pasando por $T e$. Este caso se ha representado en la Fig.5.7. $T_{e}$ y $T_{s}$ son coincidentes.
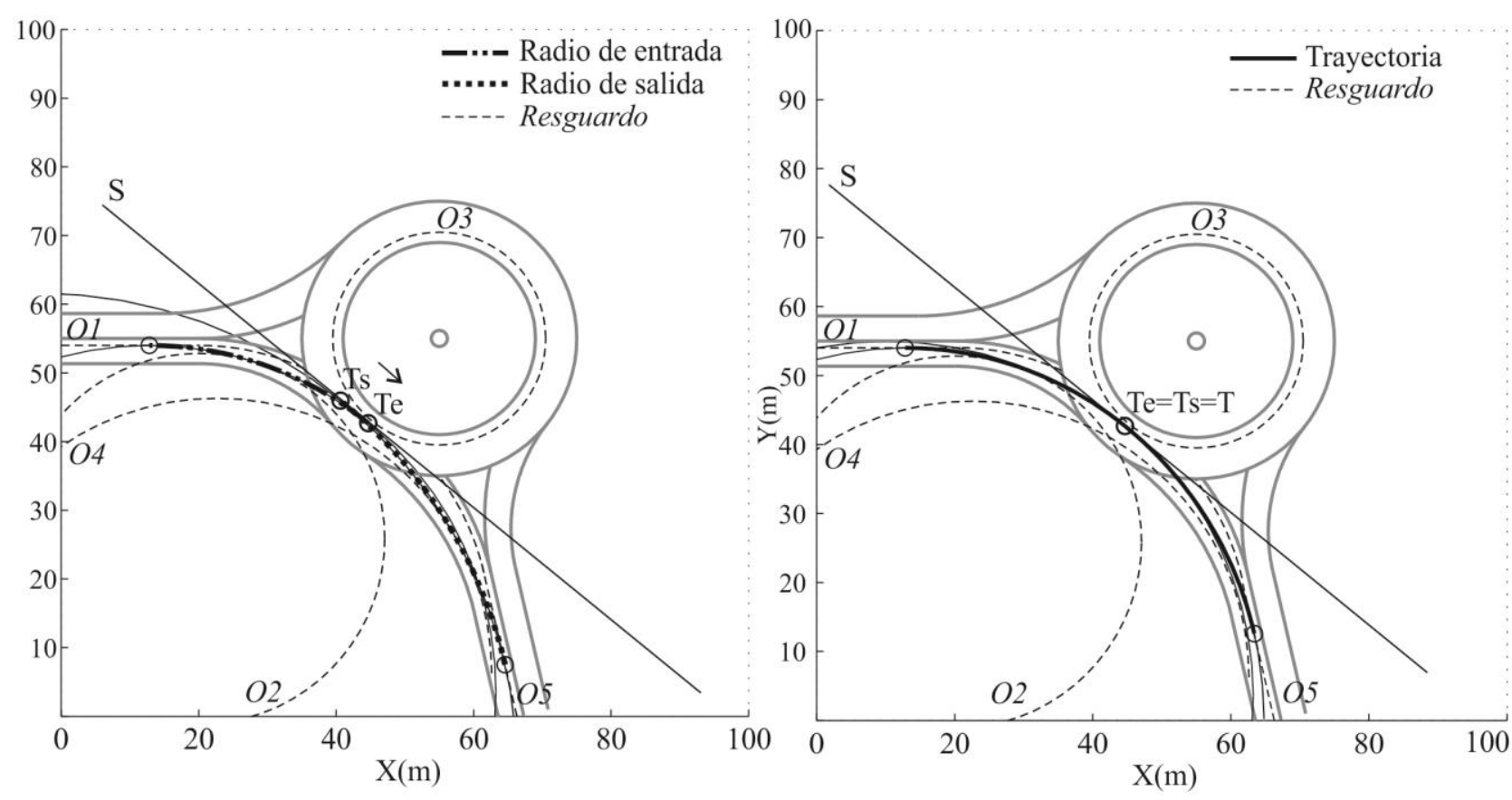

Figura 5. 7 Reconstrucción de la trayectoria directa. 
5.3.2.2 Metodología para la trayectoria con deflexión

El cálculo de la trayectoria con deflexión se realiza a partir de los puntos $P_{e}, P_{c}$ y $P_{s}, \mathrm{y}$ se deben seguir los siguientes pasos (Fig.5.8):

- Dibujo de un círculo denominado $C_{p}$ que pase por los tres puntos $P_{e}, P_{c}$ y $P_{s}$.

- Cálculo del radio de entrada: círculo tangente a $O_{1}, O_{2}$ y $C_{p}$.

- Cálculo del radio de salida: círculo tangente a $O_{4}, O_{5}$ y $C_{p}$.

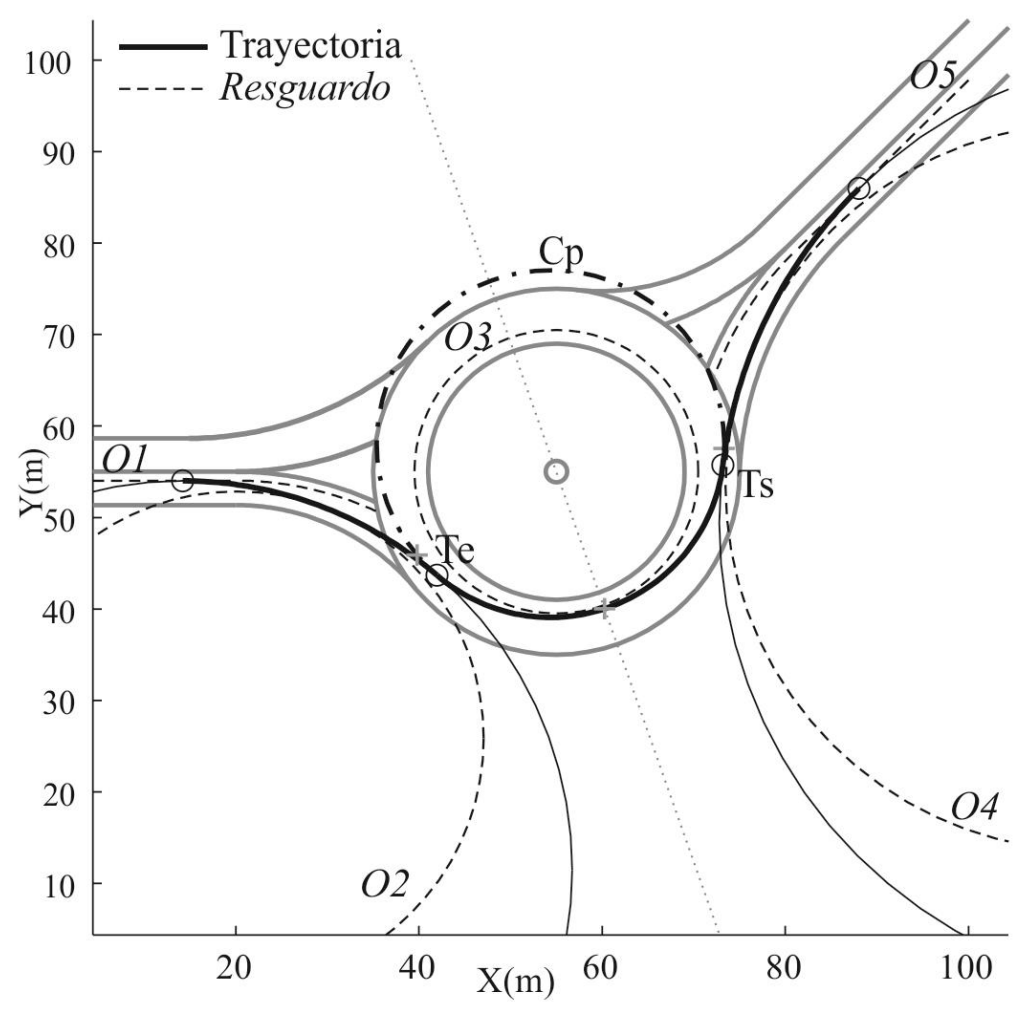

Figura 5. 8 Cálculo de la trayectoria con deflexión.

\subsubsection{Generación de la trayectoria más rápida}

La trayectoria más rápida entre una entrada y una salida se selecciona entre un conjunto de trayectorias factibles. 
A continuación se describe el procedimiento de cálculo para una entrada y una salida. Éste debe repetirse para todos los posibles movimientos que puedan definirse en la glorieta.

\section{Etapa 1. Datos de partida}

Los datos de partida son la geometría, el ángulo entre los ejes de las alineaciones de los accesos y los resguardos específicos para la entrada y la salida.

\section{Etapa 2. Cálculo de las Trayectorias Directas}

En primer lugar se generan un conjunto de posibles puntos $P_{e}$ y $P_{s}$ situados en la entrada y la salida respectivamente (Fig.5.9). Previamente se deben definir los elementos geométricos auxiliares $O$.

El conjunto de puntos $P_{e}$ se sitúan en el círculo inscrito y se distribuyen uniformemente en el tramo comprendido entre los puntos de intersección de éste con los elementos $O_{1}$ y $\mathrm{O}_{2}$.

El conjunto de puntos $P_{s}$ se sitúan en el círculo inscrito y se distribuyen uniformemente en el tramo comprendido entre los puntos de intersección de éste con los elementos $O_{4} \mathrm{y}$ $\mathrm{O}_{5}$.

El número de posibles puntos $P_{e}$ y $P_{s}$ establece el nivel de precisión que se desea en el cálculo ya que cada pareja de puntos define una posible solución. Con el objeto de minimizar la carga computacional del algoritmo, se inicia con un número de puntos reducido que fija el usuario $(Q)$, y en caso de no encontrar ninguna solución factible se eleva progresivamente hasta un máximo $(R)$.

Para cada pareja de posibles puntos $P_{e}$ y $P_{s}$ se aplica la metodología presentada en el apartado 5.3.2.1. Por tanto, el algoritmo se aplica un total de $P_{e}$ x $P_{s}$ veces y se obtienen soluciones factibles y no factibles. 

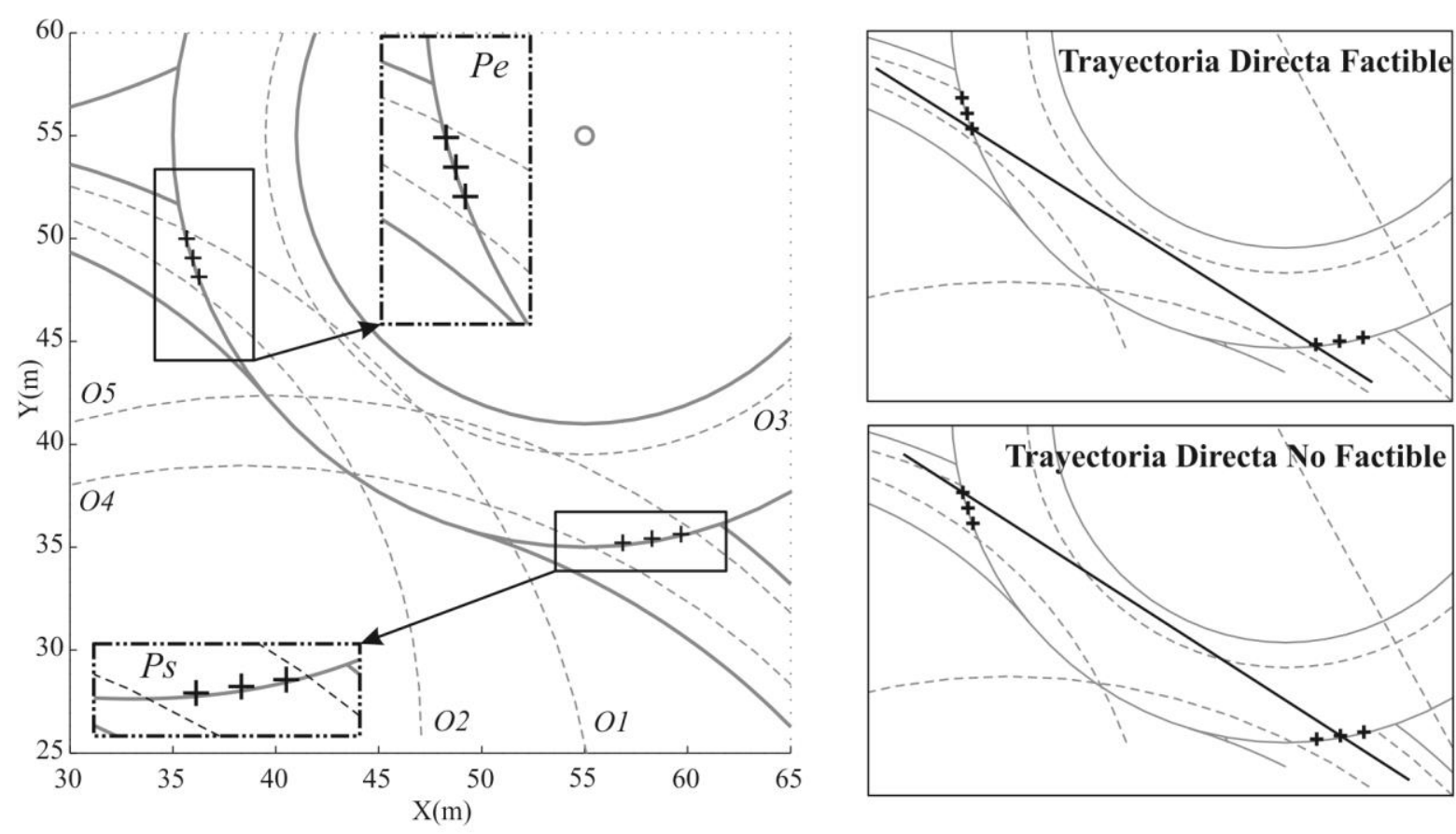

Figura 5. 9 Definición de los puntos de entrada y salida (TD).

Si no se encuentra ninguna solución factible, el movimiento es una trayectoria con deflexión. En caso contrario, se salta a la Etapa 3.

\section{Etapa 3. Cálculo de las trayectorias con deflexión}

Para procesar este paso es necesario generar el conjunto de puntos $P_{e}, P_{c}$ y $P_{s}$. Para obtenerlos hay que seguir los siguientes pasos (Fig.5.10):

- Dibujo de una circunferencia $C_{1}$ tangente a $O_{2}, O_{3}$ and $O_{4}$. Los puntos de tangencia se localizan en la entrada, en el anillo y en la salida.

- A continuación, se definen tres líneas $L_{1}, L_{2}$ y $L_{3}$ desde cada punto de tangencia hasta el centro de $C_{l}$. El conjunto de posibles puntos $P_{e}, P_{c}$ y $P_{s}$ están situados uniformemente repartidos a lo largo de estas líneas, empezando en el punto de tangencia y hasta una distancia igual a la cuarta parte de la anchura de la calzada anular. Como en la etapa anterior, el algoritmo se inicia con un número reducido de puntos y se aumenta hasta un máximo si se desea mayor precisión (se tantean un número mayor de soluciones). 
A cada combinación de puntos $P_{e}, P_{c}$ y $P_{s}$ se le aplica la metodología descrita en el apartado 5.3.2.2. El número total de soluciones ejecutadas será igual a $P_{e} \times P_{s} \times P_{c}$.
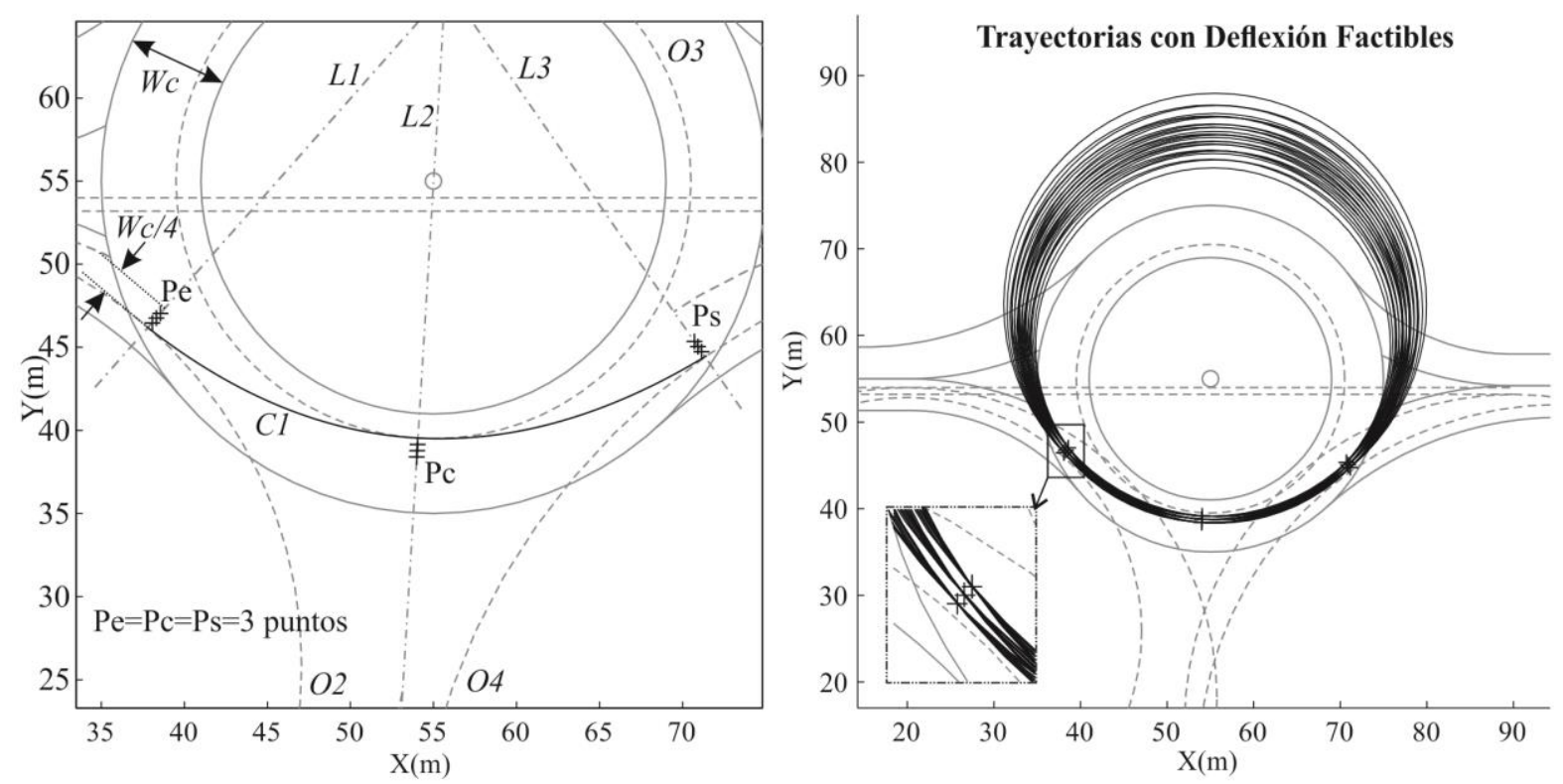

Figura 5. 10 Definición de los puntos auxiliares (TDF).

\section{Etapa 4: Selección de la trayectoria}

En este última etapa se selecciona una trayectoria entre el haz de soluciones factibles que se haya generado.

Como se ha expuesto en el capítulo 2 (Antecedentes), en muchos estudios se considera que el radio de entrada de la trayectoria es un parámetro crítico para la seguridad: cuanto mayor es su valor, mayor es el riesgo. Por este motivo, se ha adoptado el criterio de seleccionar la trayectoria que maximice el radio de entrada.

La estructura del programa descrita en pseudocódigo se presenta en la página siguiente. 
Programa: Cálculo automático de las trayectorias (AX-2)

1. LEER Datos;

//Entrada: datos de partida//

2. LEER Res;

//Entrada: geometría//

3. FUNCIÓN definición de los elementos geométricos auxiliares $O$;

4. CONDICIONAL si el ángulo entre la entrada y la salida es menor que $180^{\circ}$ entonces

5.

FUNCIÓN generar $Q$ puntos $P_{e}$ y $P_{s}$;

6. FUNCIÓN generar rectas en $S$;

7.

CONDICIONAL si no existe ninguna recta en $\mathrm{S}$ entonces

8. IMPRIMIR "búsqueda exhaustiva método directo"

9. MIENTRAS contador sea igual que 0 entonces

10. introduzco 10 nuevos puntos en $Q$;

11. FUNCIÓN generar rectas $S$;

12. CONDICIONAL si $Q$ es menor que $R$ entonces

13. contador es igual al número de rectas en $S$;

14. $\mathrm{Km}=1$;

15. en otro caso

16. $\mathrm{Km}=2$; romper

17. FIN CONDICIONAL

18. FIN MIENTRAS

19. en otro caso

20. $\mathrm{Km}=1$;

21. FIN CONDICIONAL

$22 . \quad$ en otro caso

$23 . \quad \mathrm{Km}=2$;

24. FIN CONDICIONAL

25. FUNCIÓN definir puntos $P_{e}, P_{c}$ y $P_{s}$.

26. SELECCIONAR CASO

27. Km=1; IMPRIMIR: "La trayectoria es directa";

28. FUNCIÓN calcular la trayectoria y selección;

//Salida: trayectorias//

29. $\mathrm{Km}=2$; IMPRIMIR: "La trayectoria es con deflexión";

30. $\quad$ FUNCIÓN calcular la trayectoria y selección;

//Salida: trayectorias//

31. FIN SELECCIÓN

32. FIN 


\subsubsection{Ejemplo de aplicación}

En este apartado se presenta un ejemplo del cálculo de las trayectorias en una glorieta de un carril. El objetivo es mostrar mediante un caso teórico toda la casuística que se ha expuesto en los aparatados anteriores.

La Tabla 5.1 contiene los datos necesarios para definir una glorieta de tres patas. La anchura de aproximación de los accesos es de $7 \mathrm{~m}$ y se han considerado los siguientes resguardos: $\mathrm{d}_{1}=1 \mathrm{~m}, \mathrm{~d}_{2}=1.5 \mathrm{~m}, \mathrm{~d}_{3}=1.5 \mathrm{~m}, \mathrm{~d}_{4}=1.5 \mathrm{~m}, \mathrm{~d}_{5}=1 \mathrm{~m}$. En la Fig. 5.11 se ha representado el caso de estudio.

\begin{tabular}{lcccccccc} 
& LE $(\mathrm{m})$ & WE $(\mathrm{m})$ & LS $(\mathrm{m})$ & WS $(\mathrm{m})$ & Xc $(\mathrm{m})$ & Yc $(\mathrm{m})$ & DIC $(\mathrm{m})$ & Wc $(\mathrm{m})$ \\
\hline Accesos & $\begin{array}{c}\text { Long. } \\
\text { isleta } \\
\text { entrada }\end{array}$ & $\begin{array}{c}\text { Anchura } \\
\text { de } \\
\text { entrada }\end{array}$ & $\begin{array}{c}\text { Long. } \\
\text { isleta } \\
\text { salida }\end{array}$ & $\begin{array}{c}\text { Anchura } \\
\text { de salida }\end{array}$ & $\begin{array}{c}\text { Coordenada X } \\
\text { del centro }\end{array}$ & $\begin{array}{c}\text { Coordenada Y } \\
\text { del centro }\end{array}$ & $\begin{array}{c}\text { Diámetro } \\
\text { exterior }\end{array}$ & $\begin{array}{c}\text { Anchura de } \\
\text { calzada } \\
\text { anular }\end{array}$ \\
\hline Pata 1 & 18 & 4.3 & 23 & 5.5 & & & & \\
Pata 2 & 21 & 4.3 & 18 & 5.5 & 55 & 55 & 60 & 6 \\
Pata 3 & 20 & 4.3 & 25 & 5.5 & & & &
\end{tabular}

Tabla 5. 1 Datos de partida. Ejemplo de aplicación del cálculo de trayectorias.

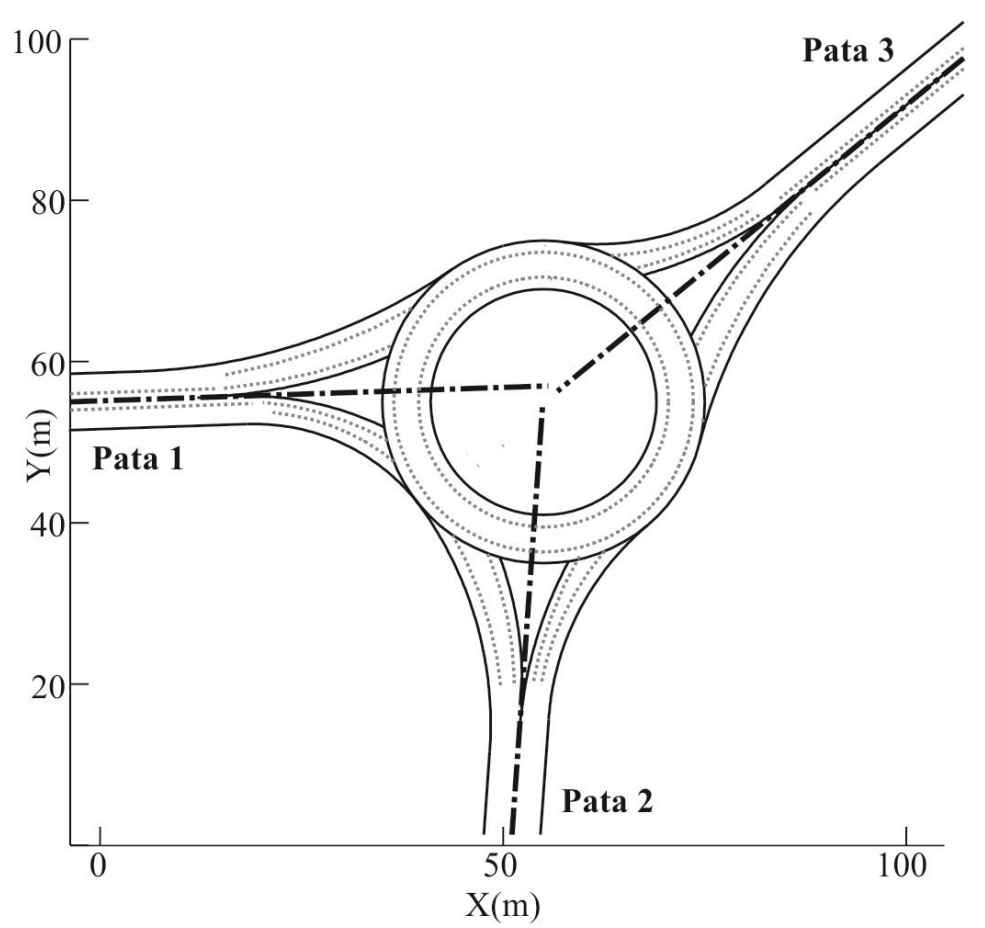

Figura 5. 11 Cálculo de trayectorias: glorieta de estudio. 
Para la metodología de cálculo de una trayectoria directa, los vectores que recogen los posibles puntos $P_{e}$ y $P_{s}$ se inician con 10 puntos cada uno y hasta un máximo de 50 . Para la metodología de la trayectoria con deflexión, se han considerado un número de posibles puntos $P_{e}, P_{c}$ y $P_{s}$ de seis.

Tras aplicar el procedimiento se obtienen seis trayectorias (no se considera el cambio de sentido) representadas en la Fig.5.12.

Los detalles de los resultados obtenidos pueden observarse en la Figura 5.13. Para cada trayectoria se pueden obtener dos gráficos: a la izquierda se representa la solución geométrica final adoptada para el movimiento, y a la derecha la combinación de valores de los radios obtenidos para las soluciones factibles (en gris) y para la solución final (negro).

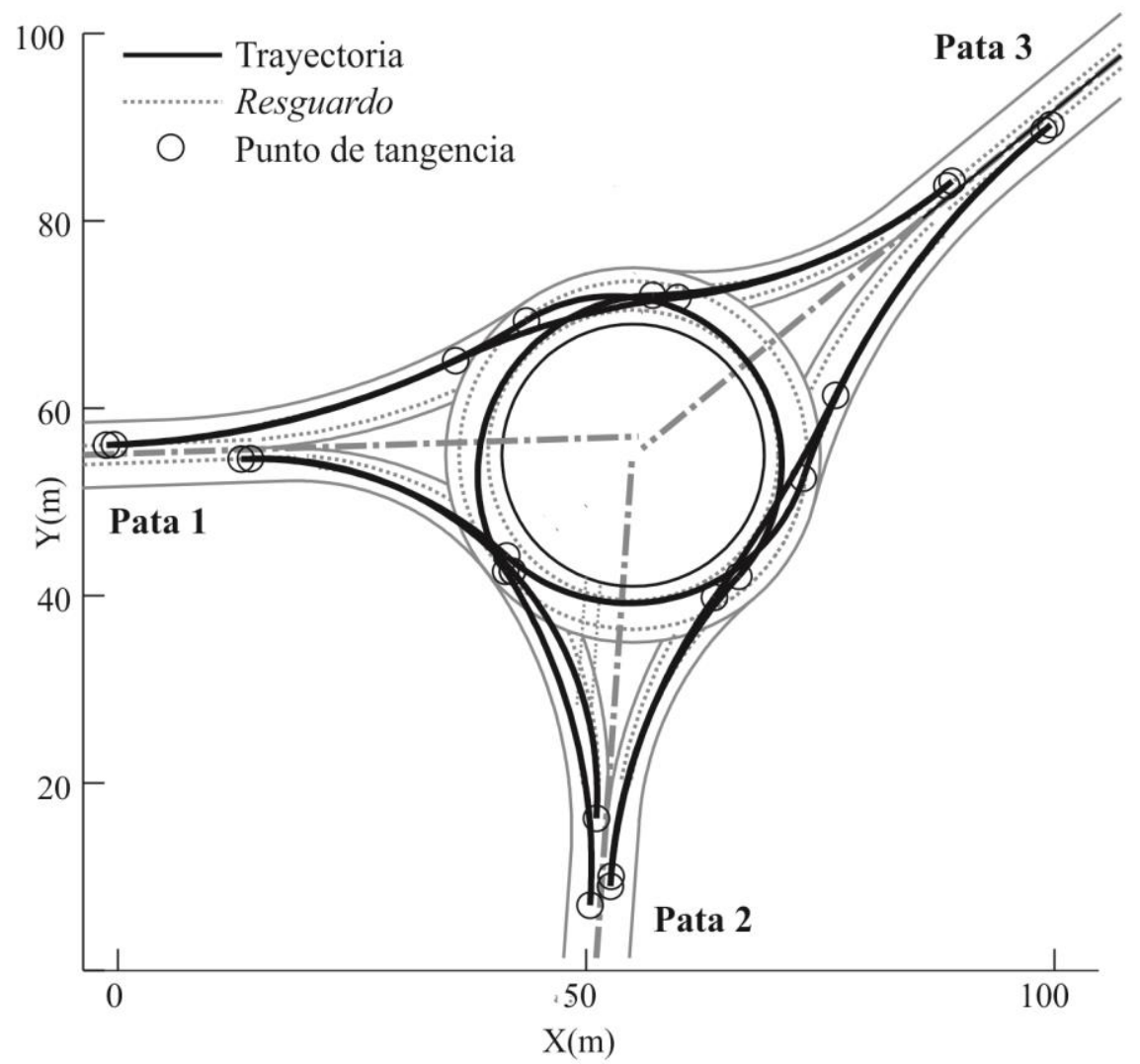

Figura 5.12 Cálculo de trayectorias: resultados del ejemplo de aplicación. 
- Movimiento con origen en el acceso 1 y final en el acceso 2.

Se trata de una trayectoria directa compuesta de dos arcos cuyos radios presentan valores muy parecidos. El resto de combinaciones factibles pasan por disminuir el radio de entrada y aumentar el de salida.

- Movimiento con origen en el acceso 1 y final en el acceso 3.

Se trata de una trayectoria con deflexión compuesta de tres arcos cuyos radios cumplen para todas las soluciones factibles: R3 (radio de salida) > R1 (radio de entrada) > R2 (radio de paso). Los radios de entrada se mantienen en el orden de entre 30 y 40m. Cuando se atraviesa el anillo casi todas las soluciones tienden a un valor para el radio de paso próximo a los $20 \mathrm{~m}$. Las condiciones favorables de la salida favorecen la definición de radios amplios en el orden de entre 80 y 100m.

- Movimiento con origen en el acceso 2 y final en el acceso 3.

Se trata de una trayectoria con deflexión compuesta de tres arcos cuyos radios cumplen para todas las soluciones factibles: R2 (radio de paso) > R3 (radio de salida) $>$ R1 (radio de entrada). Esta tendencia se debe a que existe un importante ángulo entre los ejes de los accesos y la presencia de la glorieta apenas provoca curvatura en las trayectorias. De hecho, este movimiento podría convertirse con facilidad en un movimiento directo pasando R2 a tener un valor infinito (una recta).

- Movimiento con origen en el acceso 2 y final en el acceso 1.

Se trata de una trayectoria con deflexión compuesta de tres arcos cuyos radios presentan la siguiente tendencia: R3 (radio de salida) $>$ R1 (radio de entrada) $>$ R2 (radio de paso). En comparación con otros movimientos similares, en este caso los valores de los radios R1 y R3 son más amplios. El valor de R2 es más reducido ya que se aumenta el desarrollo por la calzada anular.

- Movimiento con origen en el acceso 3 y final en el acceso 1.

Se trata de una trayectoria con deflexión compuesta de tres arcos cuyos radios cumplen para todas las soluciones factibles: R3 (radio de salida) > R2 (radio de paso) $>$ R1 (radio de entrada). Esta tendencia es debida al importante ángulo entre los ejes de las alineaciones de acceso, aunque en este caso la isleta provoca cierta curvatura en las diferentes trayectorias.

- Movimiento con origen en el acceso 3 y final en el acceso 2.

Se trata de una trayectoria con deflexión cumpliéndose para todas las soluciones factibles que R3 (radio de salida) > R1 (radio de entrada) > R2 (radio de paso). 

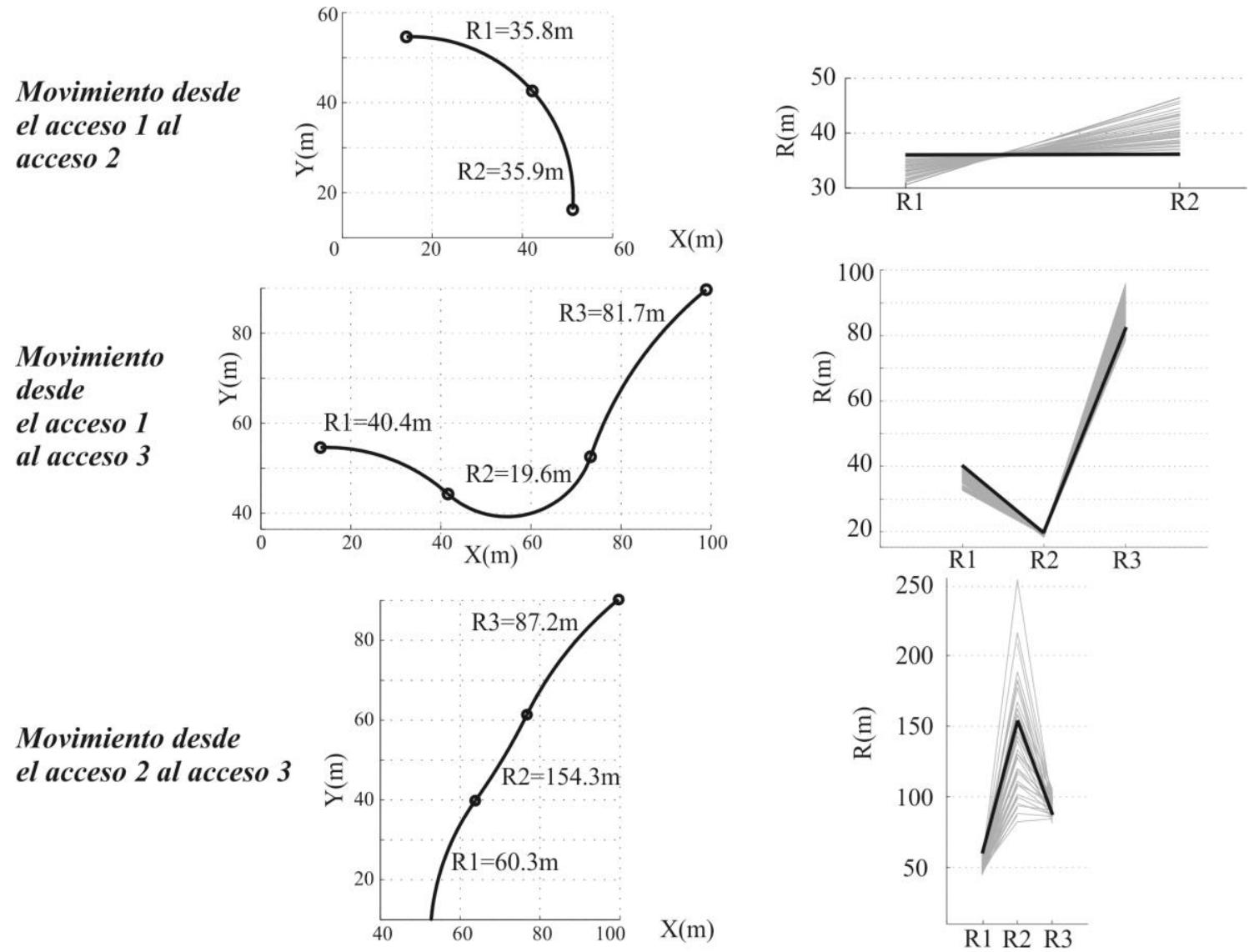

Movimiento desde el acceso 2 al acceso 3
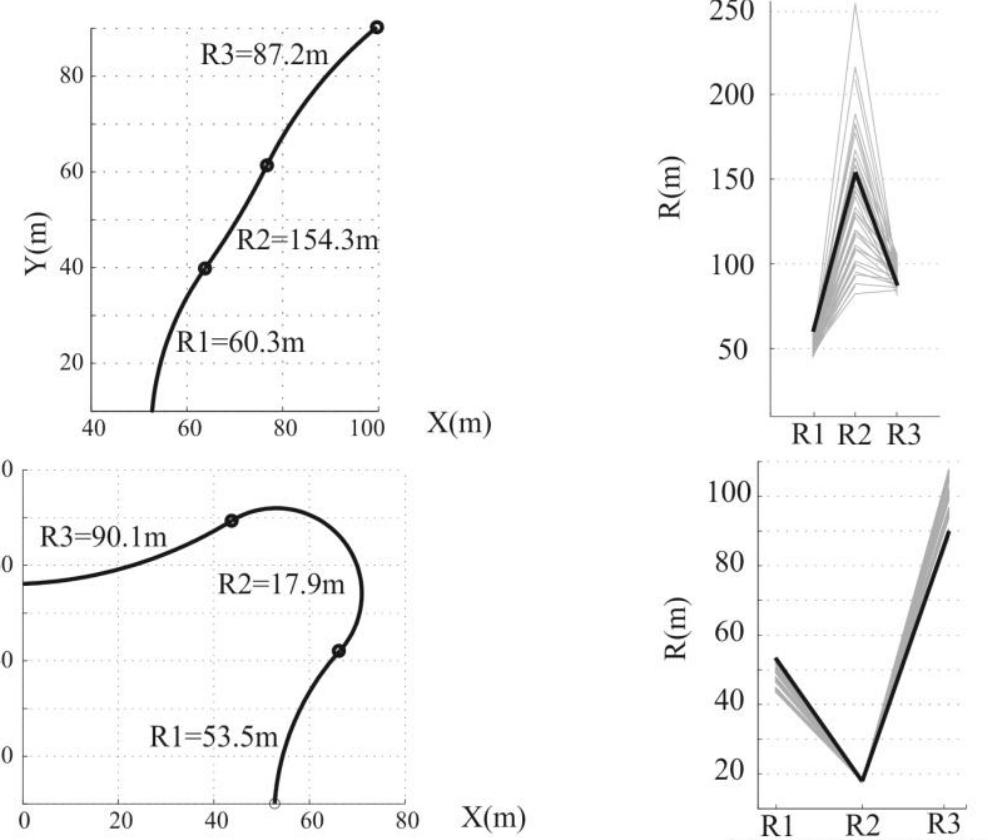

Movimiento desde el acceso 2 al acceso 1
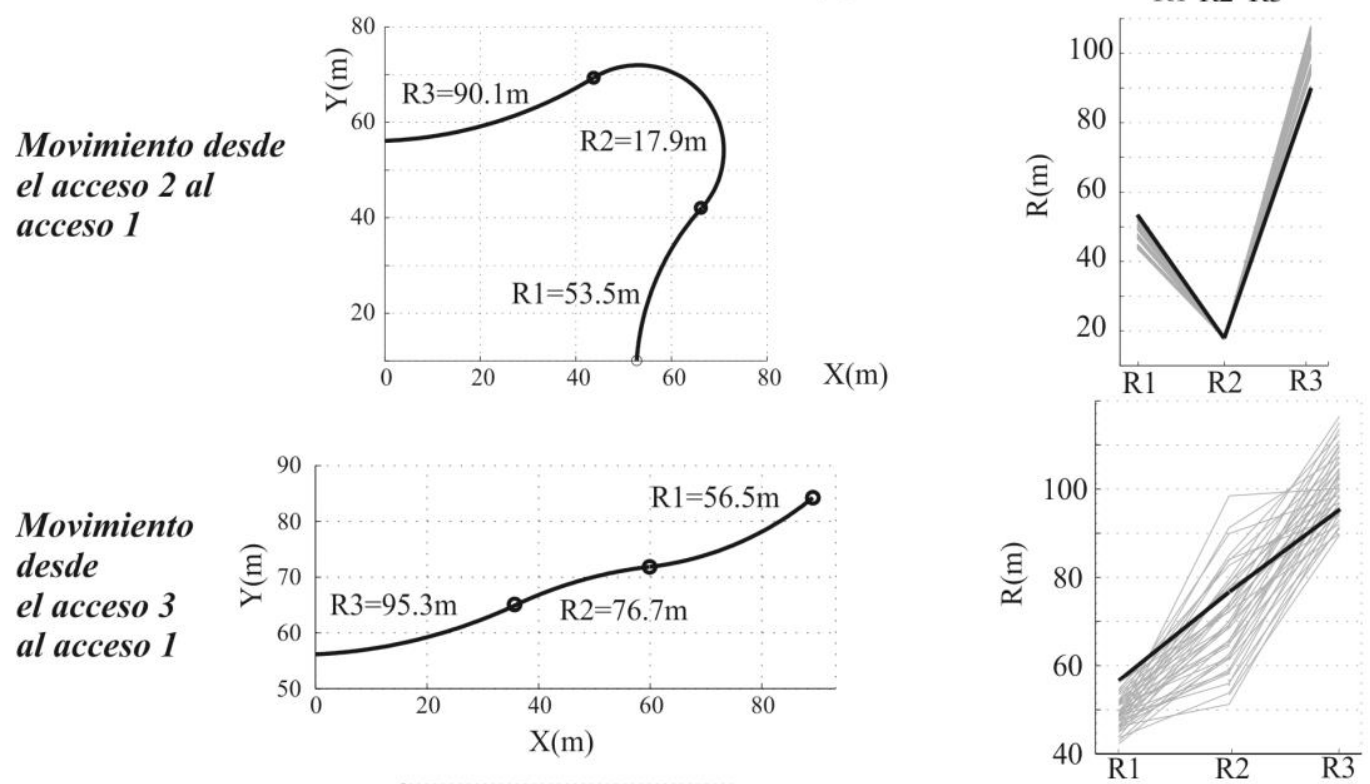

Movimiento desde el acceso 3 al acceso 2
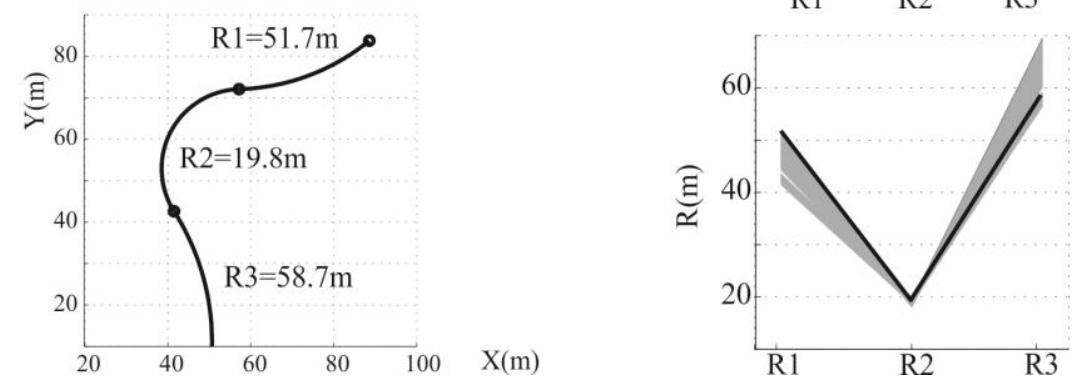

Figura 5.13 Cálculo de trayectorias: resultados del ejemplo de aplicación (II). 


\subsubsection{Cálculo de las velocidades}

Para el cálculo de las velocidades a partir de los radios de las trayectorias calculados se sigue la formulación especificada en la norma de Estados Unidos de glorietas (NCHRP, 2010):

$$
\begin{array}{ll}
V=3,4415 R^{0,3861} & \text { para peralte }+0,02 \\
V=3,4614 R^{0,3673} & \text { para peralte de }-0,02
\end{array}
$$

donde $R$ representa al radio de la trayectoria en pies y $V$ la velocidad en millas por hora.

\subsection{REGIÓN DE CENTROS FACTIBLES (AX-3)}

La delimitación de la región de centros factibles FCA se base en el establecimiento de tres condiciones:

1. Los ejes de los accesos deben intersectar la isleta central.

2. El borde exterior de cada calzada de aproximación y el borde exterior de la calzada de salida consecutiva se deben cruzar en un punto interior al círculo inscrito.

El cumplimiento de estas condiciones permite la aplicación del procedimiento descrito en el apartado 5.2.

3. Si se calcula el arco común entre una entrada y una salida (apartado 5.2.2), el radio debe satisfacer la dimensión mínima establecida en el sistema de restricciones (condiciones 3 y 4 ).

El proceso de cálculo de la región es secuencial. En primer lugar, se genera una nube de puntos de posibles centros tan amplia como se quiera. La densidad de este conjunto 
determina la precisión a la hora de establecer el contorno cerrado que defina la FCA. En segundo lugar, se aplica a cada posible centro las condiciones especificadas anteriormente, considerando que la glorieta tiene el diámetro exterior con valor mínimo (ya que es el caso más restrictivo) fijado en los datos de partida (contenido en DatosAG.gen_inf). Si se satisfacen, el punto es clasificado como factible; si no, como no factible. Por último, se define un casco convexo que contenga en su interior exclusivamente puntos factibles.

Este casco convexo define un área que se utiliza para la generación aleatoria de las coordenadas que definen la posición del centro del anillo. Cuando se aplica el algoritmo de optimización (operadores de cruce y mutación) se comprueba de igual forma que el posible centro generado se encuentra dentro de este contorno. En caso de que se sitúe fuera se repara su valor hasta el punto más cercano que sea interior al contorno.

En la Fig.5.14 se muestra un ejemplo de cálculo para una glorieta de tres accesos. En el gráfico de la izquierda se considera un diámetro mínimo de $35 \mathrm{~m}$. En el de la derecha, un diámetro mínimo de 45m. Para los dos casos se representa en amarillo la nube de puntos original. En verde, se muestran los puntos que cumplen con la condición 1. En cián, los puntos que cumplen con la condición 1 y 2 . Por último, en rojo los puntos que definen del contorno cerrado y que delimitan puntos que cumplen las tres condiciones.
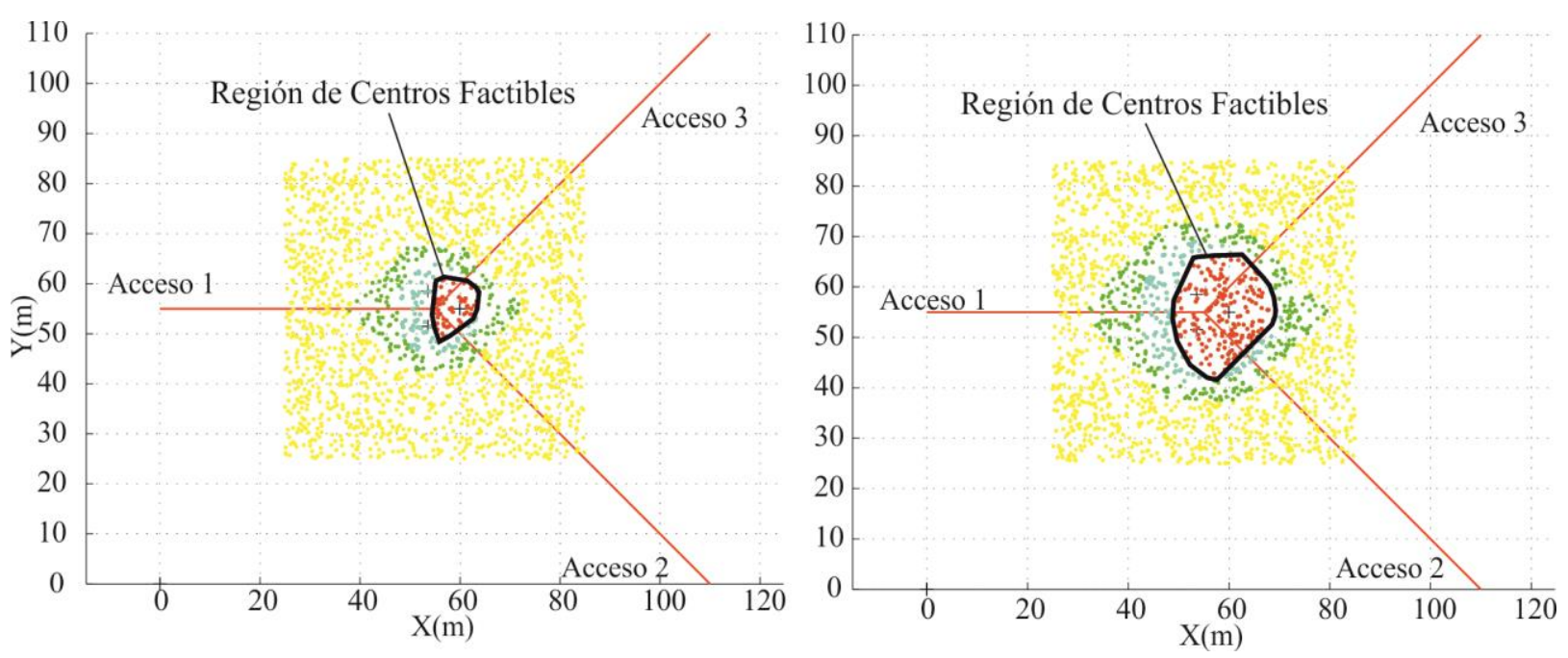

Figura 5. 14 Cálculo de la región de centros factibles (FCA). 


\section{CAPÍTULO 6. APLICACIONES EXPERIMENTALES}

\subsection{INTRODUCCIÓN}

En este capítulo se presenta la aplicación de los códigos informáticos generados en la resolución de dos casos experimentales de forma que se pueda contrastar la metodología desarrollada.

Con el objetivo de analizar el comportamiento del modelo en diferentes situaciones, se han seleccionado dos glorietas con diferentes condicionantes de proyecto. En primer lugar, se analiza el caso de la conversión de una intersección convencional a glorieta de un solo carril. En segundo lugar, se describe el caso de la remodelación de una glorieta multicarril ya existente. En ambos ejemplos se ha buscado que la intersección se sitúe en un ámbito interurbano con el menor número de patas posible (tres) ya que esto evita restricciones innecesarias en el análisis del funcionamiento del modelo y de la búsqueda de la posición de la glorieta.

\subsection{CONSTRUCCIÓN DE UNA NUEVA GLORIETA DE UN CARRIL}

El primer caso de estudio se refiere a la construcción de una nueva glorieta en una intersección convencional de tres tramos canalizada con isletas y lágrima central (Fig.6.1). La morfología se completa con una cuña de deceleración en el movimiento entre la pata situada al sur hacia la pata situada en el este. 


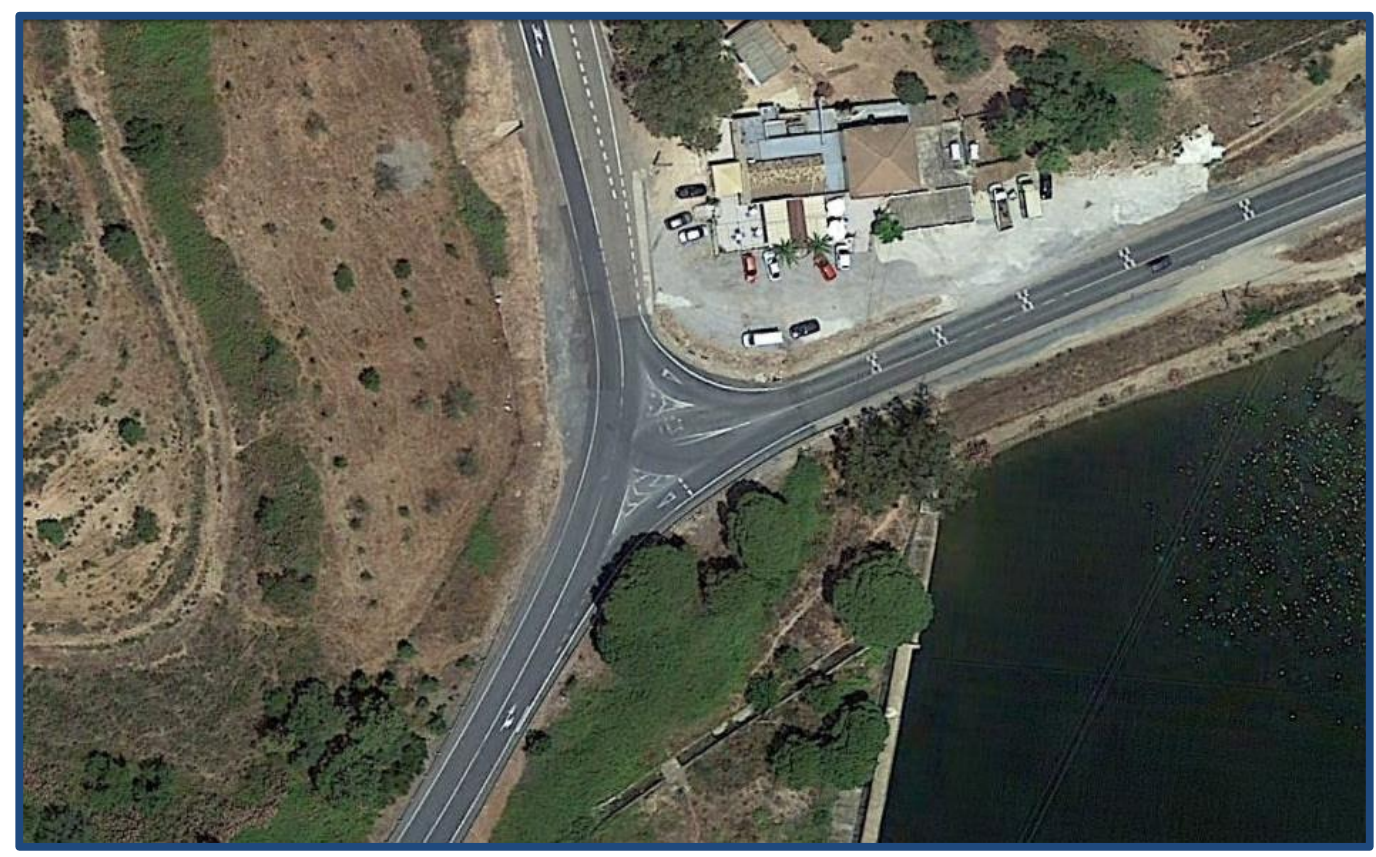

Figura 6. 1 Caso I. Conversión de un nudo de tres tramos a glorieta. Fuente: Google Earth.

Los problemas en este nudo están relacionados con las elevadas intensidades de giro a izquierdas desde la vía prioritaria (la norte-sur) a la secundaria (al este). Además, debido a la implantación en un medio interurbano, se esperan elevadas velocidades. Por estos motivos, se ha supuesto que se va a convertir a una intersección en glorieta manteniendo las alineaciones de las carreteras existentes.

\subsubsection{Datos de partida}

El trazado de los accesos se deduce a partir de los ejes de las alineaciones existentes (Fig.6.2). La anchura de calzada es igual a $7 \mathrm{~m}$ y se supone bombeo (2\%).

Como resultado del estudio en la fase preliminar se han deducido una serie de condiciones de mínimos al valor de algunos parámetros y que tienen en cuenta los objetivos de capacidad, el área barrida por el vehículo patrón y el solape de trayectorias naturales (Tabla 6.1). No se han previsto pasos de peatones y ciclistas. 

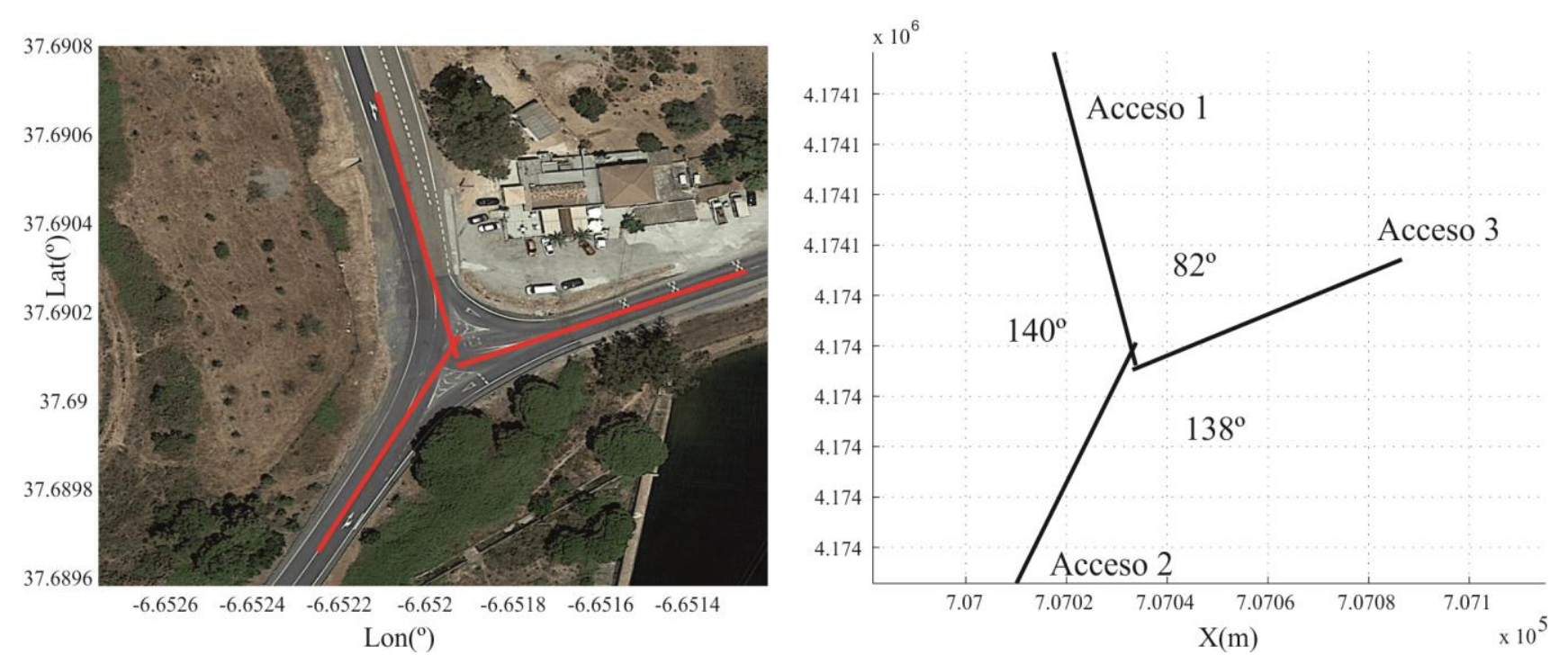

Figura 6. 2 Caso I. Datos de partida: alineaciones de los accesos.

\begin{tabular}{|c|c|c|c|c|c|}
\hline & $\begin{array}{c}\text { Normas } \\
\text { de Diseño }\end{array}$ & Capacidad & $\begin{array}{l}\text { Acomodo } \\
\text { veh. Tipo }\end{array}$ & $\begin{array}{c}\text { Solape de } \\
\text { trayectorias }\end{array}$ & $\begin{array}{l}\text { Velocidades } \\
\text { máximas }\end{array}$ \\
\hline Diámetro exterior (m) & & 35 & 40 & & \\
\hline Anchura de la calzada anular (m) & & 5 & 5 & & \\
\hline Long. isleta en la entrada (m) & & 15 & & & \\
\hline Anchura de entrada (m) & & 4 & & & \\
\hline Long. isleta en la salida (m) & 15 & & & & \\
\hline Anchura de salida(m) & 5 & & & & \\
\hline $\begin{array}{c}\text { Radio del borde exterior de } \\
\text { entrada }(\mathrm{m})\end{array}$ & & & & 25 & \\
\hline $\begin{array}{c}\text { Radio del borde exterior de } \\
\text { salida }(\mathrm{m})\end{array}$ & & & & 25 & \\
\hline Velocidad de entrada $(\mathrm{km} / \mathrm{h})$ & & & & & 50 \\
\hline Velocidad de salida $(\mathrm{km} / \mathrm{h})$ & & & & & 50 \\
\hline Velocidad de paso $(\mathrm{km} / \mathrm{h})$ & & & & & 45 \\
\hline
\end{tabular}

Tabla 6. 1 Caso I. Datos de partida: valores mínimos de los parámetros geométricos.

Se han considerado en el cálculo de trayectorias los siguientes resguardos: $d_{1}=1 \mathrm{~m}, \mathrm{~d}_{2}=$ $1.5 \mathrm{~m}, \mathrm{~d}_{3}=1.5 \mathrm{~m}, \mathrm{~d}_{4}=1.5 \mathrm{~m}, \mathrm{~d}_{5}=1 \mathrm{~m}$. 
La máxima diferencia de velocidad admisible tanto en una misma trayectoria como entre trayectorias que se cruzan para evaluar las dos componentes de la función objetivo es de $20 \mathrm{~km} / \mathrm{h}$.

Por último, los parámetros del algoritmo genético que se van a adoptar son:

- Tamaño de la población: 60.

- En cada generación se aplica una vez el conjunto de operadores de mutación y cruce.

- Número mínimo de iteraciones 200, con un máximo de 400 generaciones.

En base a estos datos, se pueden definir los umbrales para las variables de decisión (Tabla 6.2):

- Coordenadas del centro $\left(X_{c}, Y_{c}\right)$. Se acotan según el espacio cerrado calculado para la región de centros factibles (Fig.6.3).

- Diámetro exterior $\left(D_{I C}\right)$. Para fijar el umbral inferior se considera la condición más restrictiva de la Tabla 6.1 y que responde al objetivo de compatibilizar el trazado con el paso del vehículo patrón. Para fijar el umbral máximo se atiende a las limitaciones de espacio ya que existe una edificación en las proximidades. Se ha adoptado un valor de $50 \mathrm{~m}$.

- Longitud de las isletas en la entradas y en las salidas ( $L E$ y $L S$ ). La glorieta se localiza en un entorno en el que son previsibles altas velocidades y, además, no se han previsto pasos para peatones por lo que se fija un límite inferior amplio. Las longitudes mínimas deberán satisfacer los valores de la tabla 6.1.

- Anchuras de entrada y de salida (WE y WS). Se fijan de acuerdo a las exigencias del estudio de capacidad, el área barrida por el vehículo patrón y a las recomendaciones de la norma aplicable.

- Radios de los bordes exteriores en las entradas y las salidas. Estos dos parámetros se obtienen una vez realizado el cálculo. Se fija un valor mínimo de $25 \mathrm{~m}$ que resulta igual al valor máximo permitido del radio del círculo inscrito. Con esto se evita que se produzca el fenómeno del solape de trayectorias. Como 
valor máximo para el encaje de un radio común entre las entradas y las salidas se establece un valor de $35 \mathrm{~m}$.

\begin{tabular}{|c|c|c|c|c|c|c|c|c|c|c|c|c|c|c|c|}
\hline$X_{c}$ & $Y_{c}$ & $D_{I C}$ & $W_{C}$ & $L E_{l}$ & $W E_{l}$ & $L S_{I}$ & $W S_{l}$ & $L E_{2}$ & $W E_{2}$ & $L S_{2}$ & $W S_{2}$ & $L E_{3}$ & $W E_{3}$ & $L S_{3}$ & $W S_{3}$ \\
\hline \multirow{2}{*}{\multicolumn{2}{|c|}{ RFC }} & 40 & 5 & 25 & 4 & 25 & 5 & 25 & 4 & 25 & 5 & 25 & 4 & 25 & 5 \\
\hline & & 50 & 6 & 40 & 5 & 40 & 6 & 40 & 5 & 50 & 6 & 40 & 5 & 40 & 6 \\
\hline
\end{tabular}

Tabla 6. 2 Caso I. Umbrales de las variables de decisión.

\subsubsection{Aplicación del modelo de optimización}

El modelo de optimización se ha ejecutado en varias ocasiones con los mismos datos de partida con el objetivo de analizar la robustez de los resultados. En particular, se han realizado cinco réplicas y se han obtenido los siguientes resultados para la mejor solución:

- Región de centros factibles.

El resultado se muestra en la Fig. 6.3 (amarillo: nube de puntos original; verde, puntos que cumplen con la condición 1; cián, puntos que cumplen con la condición 1 y 2 ; y, rojo, puntos que cumplen las tres condiciones).

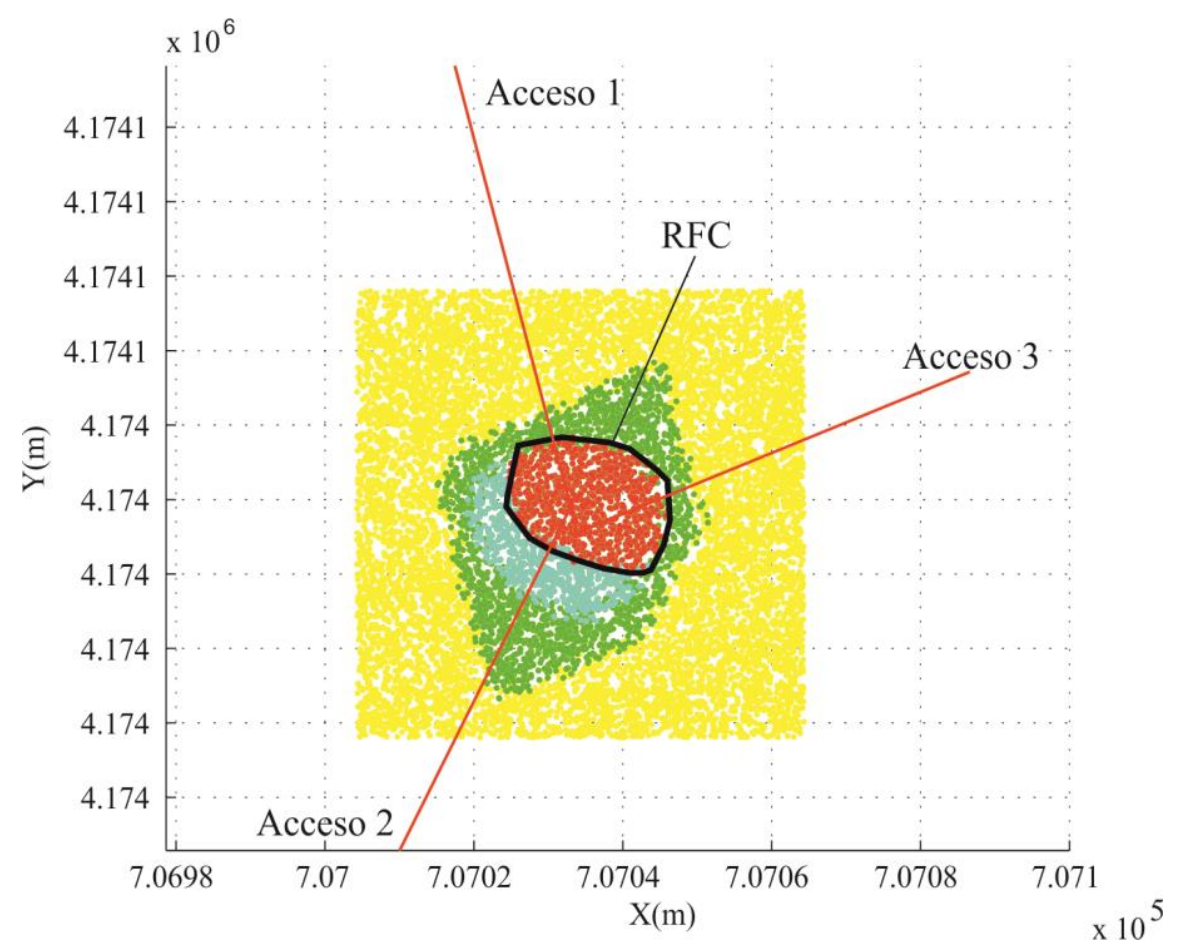

Figura 6. 3 Caso I. Región de centros factibles. 
- Huella de todas las soluciones geométricas factibles calculadas.

En la Fig. 6.4 se muestra la sombra de todos los individuos factibles (representados por su trazado geométrico) que se han considerado para obtener la solución óptima.

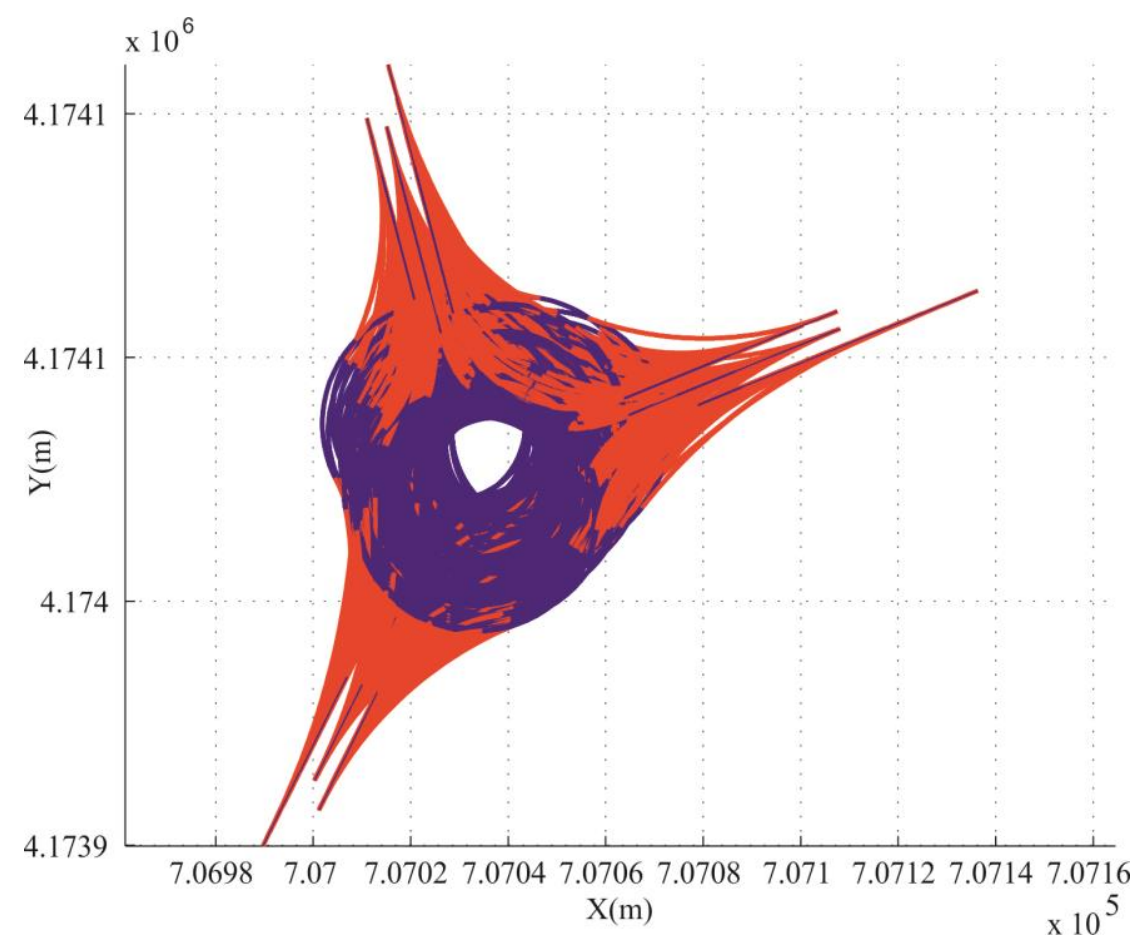

Figura 6. 4 Caso I. Huella de las soluciones geométricas factibles.

- Evolución de la función objetivo con las generaciones.

En la Fig.6.5 se ha representado la evolución del valor de la función objetivo frente al número de generaciones en las cinco réplicas del programa. En todos los casos, hacia la generación número 250 se produce una variación residual del valor de la función. 


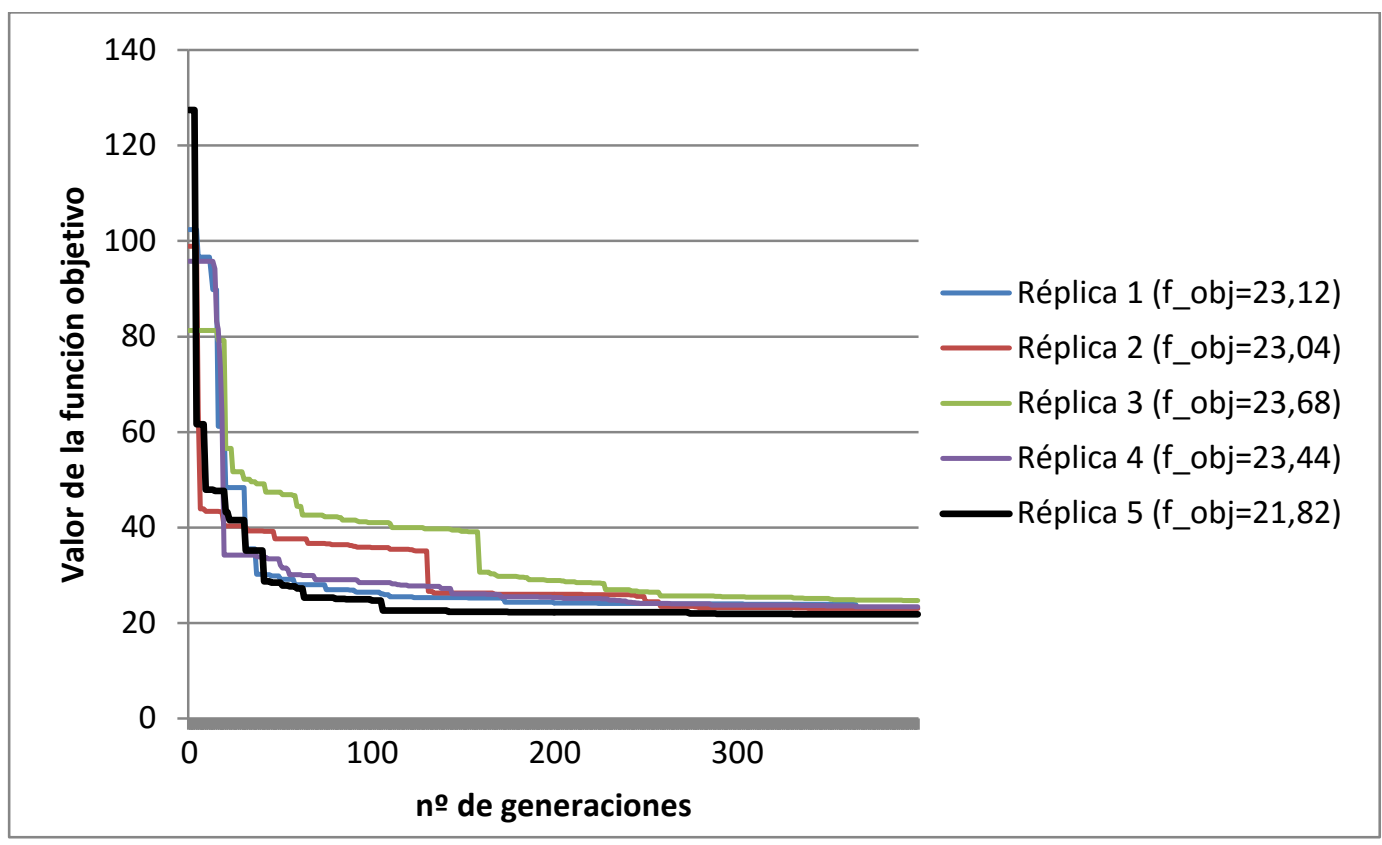

Figura 6. 5 Caso I. Evolución del valor de la función objetivo con las generaciones.

- Geometría y trayectorias.

En la Fig.6.6 se muestra la geometría y las trayectorias resultantes de la aplicación del procedimiento en la réplica con mejor valor de la función objetivo. A excepción del movimiento entre los accesos 1 y 3 , todas son trayectorias con deflexión.

- Implantación en el terreno de la solución geométrica.

En la Fig. 6.7 se representa el trazado con su implantación en el territorio. Como se puede observar, la solución es compatible con los elementos exteriores del entorno (la edificación y el embalse de aguas). 


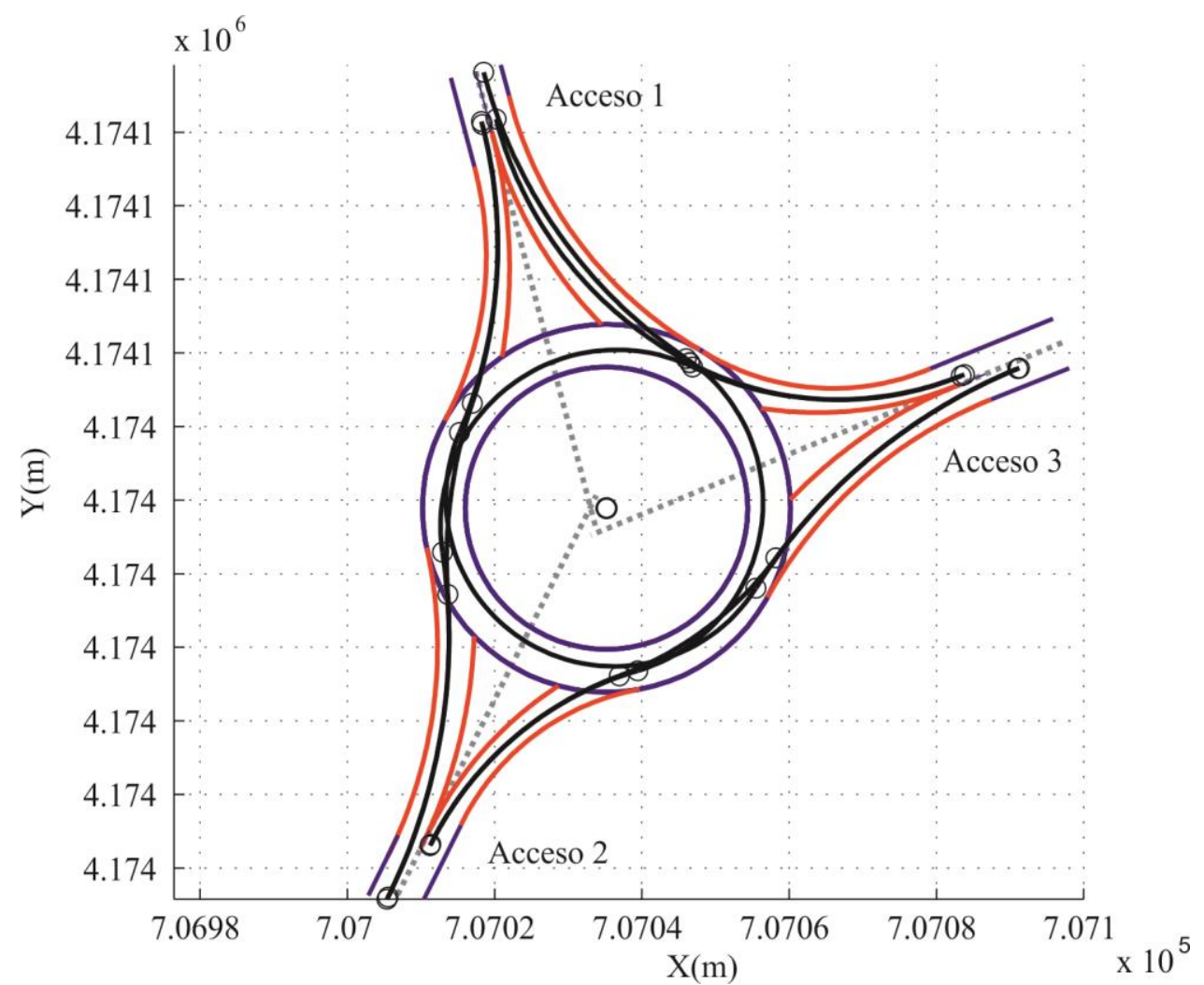

Figura 6. 6 Caso I. Solución (geometría y trayectorias).

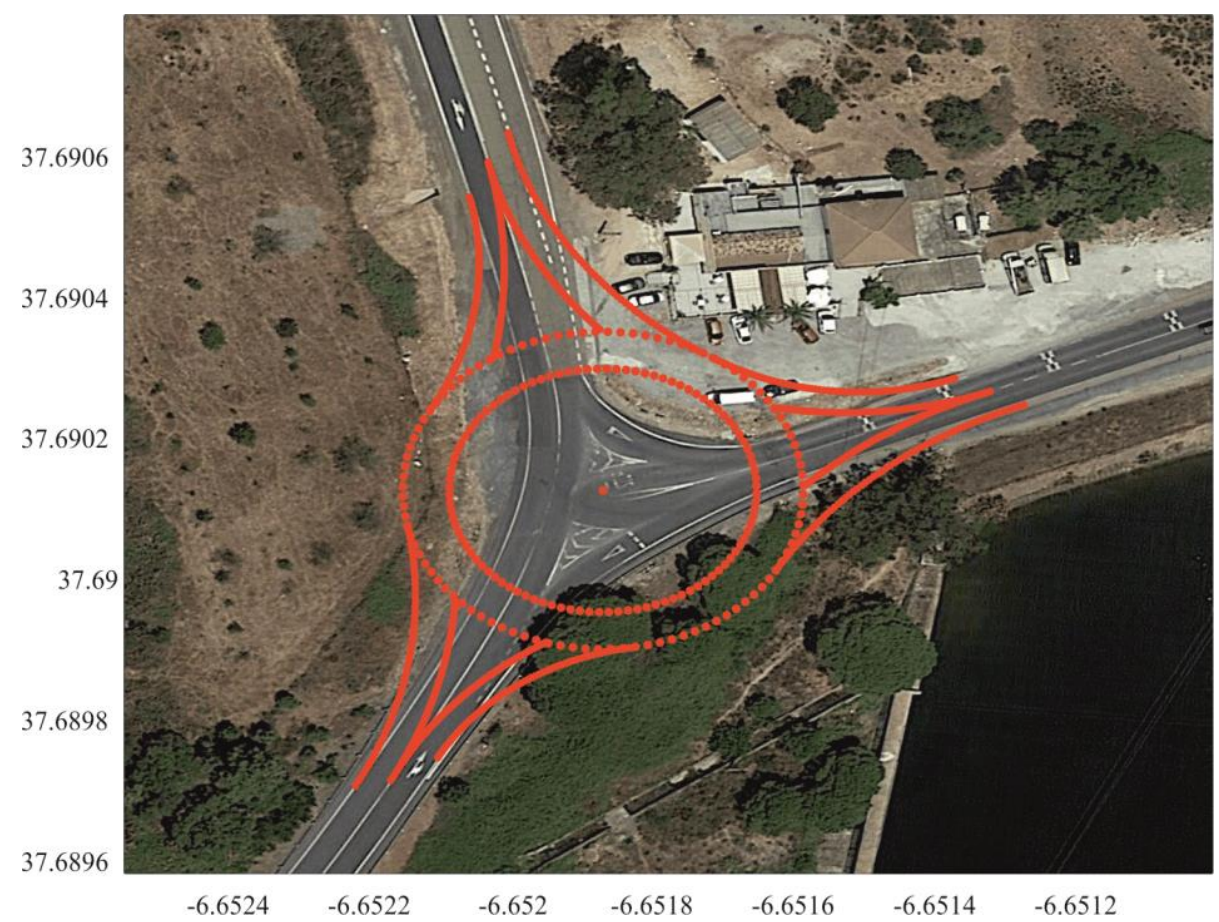

Figura 6. 7 Caso I. Solución (implantación en el territorio).

Los valores de las variables de decisión y velocidades para la mejor solución se muestran en las Tablas 6.3 y 6.4 respectivamente. 


\begin{tabular}{|c|c|c|c|c|c|c|c|c|}
\hline & $\mathrm{LE}(\mathrm{m})$ & $\mathrm{WE}(\mathrm{m})$ & $\mathrm{LS}(\mathrm{m})$ & WS (m) & $\mathrm{Xc}(\mathrm{m})$ & Yc (m) & DIC (m) & $\mathrm{Wc}(\mathrm{m})$ \\
\hline Acceso 1 & 29 & 4,0 & 29 & 5,3 & & & & \\
\hline Acceso 2 & 25 & 4,1 & 28 & 5,0 & $707.035,2$ & $4.174 .028,9$ & 49,9 & 5,8 \\
\hline Acceso 3 & 26 & 4,0 & 26 & 5,1 & & & & \\
\hline
\end{tabular}

Tabla 6. 3 Caso 1. Solución: valores de las variables de decisión.

En las entradas, los radios de los bordes exteriores resultantes son: 47m (acceso 1), 34m (acceso 2) y 34m (acceso 3). En las salidas, los radios de los bordes exteriores resultantes son: 56m (acceso 1), 64m (acceso 2) y $61 \mathrm{~m}$ (acceso 3 ).

A la vista de estos resultados, se puede concluir para el trazado de las patas de acceso que los valores de las variables de decisión $L E, W E, L S$ y $W S$ tienden a los mínimos prefijados de $25 \mathrm{~m}, 4 \mathrm{~m}, 25 \mathrm{~m}$ y $5 \mathrm{~m}$ respectivamente. Para el trazado de la cazada anular el modelo ofrece valores de $D_{I C}$ y $W_{c}$ que tienden a los máximos prefijados de $50 \mathrm{~m}$ y $6 \mathrm{~m}$ respectivamente. Los radios de entrada exteriores se encuentran en un margen de entre $34 \mathrm{~m}$ y $47 \mathrm{~m}$. Los radios de salida exteriores se encuentran en un margen de entre $56 \mathrm{~m}$ y $64 \mathrm{~m}$.

\begin{tabular}{lccc}
\hline & $\begin{array}{c}\mathrm{V}_{\mathrm{e}} \\
(\text { entrada })\end{array}$ & $\begin{array}{c}\mathrm{V}_{\mathrm{p}} \\
\text { (paso) }\end{array}$ & $\begin{array}{c}\mathrm{V}_{\mathrm{s}} \\
\text { (salida) }\end{array}$ \\
\hline \multicolumn{4}{c}{ Trayectoria desde el acceso 1 a } \\
\hline Acceso 2 & $44,5(39 \mathrm{~m})$ & 44,5 & 47,7 \\
Acceso 3 & $43,8(43 \mathrm{~m})$ & 27,2 & 46,7 \\
\hline \multicolumn{4}{c}{ Trayectoria desde el acceso 2 a } \\
\hline Acceso 3 & $38,7(35 \mathrm{~m})$ & 38,5 & 47,0 \\
Acceso 1 & $38,4(38 \mathrm{~m})$ & 27,6 & 44,7 \\
\hline Acceso 1 & Trayectoria desde el acceso 3 a & 40,4 \\
Acceso 2 & $38,3(38 \mathrm{~m})$ & 37,7 & 47,3 \\
Nota: entre paréntesis se indica la longitud del radio calculado para estimar \\
la velocidad de entrada.
\end{tabular}

Tabla 6. 4 Caso I. Solución: velocidades. 
En cuanto a las velocidades, la presencia de la glorieta provoca la moderación de las velocidades manteniéndose todas con valores inferiores a $50 \mathrm{~m} \mathrm{~km} / \mathrm{h}$. En el caso de los radios de entrada, las longitudes de los arcos son inferiores a los 50m que recomiendan las normativas de EE.UU (NCHRP, 2010) y Reino Unido (HA, 2007). Para mejorar estas longitudes es necesario aumentar la longitud mínima de la isleta deflectora y el valor mínimo del diámetro exterior. Esta posibilidad se tanteó en las pruebas experimentales pero se observó que las soluciones afectaban a la edificación situada en las proximidades de las vías actuales.

De los resultados del análisis de consistencia se desprende que las diferencias de velocidad entre las corrientes en conflicto (componente 1) presentan un rango de variación de entre $10 \mathrm{~km} / \mathrm{h}$ y $17 \mathrm{~km} / \mathrm{h}$, con una media de $13 \mathrm{~km} / \mathrm{h}$. Para las diferencias de velocidad entre los elementos geométricos de una misma trayectoria (componente 2) se obtiene un rango de variación de entre $0 \mathrm{~km} / \mathrm{h}$ y $19 \mathrm{~km} / \mathrm{h}$, con una media de $9 \mathrm{~km} / \mathrm{h}$. El valor de la función objetivo final es de 21,82. Las variables cumplen con el sistema de restricciones definido.

Por tanto, mediante la aplicación del modelo de optimización es posible generar de forma automática una solución geométrica válida para una glorieta de un carril que minimiza la consistencia de velocidades (maximiza la seguridad) y satisface el resto de objetivos del trazado en planta.

\subsection{REMODELACIÓN DE UNA GLORIETA EXISTENTE.}

En el segundo caso de aplicación se analiza la posibilidad de la remodelación de una glorieta existente (Fig.6.8). Presenta tres accesos con diferentes números de carriles: el acceso 1 tiene dos carriles de entrada y dos carriles de salida; el acceso 2, tiene dos carriles de entrada y un carril de salida; y, por último, el acceso 3 que tiene dos carriles de entrada (con abocinamiento) y un carril de salida. El diámetro exterior es de $50 \mathrm{~m}$ aproximadamente. 


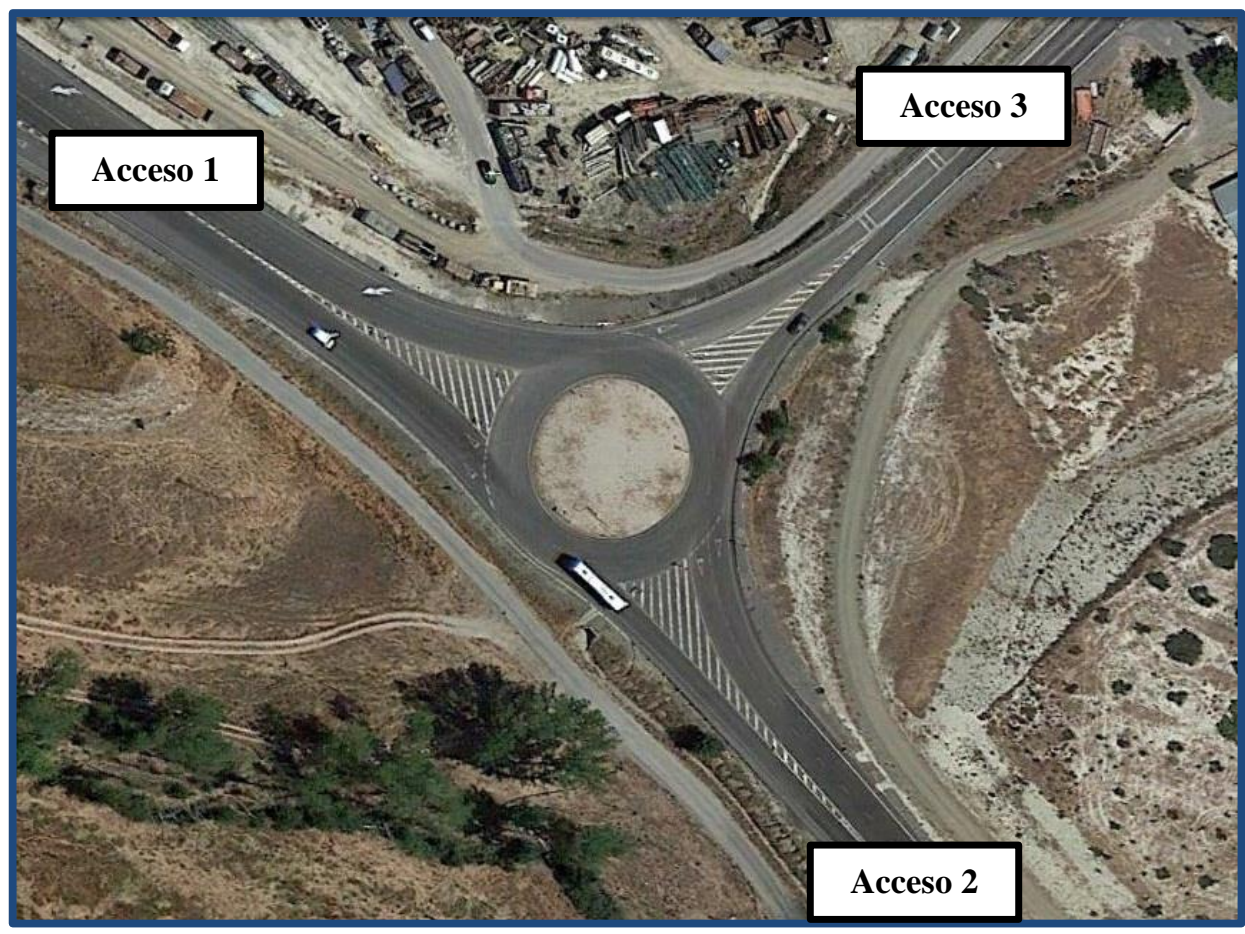

Figura 6. 8 Caso II. Remodelación de una glorieta multicarril. Fuente: Google Earth.

La vía prioritaria (conexión del acceso 1 y 2) presenta una elevada intensidad de tráfico. La glorieta presenta problemas debido a las elevadas velocidades en el movimiento desde el acceso 1 hacia el acceso 2. Se supone que se ha previsto la reubicación de la glorieta con el objetivo de moderar las velocidades y mejorar la consistencia del diseño. Se mantiene la misma configuración de carriles.

\subsubsection{Datos de partida}

El trazado de los accesos se deduce a partir de los ejes de las alineaciones existentes (Fig. 6.9). La anchura de los carriles es igual a 3,5m y se supone bombeo (2\%). 

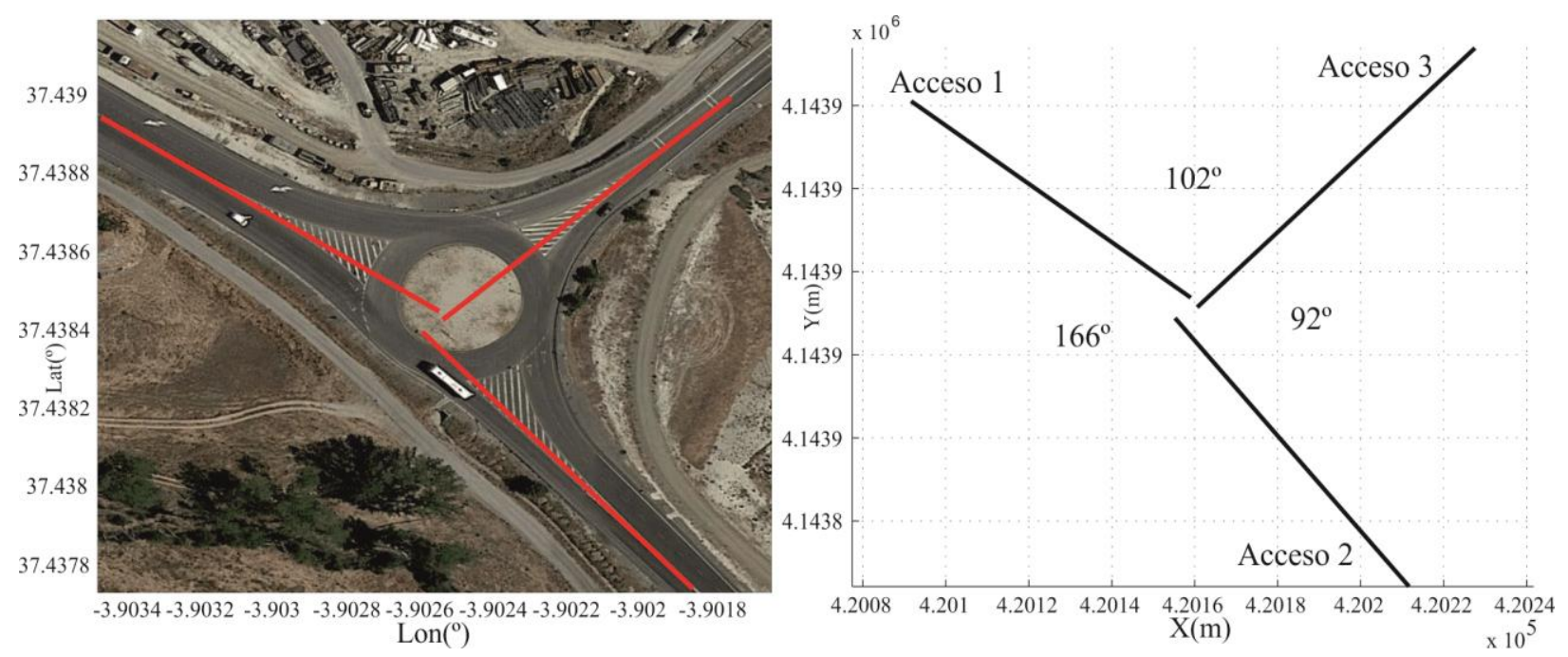

Figura 6.9 Caso II. Datos de partida: Alineaciones de los accesos.

Como resultado del estudio en la fase preliminar se han deducido una serie de condiciones de mínimos al valor de algunos parámetros y que tienen en cuenta los objetivos de capacidad, el área barrida por el vehículo patrón y el solape de trayectorias naturales (Tabla 6.5). No se han previsto pasos de peatones y ciclistas.

\begin{tabular}{|c|c|c|c|c|}
\hline $\begin{array}{c}\text { Normas } \\
\text { de Diseño }\end{array}$ & Capacidad & $\begin{array}{c}\text { Acomodo } \\
\text { veh. Tipo }\end{array}$ & $\begin{array}{c}\text { Solape de } \\
\text { trayectorias }\end{array}$ & $\begin{array}{c}\text { Velocidades } \\
\text { máximas }\end{array}$ \\
\hline
\end{tabular}

\begin{tabular}{|c|c|c|c|c|c|}
\hline Diámetro exterior (m) & & 50 & 55 & & \\
\hline Anchura de la calzada anular (m) & & 8 & 7 & & \\
\hline Long. Isleta en la entrada (m) & & 15 & & & \\
\hline Anchura de entrada (m) & & 7,5 & & & \\
\hline Long. Isleta en la salida (m) & 15 & & & & \\
\hline Anchura de salida 1 carril (m) & 5 & & & & \\
\hline Anchura de salida 2 carriles (m) & 8 & & & & \\
\hline $\begin{array}{c}\text { Radio del borde exterior de } \\
\text { entrada }(\mathrm{m})\end{array}$ & & & & 30 & \\
\hline $\begin{array}{c}\text { Radio del borde exterior de } \\
\text { salida }(\mathrm{m})\end{array}$ & & & & 30 & \\
\hline Velocidad de entrada $(\mathrm{km} / \mathrm{h})$ & & & & & 50 \\
\hline Velocidad de salida $(\mathrm{km} / \mathrm{h})$ & & & & & 50 \\
\hline Velocidad de paso $(\mathrm{km} / \mathrm{h})$ & & & & & 50 \\
\hline
\end{tabular}

Tabla 6. 5 Caso II. Datos de partida: valores mínimos de los parámetros geométricos. 
Se han considerado en el cálculo de trayectorias los siguientes resguardos: $\mathrm{d} 1=1 \mathrm{~m}, \mathrm{~d} 2$ $=1.5 \mathrm{~m}, \mathrm{~d} 3=1.5 \mathrm{~m}, \mathrm{~d} 4=1.5 \mathrm{~m}, \mathrm{~d} 5=1 \mathrm{~m}$.

La máxima diferencia de velocidad admisible tanto en una misma trayectoria como entre trayectorias que se cruzan para evaluar las dos componentes de la función objetivo es de $20 \mathrm{~km} / \mathrm{h}$.

Por último, los parámetros del algoritmo genético que se van a adoptar son:

- Tamaño de la población: 60.

- En cada generación se aplica una vez el conjunto de operadores de mutación y cruce.

- Número mínimo de iteraciones 200, con un máximo de 400 generaciones.

En base a estos datos, se pueden definir los umbrales para las variables de decisión (Tabla 6.6):

\begin{tabular}{|c|c|c|c|c|c|c|c|c|c|c|c|c|c|c|c|}
\hline$X_{c}$ & $Y_{c}$ & $D_{I C}$ & $W_{C}$ & $L E_{1}$ & $W E_{1}$ & $L S_{I}$ & $W S_{1}$ & $L E_{2}$ & $W E_{2}$ & $L S_{2}$ & $W S_{2}$ & $L E_{3}$ & $W E_{3}$ & $L S_{3}$ & $W S_{3}$ \\
\hline \multirow{2}{*}{$\mathrm{RFC}$} & 55 & 8,0 & 20 & 7,5 & 20 & 8 & 25 & 7,5 & 25 & 5 & 20 & 7,5 & 20 & 5 \\
\cline { 2 - 33 } & 60 & 8,5 & 50 & 8,0 & 50 & 9 & 50 & 8,0 & 50 & 6 & 50 & 8,0 & 50 & 6 \\
\hline
\end{tabular}

Tabla 6. 6 Caso II. Umbrales de las variables de decisión.

Siendo: diámetro exterior $\left(D_{I C}\right)$, anchura de la calzada anular $\left(W_{C}\right)$, coordenadas del centro $\left(X_{c}, Y_{c}\right)$, longitud de la isleta en la entrada $(L E)$, anchura en la entrada $(W E)$, longitud de la isleta en la salida $(L S)$ y anchura en la salida $(W S)$.

\subsubsection{Aplicación del modelo de optimización.}

El modelo de optimización se ejecutó en varias ocasiones con los mismos datos de partida con el objetivo de analizar la robustez de los resultados. En particular, se realizaron cinco réplicas y se obtuvieron los siguientes resultados para la mejor solución: 
- Región de centros factibles.

El resultado se muestra en la Fig. 6.10 (amarillo: nube de puntos original; verde, puntos que cumplen con la condición 1; cián, puntos que cumplen con la condición 1 y $2 ; \mathrm{y}$, rojo, puntos que cumplen las tres condiciones).

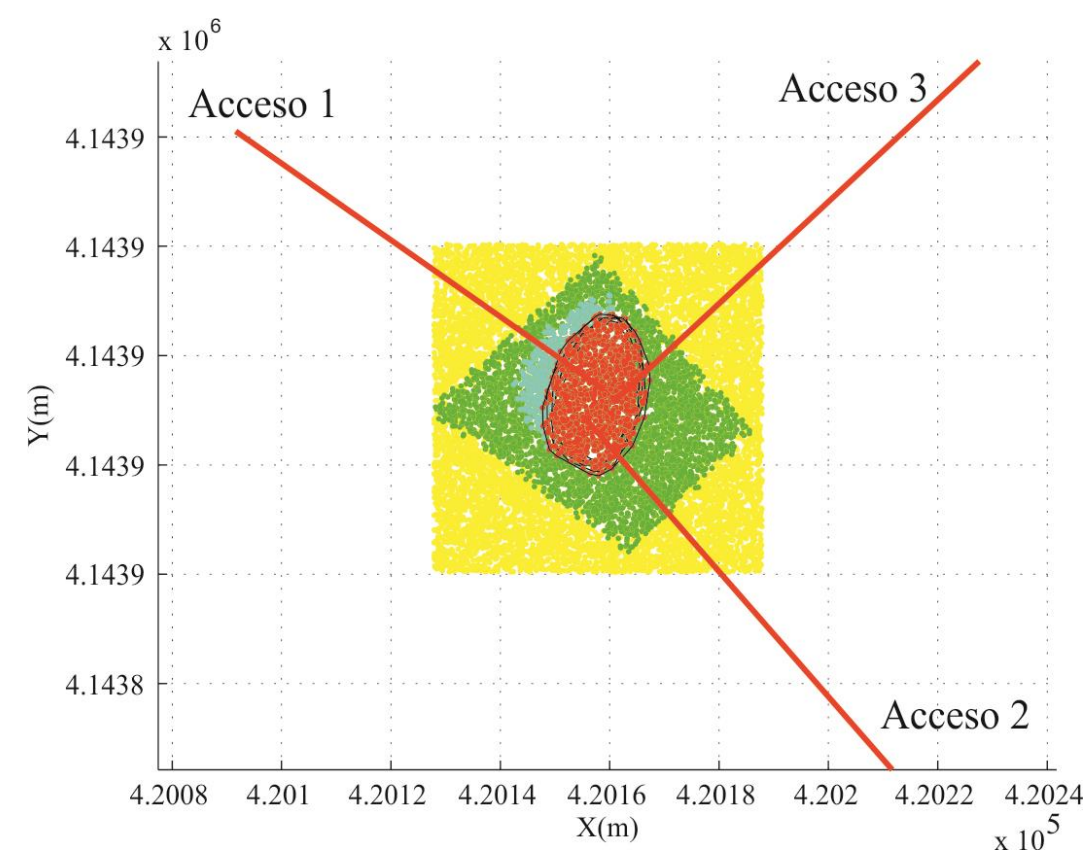

Figura 6. 10 Caso II. Región de centros factibles.

- Huella de todas las soluciones geométricas factibles calculadas.

En la Fig. 6.11 se muestra la sombra de todos los individuos factibles, representados por su trazado geométrico, que se han tanteado para obtener la solución óptima. 


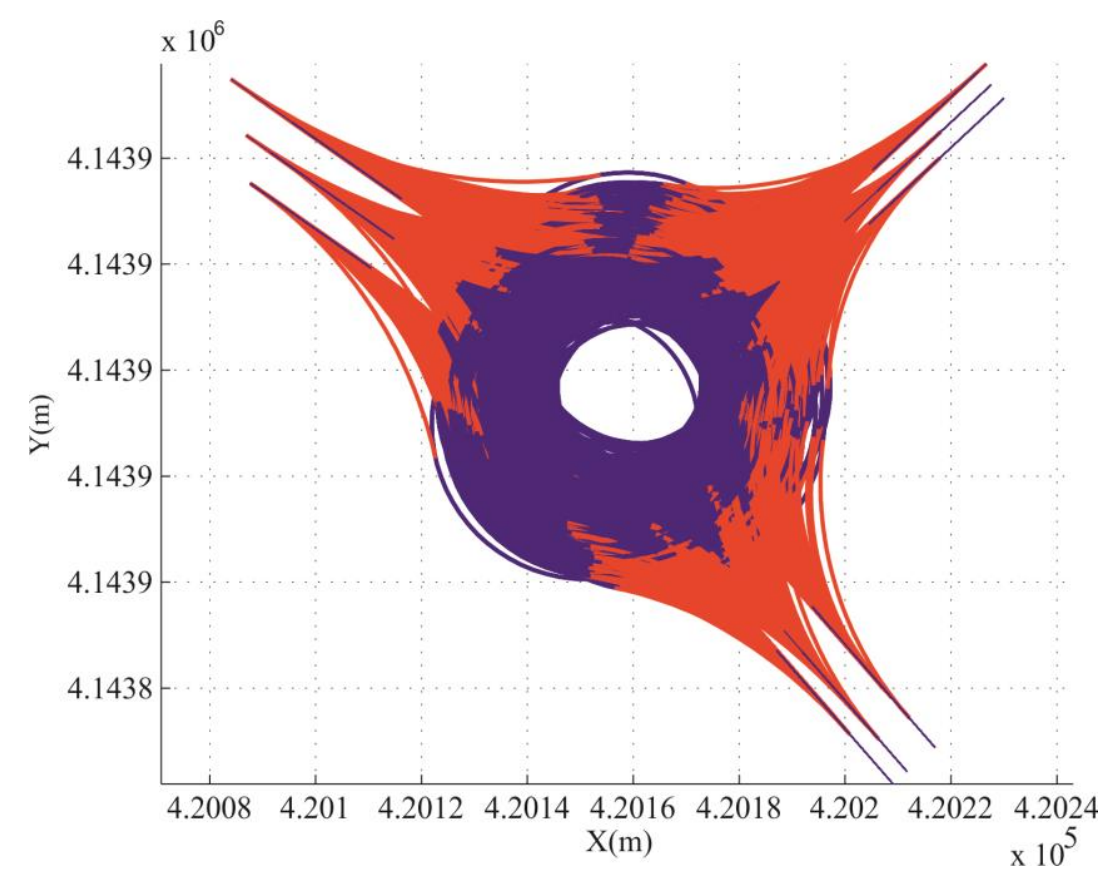

Figura 6. 11 Caso II. Huella de las soluciones geométricas factibles.

- Evolución de la función objetivo con las generaciones.

En la Fig.6.12 se ha representado la evolución del valor de la función objetivo frente al número de generaciones en las cinco pasadas del programa. En todos los casos, hacia la generación número 300 se produce una variación residual del valor de la función objetivo.

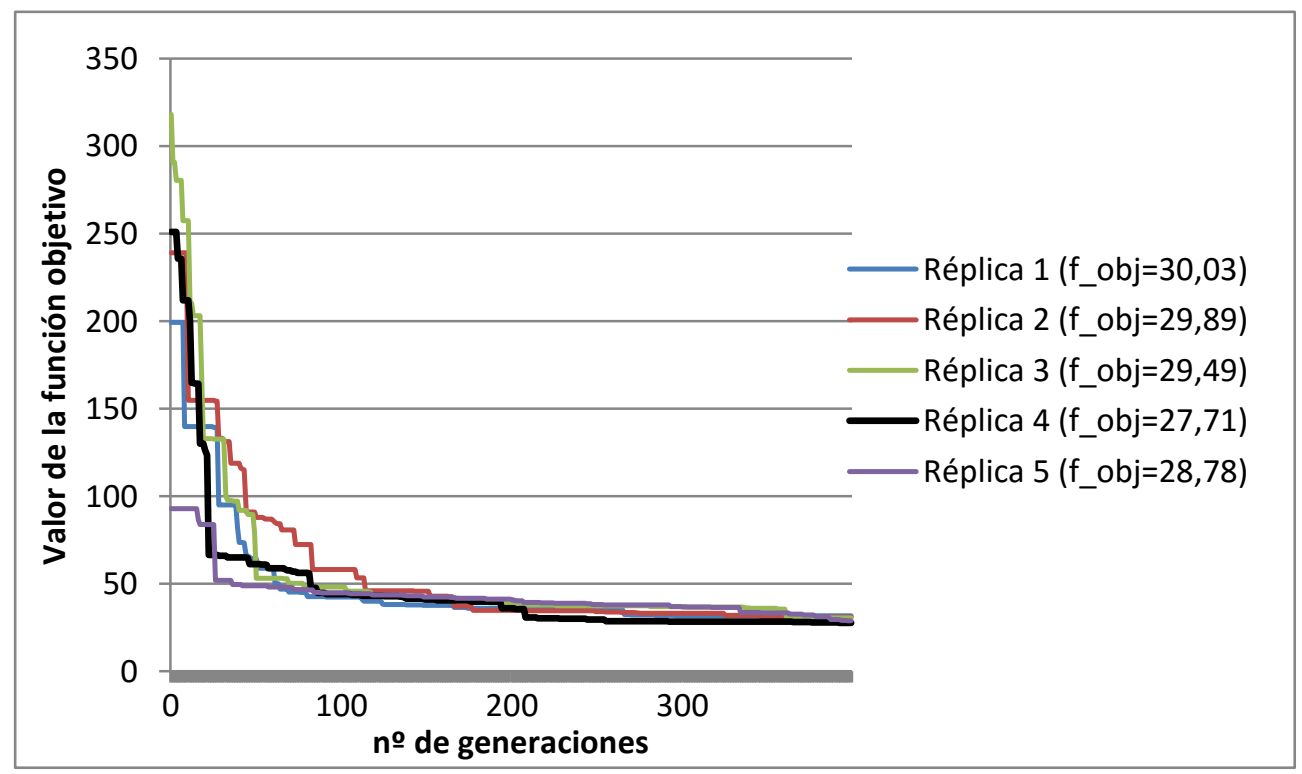

Figura 6. 12 Caso I1. Evolución del valor de la función objetivo con las generaciones. 
- Geometría y trayectorias.

En la Fig.6.13 se muestra el resultado de la geometría y las trayectorias resultantes. Los movimientos entre las patas 2 a 3, y 3 a 1 son trayectorias directas. El resto son trayectorias con deflexión.

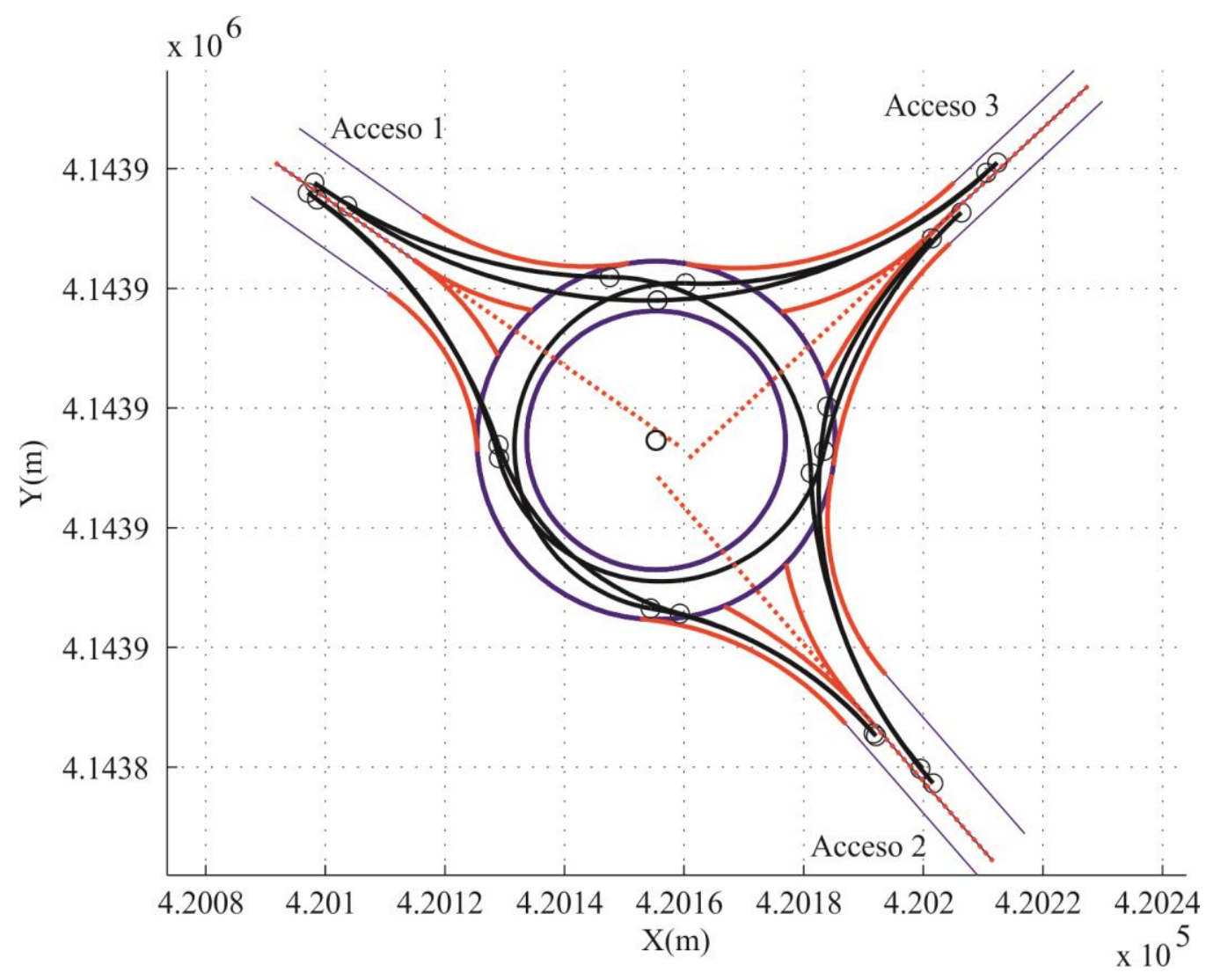

Figura 6. 13 Caso II. Solución (geometría y trayectorias).

- Implantación en el terreno de la solución geométrica.

En la Fig. 6.14 se representa el trazado obtenido con el procedimiento de búsqueda con su implantación en el territorio. Como se puede observar, la solución es compatible con los elementos exteriores del entorno aunque se debe reponer un camino lateral situado en la margen derecha de la vía prioritaria 


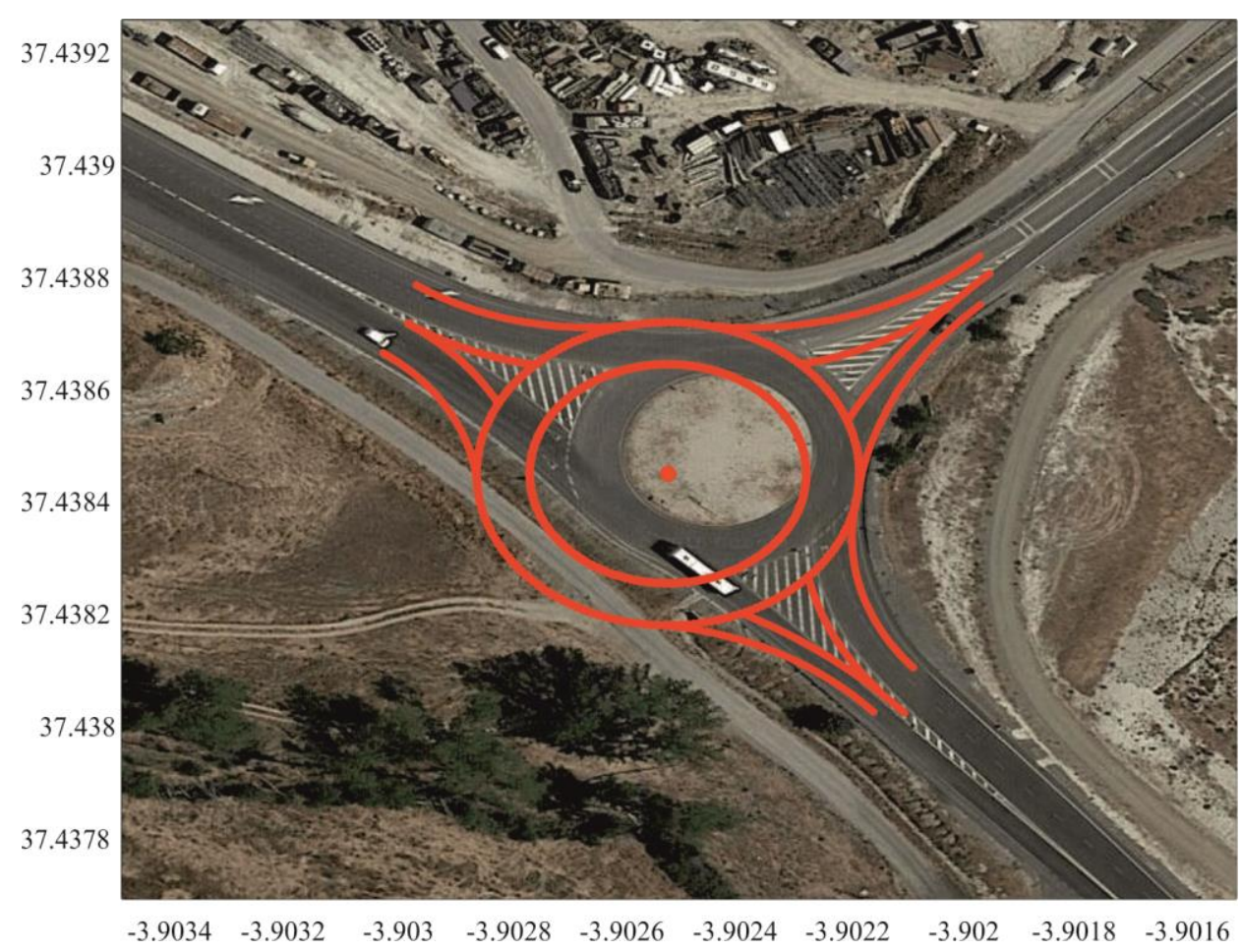

Figura 6. 14 Caso II. Solución (implantación en el territorio).

Los valores de las variables de decisión y las velocidades para la mejor solución se muestran en las Tablas 6.7 y 6.8 respectivamente.

\begin{tabular}{ccccccccc}
\hline & LE $(\mathrm{m})$ & WE $(\mathrm{m})$ & LS (m) & WS (m) & Xc (m) & Yc (m) & DIC (m) & Wc (m) \\
\hline Acceso 1 & 20,1 & 7,5 & 21,4 & 8,1 & & & & \\
Acceso 2 & 26,4 & 7,7 & 26,7 & 5,1 & $420.157,8$ & $4.143 .893,7$ & 59,9 & 8,3 \\
Acceso 3 & 20,1 & 7,6 & 38,4 & 5,1 & & & & \\
\hline
\end{tabular}

Tabla 6. 7 Caso II. Solución: valores de las variables de decisión.

En las entradas, los radios de los bordes exteriores resultantes son: $36 \mathrm{~m}$ (acceso 1), 41m (acceso 2) y 43m (acceso 3). En las salidas, los radios de los bordes exteriores resultantes son: 48m (acceso 1), 47m (acceso 2) y 63m (acceso 3).

A la vista de estos resultados se puede concluir para el trazado de los accesos que los valores de $L E, W E, L S$ y $W S$ tienden a los mínimos prefijados. Para el trazado del anillo, el modelo ofrece un valor de $D_{I C}$ que tiende al máximo prefijado de $60 \mathrm{~m}$ y un valor intermedio para $W_{C}$. Los radios de entrada exteriores se encuentran en un margen de 
entre $36 \mathrm{~m}$ y $43 \mathrm{~m}$. Los radios de salida exteriores se encuentran en un margen de entre $47 \mathrm{~m}$ y $63 \mathrm{~m}$.

\begin{tabular}{lccc}
\hline & $\begin{array}{c}\mathrm{V}_{\mathrm{e}} \\
(\text { entrada) }\end{array}$ & $\begin{array}{c}\mathrm{V}_{\mathrm{p}} \\
\text { (paso) }\end{array}$ & $\begin{array}{c}\mathrm{V}_{\mathrm{s}} \\
\text { (salida) }\end{array}$ \\
\hline \multicolumn{4}{c}{ Trayectoria desde el acceso 1 a } \\
\hline Acceso 2 & $49,7(52 \mathrm{~m})$ & 35,0 & 43,2 \\
Acceso 3 & $47,6(53 \mathrm{~m})$ & 29,3 & 46,9 \\
\hline \multicolumn{4}{c}{ Trayectoria desde el acceso 2 a } \\
\hline Acceso 3 & $46,3(68 \mathrm{~m})$ & 46,3 & 40,0 \\
\hline Acceso 1 & $48,1(57 \mathrm{~m})$ & 31,6 & 48,9 \\
\hline Acceso 1 & $46,7(56 \mathrm{~m})$ & 49,9 \\
Acceso 2 & $42,5(48 \mathrm{~m})$ & 29,1 & 42,4 \\
Nota: entre paréntesis se indica la longitud del radio calculado para estimar &
\end{tabular}

Tabla 6. 8 Caso II. Solución: velocidades.

En cuanto a las velocidades, la presencia de la glorieta provoca la moderación de las velocidades manteniéndose todas con valores inferiores a $50 \mathrm{~m} \mathrm{~km} / \mathrm{h}$. En el caso de los radios de entrada, las longitudes de los arcos son próximas o superiores a los 50m que recomiendan las normativas de EE.UU (NCHRP, 2010) y Reino Unido (HA, 2007).

De los resultados del análisis de consistencia se desprende que las diferencias de velocidad entre las corrientes en conflicto (componente 1) presentan un rango de variación de entre $11 \mathrm{~km} / \mathrm{h}$ y $20 \mathrm{~km} / \mathrm{h}$, con una media de $17 \mathrm{~km} / \mathrm{h}$. Para las diferencias de velocidad entre los elementos geométricos de una misma trayectoria (componente 2) se obtiene un rango de variación de entre $0 \mathrm{~km} / \mathrm{h}$ y $18 \mathrm{~km} / \mathrm{h}$, con una media de $11 \mathrm{~km} / \mathrm{h}$. El valor de la función objetivo final es de 27,71. Las variables cumplen con el sistema de restricciones definido.

Por tanto, mediante la aplicación del modelo de optimización es posible generar de forma automática una solución geométrica válida para una glorieta multicarril que 
minimiza la consistencia de velocidades (maximiza la seguridad) y satisface el resto de objetivos del trazado en planta.

\subsection{ANÁLISIS DEL COMPORTAMIENTO DEL MODELO}

Tras las aplicaciones del modelo a los casos experimentales se pueden deducir una serie de conclusiones.

- El programa ha resuelto de forma satisfactoria la definición de la geometría y las trayectorias de acuerdo al procedimiento propuesto. El trazado de las trayectorias se ajusta bien a los resguardos y a la geometría, y permite analizar la consistencia. Los resultados de ambos casos experimentales son además consistentes con los que cabría esperar en la práctica real.

- Con las aplicaciones llevadas a cabo, se contrasta que el modelo funciona con arreglo a los objetivos y las restricciones establecidas.

- Las soluciones convergen de manera satisfactoria hacia un óptimo global conforme a los criterios de consistencia establecidos para la definición de la función objetivo.

- El algoritmo genético aplicado en el modelo presenta "robustez" si se observan las mínimas diferencias entre los valores de la función objetivo obtenidos en las diferentes réplicas de un mismo caso de estudio. La convergencia es también satisfactoria ya que con aproximadamente 250 generaciones se converge hacia el óptimo.

- El modelo ofrece soluciones con una geometría válida que podría adoptarse para el proyecto de una glorieta. Para esto solamente es necesario desarrollar una herramienta que permita obtener un listado de puntos a partir de las alineaciones básicas que te ofrece la aplicación informática. 


\section{CAPÍTULO 7. CONCLUSIONES}

\subsection{INTRODUCCIÓN}

En este último capítulo se presentan las principales conclusiones que se han obtenido en la investigación. También se resumen las aportaciones originales de la tesis y se proponen posibles líneas de investigación como continuación del trabajo realizado.

\subsection{CONCLUSIONES}

Las principales conclusiones obtenidas en esta tesis se pueden resumir en los siguientes puntos:

- El diseño en planta de glorietas es un trabajo iterativo en el cual hay que considerar un número importante de variables y que, a pesar del continuo perfeccionamiento de las técnicas de trazado, no se encuentra totalmente mecanizado. Este problema se ha abordado en esta tesis definiendo un modelo matemático que capta la esencia del problema real y que mediante su resolución permite dirigir una búsqueda hacia la solución óptima con un considerable ahorro de tiempo para el proyectista.

- El resultado de la aplicación del modelo de optimización es el valor de las variables de decisión y que están representadas por los siguientes parámetros geométricos: las coordenadas del centro de la glorieta, el diámetro exterior, la anchura de la calzada anular, las longitudes de las isletas deflectoras y las anchuras de las entradas y salidas de las patas de acceso. La definición de la geometría a partir de las variables de decisión es posible aplicando un procedimiento que se ha desarrollado en esta tesis. 
- El criterio que permite juzgar la calidad de las distintas soluciones se centra en la evaluación de la consistencia de velocidades, concepto de referencia recogido en las principales normas de diseño para considerar la seguridad de un diseño. El cálculo de la consistencia se sustenta en un procedimiento de modelado de las trayectorias de los vehículos más rápidos y en una posterior evaluación de las velocidades. En esta tesis se ha desarrollado un algoritmo para definir las trayectorias y las velocidades a partir de la geometría de la glorieta.

- El resto de objetivos del trazado en planta se consideran como restricciones del problema de optimización y para tenerlos en cuenta es necesario realizar un estudio preliminar que incluya el análisis de los tráficos, la selección de un vehículo patrón y la identificación de las necesidades de los usuarios no motorizados. No obstante, es recomendable realizar una comprobación a posteriori sobre el diseño seleccionado utilizando otras aplicaciones informáticas.

- Para poder ejecutar el modelo de optimización el usuario sólo necesita establecer como datos de partida la geometría de las patas de acceso y los umbrales de variación de los parámetros geométricos. En el caso de las coordenadas del centro de la glorieta, debido a su dependencia con las condiciones particulares del entorno, los límites de variación se definen de acuerdo a un procedimiento desarrollado en este tesis y que establece una región cerrada en el espacio de forma que los puntos situados dentro de ella tienen como resultado una solución geométrica válida.

- La resolución del modelo matemático se realiza utilizando un algoritmo genético, técnica que mediante la generación de una población inicial (o de soluciones potenciales del problema) y la aplicación de unos operadores genéticos permite asegurar que las soluciones se aproximan de forma monótona a un óptimo global. Se contrasta que este tipo de técnicas de optimización pueden ser empleadas de forma satisfactoria en el diseño de carreteras y de sus elementos. 
- Los procedimientos desarrollados se han aplicado en la resolución de dos casos prácticos, uno para una nueva glorieta de un carril y el otro para la remodelación de una glorieta multicarril. Los resultados muestran en ambos casos que las soluciones convergen hacia el óptimo de diseño en el cual se minimiza la consistencia de velocidades y se satisface el sistema de restricciones establecido. Se concluye finalmente que el procedimiento puede ser aplicado con éxito a los casos que se presentan en la práctica profesional.

\subsection{Principales APORTACIONES}

Las principales aportaciones que se pueden considerar como resultado de la investigación son:

- Análisis pormenorizado de los procedimientos de diseño en planta de glorietas, detallando los criterios necesarios para evaluar la geometría, las técnicas de trazado existentes y los criterios especificados en las principales normas de diseño a nivel internacional.

- La definición de un modelo matemático que capta la esencia de la problemática asociada a la definición del trazado en planta de glorietas y que se resuelve mediante la aplicación de un procedimiento heurístico de optimización.

- Consideración en el modelo de optimización como variables a las coordenadas del centro de la glorieta. El procedimiento desarrollado no se encuentra limitado por la posición y el ángulo de los ejes de las patas que acceden a la intersección.

- Desarrollo de un procedimiento que permite construir de forma automática la geometría en planta de una glorieta a partir de los valores de cuatro parámetros geométricos para definir la calzada anular y cuatro parámetros geométricos para definir las patas de acceso. El proceso considera la posible interferencia entre una entrada y la salida consecutiva. 
- Desarrollo de un procedimiento que permite modelar de forma automática todas las posibles trayectorias de paso por una glorieta, independientemente del número de accesos y de la posición de las patas de acceso y la calzada anular. Los movimientos se agrupan de a acuerdo a dos tipos, denominados movimiento directo y movimiento con deflexión.

\subsection{FUTURAS LÍNEAS DE INVESTIGACIÓN}

A partir del trabajo realizado en esta tesis, se proponen para futuros estudios las siguientes líneas de investigación:

- Extender el modelo de optimización considerando nuevos objetivos dependientes de la geometría, como puede ser la capacidad o el coste de construcción, aplicando técnicas de resolución multiobjetivo.

- Ampliar la definición realizada a la región bidimensional donde se sitúan los posibles centros de la glorieta, denominada "región de centros factibles", para considerar las restricciones asociadas a la afección de edificaciones y servicios existentes en el entorno.

- Considerar como variables de decisión las alineaciones de las patas de acceso y nuevos parámetros que tengan en cuenta formas irregulares en la calzada anular.

- Validar mediante el estudio de los movimientos reales de los vehículos a su paso por glorieta el procedimiento de cálculo de trayectorias.

- Definir un modelo tridimensional que considere la optimización de las alineaciones verticales y el movimiento de tierras. 


\section{CAPÍTULO 8. BIBLIOGRAFía}

ADA COUNTY HIGHWAY DISTRICT (ACHD) (2011): Roundabout Design Guide. Policy Manual. Section 5188 Appendix A. Idaho. EEUU.

AKÇELIK, R. (2004): Roundabouts with unbalanced flow patterns. ITE 2004 Annual Meeting, Lake Buena Vista, Florida, USA.

AKÇELIK AND ASSOCIATES (2004): SIDRA User Guide (for version 2.1). Akcelik and Associates Pty Ltd. Melbourne. Australia.

AKÇELIK R. (2008): The Relationship between Capacity and Driver Behaviour. Paper presented at the TRB National Roundabout Conference, Kansas City, MO, EEUU.

ALPHAND, F., NOELLE, U., y GUICHET, B. (1991): Roundabouts and road safety: State of the art in France. Intersections without traffic signals II. W. Brilon, ed., Springer-Verlag, 126-140. Berlin. Germany.

AMBADIPUDI, R. (2008): Approaches to Modeling Complicated Roundabout Scenarios. Presented at National Roundabout Conference. TRB. Kansas City, Missouri. EEUU.

AMERICAN ASSOCIATION OF STATE HIGHWAY AND TRANSPORTATION OFFICIALS (AASHTO) (2001): A Policy on Geometric Design of Highways and Streets. Washington, D.C. EEUU.

AMERICAN ASSOCIATION OF STATE HIGHWAY AND TRANSPORTATION OFFICIALS (AASHTO) (2004): A Policy on Geometric Design of Highways and Streets. Washington, D.C. EEUU. 
ANGELASTRO, M. (2010): The Influence of the Driver Sight Distance on Crash Rates and Driver Speed at Modern Roundabouts in the United States. ITE Journal. Institue of Transportation Engineers, pp-28. Boston, EEUU.

ANGElASTRO, M., MEHTA, Y. y McFADDEN, J. (2012): Evaluation of Sight Distance and Crash Rates at Roundabouts in the United States. Presented at $91^{\text {st }}$ Annual Meeting. Transportation Research Board of the National Academies. Washington, DC. EEUU.

ANTOINE, D. (2005): The safety of Roundabouts and Traffic Lights in Belgium. Proceeding of National Roundabout Conference. TRB. Vail, Colorado. EEUU.

ARNDT, O. (1991): Roundabout Safety Study: Effect of Geometry on Accident Rate. Transport Technology Division, Report DSB01. Queensland Department of Transport. Brisbane, Australia.

ARNDT, O. y TROUTBECK, R. (1995): Relationship Between Roundabout Geometry and Accident Rates. International Symposium on Highway Geometric Design Practices. TRB. Boston, Massachusetts.

ARNDT, O. (1998): Relationship Between Roundabout Geometry and Accident Rates. Report Number ETD02, Queensland Department of Main Roads. Brisbane, Australia.

ARNDT, O. (2008): Speed control at roundabouts - Use of maximum entry path radii. Proceedings of the 23rd ARRB Conference, Adelaide, Australia.

ASSOCIATION OF SWISS ROAD AND TRAFFIC ENGINEERS (VSS) (1999). Carrefours. Carrefours giratoires. Swiss Standard SN 640 263. Zurich, Swiss.

ATHANASSOUlIS, G. y CALOGERO, V. (1973): Optimal Location of a New Highway from A to B - A Computer Technique for Route Planning. PTRC Seminar Proceedings on Cost Models and Optimization in Highways (Session L9). London, UK. 
ATKINSON, J. (2014): Temporary Traffic Control for Building and Maintaining Single and Multi-Lane Roundabouts. Presentation of $4^{\text {th }}$ International Conference of Roundabouts. TRB. Seattle. EEUU.

AUSTROADS (1993). Roundabouts: Guide to Traffic Engineering Practice, Part 6. Association of Australian State Road and Transport Authorities. Sydney, Australia.

AUSTROADS. (2011). Roundabouts: Guide to Road Design. Part 4B. Association of Australian State Road and Transport Authorities. Sydney, Australia.

AVGOUSTIS, A. (2008): Road Markings to Increase Roundabout Lane Utilization and Safety in Cyprus. Presented at National Roundabout Conference. TRB. Kansas City, Missouri. EEUU.

BARANOWSKI, B. (2014): Turboroundabout? Re-design of the 14-year Old Deer Valley Rondabout. Presentation of $4^{\text {th }}$ International Conference of Roundabouts. TRB. Seattle. EEUU.

BARED, J. y AFSHAR, A. (2008): Planning Capacity Models by Lane for 2- and 3Lane Roundabouts. Proceeding of National Roundabout Conference. TRB. Kansas City, Missouri. EEUU.

BASTOS, A. y MAIA, A. (2006): Dimensionamento de Rotundas. Caracterização funcional, dimensionamento operacional e projecto geométrico. Edição FCTUC. Coimbra. Portugal.

BENTLEY P. (2002): Evolutionary design by computers. Morgan Kaufmann Publishers. San Francisco, CA. EEUU.

BERRUEZO, P (2009): Diseño de glorietas suburbanas. Notas del Curso sobre Diseño Geométrico de Carreteras. CEDEX. Madrid. 
BRILON, W. (2008): Roundabouts in Germany - a Estate of the Art-Report. Presented at National Roundabout Conference. TRB. Kansas City, Missouri. EEUU.

BRILON, W. (2014): Roundabouts: A Estate of the Art in Germany. Presented at $4^{\text {th }}$ International Conference of Roundabouts. TRB. Seattle. EEUU.

BRILON, W. y STUWE, B. (1993): Roundabouts in Germany: Recent results regarding capacity and safety. Actes du Seminaire "Giratoires 92". Centre d'Etudes des Transports Urbains (CERTU), pp 41-52. Nantes. France.

BRILON, W. y WU, N. (2008): Kapazitaet von Kreisverkehren Aktualisierung. (Capacity of roundabouts). Strassenverkehrstechnik, Nr. 5, S. $280-288$.

BROWN, M. (1995). State of the Art Review - The Design of Roundabouts. TRL, HMSO, London. UK.

BRUDE, U. y LARSSON, J. (1999): Roundabouts from a traffic safety point of view. VTI-meddelande 864. Swedish National Road and Transport Research Institute (VTI). Linköping. Sweden.

BRUDE, U. y LARSSON, J. (2000): What Roundabout Design Provides the Highest Possible Safety from a Traffic Safety Point of View? Nordic Road and Transport Research, No. 2. Swedish National Road and Transport Research Institute (VTI). Linköping. Sweden.

BUTCH, W. (2008): Roundabout Capacity Analysis - A Practitioners Guide to Managing and Minimizing Risk and Uncertainty. Proceeding of National Roundabout Conference. TRB. Kansas City, Missouri. EEUU.

CAAMAÑO, P. (2010): Caracterización de espacios de calidad y algoritmos evolutivos en problemas de optimización con codificación real. Tesis Doctoral. Depart. Computación Facultad de Informática Universidad da Coruña. España. 
CAMPBELL, D., JURISICH, I. y DUNN, R. (2011): Improved Safety Features for Multilane Roundabouts. Proceeding of $3^{\text {rd }}$ International Conference of Roundabout. TRB. Carmel, Indiana. EEUU.

CAPILUPPI G. F., GALLELLI V. y VAIANA R. (2006): Intersezioni a raso con soluzione a rotatoria dissimmetrica: un caso di studio. Proceedings of 16th National SIIV Congress - Adeguamento e Manutenzione delle strade esistenti, Arcavacata di Rende (CS), (www.siiv.it).

CARRASCO, M. (1996): AutoTurn V 3.0. Transoft Solutions. Richmond BC, Canada.

CARROLL C. (1961): The created response surface technique for optimizing nonlinear, restrained systems. Operations Research, 9:169-185.

CASTRO, M., IGLESIAS, L., y RODRÍGUEZ-SOLANO, R. (2006): Desarrollo de un sistema para el análisis de la consistencia del trazado de carreteras. Internal Rep. Universidad Politécnica de Madrid. España.

CASTRO, M., SÁNCHEZ, J., VAQUERO, C., IGLESIAS L. y RODRÍGUEZSOLANO, R. (2008a): Highway safety analysis using geographic information systems safety. Proceedings of the Institution of Civil Engineers - Transport, Volume 161, Issue 2, (91-97).

CASTRO, M., IGLESIAS, L., RODRÍGUEZ-SOLANO, R. y SÁNCHEZ, J. (2008b): Automated GIS-Based system for speed estimation and highway safety evaluation. Journal of computing in civil engineering, 22:5 (325).

CHAN, C. (2012): An Investigative Study on Standardizing the Roundabout Entry Paths of Semitrailers. Proceeding of $91^{\text {st }}$ Annual Meeting. Transportation Research Board of the National Academies. Washington, DC. EEUU.

CHAPRA, S. y CANALE. R. (1988): Numerical Methods for Engineers. McGraw-Hall, Inc. New York. EE.UU. 
CHARD, B. (1997): Arcady Health Warning: Account for unequal lane usage or risk damaging the Public Purse. Traffic Eng. and Control, 38(3), pp 122-132.

CHEN, B., PERSAUD, B., y LYON, C. (2011). Effect of Speed on Roundabout Safety Performance-Implications for Use of Speed as a Surrogate Measure. Proceeding of $91^{\text {st }}$ Annual Meeting. Transportation Research Board of the National Academies. Washington, DC. EEUU.

CHEN, Y., PERSAUD, B., SACCHI, E. y BASSANI, M. (2013): Investigation of models for relating roundabout safety to predicted speed. Accident Analysis and Prevention, Volume 50, pages 196-203.

CHEU, R., DURAN, C. y MOORE, W. (2011): Entry Capacity Adjustment Factors for Pedestrians at U.S. Roundabouts. Proceeding of $3^{\text {rd }}$ International Conference of Roundabout. TRB. Carmel, Indiana. EEUU.

COELlO, A. (2012): Introducción a la Computación evolutiva (notas del curso). Dep. de Computación. Instituto Politécnico Nacional. México.

COURANT R. (1943): Variational methods for the solution of problems of equilibrium and vibrations.

CRAENEN, B., EIBEN, A. y VAN HEMERT, J. (2003): Comparing evolutionary algorithms on binary constraint satisfaction problems. IEEE Transactions on Evolutionary Computation, 7(5), 424-444.

CROWN, R. (1992): RODEL An Interactive Model for Predicting the Effect of Detailed Roundabout Geometry on Accidents, Capacity, Queues and Delays. Paper of International Symposium “Giratoires 92”. Nantes. France.

CROWN, R. y JOHNSON, M. (2005): Introduction to RODEL. Proceeding of National Roundabout Conference. TRB. Vail, Colorado. EEUU. 
DANIELS, S., BRIJS, T., NUYTS, E. y WETS, G. (2008): Roundabouts and safety for bicyclists: empirical results and influence of different cycle facility designs. Presented at National Roundabout Conference. TRB. Kansas City, Missouri. EEUU.

DARDER, V. (2005): Funciones de las rotondas urbanas y requerimientos urbanísticos de organización. Minor Thesis, Universitat Politècnica de Catalunya. Barcelona. España.

DAVIS, L. (1991): Handbook of Genetic Algorithms. Van Nostrand Reinhold, New York, New York. EEUU.

DE JONG, K. (1975): An Analysis of the Behaviour of a Class of Genetic Adaptative Systems. Ph. D. Thesis, University of Michigan, Ann Arbor. EEUU.

DE LA HOZ, C. y POZUETA, J. (1995): Recomendaciones para el diseño de glorietas en carreteras suburbanas. Dirección General de Transportes. Madrid (Comunidad Autónoma). España.

EASA, S. (1988): Selection of Roadway Grades that Minimize Earthwork Cost using Linear Programming. Transportation Research-A, Vol. 22, No. 2, pp. 121-136.

EASA, S. y MEHMOOD, A. (2004). Optimizing geometric design of single-lane roundabouts: consistency analysis. Canadian Journal of Civil Engineering 31(6): 10241038.

EASA, S. y MEHMOOD, A. (2006). Optimizing geometric design of roundabouts multi-objective analysis. Canadian Journal of Civil Engineering 33: 29-40.

FEDERAL HIGHWAY ADMINISTRATION (FHWA) (2000). "Roundabouts: An information guide”. Publication Number FHWA-RD-00-067, Virginia, USA.

FEDERAL HIGHWAY ADMINISTRATION (FHWA) (2004): IHSDM Design Consistency Module. Engineer's Manual. Washington, DC. EE.UU. 
FIACCO, A., Y MCCORMICK, G. (1966): Extensions of SUMT for nonlinear programming: Equality constraints and extrapolation. Management Science, 12(11):816-828.

FIGUEROA, A. y TARKO, A. (2007): Speed Changes in the vicinity of horizontal curves on two-lane rural roads. Journal of Trasnportation Engineering-ASCE. Vol. 133.

FITZPATRICK, K., WOOLDRIDGE, M., TSIMHONI, O., COLLINS, J., GREEN, P., BAUER, K. M., et al. (2000a): Alternative Design Consistency Rating Methods for Two-Lane Rural Highways. Federal Highway Administration - U.S. Department of Transportation. FHWA-RD-99-172. Washington, DC. EE.UU.

FITZPATRICK, K., WOOLDRIDGE, M., TSIMHONI, O., COLLINS, J., GREEN, P., BAUER, K. M., et al. (2000b): Evaluation of Design Consistency Methods for TwoLane Rural Highways, Executive Summary. Federal Highway Administration - U.S. Department of Transportation. FHWA-RD-99-173. Washington, DC. EE.UU.

FLANNERY, A. y ELEFTERIADOU, L. (1999): A Review of Roundabout Safety Performance in the United States. Proceeding of $21^{\text {st }}$ Century ITE International Conference. ITE. Kissimmee, Florida. EEUU.

FORTUIJN, L. y HARTE, V. (1997): Multilane Roundabouts: exploring new models. Traffic Engineering Working Days, CROW. Ede, Netherlands.

FWA, T. (1989): Highway Vertical Alignment Analysis by Dynamic Programming. Transportation Research Record 1239, TRB, National Research Council, Washington, D.C., pp. 1-9.

GALLELLI V., CAPILUPPI G.F. y VAIANA R. (2007): Roundabouts performances analysis: comparison between classical methodologies, micro-simulation and field measuring. Communication to the XXII European Conference on Operational Research, Road Traffic Management Session, Prague. 
GALLELLI, V. y VAIANA, R. (2008): Roundabout intersections: evaluation of geometric and behavioural features with Vissim. Presented at National Roundabout Conference. TRB. Kansas City, Missouri. EEUU.

GALlELli, V., VAIANA, R. Y IUELE, T. (2014): Comparison between Simulated and Experimental Crossing Speed Profiles on Roundabout with Different Geometric Features. Procedia - Social and Behavioral Sciences 111(0): 117-126.

GARBER, N. Y GADIRAJU, R. (1989): Factors affecting speed variance and its influence on accidents. Transportation Research Board, Transportation Research Record. 1213.

GBOLOGAH, F. (2014): Evaluation of Roundabout Illumination and Safety. Presented at $4^{\text {th }}$ International Conference of Roundabouts. TRB. Seattle. EEUU.

GENERALITAT DE CATALUNYA (GC) (2006): Instrucció per al disseny i projecte de rotondes (esborrandy). Departament de Política Territorial i Obres Públiques. España.

GINGRICH, M. (2008): Mitigating Truck Rollovers: Approaches for Circulating Roadway Crown. Presented at National Roundabout Conference. TRB. Kansas City, Missouri. EEUU.

GLOVER, F (1983): Tabu Search, Part I. ORSA Journal on Computing, 1, pp. 190206.

GLOVER, F., LAGUNA AND M. y MARTÍ, R. (2002): New Ideas and Aplications of Scatter Search and Path Relinking: Advances and Aplications, to appear in Theory and Applications of Evolutionary Computation: Recent Trends, A. Ghosh and S. Tsutsui (Eds.), Springer-Verlang. 
GOH, C., CHEW, E., y FWA, T. (1988): Discrete and Continuous Model for Computation of Optimal Vertical Highway Alignment. Transportation Research-B, Vol. 22, No. 9, pp. 399-409.

GOLDBERG, D. (1989): Genetic Algorithms in Search, Optimization and Machine Learning. Addison-Wesley Publishing Co., Reading, Massachusetts, EEUU.

GRANT, T. y NICHOLSON, A. (2003): Rural roundabouts and their application in New Zealand. Proceeding of the Technical Conference of the Institution of Professional Engineers. New Zealand.

GREFENSTETTE, J. (1986): Optimization of Control Parameters for Genetic Algorithms. IEEE Trans. Syst., Man, Cyber. SMC-16, pp. 122-128.

GUICHET, B. (1997): Roundabouts in France: development, safety, design and capacity. Proceedings of the 3rd International Symposium on Intersections without Traffic Signals, pp100-105. Portland, Oregon. EEUU.

GUICHET, B. (2005): Evolution of roundabouts in France and new uses. Proceeding of National Roundabout Conference. TRB. Vail, Colorado. EEUU.

GUICHET, B. (2008): French Roundabouts Today. Presented at National Roundabout Conference. TRB. Kansas City, Missouri. EEUU.

GUSTAFSON, J. (2011): Two years Later - Safety, Operations, and Education Lessons from Minnesota's First Two Lane-Roundabout. Presented at $3^{\text {rd }}$ International Conference of Roundabout. TRB. Carmel, Indiana. EEUU.

HARPER, N. y DUNN, R. (2003): Accident prediction at urban roundabouts in New Zealand - some initial results. 26th Australasian Transport Research Forum. Wellington, New Zealand. 
HASSAN, Y., GIBREEL, G., y EASA, S. (2000): Evaluation of highway consistency and safety: Practical application. J. Transp. Eng., 126-3, 193-201.

HAWKINS, H. (2011): Signing and Marking of Roundabouts. Presented at $3^{\text {rd }}$ International Conference of Roundabout. TRB. Carmel, Indiana. EEUU.

HICKS, T. (2005): The Maryland experience. Presented at National Roundabout Conference. TRB. Vail, Colorado. EEUU.

HIGHWAYS AGENCY (HA) (2007): Geometric Design of Roundabouts. Design Manual of Roads and Bridges, TD 16/07. London, UK.

HIGHWAY CAPACITY MANUAL (HCM) (2010). Transportation Research Board of the National Academies. Washington, D.C., EEUU.

HORBY G. (2003): Generative representations for evolutionary design automation. $\mathrm{Ph}$. D. Dissertation. Departament of Computer Science. Brandeis University. Walthman. EEUU.

HUGHES, R. (2008): Toward a Sustainable Concept of Pedestrian Accessibility. Presented at National Roundabout Conference. TRB. Kansas City, Missouri. EEUU.

INMAN, V., SHAFER, T. y KATZ, B. (2003): Field Observations Of Path And Speed Of Motorists At Double-Lane Roundabouts. Proceeding of $2^{\text {nd }}$ Urban Street Symposium. Anaheim, California. EEUU.

INMAN, V. (2008): Roundabout Signalization: Literature Review. Presented at National Roundabout Conference. TRB. Kansas City, Missouri. EEUU.

INSTITUTE OF TRANSPORTATION ENGINEERS (ITE) (2008): Enhancing Intersection Safety Through Roundabouts. International Report IR-127. Washington. EEUU. 
ITALIAN MINISTRY OF INFRASTRUCTURES AND TRANSPORTS (MIT) (2006).

Guidelines for the Design of Road Intersections. Decree 19 April 2006. Rome, Italy.

HILLIER, F. y LIEBERMAN, G. (2010): Introducción a la Investigación de Operaciones. McGraw Hill (novena edición).

HOGAN, J. (1973): Experience with OPTLOC - Optimum Location of Highways by Computer. PTRC Seminar Proceedings on Cost Models and Optimization in Highways (Session L10). London. UK.

HOLlAND, J. (1962a): Concerning efficient adaptive systems. In M. C. Yovits, G. T. Jacobi, and G. D. Goldstein, editors, Self-Organizing Systems-1962, pages 215- 230. Spartan Books, Washington, D.C., EEUU.

HOLLAND, J. (1962b): Outline for a logical theory of adaptive systems. Journal of the Association for Computing Machinery, 9:297-314.

HOLlAND, J. (1975): Adaptation in Natural and Artificial Systems. University of Michigan Press, Ann Arbor, Michigan. EEUU.

HOMAIFAR, A., LAI, S. y QI, X. (1994): Constrained optimization via genetic algorithms. Simulation, 62, 242-254.

HOWARD, B., BRAMMICK, Z. y SHAW, J. (1968): Optimum Curvature Principle in Highway Routing. Journal of the Highway Division. ASCE, Vol. 94, No. HW1, pp. 6182.

HU, T., KAHNG, A. y TSAO, C. (1995): Old bachelor acceptance: a new class of non-monotone threshold accepting methods. ORSA Journal on Computing 7:417-425.

ISEBRANDS, H. (2009): Crash Analysis of Roundabouts at High-Speed Rural Intersections. Transportation Research Record: Journal of the Transportation Research Board, pp: 1-7. TRB. Washington, DC. EEUU. 
ISEBRANDS, H. (2011): Quantifying safety and speed data for rural roundabouts with high-speed approaches. Graduate Thesis and Dissertations. Iowa State University. EEUU.

ISEBRANDS, H.. HALLMARK, S. y HAWKINS, N. (2015): Approach Speed Effects at Rural High-Speed Intersections: Roundabouts Vs Two-Way Stop Control. Proceeding of $94^{\text {th }}$ Annual Meeting. Transportation Research Board of the National Academies. Washington, DC. EEUU.

JHA, M. (2000): A Geographic Information Systems-Based Model for Highway Design Optimization. University of Maryland, College Park. Ph. D. dissertation.

JONG, J. (1998): Optimizing Highway Alignments with Genetic Algorithms. University of Maryland, College Park. Ph. D. dissertation.

JURISICH, I. y ASMUS, D. (2014): Reducing Speeds: The C-Roundabout. Presented at $4^{\text {th }}$ International Conference on Roundabouts. TRB. Seattle, EEUU.

KENNEDY, J., PEIRCE, J. y SUMMERSGILL, I. (2005): Review of Accident Research at Roundabouts. Proceeding of National Roundabout Conference. TRB. Vail, Colorado. EEUU.

KENNEDY, J. (2007): International comparison of roundabout design guidelines. Project Report PPR206. TRL limited. Crowthorne, London. England.

KENNEDY, J. (2008): The UK Standards for Roundabouts and Mini-Roundabouts. Proceeding of National Roundabout Conference. TRB. Kansas City, Missouri. EEUU.

KIM, E. (2001): Modeling Intersections and Other Structures in Highway Alignment Optimization. University of Maryland, College Park. Ph. D. dissertation. 
KIM, E., JHA, M. y BONGSOO, S. (2003): A stepwise highway alignment optimization using genetic algorithms. Annual meeting of the Transportation Research Board. Paper No. 03-4158.

KIMBER, R. (1980): The traffic capacity of Roundabouts. Report LR 942. TRL Laboratory. Crowthorne, London. England.

KIRKPATRICK, S., GELATT, C.D. y VECCHI, M.P. (1983): Optimization by simulated annealing. Science 220: 671-680.

KNOSTMAN, J.T. (2008): Fastest Path Speed Evaluations; Design Vs Actual Multilane Roundabouts. Presented at National Roundabout Conference. TRB. Kansas City, Missouri. EEUU.

KRAMMES, R., BRACKETT R., SHAFER M., OTTESEN J., ANDERSON I., FINK K., COLlinS K., PENDLETON O. y MESSER C. (1995): Horizontal Alignment Design Consistency for Rural Two-Lane Highways. Federal Highway Administration, Report No. FHWARD-94-034. Washington, DC. EEUU.

KUHLOW, K. (2011): Roundabout Geometric Design. Presented at $3^{\text {rd }}$ International Conference of Roundabout. TRB. Carmel, Indiana. EEUU.

LALANI, L. (1975): Roundabouts: Impact on accidents. Greater London Intelligence Quarterly No. 32, 31-36. United Kingdom.

LAMM, R., CHOUEIRI, E. M., HAYWARD, J. C. y PALURI, A. (1988): Possible design procedure to promote design consistency in highway geometric design on twolane rural roads. Transportation Research Record. 1195, 111-122.

LAMM, R., BECK, A., RUSCHER, T., MAILAENDER, T., CAFISO, S., y LACAVA, G. (2007): How to make Two-Lane Rural Roads Safer. WIT Press, Southampton. UK. 
LEE, C. y DAHL, J. (2011): Factors Affecting Capacity Estimation for Roundabouts with High Truck Volume. Presented at $3^{\text {rd }}$ International Conference of Roundabout. TRB. Carmel, Indiana. EEUU.

LENTERS, M. (2005): Safety Auditing Roundabouts. Presented at National Roundabout Conference. TRB. Vail, Colorado. EEUU.

LUTTINEN, T. (2003): Capacity at Unsignalized Intersections. TL Consulting Engineers, Ltd. Lahti .TL Research Report No 3. ISBN 952-5415-02-3, ISSN 14583313.

LYON, C., CHAN, S. y PERSAUD, B. (2014): A Model for Average Speed Estimation and Crash Prediction using Vehicle Path data. Presented at $4^{\text {th }}$ International Conference of Roundabouts. TRB. Seattle. EEUU.

MAYCOCK, G. y HALL, R. (1984): Accidents at 4-arm roundabouts. Report LR 1120. TRL Laboratory. Crowthorne, London. England.

McCUllOCH, H. (2005): Roundabout Lessons Learned the Hard Way in New York States. Presented at National Roundabout Conference. TRB. Vail, Colorado. EEUU.

McCULlOCH, H. (2008): Issues with Roundabout Capacity Software. Presented at National Roundabout Conference. TRB. Kansas City, Missouri. EEUU.

McCULlOCH, H. (2011): Entry Path Overlap - What is it and how to Fix it. Presented at 3rd International Conference of Roundabout. TRB. Carmel, Indiana. EEUU.

MERINO M. (2013): Técnicas clásicas de optimización. Apuntes del Master en Modelización e Investigación Matemática, Estadística y Computación. Universidad del País Vasco. España.

MICHALEWICZ, Z. (1996): Genetic Algorithms + Data Structures = Evolution Programs. Springer-Verlag, New York, third edition. 
MICHALEWICZ, Z. Y NAZHIYATH, G. (1995): Genocop III: A co-evolutionary algorithm for numerical optimization with nonlinear constraints. In David B. Fogel, editor, Proceedings of the Second IEEE International Conference on Evolutionary Computation, pages 647-651, Piscataway, New Jersey. IEEE Press.

MICHALEWICZ, Z. Y XIAO, J. (1995): Evaluation of Paths in Evolutionary Planner/Navigator. In Proceedings of the 1995 International Workshop on Biologically Inspired Evolutionary Systems, pages 45-52, Tokyo, Japan.

MINISTERIO DE OBRAS PÚBLICAS Y URBANISMO (MOPU) (1989): Recomendaciones sobre glorietas. Textos de la Dirección General de Carreteras. Madrid. España.

MINISTERIO DE FOMENTO (MF) (2012): Guía de Nudos Viarios. Dirección General de Carreteras. Madrid. España.

MINISTERIO DE FOMENTO (MF) (2016): Norma 3.1.I.C Trazado. Dirección General de Carreteras. Madrid. España.

MONTELLA, A. (2011). Identifying crash contributory factors at urban roundabouts and using association rules to explore their relationships to different crash types. Accident Analysis and Prevention 43(4): 1451-1463.

MONTElla, A., S. TURNER, S. CHIARADONNA y D. ALDRIDGE (2012): Proposals for Improvement of the Italian Roundabout Geometric Design Standard. Procedia - Social and Behavioral Sciences 53(0): 189-202.

MOSCATO, P. (1989): On evolution, search, optimization, genetic algorithms and martial arts: Towards memetic algorithms. Caltech Concurrent Computation Program, C3P Report, 826. 
MURCHLAND, J. (1973): Methods of Vertical Profile Optimization for an Improvement to an Existing Road. PTRC Seminar Proceedings on Cost Models and Optimization in Highways, Session L12. London, UK.

MUSSONE, L., MATTEUCCI, M., BASSANI, M. y RIZZI, D. (2011): Traffic Analysis in Roundabout Intersections by Image Processing. Preprints of the 18th IFAC World Congress. Milano. Italy.

NATIONAL COOPERATIVE HIGHWAY RESEARCH PROGRAM (NCHRP). (2003): A Guide for Addressing Unsignalized Intersection Collisions. Rep. No. 500, Transportation Research Board of the National Academies. Washington, DC. EEUU.

\section{NATIONAL COOPERATIVE HIGHWAY RESEARCH PROGRAM (NCHRP).} (2007a): Roundabouts in the United States. Rep. No. 572, Transportation Research Board of the National Academies. Washington, DC. EEUU.

\section{NATIONAL COOPERATIVE HIGHWAY RESEARCH PROGRAM (NCHRP).} (2007b): Accesible Pedestrian Signals: A Guide to Best Practices. Rep. No. 117A. Transportation Research Board of the National Academies. Washington, DC. EEUU.

NATIONAL COOPERATIVE HIGHWAY RESEARCH PROGRAM (NCHRP). (2008): Guidelines for Selection of Speed Reduction Treatments at High-Speed Intersections. Rep. No. 613, Transportation Research Board of the National Academies. Washington, DC. EEUU.

\section{NATIONAL COOPERATIVE HIGHWAY RESEARCH PROGRAM (NCHRP).} (2010): Roundabouts: An information guide 2nd edition. Rep. No. 672, Transportation Research Board of the National Academies. Washington, DC. EEUU.

NICHOLSON, A., ELMS, D. y WILLIMAN A. (1973): A Variational Approach to Optimal Route Location. The Journal of the Institution of Highway Engineers, Vol. 23, pp. 22-25. 
O’BRIEN, A. (2011): Design Developments for cyclists at roundabouts in Australia (\& NZ). Presented at 3rd International Conference of Roundabout. TRB. Carmel, Indiana. EEUU.

OECD (1973): Optimisation of Road Alignment by the Use of Computers. Organization of Economic Co-operation and Development. Paris, France.

OTTESEN, J. y KRAMMES, R. (2000): Speed-profile model for a design consistency evaluation procedure in the United States. Transportation Research Record. 1701, 7685.

PARKER, N. (1977): Rural Highway Route Corridor Selection. Transportation Planning and Technology, Vol. 3, pp. 247-256.

PERSAUD, B., RETTING, R., GARDER, P. y LORD, D. (2001): Safety Effect of Roundabout Conversions in the United States: Empirical Bayes Observational BeforeAfter Study. Transportation Research Record No. 1751, 1-9. Transportation Research Board of the National Academies. Washington, DC. EEUU.

PERSAUD, B., CRAIG, L., AIMEE, F., RODERGEDTS, L. Y WEMPLE, B. (2005): NCHRP 3-65: Preliminary Safety Findings. Presented at National Roundabout Conference. TRB. Vail, Colorado. EEUU.

POLUS, A. y DAGAN, D. (1987): Models for evaluating the consistency of highway alignment. TRB. Transport Research Record 1122. Washington, DC. EE.UU.

PTV VISSIM (2007): User's Manual 5.0. Planung Transport Verkehr AG, D-76131 Karlsruhe. Germany.

PUY HUARTE, J. (1973): OPYGAR: Optimisation and automatic design of highway profiles. PTRC Seminar Proceedings on Cost Models and Optimisation in Highways (Session L13), London. UK. 
QUEENSLAND DEPARTMENT OF MAIN ROADS (QDMR) (2006): Roundabouts.

Chapter 14 of the Road Planning and Design Manual. Brisbane, Australia.

RAMOS, L., ROCCI, S. y SHIHUNDU, D. (2010): Un proceso mejorado de Diseño de Glorietas mediante análisis asistido por ordenador. Proceedings of the 4th International Symposium on Highway Geometric Design. TRB and Polytechnic University of Valencia. Valencia, España.

RENCELJ, M., TOLLAZZI, T. y TURNEK, S. (2011): Slovenian experience with "Turbo-roundabouts". Presented at 3rd International Conference of Roundabout. TRB. Carmel, Indiana. EEUU.

REVELLE, C., WHITLATCH, E., y WRIGHT, J. (1997): Civil and Environmental Systems Engineering. Prentice Hall. New Jersey. EE.UU.

RICHARDSON, J., PALMER, M., LIEPINS, G. Y HILlIARD, M. (1989): Some Guidelines for Genetic Algorithms with Penalty Functions. In J. David Schaffer, editor, Proceedings of the Third International Conference on Genetic Algorithms, pages 191197, George Mason University. Morgan Kaufmann Publishers.

RIDDING, C. (2014): Vulnerable Road Users at Roundabouts in the UK. Presented at $4^{\text {th }}$ International Conference on Roundabouts. TRB. Seattle, EEUU.

RITCHIE, S. (2005): High speed Approaches at Roundabouts. Presented at National Roundabout Conference. TRB. Vail, Colorado. EEUU.

RITCHIE, S. (2008): Thinking through a Roundabout Design. Presented at National Roundabout Conference. TRB. Kansas City, Missouri. EEUU.

RITCHIE, S. y BUTCH, W. (2011): Design Guidelines for Accommodating Trucks at Multi-Lane Roundabouts. Presented at 3rd International Conference of Roundabout. TRB. Carmel, Indiana. EEUU. 
ROBINSON, D. L. (1998): “Accidents at roundabouts in New South Wales”. Road and Transport Research, Vol 7, No. 1.

RODERGERDTS, L. y ROBINSON, B. (2004). Capacity and Performance of Roundabouts: A Summary of Recommendations in the FHWA Roundabout Guide. Kittelson \& Associates, Inc., USA.

RODERGEDTS, LEE A. (2008): Overview of Roundabouts in the United States. Presented at National Roundabout Conference. TRB. Kansas City, Missouri. EEUU.

RODERGEDTS, LEE A. (2011): Operational Analysis of Roundabouts. Presentation of $3^{\text {rd }}$ International Conference of Roundabout. TRB. Carmel, Indiana. EEUU.

RODEL (2002). User's Manual. Rodel Software Ltd and Staffordshire County Council. United Kingdom.

SALAMATI, K. (2011). Empirical Evaluation of lane-by-lane capacities congested triple-lane roundabout approaches. Presented at 3rd International Conference of Roundabout. TRB. Carmel, Indiana. EEUU.

SAWERS, C. (2011): Truck Rollover at Roundabout. Presented at 3rd International Conference of Roundabout. TRB. Carmel, Indiana. EEUU.

SCHAFFER, J., CARUANA, R., ESHELMAN, L. Y RAHARSHI D. (1989): A Study of Control Parameters Affecting Online Performance of Genetic Algorithms for Function Optimization. Proceedings of the Third International Conference on Genetic Algorithms, pages 51-60, San Mateo, California. EEUU.

SCHOON, C. y VAN MINNEN, J. (1993): Accidents on Roundabouts: Second Study into the Road Hazard Presented by Roundabouts, Particularly with Regard to Cyclists and Moped Riders”. R-93-16. SWOV Institute for Road Safety Research. Netherlands. 
SCOTT, J. (2008): Using VISSIM to Model Roundabouts in a Roadway System. Presented at National Roundabout Conference. TRB. Kansas City, Missouri. EEUU.

SERVICE D'ETUDES TECHNIQUES DES ROUTES ET AUTOROUTES (SETRA) (1998a): The Design of Interurban Intersections on Major Roads: At-grade Intersections. Bagneux, Cedex. France.

SERVICE D'ETUDES TECHNIQUES DES ROUTES ET AUTOROUTES (SETRA). (1998b): Accidents at intersections: The use of models to predict average accidents rates.” Memorandum. Bagneux, Cedex. France.

SHAW, J. Y HOWARD, B. (1981): Comparison of Two Integration Methods in Transportation Routing. Transportation Research Record 806, pp. 8-13.

SHAW, J., Y HOWARD, B, (1982): Expressway route optimization by OCP. Transportation Engineering Journal of ASCE 10-8, 227-243.

SPACEK, P. (2004): The basis of the Swiss design standard for roundabouts. TRB 2004 Annual Meeting. TRB. Washington, DC. EEUU.

STANEK, D. (2011): Comparing Roundabout Capacity Analysis Methods, or How the selection of Analysis Method can affect the design. Presented at 3rd International Conference of Roundabout. TRB. Carmel, Indiana. EEUU.

TANNER, J.(1967): The capacity of an uncontrolled intersection. Biometrica, 54 (3 and 4), pp. $657-658$.

THOMSON, N. y SYKES, J. (1988): Route Selection through a Dynamic Ice Field Using the Maximum Principle. Transportation Research-B, Vol. 22B, No. 5, pp. 339356.

TOLLAZI, T. y RENCELJ, M. (2014): Modern and Alternative Types of Roundabouts. Presented at 4th International Conference of Roundabouts. TRB. Seattle. EEUU. 
TRACZ, M. (2011): Roundabouts with Traffic Signals. Presented at 3rd International Conference of Roundabout. TRB. Carmel, Indiana. EEUU.

TRANSFUND (Traffic Design Group) (2002): The Ins and Outs of Roundabouts Safety Auditors. New Zealand.

TRANSPORTATION RESEARCH BOARD (TRB) (1984): 55: A decade of experience. Transportation Research Board Special report 204. Washington, DC. EE.UU.

TRIETSCH, D. (1987a): A Family of Methods for Preliminary Highway Alignment. Transportation Science, Vol. 21, No. 1, pp. 17-25.

TRIETSCH, D. (1987b): Comprehensive Design of Highway Networks. Transportation Science, Vol. 21, No. 1, pp. 26-35.

TROUTBECK, R.J. (1989): Evaluating the Performance of a Roundabout. Special Report SR 45. ARRB Transport Research Ltd, Vermont South, Victoria, Australia.

TRUEBLOOD, M. (2011): Retrofitting Closely Spaced Intersections Using the PeanutTurbo Roundabout Concept. Presented at 3rd International Conference of Roundabout. TRB. Carmel, Indiana. EEUU.

TURNER, A. y MILES, R. (1971): A Computer Assisted Method of Regional Route Location. Highway Research Record 348, pp. 1-15.

TURNER, S., WOOD, G. y ROOZENBURG, A. (2006): Accident prediction models for Roundabout. Beca Infraestructure Ltd. Auckland, New Zealand.

TURNER, S. y ROOZENBURG, A. (2007): Roundabout Safety - Influence of Speed, Visibility and Design. Institution of Professional Engineers New Zealand. Wellington. New Zealand. 
URRACA, J. (2009): Nudos de Carreteras. Capítulo 4. Asociación Española de la Carretera. Madrid. España.

VOIGT, A. (1996): Evaluation of alternative horizontal curve design approaches on rural two-lane highways. Texas Transport Institute. Report No. TTI-04690-3.

WAN, F. (1995): Introduction to the Calculus of Variations and its Applications. Chapman \& Hall, New York. EE.UU.

WALLWORK, M. (2014): Improving Roundabout Design Quality in the US. Presented at $4^{\text {th }}$ International Conference of Roundabouts. TRB. Seattle. EEUU.

WARREN, D. (1982): Synthesis of safety research related to traffic control and roadway elements. Federal Highway Adm. Report no. FHWA-TS-82-233.

WEINBERGER, S. (2005): Failing into the Place: The Case of the Blue Lake Roundabout. Presented at National Roundabout Conference. TRB. Vail, Colorado. EEUU.

WETZEL, A. (1983): Evaluation of the effectiveness of genetic algorithms in combinatorial optimization. $\mathrm{PhD}$ thesis, University of Pittsburgh, Pittsburgh, Philadelphia. USA

WISCONSIN DEPARTMENT OF TRANSPORTATION (WisDOT) (2008). Roundabout Guide. Madison, EEUU.

XIAO, J., MICHALEWICZ, Z. y TROJANOWSKI, K. (1997): Adaptive Evolutionary Planner/Navigator for Mobile Robots. IEEE Transactions on Evolutionary Computation, 1(1):18-28.

YENIAY O. (2005): Penalty function methods for constrained optimization with genetic algorithms. Mathematical and Computational Applications, Vol. 10, No. 1, pp. 45-56. 
YEPES, V (2002): Optimización heurística económica aplicada a las redes de transporte del tipo VRPTW. Tesis Doctoral. Universidad Politécnica de Valencia, Dpto. Ingeniería del Transporte. $352 \mathrm{pp}$.

ZIRKEL, B., PARK, S., MCFADDEN, J., ANGELASTRO, M. y MCCARTHY, L. (2013): Analysis of Sight Distance, Crash Rate, and Operating Speed Relationships for Low-Volume Single-Lane Roundabouts in the United States. Journal of Transportation Engineering-Asce 139(6): 565-573. 